\title{
The Transformation of Welfare States?
}

This accessible work provides a 'political sociology' of welfare states in industrial societies, with both historical and contemporary perspectives. Ellison focuses on the social and political underpinnings of a number of welfare regimes and looks at the transformations they have undergone and the challenges they face.

This book assesses current debates about the role of 'globalization' in welfare state change, paying particular attention to contemporary views about the capacity of embedded institutional structures to limit the effects of global economic pressures. Ellison assesses the changing nature of social policies in nine OECD countries - selected to include 'liberal', 'social democratic' and 'continental' welfare regimes. Taking labour market and pension policies as the main areas of investigation, this volume provides 'snapshots' of welfare reform in each case, charting the ways in which different regimes 'manage' the range of challenges with which they are confronted. Ultimately, the book suggests that all contemporary welfare regimes are experiencing a level of 'neoliberal drift'. As yet, this trend towards liberalization remains constrained in those countries with more 'coordinated' economies and institutionalized forms of social partnership - but the question is for how long?

This book will be of great interest to students and scholars of International Politics, Sociology and Social Policy.

Nick Ellison is Senior Lecturer in Sociology and Social Policy at the University of Durham. He has published widely in the area of the politics of social policy. 



\title{
The Transformation of Welfare States?
}

\author{
Nick Ellison
}

Routledge
(2)
LONondor \& Francis Group
LONDON AND NEW YORK 
First published 2006

by Routledge

Published 2017 by Routledge

2 Park Square, Milton Park, Abingdon, Oxon OX14 4RN

711 Third Avenue, New York, NY 10017, USA

Routledge is an imprint of the Taylor \& Francis Group, an informa business

Copyright (C) 2006 Nick Ellison

Typeset in Baskerville by

HWA Text and Data Management, Tunbridge Wells

The Open Access version of this book, available at www.tandfebooks.com, has been made available under a Creative Commons Attribution-Non

Commercial- No Derivatives 4.0 license.

British Library Cataloguing in Publication Data

A catalogue record for this book is available from the British Library

Library of Congress Cataloging-in-Publication Data

Ellison, Nicholas, 1952

The transformation of welfare states? / Nick Ellison.

p. $\mathrm{cm}$.

Includes bibliographical references and index.

1. Public welfare. 2. Social policy. 3. Welfare state. 4. Globalization-

Social aspects. I. Title.

HV31.E553 2005

$361.6^{\prime} 5-\mathrm{dc} 22$

2005007664

ISBN 13: 978-0-415-14250-2 (hbk)

ISBN 13: 978-0-415-14251-9 (pbk) 
For Sarah and Hannah 



\section{Contents}

List of tables viii

Preface ix

1 'Globalization', institutions and welfare regimes 1

2 The challenge of globalization 23

3 Globalization and welfare regime change $\$$

4 Towards workfare?Changing labour market policies $\quad 77$

5 Labour market policies in social democratic and $\begin{array}{ll}\text { continental regimes } & 100\end{array}$

6 Population ageing, GEPs and changing pensions systems 126

7 Pensions policies in continental and social democratic
regimes

8 Conclusion: dNare regimes in a liberalizing world 178

Bibliography $\quad 195$

$\begin{array}{ll}\text { Index } & 215\end{array}$ 


\section{Tables}

$\begin{array}{lll}1.1 & \text { Welfare regime indicators (1980) } & 19\end{array}$

1.2 Production regimes: labour market indicators (1980) 20

2.1 Exports and imports as percentage of GDP 30

2.2 Growth of manufacturing production and exports in newly industrializing economies 31

2.3 Cross-national variation in globalization 35

2.4 Stocks of outward FDI by major investing economies, 1960-94 35

2.5 Stocks of inward FDI by host economies, 1960-94 35

2.6 Gross capital inflows 38

4.1 Growth of long-term unemployment as a percentage of total unemployment in OECD countries $\quad 79$

4.2 Employment in services as a percentage of civilian employment 80

4.3 Female labour force as a percentage of total labour force 80

4.4 Part-time employment as a percentage of total employment and women's share in part-time employment

6.1 Old age pension spending as a percentage of GDP in selected OEGD countries, 2000

6.2 Old age dependency ratios in selected OECD countries 129

6.3 Life expectancy at birth (years) in selected OEGD countries 132

6.4 Pension fund assets as a percentage of GDP in selected OECD
countries 


\section{Preface}

For well over a decade now, a good deal of scholarly attention has been paid to welfare state 'crisis' in the 'advanced' capitalist democracies. Much of this intellectual effort has been fruitful - at least in the sense that possible causes of welfare state 'retrenchment' have been thoroughly discussed and awareness of the challenges that face mature welfare systems has consequently increased. Understandably, however, in view of the complexities involved, there is little consensus either about the root causes of welfare state change, or the extent of change itself. Disagreements can be quite fundamental. Few concessions are given, for example, by those who believe that 'globalization' lies at the root of the problems that so many welfare systems are encountering, or by their critics, who are equally convinced that global pressures exercise relatively little influence over welfare state change. Whether economic 'globalization' encourages a 'race to the bottom' as national governments cut social spending and liberalize their welfare arrangements in an effort to attract inward investment remains a serious point of contention. Nevertheless, there is a sense in which the 'great globalization debate' has moved on from the height of its influence in the early-to-mid 1990s. What has been rather mischievously referred to as 'business school globalization' appears to be on the wane - outside business schools at least - and, increasingly, attention is being given to other factors not directly associated with this phenomenon - rapid population ageing or changing patterns of employment, for instance. More recently, interest has focused on the ability of welfare regimes to resist - or, better, to 'adjust' to the pressures that confront them in ways that preserve their key characteristics. Here the capacity of the institutional structures and assumptions that became so deeply, if differentially, embedded within postwar welfare regimes becomes the focus of interest, the 'institutionalist' argument being that they 'set limits' to global economic pressures.

These issues and debates are the main theoretical concern of this book. To address them adequately 'globalization' is 'brought back in' as a major phenomenon, the potential influence of which remains of great significance to welfare regime change. But the role of institutions is held to be equally important - the interrelationship between these two poles in different welfare regimes being the main point of attention. This is not purely a book concerned with theoretical accounts of welfare regime change, however. Just as important is the manner in 
which social policies in particular welfare systems are changing and what can be said about the causal roles of global, institutional and 'contingent' factors as processes of change unfold. To this end, the greater part of this volume takes the form of an extended assessment of social policy change in nine welfare regimes, the focus being on the core areas of labour market policy and old age pensions. Combining conclusions from the theoretical discussion with insights gained from the analysis of contemporary change in different welfare regimes, one contention here is that 'globalization' plays a significant, if largely indirect, role in welfare reform - global economic pressures being influenced or conditioned by institutional and other factors. Such a verdict is hardly new, of course: a good deal of the recent literature on welfare state change comes to a similar conclusion. The real issue, however, is that 'change' is an ongoing process and, while the pace may be slow, the direction of change appears broadly to favour market solutions. Obviously, such a statement needs to be justified, particularly as it is not suggested here that regimes that are embracing market-oriented change are necessarily doing so with enthusiasm, let alone that the much-heralded 'race to the bottom' is ever likely to become a reality. The analysis of theoretical approaches to welfare regime change, which stresses the importance of a 'weak globalization' perspective, together with the examination of policy developments and institutional change in the nine case studies provides sufficient evidence to substantiate this claim.

In terms of structure, Chapter One sets the scene with an introductory discussion which outlines the main parameters of the debate between globalization enthusiasts and institutionalists, before moving on to examine the concept of 'welfare regime' in some detail. Justifications for the choice of countries and welfare areas are provided towards the end of this chapter. Chapter Two examines the globalization thesis more closely, concentrating primarily on the economic dimension, before considering the issue of whether or not global economic pressures are undermining the core institutions of the nation-state. These themes are continued into Chapter Three, but with the focus shifting to debates about the specific impact of globalization on welfare regimes. This chapter also provides introductory snapshots of the nine case studies, through an initial assessment of their recent political and economic fortunes, including a brief consideration of the interrelationship between global, institutional and 'contingent' factors as changes in welfare provision unfold. Thereafter the following four chapters examine contemporary developments in labour market and pensions policies. In each case, the prevailing policy context is considered before the discussion moves to an assessment of policy shifts in the nine countries.

Many people have helped in the preparation of this book - some of whom are quite unaware of the uses to which their advice and information have been put. Thanks must go to my colleagues in the School of Applied Social Sciences in Durham for allowing me two periods of research leave to get to grips with what, for me, is a new area of research. Thanks, too, to the Department of Sociology and Anthropology at Simon Fraser University, Vancouver, for giving me the space, time and library facilities needed to begin this study. More specifically, Dan Finn, Karl Hinrichs, Jon Kvist, Einar Overbye, Nils Ploug and Barbara Sianesi answered 
Preface xi

my emailed questions fully and with speed, as did Tito Boeri and Maurizio Franzini. Hermann Schwartz not only replied to my enquiries but told me that the area of welfare state change is a 'conceptual nightmare' - he's right. Chris Pierson read some of the typescript and Richard Parry all of it. Their advice was much appreciated and thanks are due to both for their interest and help. Taking the time to read lengthy typescripts is a mark of generosity in what are inevitably busy academic lives. As to the final result, errors of fact and interpretation are, of course, my responsibility alone. 



\section{1 'Globalization', institutions and welfare regimes}

This book takes as axiomatic the fact that welfare states in the 'mature democracies' are changing. According to many observers, 'globalization' is somehow responsible for the development of different social policy alternatives in contemporary welfare systems and it is primarily this issue that will be considered in detail throughout this volume. However, the apparently simple relationship between 'globalization' and welfare regime change is of course nothing of the sort. For one thing, the nature and extent of global challenges are hotly contested and it is not clear that the - primarily economic - pressures involved have had the impact on welfare policies that globalization enthusiasts claim. Certainly, the argument here does not hold that welfare systems in the OECD are embarked upon an inexorable 'race to the bottom' in which rampant globalization forces once-autonomous nation-states to outdo one another in their efforts to cut social spending, maintain low interest and tax rates, and thus remain economically attractive for inward investment - a sort of economic beauty contest in which multinational corporations sit as judge and jury. Arguments of this nature will be examined in the course of this volume but, on the whole, they will be rejected in favour of an analysis that presents a more complex and mixed picture of the fortunes of contemporary welfare regimes.

Such an analysis certainly recognizes that globalization has influenced welfare policies in different welfare systems - indeed a key argument of this book is that 'neoliberal drift' is an important phenomenon from which few regimes are entirely immune. The difficulty, though, is how best to understand the pressures and counterpressures to which national governments are increasingly subject while bearing in mind that their welfare systems, which have become deeply embedded over time, are unlikely simply to 'collapse' in the face of new challenges. As an initially schematic starting-point, two significant dimensions of discussion need some elaboration before being explored more fully in Chapters Two and Three. First, the economic dimension is important in its own right and 'globalization', however contentious the term appears to be, is an immensely significant issue. Some observers, for example (see Giddens, 1990, 2000), argue that the increasing power of global capital constitutes by far the most serious difficulty for national governments struggling to manage welfare systems in increasingly open economies. Others appear equally convinced that the pressures confronting contemporary welfare systems are more attributable to endogenous economic difficulties, particularly 
the domestic roots of deindustrialization and the turn towards the service economy. An alternative perspective would play down the causal significance of economic factors to suggest that institutional infrastructures can prevent, or at least mitigate, pressures in ways that preserve the core characteristics of national welfare systems as these developed over the second half of the last century. Whether or not these 'institutionalist' arguments are accepted, they have come to influence perceptions of contemporary welfare state politics in some quarters in recent years, acting as a significant counterpoint to those who believe that economic pressures - 'global' or 'domestic' - can directly account for welfare regime change.

But to conceive change in terms of these stark binaries is itself problematic as the discussion below suggests. If these key perspectives broadly frame the main concerns examined in this book, it is important to understand not only how they might 'condition' one another - the interrelationship between economic and institutional factors being of central significance - but also how this 'economic-institutional nexus' organizes other factors which also play a major role. Here shifting demographic patterns are amongst the most important new challenges facing national welfare systems, the contention being that these do not somehow lie outside the nexus but are very much a part of it - as the discussion of the changes currently being made to pensions systems demonstrates (see Chapters Six and Seven).

In essence, the argument here is that national welfare systems are changing as new economic pressures interact with existing institutional arrangements - political, social and cultural - in ways that render the latter less stable. This embryonic instability means that welfare systems are becoming more vulnerable to other challenges that confront them - less able, for example, to rely on the 'traditional' policy solutions and institutional configurations that characterized welfare politics throughout the postwar period. Clearly the nature of change will depend on the particular welfare system in question - and a short discussion about the nature of 'welfare regimes' will be conducted below. Before getting to this, however, a brief assessment of the key themes of 'institutionalism' and 'globalization' is required.

\section{Institutions, 'globalization' and retrenchment politics}

As March and Olsen (1998: 948) state, institutionalization refers to processes that involve 'the development of practices and rules in the context of using them [that have] earned a variety of labels ... which refer to the development of codes of meaning, ways of reasoning, and accounts in the context of acting on them'. So far as welfare is concerned, the main contention behind the institutionalist position is that the embedded organizational structures on which particular policies rest, together with the assumptions and expectations about the nature of 'welfare' that develop over time among interested parties, conspire to make radical reform difficult. Paul Pierson (1996: 152) notes, for instance, that 'relatively stable, routinized arrangements structure political behavior'. Depending to a degree on regime type, those who are critical of the extensive state-based welfare systems which developed among the advanced democracies, mainly in the postwar period, can find it difficult to formulate policy alternatives acceptable to a range of interests 
which have come to depend - socially, economically, culturally - on specific forms of welfare provision. There are a number of reasons why this may be the case, the precise argument varying according to different interpretations of the institutionalist position. Rational choice institutionalists, for instance, contend that 'actors follow a logic of expected consequences within institutional constraints' (Beyeler 2003: 154), the suggestion being that change will only occur 'because of shifts in the actors' opportunity structure'. In short, the core focus is on 'how individuals build and modify their institutions to achieve their interests' (Campbell, 2004: 15). A second, more 'sociological' variant of institutionalist thinking argues that social actors 'behave according to a logic of appropriateness within their institutionally defined roles' (Beyeler, 2003: 154). Behaviour here is less 'rational' and more likely to be generated through the sense of identity that institutions can create in both individual and collective actors. Importantly, according to Beyeler (2003: 157), in the sociological institutionalist view 'the autonomy of actors is based on rather than restricted by institutions' with the result that 'institutions are changed if the underlying values are eroding and identities with the previous institution get weaker'.

These differing approaches are best understood as ideal types within the institutionalist paradigm. In effect they form the two ends of a continuum of potential behavioural responses to pressures for change with the pure 'rational actor' model at one end and the more sociological, identity-driven model of institutional attachment and belonging at the other. Significantly for the discussion here, Beyeler (2003: 158) notes that the further that strict rationality arguments are relaxed the easier it becomes to understand that 'policy-making can clearly not be conceived as a simple functional reaction to changes in the environment'. Struggles and power conflicts will emerge in key areas of institutional change with different actors adopting different positions and strategies depending on their particular interests and location within the prevailing institutional structure - that is to say, their 'location' within the sets of 'rules, norms, institutions and identities that drive human action' (see March and Olsen, 1998: 958) in particular ways and specific contexts.

That individuals act in a more complex and bounded manner than would be dictated by pure 'rational' self-interest opens up important dimensions of debate about the nature of path-dependent change and institutional stickiness. These include the need to consider both the 'formal' and 'informal' factors that may conspire to reduce the potential for radical change while permitting 'adjustments' to existing policies and practices. At the formal level of the nation state, for example, 'veto points' may be expressly written into constitutional design in order to guard against the prospect of damaging changes driven through by unrepresentative or overpowerful interests. Reinforced majorities may be required for major reforms, while in consociational systems minorities have a constitutional right to block certain types of reform proposal. In federal and/or bicameral political systems there are formal mechanisms for controlling over-enthusiastic governmental executives either through countervailing power from devolved legislatures or the capacity of second, or upper, assemblies to block or delay proposed legislation. Constitutional arrangements such as these can become an entrenched part of political culture 
and national identity with the result that they are likely to prove 'sticky' when confronted by pressures for change. Less formally - and irrespective of constitutional considerations - the 'embeddedness' of policies within both the state and civil society can be highly significant, with 'policy legacies' or 'feedback' exercising powerful sway over attempts to change existing forms of provision, delivery mechanisms and, indeed, the historically induced, cultural assumptions that citizens themselves hold about the role and purposes of (in this case) welfare. The 'increasing returns' generated as a result mean that decisions taken at earlier points of policy history can become self-reinforcing or 'path-dependent'. In this way, as Pierson (2000a: 491 original emphasis) notes, 'it is not just that institutional arrangements make reversal of course difficult. Individual and organizational adaptations to previous arrangements may also make reversal unattractive'. Core elements of welfare systems offer particularly clear examples of the issues at stake here. Pierson (1998: 552) notes that 'huge segments of the electorates of advanced industrial societies rely on the welfare state for a large share of their income' and, further, that 'deeply institutionalized programs like health care and pensions [mean that] social actors are likely to place high value on predictability and continuity in policy' (Pierson, 1998: 555). In consequence, it is hardly surprising if proposals for social reform are often closely contested by different interests and that political outcomes tend to favour evolutionary adjustment and the status quo (Ingram and Clay, 2000) over radical change where assumptions about the nature and role of central services - and the identities that are therefore bound into them - encounter external challenges. In this way, such external pressures are socially, politically and culturally 'mediated', the argument being that the relationship between these pressures and the attempts by governments and other actors to manage them will be both complex and non-linear.

Conducted at this level of generalization, it seems sensible to suggest that the inclusion of 'complexity' - to employ a useful shorthand - in the discussion appears to justify the institutionalist viewpoint over those who argue that global economic pressures can have a direct 'hypodermic' effect on national governments and their populations. However, there are a number of weaknesses associated with the institutionalist position that need to be taken into account which undermine its potential influence. It is clear from recent work by Campbell (2004) that institutionalists tend to operate with ill-defined notions of change and loose conceptions of 'institutions' with the result that it is not always clear which types of change, levels of institutional analysis, time frames and so on are being examined. This lack of specificity obviously affects efforts to track and explain patterns of institutional change. Going further, Campbell (2004: 66) also points out that the processes or 'mechanisms' to which institutionalists refer when analysing the underlying reasons for the prevalence of incremental or evolutionary change are often poorly specified. 'Path-dependence' tends to be intuitively associated with incremental shifts but, despite Pierson's (2000b) efforts to furnish the idea with the additional notions of feedback mechanisms and increasing returns, Campbell believes these processes need to be better articulated.

These points are not trivial, for how core variables and processes are defined 
and understood influences and conditions perceptions of the consequences of change. For example, an analysis of the development of 'privatization' and devolution policies in the welfare arena across the majority of OECD countries could lead to different understandings of welfare state change depending on preconceptions about the role of the state, the history of welfare state development in particular countries and the responses of the institutional actors involved. The 'typical' institutionalist response would argue that privatization has become a particular technology of the state, which has been appropriated in ways that enable the latter to continue to play a central role in the development and delivery of social policies. In this way, Smith (2002: 82-3 my emphasis) can argue that although

government social policy increasingly relies upon a mixed public/private delivery system characterized by extensive contracting between government and nonprofit and for-profit service providers [and] tax credits for private organizations to pursue specific public policy goals ... and allowances and vouchers for housing, childcare and other services ... the rise of these new tools has offered government new opportunities to regulate private social and health organizations.

However, others could argue with equal justification that this shift towards a regulatory state constitutes more than merely an incremental adjustment of existing practices. On this view, the explanations associated with theories of evolutionary change - path-dependence, increasing returns, 'lock-in' effects and so on - cannot account alone for the emergence of new policies, or the reconfiguration of old ones, on the scale experienced in many of the mature democracies in recent years.

It may be that it is not possible to resolve differences of perception of this kind. Institutionalist conceptions of change and the pressures that drive it may simply be too elastic to permit anything more than a broad account of the possible forces at work and factors involved. To take one further example, it has been suggested by Rothstein (1998) that core institutional components of welfare are likely to persist, even as changes occur, owing to the influence of historically and culturally embedded assumptions (and it could be added 'identities') about the role of welfare in any particular polity. So Rothstein (1998: 214) can argue with reference to Sweden that citizens' demands for 'freedom of choice and self-determination by no means spell the end of the universal welfare policy'. This conviction is based on the view that 'how extensive the public commitment to the well-being of citizens should be is an altogether distinct question from whether or not the services following on this commitment should be produced by organizations which are publicly owned' (Rothstein, 1998: 215). The statement is significant because it appears to suggest that the institutional and cultural parameters of Swedish welfare universalism persist even as the state's role and indeed citizens' behaviour, change. Of course, Rothstein may be correct to argue that there is a distinction between a public commitment to the universal welfare state and the delivery mechanisms required to sustain it. Even so, if the Swedish welfare regime does indeed remain formally attached to its universalist principles, could changing citizen perceptions together with the 
persistent policy changes of the kind implemented in recent years hollow out these principles in a way that ultimately forces a transformation of the role and purposes of welfare? If such a shift was to occur, how sure could institutionalists be of identifying the precise point at which the cumulative impact of change pushed institutionalized practices, norms and values beyond what could be anticipated from persistent incremental adjustment?

In view of these considerations, institutionalist arguments seem to be important for two reasons. First, they act as reminders of the complexities of embedded social, political and cultural arrangements in national welfare regimes, the existence of which reduce the likelihood of external pressures exerting a direct or linear transformative influence on national institutions. Second, however, because the institutionalist perspective is vulnerable to the criticism that it lacks conceptual rigour, it acts as reminder of the necessity not only to be as clear as possible about the definition of key concepts - 'change', timescale and even the notion of 'institution' itself - but also of the need to recognize that the identification of 'complexity' as a core issue is no substitute for the careful consideration of the mechanisms and processes which mediate external pressures. It would be dangerous to assume that, because the impact of external pressures may be nonlinear, they are somehow not important or do not exercise much influence over institutional change. And it is for this reason that it is important to conceptualize the relationship between exogenous pressures and welfare institutions (in the broadest sense) in terms of an economic-institutional nexus within which the balance of influence will shift according to regime type and depending on the mix of factors involved. While it may be correct, for instance, to argue that 'globalization' is unlikely to undermine existing arrangements entirely - and to produce statistical evidence to support such a conclusion (see Castles, 2001, 2004; Swank, 2002) - the manner in which global economic pressures (GEPs) impact on different welfare regime types will vary. For those better disposed towards the globalization thesis than institutionalists tend to be, the point is not always to endorse the thesis wholesale but to investigate the extent to which GEPs influence the institutional character of different regimes and vice versa as governments attempt to deal with both global pressures and a range of contingent factors, some of which will be 'domestic' in origin. Within the global-institutional nexus, GEPs may corrode existing practices and identities in certain cases or reinforce particular tendencies and arrangements in others. Conversely these pressures themselves can be accommodated, increased or reduced depending on prevailing institutional arrangements and predispositions.

Certainly for Gilbert (2002) and others like Jessop (1994, 2002), welfare states have changed dramatically as part of a broader transformation of the state itself and GEPs are held to play a significant part in this process. Gilbert (2002: 15) suggests, for example, that 'the evidence indicates that a basic shift has occurred in the institutional framework for social protection ... most prominently in the United States and England, with other advanced industrialized nations moving steadily in the same direction'. This shift takes the form of a move from the 'welfare state' of the postwar world to the 'enabling state' of the late twentieth-early twenty-first 
centuries and is being driven by a combination of factors, of which 'the globalization of the economy' (Gilbert, 2002: 37) is amongst the most prominent.

Jessop regards the changing nature of welfare as part of a wider global transition from Fordist to post-Fordist modes of capitalist accumulation. In relation to welfare states, the move is conceptualized as a transition from the 'Keynesian Welfare National State' to the 'Schumpeterian Competition State'. The processes associated with this Schumpeterian turn are at their most visible in the 'Atlantic economies' of the USA, the UK and (because they increasingly became part of this economic bloc owing to their relationship with the UK and military connections with the USA) Australia and New Zealand - although they are also beginning to emerge elsewhere. For the traditional welfare state, the hallmarks of change are the use of social policy to 'enhance the flexibility of labour markets and to create flexible, enterprising workers [as well as to] put downward pressure on the social wage' (Jessop, 2002: 168) in order that states remain competitive in the global marketplace. Importantly, however, Jessop does not argue that these changes in accumulation regimes fundamentally undermine all forms of domestic welfare provision. $\mathrm{He}$ acknowledges that different systems will exhibit path-dependent variations in their developing welfare mixes - so institutional structures count - the implication being that nation-states, particularly those outside the liberal economies, may be able to redesign forms of collective partnership and 'recalibrate existing institutions to deal with new problems' (Jessop, 2002: 171). In short, politics still matters, although 'context' is important. This latter dimension is particularly significant because, as Jessop is concerned to point out, in a prevailing environment where the 'national spatial scale' has lost the 'taken-for-granted primacy it held in postwar Atlantic Fordist regimes, no other scale of economic and political organization ... has yet acquired a similar primacy in the current phase of the after-Fordist period' (Jessop, 2002: 179). Even so, the 'global', for Jessop, constitutes an alternative spatial scale, albeit one that exists alongside national, regional and local spaces around and within which competitive economic activities take place, rather than dominating them.

There is a tension here between the 'global' and the 'national' or 'local' that needs to be examined in more detail. According to Jessop (2002: 181),

whereas the capitalist law of value increasingly operates globally, subjecting all economic and economically relevant activities to the audit of the world market, the pursuit of place-specific competitive advantages by firms, states and other actors is still rooted in local, regional or national specificities.

Now, as they become more fluid and loosen from their postwar moorings, welfare systems are emerging as a major example of a 'place-specific advantage'. Because they remain almost by definition national/local, welfare systems can be routed into governmental efforts to (re)construct economies in ways that contribute to their capacity to perform in the global marketplace. These efforts do not mean that welfare per se is neglected - but existing arrangements will come under scrutiny in ways that are likely to threaten the interests of those who have come to depend on them. In this sense, welfare systems stand on shaky ground - are 'unsettled' as 
John Clarke (2004) would say - and this verdict can be extended past Jessop's Atlantic Fordist regimes to other OECD states as subsequent chapters of this book demonstrate. It is in this indirect manner that 'globalization' can be said to have a hand in conditioning welfare state change.

But what hand? These observations say little or nothing about the direction of causation or the relative strength of global influence. 'Globalization' is likely to be implicated in the loosening of postwar welfare structures in the advanced economies but, as intimated above, to acknowledge that GEPs can act as conditioning factors is not to suggest that the causal sequence of changes among different welfare systems necessarily begins with them, let alone that they are solely responsible for the strains that many systems are experiencing. Indeed this is the difficulty with the many efforts that have been made to establish a linear relationship between particular pressures, for example the increasing 'openness' of trade which is frequently taken as a measure of 'globalization', and welfare state change (see Chapter Two and, for instance, Garrett, 1998; Castles, 2001). The discussion above outlined the contention, discussed in depth elsewhere, that economic and social policies are more closely intertwined than is often supposed - the point being that causality can flow in both directions, with socio-political influences capable of influencing economic outcomes as well as vice versa. Rieger and Leibfried (2003: 14) are surely right, for example, to point out that 'the raison d'être of the welfare state is its use of political power to supplant, complement or modify operations of the market system in order to achieve discrete results which the market would not achieve on its own'. This formulation is widely accepted, particularly where the historical development of welfare states is concerned (Polanyi, 1957). However, a slightly different point made by these commentators may be equally valid. Rieger and Leibfried contend that the re-emergence of market influence in many mature welfare regimes in the past twenty years has as much to do with 'politics' as 'economics'. Pace institutionalism, Rieger and Leibfried (2003: 29-30) argue that, over the past twenty years or so, voters have come to see that in the postwar political currency of social spending 'government and politics have reached the limits of what they had promised to provide' and voted for governments that have advocated reductions in public spending and the increased influence of markets. The upshot of this 'growth to limits' argument is that

the conditions that are currently described as globalization were created and advanced both in terms of their institutional foundations and their dynamic by parliamentary, democratically legitimated decisions [and]...Globalization was and is subject to an ongoing plebiscite of consumers and voters and is shaped by this perpetual plebiscitum.

(Rieger and Leibfried, 2003: 31)

There is at least some truth in these statements, although the particular construction of voter rationality as an acknowledgement that welfare has grown to limits, as opposed to merely being an expression of a short-term desire for tax cuts and other immediate individual benefits, may be open to doubt. The main point here, though, is the idea that the economic and the political spheres are permeable, 
'related' and fluid, each conditioning and influencing the other. As Clarke (2004: 76) notes, 'the state has secured the conditions of capital accumulation. It has institutionalized and legitimated the core interests and orientations of capital (not least in legal forms). It has attempted to create the social (and economic) peace advantageous to continued profitability'. And yet, it seems equally valid to suggest that the ways in which the state works to secure conditions for capital accumulation have been disrupted by significant changes in the concentration and behaviour of capital, particularly at the global level. While such a judgement does not deny the continued significance of state efforts to support capital, GEPs, at least as presently configured, are also capable of challenging and conditioning political responses (the nature and extent of this conditioning naturally being influenced by local context and regime type).

On this view, the existence of both economic constraints on political demands for particular welfare solutions and political limits on the impact of economic pressures needs to be acknowledged. In other words, the economic and political spheres are simultaneously interrelated and in tension: 'economics' can escape 'politics' and vice versa even as both spheres remain interdependent. This uneasy relationship is almost necessarily the case because, as Rieger and Leibfried (2003: 51) note, 'the parameters of welfare state intervention - the widespread experience of social insecurity and economic scarcity - have not disappeared in the new international economic world'. There is a continued need to pursue what the old British socialists called 'social amelioration' in all regime types - and all the more so because governments in all welfare regimes are having to deal with a range of new social risks (Taylor-Gooby, 2004). A key factor here is how different regimes organize such provision in the increasingly fast moving, competitive global economic environment.

Before moving on to a brief consideration of the nature of welfare regimes, one final issue concerning the broad nature of 'globalization' needs some attention. Whatever its precise nature and impact, the above discussion treats 'globalization' (or GEPs as the preferred term) as potentially having a significant material influence on sovereign nation-states and their welfare systems. While, as Chapters One and Two suggest, some observers believe that the extent of this influence is exaggerated, they nevertheless treat GEPs as 'real'. An alternative view, however, understands 'globalization' as a 'myth', constructed by politicians and others keen to retrench on domestic social spending in favour of 'capital friendly' economic policies and the prospect of a global free market. The concern is that the myth of the omnipotence of global markets and their capacity to reduce the economic sovereignty of nation-states will escape the 'natural' confines of neoliberal party politics and infect social democratic politicians in particular and left-inclined regimes more generally. Hay (2000: 151), for example, has suggested that social democratic systems, historically characterized by their adherence to centralized structures of economic and industrial relations as well as welfare provision, may actually be under less threat from globalizing processes per se than from infection by 'ideas about globalization ... [which] continue to be internalized as common sense among politicians of the nominal left'. If he is correct, the risk is that left-of-centre political parties and governments could drop their resistance to laissez-faire economic 
strategies, and accept the neo-liberal baggage of dual-labour markets, tax cuts and welfare retrenchment, on the basis of rhetorical appeals grounded in particular discourses of globalization (Hay and Rosamund, 2002) rather than observed or 'established' evidence of the impact of external economic constraints. The 'logic of no alternative' would prevail.

There is something to recommend this position because it can account for why certain social democratic parties - New Labour in the UK being a foremost example - have adjusted their social policies so markedly in a neoliberal direction in recent years. Again, it is unlikely that the precise nature of the constraints imposed by GEPs can ever be accurately quantified in economic or political terms, so there will always be a space in which rhetoric and myth will operate, particularly in the political realm. As Hay and Rosamund (2002: 148) note, 'it is the ideas that actors hold about the context in which they find themselves rather than the context itself which informs the way in which actors behave'. However, to leave the issue at this point is hardly sufficient because 'context', though discursively 'informed' is rarely only discursively constructed. Of course, even if context was all, a rather cheap shot at the myth thesis would argue that GEPs appear to impact on the social policies of different welfare regimes in one way or other and, to this extent, 'globalization' matters irrespective of its status. GEPs, in other words, are 'real' if they are 'real in their effects'. More substantively, though, the interrelated nature of the economic and political spheres referred to here, and particularly the argument that capital and the state condition and legitimate one another, suggests that there is more than just political rhetoric at work. The presence of a discursive dimension - including the tendency of politicians and policy-makers to deploy certain rhetorics in particular contexts as a means of justifying unpopular policies - is beyond doubt but it is equally likely that political argument about the role of the state and its relation to capital cannot simply be reduced to 'discourse'. It is far from clear that politicians and policy-makers are capable of developing, let alone sustaining, sophisticated discourses and their accompanying rhetorics in the absence of at least a degree of 'hard evidence', although this evidence will inevitably be open to interpretation and tailored to context. The further point made by Hay and Rosamund (2002: 163), of course, is that 'the deployment as political rhetoric of discourses of globalization ... is both strategic and by no means homogeneous, varying significantly from national context to national context and, indeed, from political party to political party'. Absolutely - but it is likely that there is more than discursive tactics at work here. Any attempt to explain the diversity of responses must take account of the prevailing nature of entrenched political/institutional/ cultural arrangements across different regimes in the OECD and the manner in which they interract with global economic challenges. As the discussion in the next section makes clear, welfare regimes differ widely in character so it is hardly surprising that their relationship with the global economy is far from uniform.

\section{Understanding welfare regimes}

To this point the discussion has proceeded with a deliberately loose understanding of the terms 'welfare state' and 'welfare regime'. However, an assessment of the 
impact of GEPs on welfare arrangements in the advanced societies needs to be preceded by a brief consideration of how the concept of a 'welfare regime' is used here.

There have been many attempts to 'classify' welfare systems over the past forty years or more beginning with the basic assumption that levels of social spending in any particular state equate with its commitment to welfare. Differences in spending levels were thought to be attributable to phenomena such as the extent of industrialization (Cutright, 1965) or the ability of key social groups to mobilize successfully in favour of particular forms of welfare provision (Korpi, 1983). More recent work on comparative welfare systems has acknowledged that, taken alone, social spending levels provide an inaccurate measure of welfare effort unless the nature of the recipients and the spending objectives are made clear. High social spending is not necessarily commensurate with the redistribution of income and wealth towards the worst off, for example, or even with a commitment to social inclusion - and here attempts to contextualize spending data by analysing the institutional features of particular welfare systems add a good deal to understandings of how and why different systems are organized as they are. This information can in turn be employed to advance comparative research by grouping together systems with similar characteristics to produce a limited number of ideal types. Richard Titmuss (1963) was one of the first to attempt to classify welfare systems in this way. His distinction between 'residual' and 'institutional' systems indicated a difference between those states that regarded the market and/or the family as the main providers of social goods and services, only protecting individuals from the consequences of market failure through the provision of minimal public services, and others where the commitment to welfare was a matter of citizenship, with universal, comprehensive protection against core risks being provided as of right.

This initial attempt to distinguish among differently constituted types of welfare system was radically improved upon by Gøsta Esping-Andersen (1990). His concept of a 'welfare regime' is now commonly used to signal the interrelationship between the nature of social goods and forms of welfare delivery, on the one hand, and the historical development and configuration of certain economic, social and political institutions that make up the wider system of governance in which these arrangements are located, on the other. In the same way as a 'production regime' refers to an extensive array of institutions, activities and interrelationships which comprise particular 'varieties of capitalism' (Soskice, 1999) or 'economic governance', a welfare regime refers to the key practices and institutional characteristics that together make up a system of 'social governance'.

In Esping-Andersen's (1999) opinion, welfare regimes in developed economies are shaped by three broad institutional dimensions which combine the core elements of a production regime with particular forms of social provision. First the labour market - the nature of work itself, the gender composition of the workforce and the structure of industrial relations - contributes towards patterns of equality and inequality, partly because the availability of employment will set limits to the ability of individuals and families to resource their own welfare provision, and partly also because general arrangements for insurance against risks largely depend on the tax and insurance contributions of a pool of fully employed individuals. Second, 


\section{2 'Globalization', institutions and welfare regimes}

the family is a major institution because forms of public welfare provision vary according to the extent to which families, and particularly women, are expected to cushion the effects of a number of 'risks' such as ill health and old age by providing unpaid care and support for their members. Finally, of course, the state, including the system of party competition, is deeply embedded in welfare provision because state-organized welfare development was a significant feature of nation (re)building in the postwar era (Esping-Andersen, 1996a: 2), and also because, during this period, state institutions were thought to guarantee higher levels of social, political and economic stability than potential counterparts in the private and voluntary sectors. To this end, as Marxists frequently used to point out (Gough, 1979; Offe, 1984), states in the developed world subsidized welfare capitalism by providing educational and training support, health care and other benefits which removed much of the burden of maintaining a healthy and educated workforce from employers.

As Esping-Andersen (1999: 5) has written, 'the sum total of societal welfare derives from how inputs from these three institutions are combined', with different combinations being associated with different types of welfare regime. When considering how regime types may be defined and categorized, it has become almost traditional to commence with Esping-Andersen's (1990) original attempt to categorize welfare regimes according to an index of 'decommodification'. This measure refers to the extent to which the different systems of social protection which developed across the advanced economies during the first two-thirds of the twentieth century relied on the market as the prime mechanism for dealing with key individual risks - unemployment, sickness and old age being the obvious examples. The model identified three clusters of welfare regimes which reflect the institutional arrangements, the associated political infrastructures and the patterns of stratification associated with these distinct forms of social governance. Briefly, Esping-Andersen (1990: 52) distinguished three regime types. Liberal regimes broadly the Anglo-Saxon countries - individualize risk and expect labour market participation to form the prime source of protection. These regimes have relatively ungenerous, means-tested benefit systems or social insurance programmes and high levels of social inequality. Moreover, social goods and services may be delivered by voluntary or private agencies at one remove from the state. Clarke's (2001: 32) view that the terms 'welfare' and 'state' can no longer always be juxtaposed as easily as they tended to be throughout the postwar period is particularly apposite when applied to liberal regimes; as he comments (Clarke, 2001: 30), the place and role of the state varies "in different "welfare mixes" or "mixed economies of welfare". Second, the 'conservative corporatist', social insurance regimes of Northern and Western Europe tend to 'collectivize' risk where income security for labour market participants is concerned, relying on employer and employee contributions to provide generous replacement rates for certain groups, mainly male breadwinners. However, these regimes are less generous when it comes to the provision of social services - in the majority of cases the family (and particularly women) is regarded as the main source of social care, supported by voluntary and private service providers. Finally, the universalist, social democratic systems of the 
Nordic countries tend to be the most highly decommodified with risk being collectivized in the form of generous 'citizen benefits' across all aspects of income security as well as universal access to social services.

How accurate does Esping-Andersen's model remain fifteen years or so after it was first developed? For all its undoubted influence, the model has never been regarded as entirely uncontentious (see for example Bambra, 2004). Criticisms are broadly of three closely related kinds. First, there are those who argue that 'three worlds' of welfare capitalism are insufficient to capture the nature of existing regime types and that, depending on the particular perspective employed, the model needs to be complemented by a 'fourth world' of one kind or other. Second, there are extensive debates about Esping-Andersen's assignation of particular countries to particular categories, with a number of attempts being made to reposition them. Third, these criticisms often lead to attempts to develop alternative classificatory systems which are held to be better able to account for the anomalous cases within Esping-Andersen's system while simultaneously accommodating fourth world regime types.

On the first count, convincing cases have been made for adding a number of fourth worlds. Huber and Stephens (2001), for example, follow Castles (1996) in querying the inclusion of Australia and New Zealand as liberal regimes, preferring to regard these Antipodean states as a fourth 'wage-earner' category, at least until the 1980s when first New Zealand and later Australia began to pursue explicitly neoliberal welfare policies. Other fourth categories have also been proposed Goodman and Peng (1996: 194) refer to 'Japan-focused East Asian welfare regimes', while Leibfried (1993), Ferrera (1996) and Bonoli (1997a) suggest that Southern European states comprise a separate 'Latin Rim' or 'Mediterranean' model owing to their tendency to have more particularistic and fragmented forms of social insurance and less robust systems of social assistance in the context of a greater reliance on the family as the major source of social care.

On the second count, the 'correct' allocation of countries to the various categories has been the subject of much scholarly debate. Van Kersbergen (1995), among others (see also Daly, 2000; Sainsbury, 1996), has questioned whether EspingAndersen's assignation of the Netherlands to the social democratic category accurately depicts the Dutch approach to welfare, which has many 'continental' elements, while Robert Goodin (2001) has argued that contemporary Dutch attitudes to employment are indicative of the Netherlands' recent turn towards 'post-productivism'. For their part, Arts and Gelissen (2002: 151) argue that 'the Netherlands is ... more a hybrid case than a prototype of a specific ideal-type', the point being that 'if one attaches more importance to certain attributes than to others ... then it is easy to arrive at different classifications'. The Dutch case is by no means the only awkward example when it comes to classifying regime types. Austria, too, is problematic, being amongst the most egalitarian regimes, owing to the strength of the Austrian labour movement, while also exhibiting distinctly 'continental' characteristics by virtue of its conservative/Catholic legacy. Again, the United Kingdom has not been universally regarded as a typical liberal or Anglo-Saxon regime - or at least not until recently. Esping-Andersen (1990) places 


\section{4 'Globalization', institutions and welfare regimes}

the UK as the least commodified of the 'liberal' group of nations but, in view of the nature and direction of developments in UK social policy, commencing in the early 1980s (Ellison and Pierson, 1998; 2003) there is good reason to regard the $\mathrm{UK}$ as a fully paid-up member of this group in the wake of eighteen years of Conservative rule.

Third, alternative forms of categorization have been suggested by a number of commentators with feminist writers leading the charge. A key issue here is the view that Esping-Andersen is too preoccupied with the state-market dimension as the primary source of variation among regime types to the exclusion of alternative dimensions of welfare which could produce different kinds of clusters. Of course, Esping-Andersen's original raison d'être was precisely his conviction that the 'powerresources' approach to welfare regime development could explain much of the variation in the ways in which different regimes have become institutionalized. 'Decommodification', in his view, lies at the heart of struggles over the nature and delivery of social goods and services, its nature in any individual case being determined primarily by 'the nature of class mobilization (especially the working class); class-political coalition structures; and the historical legacy of regime institutionalization' (Esping-Andersen, 1990: 29). Nevertheless, alternative methods of classifying welfare systems have proved influential. O'Connor (1996: 60) has noted, for example, that the privileging of decommodification elevates 'the class-citizenship aspect of social rights and stratification with fairly minimal attention to other bases of stratification'. Social rights and entitlements, irrespective of gender, are certainly important but, as O'Connor (1993: 513) points out elsewhere, 'before decommodification becomes an issue for individuals a crucial first step is access to the labour market' because 'limitation of access ... may be the result of systemic discrimination or inequality of condition, such as that associated with caring responsibilities'. On this basis, the categorization of welfare systems according to their approximation to the 'male breadwinner model' (Lewis, 1992) produced a typology of regimes that cut across Esping-Andersen's three worlds.

Other approaches also produce configurations of welfare regimes that differ from those proposed by Esping-Andersen. Daly and Lewis (2000) have suggested that 'social care' - the manner in which different regimes organize the care of children and older people - constitutes one such example. According to Orloff (1993: 312), care services among the Nordic countries are not particularly similar with day care provision in Norway being 'much less developed' than in Sweden, while in the 'conservative-corporatist' countries, France provides many services for working mothers, while 'Germany promotes housewifery by offering few services'. Recent work on the provision of social care by Daly and Rake reinforces this view that the nature and extent of provision appears to be at variance with the 'three worlds' model. As they (Daly and Rake, 2003: 69) state, countries such as Germany, the Netherlands and the UK have 'relatively meagre' provision, with caring bearing much more heavily on women than is the case in Sweden or France. Italy and the USA, on the other hand, 'defy a conventional explanatory framework' because, in the former case, women's employment is fairly constrained and, in the latter, public care provision for children and older people is limited, although women have greater access to the labour market. 
From a perspective that wants to ensure that significant dimensions of the welfare mix are not ignored, these criticisms are important. In response, Esping-Andersen (1999: 61) has recently attempted to capture women's position in, and the relative contribution of the family to, welfare systems in different countries through the concept of 'de-familialization' (see Lister, 1994 in Baldwin and Falkingham). He argues that some countries - essentially the Nordic ones - do not treat the family as 'the primary locus of welfare' because state-provided social care and child allowances are available to all as a citizen right, thereby affording women the opportunity of much greater access to the labour market. Elsewhere, liberal and conservative corporatist nations continue to exhibit high degrees of familialization, albeit in different ways and for different reasons. Liberal states 'view servicing as a natural market activity, as an individual responsibility; conservatives insist that it be the prerogative of families' (Esping-Andersen, 1999: 76). Where liberal regimes are concerned, however, better off groups can 'de-familialize' because they can afford private care services, but this market-led approach only has a marginal public dimension and consequently accentuates both gender and class inequalities. Many conservative states, on the other hand, are characterized by a lack of generosity with regard to social assistance and, even with the numbers of women entering paid employment rising rapidly, certain nations, such as Germany and Japan, continue to demonstrate gendered assumptions about the role of the male breadwinner and, by extension, the expected role of women as unpaid carers and houseworkers.

The key feature of the concept of de-familialization is whether or not it can satisfactorily integrate the ways in which women and families are positioned in relation to welfare provision in different countries into the 'three worlds' model. In this regard, Paul Pierson (2000c: 801) points out that the concept closely parallels that of decommodification with 'a focus on gender issues [reinforcing] rather than [challenging] the now standard trichotomy of liberal, conservative and social democratic welfare states' - a view which accords with Lister's (1994) contention that both decommodification and defamilialization are important criteria for evaluating social rights. Bambra's (2004: 207-8) study bears out Pierson's conclusion, arguing that 'there are striking similarities between arrangements of countries in Esping-Andersen's decommodification regimes and the defamilisation (sic) groups [of countries] ... [and that] the "three worlds of welfare" typology is not altered in any significant way by the addition of a more overtly gendered approach'. So, according to these observers, and including family policies as a core dimension of the welfare mix, the three worlds approach remains plausible although anomalies are inevitable. Taking labour market regulation, welfare state organization and families as key organizing features, Esping-Andersen (1999: 856) presents the following clustering of regimes that broadly accords with his original classification:

- Labour markets are less regulated in the liberal countries (but including Denmark) and strongly regulated in the conservative corporatist states, with the remaining Nordic countries together with Japan, the Netherlands and Ireland constituting a 'medium regulation' group. 
16 'Globalization', institutions and welfare regimes

- Welfare state organization can be categorized in terms of a residual group (again the Anglo-Saxon countries make up the membership of this cluster), a universalist group, which comprises the Nordic countries and the Netherlands, and a social insurance group comprised of the conservative Continental European countries and Japan.

- Family policies can initially be divided between the 'familialist' nations essentially the Continental conservative regimes including the Netherlands and 'non-familialist' nations. However, this latter category falls into two types: the liberal states (which can only be categorized as 'familialist' if the fact that the bulk of care arrangements are privately organized is disregarded), and the Nordic states, some of which are extensively de-familialized.

'Fourth worlds' are rejected for a number of reasons not the least of which is the pragmatic need for analytical 'parsimony' - the contention being that ever greater refinement of categories risks compromising the attempt to classify regime types by effectively returning analysis to individual case studies. That said, EspingAndersen is prepared to recognize that certain elements of fourth world regimes should be accommodated within his schema. For example, he broadly accepts Castles' view that the strength of early labour movements in New Zealand and Australia led to the development of wage-earner regimes in these countries. Even so, Esping-Andersen argues that the move towards neoliberal solutions in New Zealand, which began in the 1980s, and a similar move in Australia in the later 1990 s, make this regime type a largely historical phenomenon. Where the Mediterranean countries are concerned, the arguments of Leibfried, Ferrera and others are rejected on the grounds that they concentrate on only one dimension of welfare governance (social assistance in Leibfried's case). Although the classification of welfare systems according to individual policy areas or particular social divisions may be an entirely valid exercise in so far as a comparative understanding of particular 'policy configurations' is important, Esping-Andersen claims that his conception of a welfare regime entails a broad aggregation of similarities (and differences) across a number of different areas of governance. He notes (EspingAndersen, 1999: 73), therefore, that "some criticisms of "the three worlds" are, in a sense, irrelevant because they are not addressing welfare regimes but individual programmes... a welfare regime typology does not stand or fall solely on one policy dimension'. What is important is to 'weigh the importance of different, possibly conflicting attributes' bearing in mind that 'one programme does not define a regime' (Esping-Andersen, 1999: 88).

\section{Utilizing welfare regime analysis}

This book is not 'about' the classification of welfare regimes. However, in order to see how different welfare systems have reacted in response to economic and political pressures over the past thirty years or so, it is important to establish a common baseline for discussion. In terms of regime types, Esping-Andersen's model continues to provide a convenient means of grouping different welfare systems as 
a foundation for further analysis. Of course, as Goodin et al. (2001: 13) make clear, while it is 'useful to try to put particular countries' welfare arrangements in some more general perspective' it is equally the case that 'no single country ... can truly be taken as representative of a regime type as a whole'. In other words, anomalies will continue to exist and differences within regimes types as well as among them are to be expected. Although, for some commentators (see Kasza, 2002), this innate diversity is sufficient to undermine the entire regimes concept, this is not the view adopted here. Treating the different regime types as broad, ideal-typical systems of welfare governance allows a sufficiently accurate initial grouping of general institutional characteristics to be able to see how countries within the different clusters behave in the paradigmatic space carved out by global economic and institutional forces discussed above. It is important to note, too, that a further advantage of the Esping-Andersen model lies in its capacity to incorporate 'production regime' characteristics as constitutive underpinnings of countries' welfare arrangements, the close connection between structures of economic production and welfare being particularly significant in relation to the impact, or otherwise, of economic globalization. However, before proceeding, one terminological modification needs to be considered and it is also necessary to incorporate 'generosity' in terms of social spending levels within the three worlds model - a theme which has become marginalized in recent debates.

The terminological modification refers to Esping-Andersen's 'conservative corporatist' group of regimes. 'Continental' is the preferred term here for two reasons. First, this label 'gets away from the misleading implication of EspingAndersen's work that the "conservative" welfare states of Continental Europe reinforce inequalities created in the market and thus preserve the stratification system' (Huber and Stephens, 2001: 87). Although, the nineteenth century origins of these 'Bismarckian' systems lie precisely in attempts to preserve status hierarchies, status differences in relation to employment have been progressively removed over the past fifty years. It is true, of course, that continental regimes remained attached to male breadwinner models of welfare over the postwar period, with the accompanying gender inequalities that this model implies. Even here, however, inequalities of this kind are not evident to the same degree in all countries in this cluster and, anyway, recent rises in the numbers of women in (largely part-time) employment have reduced the salience of this feature (Lewis, 2001; Pascall and Lewis, 2004). Particular care has to be taken when discussing continental regimes because there is a greater degree of institutional diversity here than elsewhere. As Daly (2000) and Hemerijck et al. (2000) recognize, although they have certain key features of welfare provision in common (most obviously extensive social insurance systems), other arrangements such as structures of industrial relations, the role played by the central state, and the degree of familialism vary considerably.

Concerning the 'generosity' dimension, in the eyes of some observers, EspingAndersen's concept of decommodification fails to take sufficient account of the different levels of coverage (the 'how much' of welfare regime activity) among different regime types. Whereas the concept can distinguish successfully among different delivery systems (the 'how' of welfare provision) by separating 
'Bismarckian' social insurance systems from those which are mainly tax financed in one way or other (frequently, and inaccurately, referred to as 'Beveridgean'), decommodification does not fully capture differences in social spending levels the original litmus test of welfare effort that now needs to be reintroduced in rather different fashion. This issue is addressed by Bonoli (1997a) who categorizes European welfare systems on two axes: levels of social spending expressed as a percentage of GDP and the percentage of social expenditure financed through social insurance contributions. The result is a typology that broadly corresponds to EspingAndersen's categories. As expected, the Nordic states appear as the most generous spenders, with universal coverage financed mainly through general taxation; the continental, social insurance states of Northern Europe are high spenders but coverage is not universal while their Southern European counterparts rely on similar delivery mechanisms but generally spend less; finally, the commodified liberal states in Europe - to which may be added other liberal regimes such as the USA, Canada, Australia and New Zealand - finance welfare effort from general taxation but spend less (and means test more) than other regime types.

Bonoli's typology is a useful additional means of understanding these specific features of welfare effort. If the drawback is that his model lacks a clear developmental or historical dimension - and only implicitly recognizes the importance of stratification on class and gender lines - it nevertheless provides a greater degree of clarity about the nature and organization of income security and a considerably clearer understanding of relative spending levels.

Integrating the concepts of commodification/decommodification, familialization/defamilialization and generosity/ungenerosity leads to a grouping of regime types that accords fairly well with Esping-Andersen's original model, the point, as suggested, being to use it as a baseline from which to discuss the nature and dynamics of subsequent policy changes in welfare regimes. There are, needless to say, exceptions and difficult cases within each of the categories.

- High decommodification, high-spending (general taxation), high coverage, defamilialized: the Nordic countries.

- Low decommodification, high-spending (social insurance), medium coverage, familialized: the continental countries including the Netherlands.

- Commodified, low-spending (usually from general taxation), high coverage, non-familialized (because 'de-familialization' relies on access to private services based on ability to pay): Anglo-Saxon countries including the erstwhile 'wageearner's states of the Antipodes.

Turning briefly to the particular regimes chosen for discussion in this volume, it is important to include those that best typified the above regime types according to data produced at the beginning of the 1980s. The accompanying Tables 1.1 and 1.2 provide data relating to welfare and production characteristics for the three core welfare regime clusters in the economically developed democracies circa 1980. As to the countries themselves, Sweden and Denmark have been chosen from the social democratic group because, though different in certain respects, they exhibit 


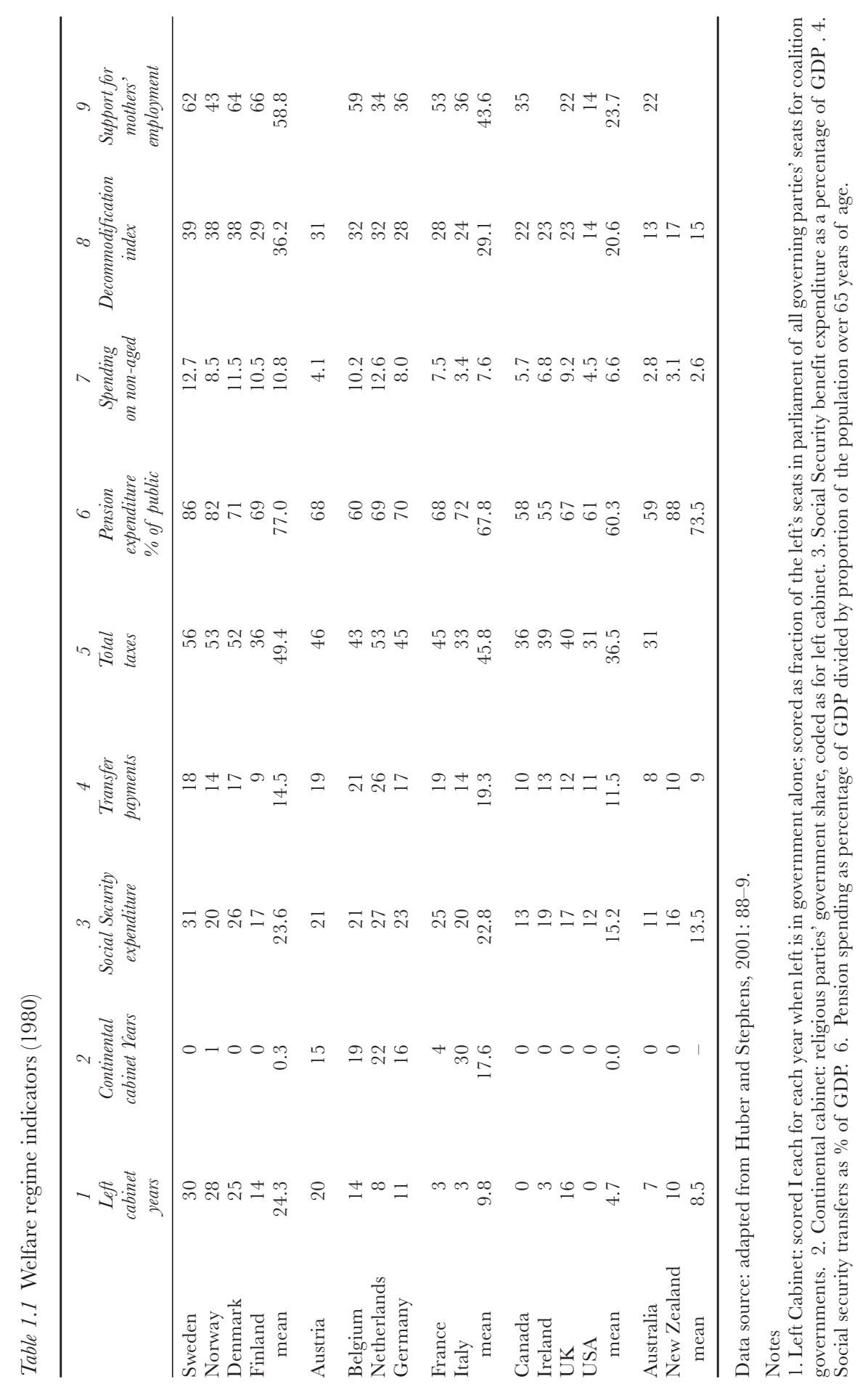




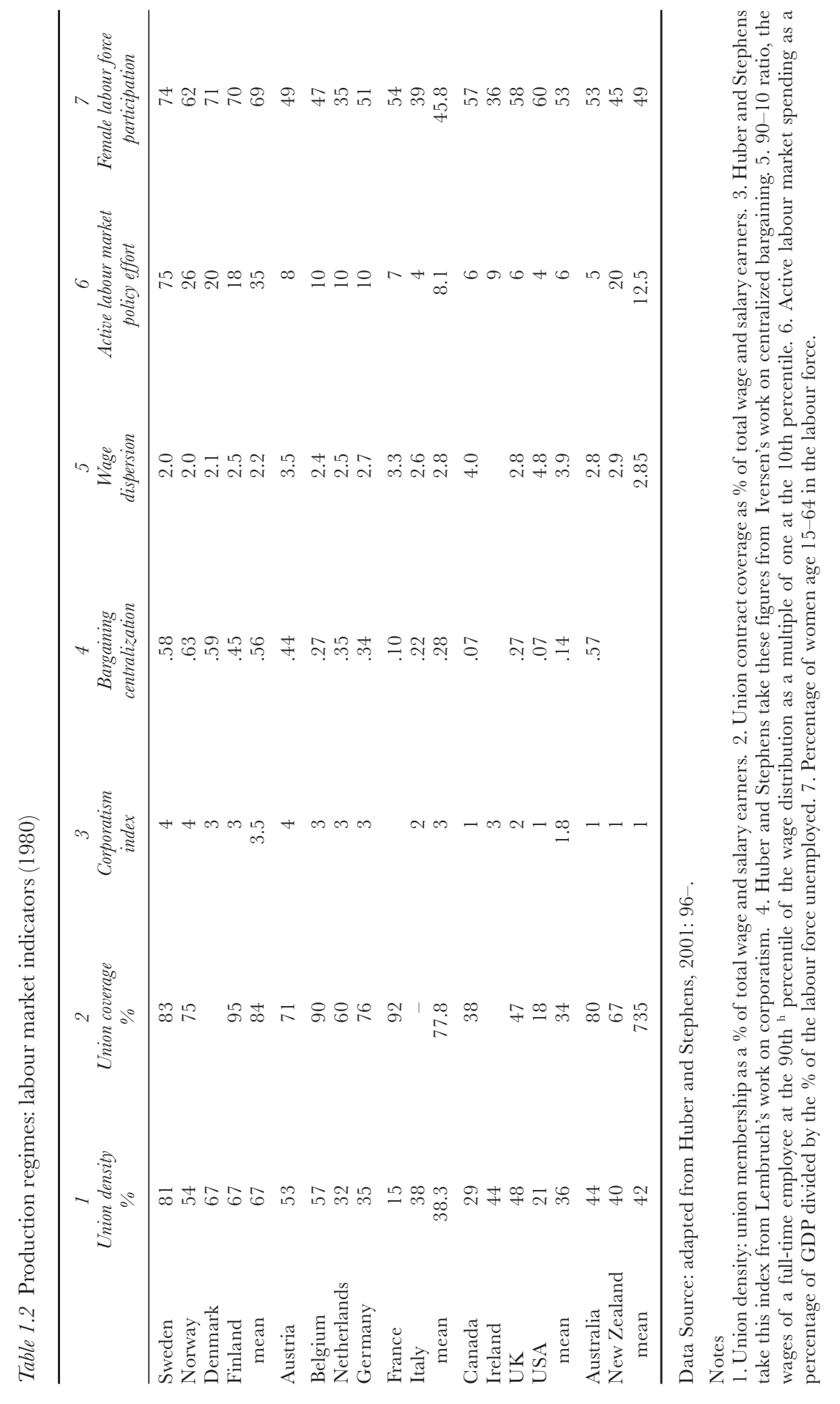


the core features both of the universalist welfare regime and the social democratic production regime. Moreover, unlike oil-rich Norway these countries were not economically advantaged during the difficult period of the 1990s and unlike Finland they were not especially disadvantaged by virtue of earlier inclusion in the old Soviet sphere of influence.

The Netherlands, Germany, France and Italy make up the continental contingent - a more disparate group but one which includes mainstream examples (Germany and France) alongside the more problematic cases of the Netherlands and Italy. An advantage of choosing these countries - as opposed to say, Ireland or Spain is that each has an extended and continuous history of welfare development on corporatist lines, dating to the aftermath of the Second World War (and in some instances to the early years of the twentieth century). In the Irish case, for example, the transition from the British 'adversarial system' of social and industrial bargaining to a more continental set of arrangements has only been made over the last ten years (Rhodes, 2001: 184). Where Spain is concerned, the structure of welfare and associated institutions is not entirely consistent with continental norms - and, of course, Spain's history of dictatorship between 1939 and 1975 means that the Spanish welfare regime has a very different historico-institutional legacy (Moreno, 2001). Looking elsewhere, Switzerland, though an interesting case because of its complex political system, which tends to facilitate institutional 'stickiness' at a time when radical adjustments appear necessary, is a hard country to classify. It has been more of a welfare state 'laggard' than the majority of continental regimes (Bonoli, 2001), while not conforming particularly closely to alternative regime types (the liberal model perhaps being the closest). Switzerland, too, is not part of the European Union, which sets Swiss governments apart from each of their continental neighbours, who have to conform, inter alia, to economic and budgetary constraints imposed by membership of European Monetary Union (EMU).

Finally, the USA, UK and Canada make up the liberal group - but with the important addition of the erstwhile wage-earner states of Australia and New Zealand. Space does not permit coverage of each of these regimes in detail so subsequent discussion will focus on the USA as perhaps the quintessential example of a 'liberal' regime, together with the UK as a leading instance of contemporary market-oriented welfare state transformation, and Australia as a further and rather different example of welfare state liberalization from 'wage-earner' origins. The significant point about the choice of these three countries is that, among them, they cover the key factors and issues currently confronting liberal regimes, each embracing the logic of change, though in different ways.

Two major areas will be used to chart policy changes: labour market policies and old age pensions. These areas tend to be the 'traditional' subjects of much comparative welfare analysis, to be sure, but as indicators of welfare regime change, they have three distinct advantages. First, irrespective of regime type, and however differently organized, 'full employment' and security in old age have been central components of welfare state effort during the postwar era. In this way, these examples provide an indication both of 'how' and 'how much' national governments were committed to ensuring protection against core risks throughout the life cycle. 
Second, the centrality of these policy areas means that they provide a clear focus for establishing the nature and direction of change. While change varies among (as well as within) different regime types as each confronts global economic, social and demographic challenges to its original postwar welfare mix, labour market and pensions policies are so intricately involved in these processes that they effectively encapsulate many of the key issues currently being faced by each of the regime categories in the developed economies. Third, both policy areas elide easily with the wider institutional basis of welfare regimes because they are deeply implicated not just in social but also in economic governance. Employers and trade unions as well as governments have always been closely concerned with the institutional construction (and now reconstruction) of labour markets and 'full employment', in addition, of course, to the issue of 'retirement' and the related question of security in old age. Again, the changing position of women in contemporary welfare regimes can also be addressed by reference to labour markets and pensions (although women's welfare clearly cannot be reduced to these areas alone). The quality and quantity of work available to women has become an immensely significant issue for governments, employers and trade unions alike in addition, obviously, to women themselves - while the changing nature of many pensions systems clearly affects women in relation to the question of retirement age, the value of their pension entitlements and, for older married women in the breadwinner states, the value of entitlements delivered through husbands' earnings. 


\section{The challenge of globalization}

This chapter examines contemporary debates about the nature of 'globalization' in a fairly wide-ranging manner. Of key importance here is the contemporary position of the nation-state and particularly the current challenges facing national governments as they attempt to formulate domestic economic and social policies in what is - arguably - an increasingly global environment. GEPs - particularly those arising from changes in international trade and finance - are perceived by globalization enthusiasts as challenging the capacity of national governments to control their economic and social policies, and undermining their ability to opt for 'generous' welfare solutions. Before examining the specific impact that these pressures might have on welfare, it is important to understand the economic aspects of the globalization debate in some detail. Thereafter, the focus will shift to an assessment of arguments for and against the view that national governments now have little control over domestic economic management. Again, without a clear understanding of this issue, which goes some way beyond social policy, narrowly conceived, it is not possible to judge how 'economics' and 'politics' interact in the welfare arena.

\section{Understanding globalization}

As a term used in both popular and academic parlance, 'globalization' seems to have become ubiquitous. Unfortunately there is little agreement about its meaning - or meanings. Part of the difficulty is that the term does not describe a discrete process, or even a series of relatively discrete processes. Instead, it is used to refer to a wide range of different social, political, cultural and economic phenomena the connections amongst which are often opaque. As Kellner (1998: 27) has noted, globalization can be used 'as a codeword that stands for a tremendous diversity of issues and problems, and that serves as a front for a variety of theoretical and political positions'. Debates about its nature - and even existence - cross disciplinary boundaries and involve very different sets of concerns. At the highest level of abstraction the word has been used by some commentators to denote a particular phase of modernity (Giddens, 1990); while for others it is employed as evidence of the beginning of a new 'global age' (Albrow, 1996) or a 'postmodern turn' (Best and Kellner, 1997). In other ways, 'globalization' is applied to specific areas of 


\section{The challenge of globalization}

society, economy or polity to provide a rationale for certain shifts and changes in particular activities. These may refer, for example, to changes in the nature of employment and production through to the impact of technological innovation on the culture industries. Again, 'globalization' has also been used to underpin explanations for the emergence of new forms of political identity and difference in the context of a perceived move away from 'formal' partisan politics to a less formal politics based upon a plural, fragmented approach to political activity symbolized by the new social movements - including, ironically, the antiglobalization protests recently witnessed in Prague, Seattle and Genoa.

Despite the futility of trying to arrive at an agreed definition of 'globalization', it is worth considering some core assumptions that underpin the majority of usages of the term. There are certain 'common denominators' which inform the majority of attempts to discuss the nature of contemporary global changes whether these are culturally, politically or economically focused. An examination of these overarching dimensions will not bring closer a single, coherent understanding of 'globalization', but it will provide a general point of entry to the complexity and detail with which debates about the term are suffused.

However variegated its meanings, a notion of greater spatial and temporal 'connectedness' lies at the core of the 'globalization' thesis. This idea is linked to the need to move beyond limiting ideas of " society" where this means a bounded system ... [to] a starting-point that concentrates upon analysing how social life is ordered across time and space - the problematic of time-space distanciation' (Giddens (1990: 64). The erosion of fixed boundaries, whether these are territorial or socio-cultural suggests an increasing degree of 'interaction across distance' - a process facilitated by dramatic advances in transport and communication technologies. While this form of interaction does not necessarily reduce the salience of local or regional relationships, there is nonetheless a sense in which 'the local' becomes networked into socio-cultural and economic contexts across the globe. For Giddens (1990: 64), then, 'globalization can ... be defined as the intensification of worldwide social relations which link distant localities in such a way that local happenings are shaped by events occurring many miles away and vice versa'. In this way it becomes possible to talk, as Held et al. (1999: 2) do, about an enormous variety of global interconnections: computer programmers in India, for example, now able to 'deliver services in real time to their employers in Europe and the USA'; or the linking of 'the cultivation of poppies in Burma ... to drug abuse in Berlin or Belfast' - the point being that 'contemporary globalization connects communities in one region of the world to developments in another continent.'

In different, though related, vein Castells' conception of the 'network society' also implies an intensified connectedness. For him, as for many others, information - 'the technology of knowledge generation, information processing and symbol communication' (Castells, 1996: 17) - facilitates the increasingly global reach of social and economic networks. Indeed, the 'new information technologies are integrating the world in global networks of instrumentality' (Castells, 1996: 22). Of course, since 1996 the technologies themselves, as well as conceptualizations of their significance and impact have become evermore sophisticated. Mitchell (2004: 207) writes, for example, that, 
Subjects, extended bodies, settlements, economies and cultures can no longer effectively be separated by skins, walls, and frontiers. They have all become inextricably embedded in dense, large-scale webs of interdependence. The child in Boston is socially and culturally linked to his grandmother in Melbourne, the server farm in Palo Alto is economically coupled to the cubicle farm in Bangalore, the cave in Afghanistan threatens the skyscraper in New York.

And yet, for all the apparent seamlessness of these connections, a further paradoxical - observation frequently made about 'globalization' is not just that global processes contribute to greater global organization, but simultaneously to increased disorganization - at a variety of levels. Observers have commented on the disorganization, or fragmentation, of individual identities (Giddens, 1991; Bauman, 2001), as well as of cities (Amin and Thrift, 2002; Graham and Marvin, 2001) and entire socio-economic systems (Castells, 1998; Sklair, 2002). The effects of disorganization are by no means all negative, but it is important to be aware of the potentially deleterious consequences of global interconnections for 'the local', whether this term refers to countries, regions, localities or individuals. In this regard, writers like Castells and Urry have noted the upsurge in regional, cultural and religious differences in many parts of the globe. Castells (1996: 24-5) comments on the apparent capacity of globalizing processes to marginalize and exclude and points to the significance of the contemporary spread of fundamentalism 'throughout the world at the historical moment when global networks of wealth and power connect nodal points and valued individuals throughout the planet, while disconnecting, and excluding large segments of societies, regions and even entire countries'. Urry (2003: 89) argues, conversely, that 'local' reactions to marginalization in an era of 'global complexity' are now being seen in 'the power of the powerless to inflict the utmost harm upon the institutions of imperial power'

This understanding of globalization as the increase in the incidence, rapidity, differential 'networkability' and increased complexity of social relations provides an initial starting-point for, but hardly exhausts, efforts to arrive at a clearer understanding of the idea. As already suggested, the reason for this is that globalization is a contested concept capable of incorporating a number of possible meanings. It is contested because, as Albrow (1996: 91) has argued, it is inherently ambiguous. For one thing the 'process' of globalization, if such it be, lacks 'a determinate end-point', hence it is impossible to arrive 'at a complete enumeration of its impact'. Even if the common assumptions about interconnection and timespace distanciation are accepted, it is not hard to see that these create as many problems as they solve. For one thing, the nature of the 'interconnectedness' produced by time-space distanciation is hard to pin down. Is it the case that the variegated processes involved in, for example, 'diasporic communities, just-in-time production and negotiated gender identity are necessarily linked to the same comprehensive and relentless process' (Albrow, 1996: 94) - let alone the 'electronomadic spatial practices' and extreme cybernetics discussed by Mitchell (2004) and others? Because mapping the causal pathways among such connections is a daunting task it is not surprising that detailed analyses of globalization tend to 


\section{The challenge of globalization}

fall into disciplinary or sub-disciplinary categories. This tendency is an implicit acknowledgement of enduring ambiguity and the unlikelihood of ever reaching beyond anodyne understandings of the global turn at supra-disciplinary levels. After all, globalizing processes in, say, the cultural sphere are likely to be of a different quality and have different effects, than those in the economic or political arenas. Moreover, even if 'effects' in a particular area do indeed have repercussions across a number of others, methodological differences within and amongst social science disciplines make the prospect of consensus about their nature difficult to establish. A further problem, of course, is that many of those involved in debates about globalization are highly sceptical about the capacity of the idea to make any significant contribution at all to an understanding of the contemporary world, the result being that debates are not only permeated by theoretical and methodological differences amongst disciplinary perspectives, but are also riven with fundamental disagreements about any potential explanatory value.

The consequences of the revolution in information and communication technologies offers an example of some of these difficulties. Although there is little disagreement about the fact of the increased speed and potential 'coverage' of information, its cultural impact is disputed. So, although Held et al. (1999: 343) can argue without fear of contradiction that 'in terms of the numbers of channels and their geographical reach, there has undoubtedly been a globalization of the telecommunications infrastructure in the postwar era', the point is to discover whether or not this process has led to greater cultural homogenization or, conversely, a degree of cultural 'hybridization'. Taking the former view, Schiller (1991) maintains that US cultural domination has been enhanced by the capacity of cable and satellite technologies to bombard others with ever-increasing amounts of US/Western cultural imagery particularly through television and film. The result, it is argued, has been a growing degree of cultural imperialism as - quite literally - the American 'view' of the world is exported across the globe. Others see this process of homogenization reflected in other areas of the cultural sphere (Ritzer, 1993).

On the other hand, Featherstone (1995), Sinclair et al. (2000) and others (see Pieterse, 2004) argue that US or Western enculturation is countered in many areas of the globe by alternative cultural images, affiliations and lifestyles that act as reminders that globalization should not be understood simply as a unidirectional, and uniform, phenomenon, even when the undoubted inequities of power, knowledge and wealth both within and among nation-states and regions are taken into account. Increased global connections are interconnections with the sense of reciprocity that this word conveys. Cultural theory is relevant to the present discussion in this regard because it acts as a reminder of what Amin (1997: 131) calls 'multiplexity' - an understanding of the effects of globalization that stresses the "intermingling of "in here-out there" processes, resulting in heterogeneity, shifting identities and multipolarity'. As Chapter One suggested, little is gained if 'globalization' is conceived as a phenomenon 'out there' creating difficulties for 'in here'. Rather global activities comingle with 'local' (national, regional, municipal)

processes in ways which involve change and adjustment but not necessarily the destruction of existing structures and institutions. 
This brief excursus into the cultural arena suggests that, here at least, globalization is regarded as a significant phenomenon. But, for present purposes, it is the range and possible impact of the economic dimension that is important. Whether the issue is the increase in transatlantic and transpacific voice paths or the latest gigabit technologies, the new communications industries have provided both the hardware and software that have expanded the data-processing capacity necessary to enable transnational corporations, particularly financial institutions, to handle vast quantities of information at high speed. Without these facilities it is hard to see how the extraordinary rise in global financial flows and the equally significant growth in global trade, discussed below, could have developed and been sustained. However, there is a good deal of disagreement about whether the rise in trade and financial flows really amounts to a 'globalized' economy of sufficient scope and power to influence national economies and the institutional structures and assumptions associated with them, not least because attitudes here are associated with broader social and political beliefs about the viability of social democratic political and welfare solutions. At the risk of some generalization, those on the political left tend to reject the idea that GEPs are actively dissolving national sovereignties, arguing instead that national governments continue to have the capacity to control their economic, and therefore social and political, destinies. In this way, social democratic political alternatives can be expected to survive because their institutional foundations are not perceived to be under terminal threat. Others of a neoliberal persuasion, however, are equally convinced that market-led economic change has compromised the social democratic vision of state-based social protection to the point where traditional conceptions of collectivist welfare no longer apply, thus ensuring the triumph of the free market.

\section{Economic globalization}

This basic cleavage, at its most stark between extreme sceptics and 'hyperglobalizers', is played out at different levels of analysis. Some of the arguments are conducted in very general terms, merely referring to key factors, the impact of which are considered to be self-evident; others, conversely, contain extremely detailed discussions which employ a range of qualitative and quantitative methodologies to examine the relationships among a number of variables considered to bear directly on the nature and extent of economic globalization. In assessing these positions, the 'weak globalization' perspective adopted here rejects the more outlandish claims of the hyperglobalizers while also acknowledging that a too-ready defence of traditional social democratic economic and welfare solutions can lead to the significance of changes in the global economic order being seriously played down. A middle way between these opposing extremes accepts evidence which indicates that certain important and far-reaching changes in the capitalist economic system have taken place, while also recognizing that their impact has been far from uniform and has, to date, involved 'adjustment' rather than social and political 'transformation' in the great majority of cases. To reprise the main argument set out in the previous chapter, what is currently being witnessed is not the victory of a rampant global capitalism which has successfully eroded the political 
and social institutions of nation-states from 'out there', but a partial reorganization of national state structures and institutions better to accommodate the new challenges and pressures which are undoubtedly arising from specific changes in the global economy. It is the nature of the relationship and mutual conditioning between global economic and national institutions that is at issue, the balance clearly differing among different types of regime. One element here, as Yeates (2001: 27) points out is that 'states [can] "deploy" social policy as part of a broader strategy of economic and industrial development', using 'the strategic importance of social policy in facilitating (or impeding) globalizing strategies'. This issue will be explored in more detail in Chapter Three.

Turning to the hyperglobalization thesis first, as evidence for their views that globalizing forces have once and forever altered the parameters of the postwar economic settlement, commentators like Ohmae (1995) point to general phenomena such as the information and communications revolution already mentioned, as well as to significant economic changes which have, in their view, created a 'borderless world'. These involve changing levels of trade as well as changes in the nature of the goods and services that are traded. In this respect, Giddens (1998: 27) has argued that 'the level of world trade today is much higher than it ever was before and involves a much wider range of goods and services'. Perhaps most important of all are changes in the behaviour of finance capital. In common with other hyperglobalizers, Giddens (1998: 27) believes that levels of finance capital and capital flows are unparalleled and the new communications technologies mean that 'fund managers, banks, corporations, as well as millions of individual investors, can transfer vast amounts of capital from one side of the world to another at the click of a mouse'. His point is that these movements can 'destabilise what might have seemed rock-solid economies - as happened in the events in Asia'.

This image of contemporary globalization is at once beguiling and threatening. A world of 'flows', capable of making and remaking entire economies and polities, can be depicted as an increasingly pluralized space (or set of spaces) in which institutions, forms of social and political belonging, even individual identities, are continually in motion, with the increased sense of 'possibility', on the one hand, or destruction of the familiar, on the other, that such a vision implies. Perceptions of this kind, however, are too often couched in general terms with only passing reference to greater detail and this can lead to the reduction of what are substantive debates about core issues concerning the nature of globalization to matters of ideology.

One difficulty is that, in the absence of such detail, debates cohere around rather loose images of economic interconnectedness which, as Lane (2000: 208) argues, assume 'the passive exposure of domestic institutional actors to influences of events happening elsewhere in the world'. Globalization in this 'passive' sense can appear important because, in a world of constrained budgets and tax regimes, it can seem as though changes in the global economy make it impossible for nationstates and their associated institutions to control their economic destinies in the way they used to do, at least during the postwar period, and that political and corporate leaderships act on this reasoning. However, it is important to be specific where possible, particularly when attempting to understand just how GEPs might 
affect national economies and, to this end, Lane's 'tight definition' of globalization, by which she means the 'active' or dynamic processes associated with degrees of trade and financial liberalization, offers a better approach to this issue.

'Trade openness', or the extent of international integration of markets in traded goods and services, as well as capital, is regarded by political economists as a key indicator of economic globalization. Although there is some agreement about the direction of integration, there is far less about either its causes or impact - the latter being of prime concern here. Of course, there are variations among the three categories in terms of both scope (the countries or regions involved in trade flows) and types of goods involved. Manufactured commodities differ from traded services and both differ from the ever-increasing range of financial goods and services traded in capital markets. The differences are significant partly because they relate to different aspects of economic governance and partly because the extent of integration varies among the categories. With regard to governance, manufactured goods are clearly more vulnerable to controls than are many services or finance for the simple reason that they continue to need to be moved physically across territorial space. Although transport costs have fallen due to cheaper fuel, containerization and other factors, national governments are still able to levy tariffs on, or more frequently create non-tariff barriers for, imported goods. The control of capital is a much more complex problem. 'Integration' raises difficulties of both extensity and measurement. The term should not be taken to imply simple 'convergence' particularly in traded goods sectors, where variations among different economies can be marked. As McKeown (1999) has pointed out, similar countries may converge as trading systems open, but convergence is less likely to take place between developed and less developed economies. Again, where capital market integration is concerned, the extent of convergence can be measured in different ways, which lead to differing interpretations of its impact on national governments. It is also worth remembering that 'capital markets' include a number of subcategories, the distinction between foreign direct investment and the various forms of portfolio investment being particularly significant.

\section{Trade openness and global markets}

If there is a modicum of agreement between sceptics and hyperglobalizers it lies in the fact that both recognize that international economic activity has grown enormously over the past thirty years. In some ways the 'facts' are not in doubt. Trade in manufactured goods has expanded in both extensity and intensity during the postwar period, increasing tenfold since the General Agreement on Tariffs and Trade (GATT) was created in 1947, and becoming ever more rapid since the early 1970s. The ratio of total exports and imports to world GDP, or exports and imports as a percentage of national GDP provide a simple way to chart trade liberalization in relation to manufactured products (see Table 2.1). As Garrett (2000: 946) has remarked, 'in 1970 exports plus imports constituted roughly one quarter of worldwide gross domestic product (GDP). By 1997, the figure had almost doubled to over $45 \%$ '. However, before accepting that the world economy has effectively become globalized, the evidence needs to be examined further. Two 
Table 2.1 Exports and imports as percentage of GDP

\begin{tabular}{lrrrrc}
\hline & 1970 & 1989 & 1994 & 1999 & 2002 \\
\hline Australia & 13.7 & 15.8 & 18.5 & 19.9 & 20.0 \\
Canada & 22.6 & 25.9 & 34.5 & 43.7 & - \\
Denmark & 27.2 & 35.1 & 35.5 & 36.9 & 45.0 \\
Finland & 24.5 & 23.6 & 35.1 & 37.5 & 38.0 \\
France & 15.1 & 21.7 & 21.5 & 26.1 & 27.0 \\
Germany & 20.4 & 30.5 & 23.6 & 29.4 & 35.0 \\
Italy & 16.2 & 19.7 & 23.9 & 25.5 & 27.0 \\
Japan & 10.8 & 10.6 & 9.3 & 10.4 & 11.0 \\
Netherlands & 47.3 & 59.9 & 55.5 & 60.6 & 62.0 \\
New Zealand & 22.6 & 27.1 & 31.4 & 31.9 & 33.0 \\
Spain & 12.5 & 17.1 & 21.0 & 27.3 & 28.0 \\
Sweden & 24.0 & 32.2 & 36.5 & 43.7 & 43.0 \\
UK & 22.3 & 23.7 & 26.4 & 25.8 & 26.0 \\
USA & 5.8 & 9.4 & 10.4 & 10.7 & 10.0 \\
\hline
\end{tabular}

Sources: compiled from OECD 2001a and World Bank 2004.

key indicators of globalization need to be considered. First, it is important to be clear about the 'convergence' issue: are patterns of economic integration genuinely 'global', or are they primarily regional? Second, to what extent, and in what manner, does closer economic integration affect the economic sovereignty of nation-states? If markets are expanding at the same time that rates of activity are increasing then national economic autonomy could be under threat, bringing Ohmae's 'borderless world' within reach.

There is little doubt that the extensity of trade has increased markedly since the 1970s. For much of the postwar period, the expansion of trade was facilitated by GATT which, though weak in some ways, nevertheless provided a forum for negotiations about tariff reductions, with most nations taking part by the late 1980s. Tariffs were indeed reduced in successive rounds of talks and GATT's successor, the World Trade Organization (WTO), founded in 1995, is a more powerful body which initially was expected to make greater headway than its successor in the reduction of non-tariff barriers. Partly because of GATT/WTO and partly, too, because of the demands from other international agencies like the World Bank and the International Monetary Fund (IMF), developing countries have been encouraged to open their markets to the point where Held et al. (1999: 165) refer to 'a sea change among developing countries, with widespread reductions in trade barriers'. It is certainly the case that the share of world exports taken by developing nations has risen over the last thirty years as Table 2.2 indicates.

But these data have to be treated with caution. Although it is clear that, both amongst developing countries and between those countries and the developed 
Table 2.2 Growth of manufacturing production and exports in newly industrializing economies

\begin{tabular}{|c|c|c|c|c|c|c|c|}
\hline & \multicolumn{2}{|c|}{$\begin{array}{c}\text { Share of world exports } \\
\%\end{array}$} & \multicolumn{3}{|c|}{ Average annual \% change } & \multicolumn{2}{|c|}{$\begin{array}{c}\text { Manufactures as \% of } \\
\text { total exports }\end{array}$} \\
\hline & 1963 & 2000 & $1970 / 80$ & $1980 / 90$ & $1990 / 99$ & 1980 & 1998 \\
\hline S. Korea & 0.01 & 2.7 & 22.7 & 12.0 & 15.6 & 89 & 91 \\
\hline Taiwan & 0.2 & 2.3 & 16.5 & NA & NA & 88 & 94 \\
\hline Hong Kong & 0.8 & 3.2 & 9.9 & 14.4 & 8.4 & 88 & 95 \\
\hline Singapore & 0.4 & 2.2 & NA & NA & NA & 43 & 86 \\
\hline Malaysia & 0.1 & 1.5 & 3.3 & 10.9 & 11.0 & 19 & 79 \\
\hline Thailand & NA & 1.1 & 8.9 & 14.1 & 9.4 & 25 & 74 \\
\hline Indonesia & NA & 1.0 & 6.5 & 2.9 & 9.2 & 2 & 45 \\
\hline Philippines & NA & 0.6 & NA & 3.5 & 9.6 & NA & 90 \\
\hline China & NA & 3.9 & 8.7 & 19.3 & 13.0 & 48 & 87 \\
\hline India & 0.8 & 0.7 & 5.9 & 5.9 & 11.3 & 51 & 74 \\
\hline Brazil & 0.1 & 0.9 & 8.6 & 7.5 & 4.9 & 37 & 55 \\
\hline Argentina & NA & 0.4 & 8.9 & 3.9 & 8.7 & 23 & 35 \\
\hline Mexico & 0.2 & 2.6 & 5.5 & 7.0 & 14.3 & 10 & 85 \\
\hline
\end{tabular}

Source: Dicken 2003: 48. Reprinted by permission of Sage Publications Ltd from Peter Dicken, Global Shift, 4th edition (C Peter Dicken 2003).

economies, trade flows have increased, it is equally clear that there is a long way to go before it would be possible to talk about a fully integrated global economy. A wealth of literature exists on this issue, and it is not necessary to rely on convinced sceptics like Hirst and Thompson (1999) to perceive the difficulties with the strong globalization thesis. For one thing, the WTO's progress in reducing trade barriers and advancing free trade principles generally appears to be limited. As Yeates (2001: 103-4) comments,

in principle international trade law requires countries to make local markets accessible to foreign investors on equal terms as domestic ones, but in practice, demands by the South that the profitable Northern markets be opened up to them were met by the exclusion by the North of certain industries from trade negotiations. To the extent that trade agreements institutionalize the exclusion of the South from Northern markets they are directly implicated in sustaining geo-economic inequalities.

This observation is endorsed by Schaeffer (2003: 243-4) who argues that large export-oriented and service industries in the northern hemisphere have benefited from the WTO 'largely because they have been able to capture markets from businesses that had long been protected by governments in Africa, Asia, Eastern Europe, Latin America and the Soviet Union'. He (Schaeffer, 2003: 244-5) goes on to note that, 
WTO rules have made it more difficult, even illegal, for raw material producers in the South to cooperate, organize cartels, restrict supplies, or raise prices. Meanwhile, the reduction of tariff barriers has exposed domestic manufacturing industries to withering competition from TNGs based in the North.

Taking account of the above, it is not surprising that in asking how far we currently are from 'a world in which markets for goods, services and factors of production are perfectly integrated', Dani Rodrik's (2000: 178) answer is that 'we are quite far'. In his view, 'contrary to conventional wisdom ... international economic integration remains remarkably limited', not least because even porous national borders, such as the US-Canadian one, 'seem to have a significantly depressing effect on commerce, even in the absence of serious formal tariff or non-tariff barriers, linguistic or cultural differences, exchange rate uncertainty, and other economic obstacles'.

Bearing in mind the misgivings voiced by Yeates and Schaeffer about the activities of the WTO, and including Rodrik's recognition that 'exchanges that cross national jurisdictions are subject to a wide array of transaction costs introduced by discontinuities in political and legal systems' (Rodrik, 2000: 179), there is good reason to be sceptical about the globalization thesis as this relates to trade integration. However, one further dimension needs to be taken into account that 'rebalances' the argument somewhat. There is evidence of increasing concentrations of economic activity in certain parts of the world, specifically among the developed economies, which may be encouraging higher levels of regional market integration. Held et al. (1999: 167), for example, point out that 'extensive as they are, trade networks still appear to be concentrated within certain geographical areas, crudely Europe, the Americas and Asia-Pacific, three trade blocs with some economic coherence and including most of the industrialized economies'. The European Union is the clearest example of a regional bloc trading arrangement, by virtue of the fact that it is an economic union, and this stands in contrast to NAFTA, which as its name suggests, is a 'free trade area', lacking the internal organization and regulatory economic regime of the EU. Asia-Pacific lags behind these blocs because 'regional arrangements ... are much looser, less formalized and more open than in the other two triad regions' (Dicken, 2003: 156). Nevertheless it is the case that intra-regional trading is growing in the Asia-Pacific area, with exports among East Asian nations becoming a greater proportion of their total exports (Park, 1994).

Disagreement about the nature these emerging regional configurations of trading arrangements lies not so much in disputes about their existence as in different understandings of the direction of future development. Commentators broadly agree that the basic triadic structure is supplemented by developing economic relationships between the dominant economies within each bloc and other smaller economies which are 'regionally specific and adjacent to one or other of the Triad members' (Hirst and Thompson, 1999: 121). Thus the USA has developed a closer trading relationship with Asian-Pacific countries like the Philippines, India and Pakistan, while the EU has created trading links with ex-Communist European 
nations (many of which have recently joined the EU), as well as with a number of African countries. Finally, Japan has close ties not only with the large regional economies of Singapore, Hong Kong and Taiwan, but also with smaller countries such as Sri Lanka and Fiji. But the issue, however, is whether the growing links within these regionally based economies point to a lack of globalization, as Hirst and Thompson (1999) believe, or whether the increasing intensity of flows, and relative lack of protectionism, among Triad members indicate a trend towards integrated markets even where these are mediated by dominant regional economies and characterized by 'non-convergent', unequal patterns of trade (Garrett, 2000; see also Ohmae, 1995).

Much depends on the angle of vision here. As Dicken (2003: 73-4) argues, if a macro-view is adopted, the global Triad 'is, in effect, sucking in more and more of the world's production, trade and direct investment [and] appears to sit astride the global economy like a modern three-legged Colossus'. However, he points out that a micro- or meso-perspective would indicate rather different levels of interconnectedness and disconnectedness, the meso-scale in particular yielding different patterns of economic activity and developing growth axes, either within nationstates or among territorially proximate economic spaces. At global level, then, it would not be inaccurate to suggest that the Triad acts a force for integration, particularly perhaps as the emergence (and recovery following the crisis of 1997) of Asia-Pacific, now with the increasing influence of China, has boosted the economic power of that region to the point where Republicans in the US Senate are demanding that the Chinese government take measures to correct its large trade surplus with the USA (Wood, 2005: 1). Even so, taking world trade as a whole, unevenness abounds, with many developing economies excluded from these globalizing processes and others remaining marginal to regional, let alone global, economic life.

\section{Capital movements and global finance}

To separate trade and capital flows from one another entirely is something of an artificial exercise. Trade openness, for instance, has been one reason for the steep rise in foreign direct investment (FDI), particularly among OECD economies. As Garrett notes, where international financial activities are concerned, developing countries remain marginal and the extensity of capital movements is not as great as it is for traded goods. Examining market integration in countries at different levels of development during the 1990s, Garrett (2000: 951) states that comparing means for the OECD countries with those of the lowest income nations 'provides stark evidence that there are ins and outs in the purportedly global economy'. With the exception of trade flows, which are roughly comparable in volumes if not composition, he argues that the 'high- and low-income groups differed dramatically ... on every other dimension of market integration'. The key elements of Garrett's table are reproduced as Table 2.3 and it is clear that, during the 1990s, FDI flows were more than twice as large, and portfolio investment 25 times as large, in the OECD in comparison with the group of low-income nations. But 


\section{The challenge of globalization}

the intensity of capital flows among the developed economies has increased dramatically and it is this feature which is particularly important for the present discussion. FDI flows provide the most common measure of capital mobility and Tables 2.4 and 2.5 provide figures for outward and inward flows of FDI for selected OECD countries, these showing marked growth, particularly after 1980.

Inward flows of FDI among OECD countries rose noticeably after 1985, although patterns are uneven. Japan, for example, has been a leading source of outward FDI yet inward flows have not grown appreciably. Again, the USA, a leading source of outward FDI in the 1970s, while remaining the largest overseas investor nevertheless saw its global share of FDI fall in the 1980s in response to rising current-account deficits, while, conversely, by the end of 2002, China had overtaken the US in FDI inflows, 'becoming the most attractive FDI destinations in the world and received $\$ 52.7$ billion in FDI' (Xiao, 2005: 3; see also Sklair, 2002: 249).

In general, the highly industrialized European countries became net exporters of FDI during the 1980s as 'virtually all restrictions on the outward movement of FDI [were] removed ... and inward investments [faced] only sectoral restrictions ...' (Simmons, 1999: 49). The driving forces behind this form of capital market liberalization are the multinational companies (MNCs). Over the past thirty years or so, the revolutions in information and communications and in transport have allowed MNCs to decentralize managerial control to affiliates in other countries and so to develop networks characterized by devolved production processes able to respond swiftly and efficiently to technological innovation and market change (Castells, 1996). Held et al. (1999: 256) also note that MNCs have increasingly contracted out business to small and medium-size enterprises (SMEs) which have lower costs and are more flexible, the consequence being that MNCs can pass on the costs of (perpetual) adjustment to changing market conditions to relatively autonomous units. It is partly for this reason that over the past twenty years MNCs have concentrated on increasing their competitive advantage not so much as direct producers but as 'processors of market information and organizers of markets'. Simmons (1999: 49) observes, for example, that new forms of direct investment have emerged over the past decade and comments that 'traditional investments in raw materials and manufacturing are an ever smaller portion of the share of FDI in the OECD'. The rise in mergers, acquisitions and strategic alliances are indicative of this trend because 'relatively fewer foreign investors are willing to start from scratch ... as firms seek to penetrate markets and tap new sources of technology cheaply and quickly' (Simmons, 1999: 49-50).

Whether or not this depiction of increasing capital movements through the medium of FDI represents an argument in favour of globalization is a moot point, however. Disagreement turns on perceptions of the relative importance of MNCs 'home' operations in relation to their overseas activities and also on attitudes to the influence of national business systems. On the first issue, Hirst and Thompson (1999: 79) argue that FDI flows tend to capture 'only what companies are "lending" to their affiliates abroad, not what they are at the same time investing in their home country or territory', the result being that the overseas orientation of the 
Table 2.3 Cross-national variation in globalization (Garrett, 2000: 950)

\begin{tabular}{lccc}
\hline & Trade/GDP\% & FDI/GDP\% & $\begin{array}{c}\text { International portfolio } \\
\text { investment/GDP\% }\end{array}$ \\
\hline High income OEGD & & & \\
M & 67 & 3.3 & 7.2 \\
SD & 37 & 2.1 & 6.9 \\
Low income & & & \\
M & 66 & 1.4 & 0.3 \\
SD & 34 & 1.4 & 0.4 \\
\hline
\end{tabular}

Source: adapted from Garrett 2000: 950.

Table 2.4 Stocks of outward FDI by major investing economies, 1960-94 (US \$bn, \% in brackets)

\begin{tabular}{lrrrrrrrrrr}
\hline & \multicolumn{2}{c}{1960} & \multicolumn{2}{c}{1975} & \multicolumn{2}{c}{1980} & \multicolumn{2}{c}{1985} & \multicolumn{2}{c}{1994} \\
\hline USA & 31.9 & $(47.1)$ & 124.2 & $(44.0)$ & 220.2 & $(42.9)$ & 251.0 & $(36.6)$ & 610.1 & $(25.3)$ \\
France & 4.1 & $(6.1)$ & 10.6 & $(3.8)$ & 23.6 & $(4.6)$ & 37.1 & $(5.4)$ & 183.3 & $(7.6)$ \\
Germany & 0.8 & $(1.2)$ & 18.4 & $(6.5)$ & 43.1 & $(8.4)$ & 59.9 & $(8.7)$ & 199.7 & $(8.3)$ \\
Netherlands & 7.0 & $(10.3)$ & 19.9 & $(7.1)$ & 42.1 & $(8.2)$ & 47.8 & $(7.0)$ & 146.2 & $(6.1)$ \\
Sweden & 0.4 & $(0.6)$ & 4.7 & $(1.7)$ & 5.6 & $(1.1)$ & 12.4 & $(1.8)$ & 51.2 & $(2.1)$ \\
UK & 12.4 & $(18.3)$ & 37.0 & $(13.1)$ & 80.4 & $(15.7)$ & 100.3 & $(14.6)$ & 281.2 & $(11.7)$ \\
Japan & 0.5 & $(0.7)$ & 15.9 & $(5.7)$ & 18.8 & $(3.7)$ & 44.3 & $(6.5)$ & 284.3 & $(11.8)$ \\
\hline
\end{tabular}

Source: Held et al. 1999: 247. Table 2.4: Stocks of outward FDI by major investing economies, 196094 (US \$bn, \% in brackets). (Reprinted by permission of Polity Press.)

Table 2.5 Stocks of inward FDI by host economies, 1960-94 (US \$bn, \% in brackets)

\begin{tabular}{|c|c|c|c|c|c|c|c|c|c|c|}
\hline \multirow[b]{2}{*}{ USA } & \multicolumn{2}{|c|}{1960} & \multicolumn{2}{|c|}{1973} & \multicolumn{2}{|c|}{1980} & \multicolumn{2}{|c|}{1985} & \multicolumn{2}{|c|}{1994} \\
\hline & 7.6 & $(13.9)$ & 17.3 & $(10.4)$ & 83.0 & $(17.2)$ & 184.6 & $(25.1)$ & 504.4 & $(21.5)$ \\
\hline France & & & 22.6 & $(4.7)$ & 33.4 & $(4.5)$ & 142.3 & $(6.1)$ & & \\
\hline Germany & & & 36.6 & $(7.6)$ & 36.9 & $(5.0)$ & 125.0 & $(5.3)$ & & \\
\hline Sweden & & & 3.6 & $(0.7)$ & 5.1 & $(0.7)$ & 19.1 & $(0.8)$ & & \\
\hline UK & 5.0 & $(9.2)$ & 14.8 & (8.9) & 63.0 & $(13.1)$ & 64.0 & $(8.7)$ & 214.2 & $(9.1)$ \\
\hline Japan & 0.1 & $(0.2)$ & 1.3 & $(0.8)$ & 3.3 & $(0.7)$ & 4.7 & $(0.6)$ & 17.8 & $(0.8)$ \\
\hline
\end{tabular}

Source: Held et al. 1999: 249. (Reprinted by permission of Polity Press.)

company is exaggerated. Their own data based on the sales, assets, profits and subsidiaries and affiliates of a large number of MNGs in core OECD countries takes account of home territory activities in addition to overseas activities. Looking at the 'ex-post economic activity engendered' rather than at the magnitude of cross-border flows themselves, Hirst and Thompson (1999: 84) conclude, inter alia, that "the "home-oriented" nature of MNC activity along all the dimensions looked 


\section{The challenge of globalization}

at remains significant [and thus] ... MNGs still rely on their "home base" as the centre for their economic activities, despite all the speculation about globalization'.

Support for the home-based orientation of MNCs also comes from work by Doremus et al. (1998: 9), who, while recognizing that 'the scope for corporate interdependence across national markets has unquestionably expanded in recent decades', argue that 'history and culture continue to shape both the internal structures of MNCs and the core strategies articulated through them'. These authors (Doremus et al., 1998: 23) perceive systematic differences among US, German and Japanese MNCs across a range of criteria - for instance, the priorities assigned to shareholders, the centrality of banking relationships and the nature and accountability of their managers - each of which can be related to institutionalized features of their respective economies. Moreover, volumes of FDI flows among these states also vary 'in ways that tend to reflect different national approaches to inward investment' (Doremus, et al., 1998: 116). The kind of differences noted refer to variations in the composition and the direction of FDI flows among the three countries. Thus the more protected, stakeholder-driven Japanese system has higher rates of outward than inward investment, with FDI flows to the US concentrated in the wholesale trade sector. Japanese MNC behaviour is also characterized by high degrees of intra-firm trading (IFT). US MNCs, conversely, reflect the short-term, shareholder-driven concerns with immediate returns typical of Anglo-American capitalism and consequently FDI flows are concentrated mainly in finance sectors and foreign manufacturing. As could be expected, US MNCs display only moderate levels of IFT. Evidence of the influence of national business systems can also be found in MNC attitudes to research and development (Pauly and Reich, 1997: 14-15; Hirst and Thompson, 1999: 91).

These key arguments from globalization sceptics counter-balance the wilder prognostications of the hyperglobalization lobby (Ohmae, 1990; Reich, 1991; Giddens, 1998), but they tend to underplay the increasing importance of capital market movements for corporate strategies. It may well be the case that MNCs remain closely associated with 'their' national business systems - but as observers have pointed out (Held et al., 1999; Dicken, 2003;) corporations have to take increasing account of the global economic environment if they are to retain or gain competitive advantage. As Held et al. (1999: 262) note, MNGs 'ability to produce in a range of countries and to realize competitive advantages generated in different locations gives them a global vision and a global competitive advantage'. According to Lane (2000: 214), for example, 'recent transformations in the global economic and technological environment have induced a number of large German firms to expand their foreign investment and co-operations and to change their internationalization strategies'. German chemical corporations were involved 'in huge cross-border mergers and joint ventures' during the 1990s, while the German car industry 'changed from multinational companies, with a clear core in Germany and more peripheral affiliates in foreign locations, to transnational companies with globally differentiated production networks' (Lane, 2000: 215). Again, the Japanese car industry shifted away from the home-based, export-driven focus of the 1970s to a global approach in the 1980 s, with production located primarily in the 
European and American markets. Japanese electronics corporations also increased FDI to Europe and America, as well as to East Asia, during this period. Now, it may well be that, in Germany for instance, the Rhenish culture (see Albert, 1992) of 'long-termism is still the predominant influence on managerial orientations and practices' (Lane, 2000: 219) and this is supported by the system of industrial relations, company law and so on (Soskice, 1997). However, as many commentators point out (see Cerny, 2000: 131), it is becoming less feasible for companies to compete purely from their home bases and, to this extent at least, it is possible to argue that the contemporary international economy has a 'global' dimension. Certainly, MNCs 'are locked into external networks of relationships with a myriad of other firms: transnational and domestic, large and small, public and private', the argument being that 'such interrelationships between firms of different sizes and types increasingly span national boundaries to create a set of geographically nested relationships from local to global scales' (Dicken, 2003: 253, original emphasis). For Dicken (2003: 12), then, in contrast to the 'shallow integration' of the global economy in the pre-1914 period, 'today, we live in a world in which deep integration organized primarily within the production networks of transnational corporations ... is becoming increasingly pervasive' (original emphasis).

A consideration of current patterns of FDI goes only some way towards providing a greater understanding of the increasing importance of global capital movements. The general picture is enhanced by an examination of the changing nature and rising incidence of portfolio investment over the past twenty years. This type of activity refers to stocks, bonds and bank loans all of which tend to be more liquid, and therefore more volatile, than FDI. The rise in this form of investment results from the combination of the progressive removal of capital controls in OECD countries between the late 1970s and late 1980s, and the subsequent desire on the part of institutional investors to reduce exposure to risk in the prevailing post-Bretton Woods environment of floating interest and exchange rates. As a number of commentators have pointed out (Cerny, 1993; Simmons, 1999; Watson, 1999), the changing composition of portfolio investment is just as significant as the increase in this form of financial activity itself. Convertibles, options, swaps and futures (Walter, 1991) have added to the volume of portfolio borrowing, Watson noting, particularly in the case of the latter, that they operate as hedging activities to reduce the potential financial impact of often volatile foreign exchange markets. Indeed, Watson (1999: 6) appears to attribute the rise (and rise) of futures markets to risk-averse behaviour, arguing that 'floating exchange rates create exactly the sort of market tensions - those associated with excessive price volatility - which futures trading thrives on'.

Of course, in the same way that rising FDI can be interpreted differentially, depending upon perceptions of the wider economic context in which changes take place, increasing portfolio investment needs to be similarly contextualized. To what extent do increases in these forms of investment indicate a move towards an integrated global financial market? Once again, the issue is a complex one and the evidence is far from conclusive when attention is paid to two common indicators of capital mobility. One indicator is the relationship between national savings and 
Table 2.6 Gross capital inflows (US \$bn)

\begin{tabular}{|c|c|c|c|c|c|c|}
\hline & & 1991 & 1993 & 1995 & 1996 & 1997 \\
\hline \multirow[t]{4}{*}{ World } & $\begin{array}{l}\text { Portfolio } \\
\text { investments }\end{array}$ & 466.4 & 754.4 & 595.1 & 919.2 & $1,002.2$ \\
\hline & $\begin{array}{l}\text { Direct } \\
\text { investments }\end{array}$ & 154.4 & 218.6 & 329.2 & 334.0 & 418.1 \\
\hline & $\begin{array}{l}\text { Other } \\
\text { investments }\end{array}$ & 104.4 & 438.7 & 775.2 & 831.9 & $1,276.9$ \\
\hline & Total & 725.2 & $1,411.7$ & $1,699.5$ & $2,085.1$ & $2,697.1$ \\
\hline \multirow[t]{3}{*}{$\begin{array}{l}\text { Industrialized } \\
\text { countries }\end{array}$} & $\begin{array}{l}\text { Portfolio } \\
\text { investments }\end{array}$ & 418.3 & 620.7 & 538.4 & 785.2 & 847.9 \\
\hline & $\begin{array}{l}\text { Direct } \\
\text { investments }\end{array}$ & 113.7 & 143.3 & 207.4 & 191.5 & 235.9 \\
\hline & $\begin{array}{l}\text { Other } \\
\text { investments }\end{array}$ & 36.7 & 359.0 & 568.0 & 694.5 & $1,154.1$ \\
\hline \multirow[t]{3}{*}{$\begin{array}{l}\text { Developing } \\
\text { countries }\end{array}$} & $\begin{array}{l}\text { Portfolio } \\
\text { investments }\end{array}$ & 31.0 & 117.1 & 47.2 & 122.0 & 126.6 \\
\hline & $\begin{array}{l}\text { Direct } \\
\text { investments }\end{array}$ & 40.7 & 75.3 & 121.8 & 142.5 & 182.2 \\
\hline & $\begin{array}{l}\text { Other } \\
\text { investments }\end{array}$ & 64.1 & 74.8 & 165.3 & 113.3 & 91.0 \\
\hline
\end{tabular}

Source: Siebert, 1999: 62

investment, the assumption being that, in an environment of perfect capital mobility shortfalls in national savings can be made up by borrowing on world capital markets at the prevailing world interest rate thereby removing the need either to drive up the domestic interest rate or, alternatively, to reduce levels of domestic investment. An influential study by Feldstein and Horioka (1980) found no evidence for this assumption, finding that changes in countries' rates of saving appeared to have a direct impact on national investment rates, leading to the conclusion that capital mobility remained low. These findings have been confirmed by many other studies over the past twenty years (see Tesar, 1991; Obstfeld, 1995). A further commonly used indicator of financial integration is the extent of interest rate convergence across markets, the assumption being that 'if capital is highly mobile internationally, then interest rates should be determined in world markets... [with] very little room for divergence across countries' (Simmons, 1999: 57). As many sceptics are quick to point out, however, evidence of convergence is hard to find. Hirst and Thompson (1999: 36) state that interest parity appears to 'hold in the Eurocurrency markets', but that deeper forms of integration, signalled 'by first uncovered interest rate parity and then real interest rate parity between deposits in different currencies' were hard to detect in the mid-1990s - although the authors acknowledge that the tests to measure the presence of forms of integration are complex and controversial. Watson (1999) concurs with this view, arguing that the lack of evidence is unsurprising in view of the increasing prominence of derivatives' markets - and particularly futures trading. On his reckoning, the emergence of these new 
instruments indicates a recognition on the part of investors of the need to hedge against risks associated with exchange and interest rate volatility, the very presence of these activities indicating low capital market integration.

Despite these arguments, those more sympathetic to the globalization thesis are not easily deflected by the apparent lack of convincing evidence about financial integration. Where the balance between savings and investment is concerned, Frankel (1991) has shown that in the USA this relationship is now less stable than it once was, concluding in a subsequent study (Frankel, 1992: 201) that 'the United States in the 1980s began to borrow on such a massive scale internationally that the traditional "Feldstein-Horioka" finding of a near-unit correlation between national savings and investment has broken down'. In support of this finding, Sinn's study of 23 OECD countries demonstrated that 'the long-term average of the relationship between the national rates of savings and investment has declined considerably, especially since 1973' (see Siebert, 1999: 63). Furthermore, the explanatory value of the indicator itself has been challenged. Krol (1996: 467) has suggested that the Feldstein-Horioka methodology, which involves regressing savings and investment for a cross-section of OECD countries and then averaging the data 'in order to remove the influence of the business cycle', is flawed. Because countries cannot maintain either surpluses or deficits on current accounts indefinitely, governments will always attempt to balance their current accounts with the result that 'country-level observations based on averages of annual data will obscure surpluses and deficits over time' the consequence being that 'savings and investment will appear more similar than they really are' (Krol, 1996: 468). Finally, in a challenging critique of the Feldstein-Horioka position, Frankel (1992) pointed out that a high savings-investment correlation is only one possible indicator of capital mobility and requires other conditions, such as real interest rate parity, to hold before it can be used to gauge the extent of capital mobility. Without these other factors, a high correlation between national savings and investment may simply be a function of currency-related factors such as exchange rate volatility.

Turning to interest rates, evidence for the presence or absence of real interest rate parity is both complex and contested, as Hirst and Thompson imply. Although there is widespread acceptance of the fact that covered interest rate differentials have decreased among OECD countries since the mid-1970s (Garrett and Mitchell, 2001), the existence of currency premiums 'consisting of an exchange risk premium plus expected real currency depreciation' (Frankel in Fuji and Chinn, 2001: 289) means that, even where covered interest rates are equalized, large differentials continue to be displayed in uncovered and real interest rates. A key issue here, however, is whether it is reasonable to assume that uncovered interest rates really provide an accurate picture of the extent of financial integration. This measure refers to situations where interest rates are equalized on assets denominated in different currencies without 'selling forward'. Where currencies can be sold forward (as they are in conditions in which covered interest rate parity holds) any differences between interest rates can be offset by the ability on the part of investors to guarantee the return in their own currency by selling the yield in advance to a forward exchange dealer at the forward exchange rate - a rate that should ensure that 
'returns on domestic currency assets are equal to the returns on foreign currency assets of equivalent risk and maturity' (see Held et al., 1999: 217). In conditions in which exchange rates do not move to offset differences in interest rates (basically where returns are not expressed in a common currency such as Eurodollars), returns are not equalized so uncovered interest rate parity does not hold - this failure to move being taken as a sign of the inability of markets to assess future shifts in exchange rates due to high levels of volatility. However, the fact that exchange rates are clearly sensitive to various forms of turbulence - capital flows, speculative bubbles and political and economic policy changes, for instance - is not taken by all commentators as an indication of an underlying lack of financial market integration. One reason for this is that the methods used to forecast exchange rates by market operators are hardly an exact science, the range of opinions among traders creating conditions 'for high volumes of trading and possibilities for speculation' and introducing a short-term focus which 'can drive the exchange rate away from its equilibrium value' (Held et al., 1999: 218). Nevertheless, despite this volatility, over the longer term there seems to be at least some evidence of interest rate parity, a recent study of the G7 countries concluding that 'by the end of the last century, real interest rates of return were virtually equalized among the key industrialized economies' (Fuji and Chinn, 2001: 306).

If such a verdict needs to be treated cautiously in view of the highly complex methodological issues involved, there is nevertheless reason to suppose that, at least among the advanced economies, an integrated capital market is gradually evolving (Walter, 1991: 209). This is not to say that such a market is either fully integrated or stable - indeed interest rate differentials persist, particularly in the short-term, and the prevailing economic environment remains highly volatile because of sensitivity to shifts in expectations about interest and exchange rate levels, and the desire to hedge against risks. Nevertheless, pace Watson, it may not necessarily be the case that continuing capital market volatility is associated with the absence of a global capital market. The above discussion suggests that the trend towards real interest rate convergence can underlie extreme short-term volatility. Moreover, in the context of twenty-four hour global stock market activity and in an environment in which major investors, including the large pension funds, now hold assets overseas, it is unlikely that decisions about capital allocation could be taken without reference to, or extensive knowledge about, global economic conditions (see Reich, 2002). To this extent it is possible to talk in terms of increasing 'enmeshment' among the metropolitan countries, if not full capital market integration, and this constitutes a factor - or rather a range of factors - which national governments need to take into account in economic and social policy formulation.

\section{Globalization and the nation-state}

The discussion so far has skirted around the question of the extent of nation-state autonomy in order to focus on some of the key economic issues relating to the nature of globalization. But no consideration of globalization, particularly one that seeks better to understand the possible connections between GEPs and welfare 
regime change, would be complete without an examination of its relationship with, and potential impact upon, the political dimension. Where an awareness of the significance of this dimension is lacking, conceptions of globalization swiftly fall prey to economic determinism, the tendency being to assume a direct causal connection between economic change at the global level and political change within nation-states (Frieden and Rogowski, 1996). As Garrett and Lange (1995: 628) have pointed out, the assumption is that

internationally generated changes in the constellation of domestic economic preferences will be quickly and faithfully reflected in changes in policies and institutional arrangements within countries. If one understands which economic interests have gained economic strength, one knows which have gained political power, and in turn how policy is likely to change.

In actuality, as intimated in Chapter One, the chain of causality is not unidirectional and it is doubtful whether changes at the political level can be 'read off' from changing economic conditions in this way.

The temptation to over-determine economic explanations is partly due to a failure to distinguish clearly between the two dimensions of globalization discussed earlier in this chapter. There is a need to separate globalization as time-space distanciation, along with its politico-cultural effects, from economic liberalization. As Helleiner (2001: 243) has pointed out, the shrinkage of time and space per sethe fact that 'actions and decisions in one part of the world [now] have greater impact on other parts of humanity and do so with greater speed' - does not logically imply the compulsory acceptance of neo-liberal economic determinism. Helleiner (2001: 244) notes, for example, that 'while globalization in the first meaning is a fact, and it may constrain some choices, it does not totally foreclose them in the way that many imply'. His main point, however, is that 'to equate [the first aspect of] globalization with external liberalization and full reliance on "marketplace magic" ... is logical confusion and quite misleading'. This argument is particularly prescient when considering the current fortunes of nation-states because it reminds us that the unquestionable increase in the range and scope of global connectedness does not necessarily imply that they are the passive victims of changing economic circumstances occurring (to echo Amin again) 'out there'. As the following discussion will suggest, although it may be that nation-states are caught between GEPs, which require endogenous policy changes, and internal institutional pressures to maintain existing policies and systemic arrangements, the resulting tension may be manageable so long as governments are prepared to adjust core economic and welfare policies.

Bearing these issues in mind it is important to consider views about the potential impact of global economic change on nation-states in some detail. Much depends, of course, on how perceptions of the relative balance between global economic and national political forces are conceived and a vast array of literature now exists which attempts to explore this relationship. To take an initial example, Michael Mann (1997: 479), like many commentators, does not dispute that fact that 'capitalist 


\section{The challenge of globalization}

commodity exchange now dominates' the global economy, partly at least because, with the demise of the socialist economies, there no longer appears to be an alternative. However, although he concedes that this 'victory' is 'obviously a major transformation', Mann argues that its impact may nevertheless be more limited than many globalization enthusiasts believe. For one thing, the fact of increased capital mobility - the key factor identified by the enthusiasts as sapping national economic autonomy - in his opinion, says little about actual power relations. With financial goods being traded many times over in a single day, this form of economic power is widely diffused and potentially fickle. So, it is plausible to suggest that flows of manufactured goods and raw materials, though smaller in volume, might nevertheless contribute to higher degrees of national autonomy purely because they have a 'much greater fixity of location' (Mann, 1997: 482) - and this in spite of increased outward investment by MNGs. On this reading, although according to Mann (1997: 489),

the capitalist economy is now significantly global, its globalism is 'impure', a combination of both the transnational and the inter-national. The potential universalism of the former is undercut by the particularisms of nation-states - and indeed also by the particularisms of human social practices at large.

So, in common with the position taken here, Mann sees a need to balance economic against politico-social factors when attempting to assess the influence of the global economy on nation-states. The implication is that nation-states possess distinctive social and political structures that can influence the manner in which transnational pressures are perceived, transmitted and managed. Indeed, Rieger and Leibfried (2003: 239, my emphasis) go as far as to claim that 'governments can, but are not obliged to, obey the price signals of the global economy for their labour and social policy'. Situated in a context of democratic politics and possessing social policies that almost by definition are designed 'to achieve outcomes that the market itself, left to its own devices, would not have produced', they are sceptical about the capacity of GEPs to displace these processes entirely and argue that 'the probability of democratic reform policy leading ... to precisely those outcomes that some consider under conditions of globalization to be clearly compelled by economic reason is very low' (Rieger and Leibfried, 2003: 239).

Precisely how these structures interact with global forces is an area of enquiry that institutionalist theorists have been attempting to develop. As Chapter One indicated, institutionalists argue that national (or sub-national) institutions are 'sticky' or 'path-dependent' and so are able to 'mediate in the relationship between internationally induced changes in the policy preferences of domestic actors, on the one hand, and political outcomes (both policy and institutional change), on the other' (Garrett and Lange, 1995: 628). Although, what 'mediation' means in this instance and precisely how path-dependent behaviour operates is not always made clear by institutionalists, it is important to examine their ideas more closely in order to judge the potential relative strength of institutional forces to offset global economic challenges. 
As to the nature of 'institutions' themselves, Chapter One briefly indicated the conceptual and definitional difficulties associated with this term. For present purposes, it is important to cut through some of the more esoteric issues involved in order to concentrate on those key elements of national economic, political and social governance that not only give regimes their particular character but that also figure prominently in the complex relationships that make up the globalinstitutional nexus. To this end, it is worth engaging with the literature that examines 'varieties of capitalism' through the concept of the 'production regime' (Soskice, 1999). The underlying assumption of this approach is that groups of economically advanced nation-states can be identified which share a number of core institutional characteristics, and which, in one way or other, 'mediate' exogenous economic pressures.

Soskice's (1999: 101) conception of a 'production regime' refers to the organization of production through markets and is used to analyse

the ways in which the microagents of capitalist systems - companies, customers, employees, owners of capital - organize and structure their interrelationships, within a framework of incentives and constraints or "rules of the game" set by a range of market-related institutions within which the microagents are embedded.

The main institutional supports for a production regime are the financial system, the industrial relations system, the educational and training system and the intercompany system - and these tend to be organized at the level of the nationstate, although there are also likely to be 'regional, sectoral and other variations'. Soskice (1999: 103-4) discusses two basic types of production regime, each characterized primarily by the 'underlying and generally long-standing differences in the nature of coordination between companies'. The uncoordinated liberal market economies (LME) of the Anglo-Saxon nations are defined by the effective absence of nonmarket coordination among companies and also a minimum of state intervention. Conversely, the coordinated market economies (CME) of Germany, Sweden, Switzerland and, rather differently,Japan, display high degrees of 'non-market coordination' among companies, with the state normally playing a frame-setting role. These regime-types can be sub-divided. Soskice distinguishes between CMEs that are coordinated at industry or sub-industry level (northwestern European countries) and those that are group-coordinated along keiretsu lines (Japan, South Korea) - both systems being differentiated from LMEs. Rather differently, but of more relevance for present purposes, Kitschelt (1999: 429) categorizes CMEs - essentially Esping-Andersen's social and Continental welfare regimes - into states which display either 'national concertation' or 'sectoral coordination' of businesses, the former referring to the centralized Scandinavian countries and the latter to the Rhenish capitalism of Germany and other northern European states, with the partial exception of France.

How robust are national-institutional architectures of this kind likely to be in the face of the kind of external economic challenges discussed in this chapter? 


\section{The challenge of globalization}

Here opinions differ. Some commentators argue that the most tightly coupled regimes - the CMEs - are increasingly falling subject to global economic pressures which threaten key elements of their production systems. An extreme version of this thesis is advanced by Crouch and Streeck (1997: 6) who argue that these societies have come under increasing pressure from an array of globalizing processes, including 'accelerated technological change, renewed price competition and the globalization of financial markets'. Specifically, 'the demise of national state capacity under globalization is likely ... to destroy a range of governance mechanisms in institutional economies whose performance depends indirectly on the support of a strong state' (Crouch and Streeck, 1997: 12-13). Centralized bargaining mechanisms in some of the Scandinavian states, which incorporate trade unions and employers, are clearly one example, and the withdrawal of state support for meso-corporatist arrangements in Japan is another. According to these authors, this erosion of state capacity is likely to move CME economies closer towards the model of the liberal production regime with its weak, decentralized trade unionism and lower levels of business coordination and state intervention. In consequence, Crouch and Streeck (1997: 13) expect to see a 'convergence of capitalist economies on an institutional monoculture of deregulated markets and hierarchies'.

To assume this degree of convergence around one model is to oversimplify the effects of global economic pressures, however. There is no need to accept the full logic of institutionalist thinking - which at its most extreme can appear too functionalist - to see that the position adopted by Crouch and Streeck comes near to the economic determinism criticized above. A rather less dramatic view, which leaves potential space for political choice, is contained in Cerny's (1990) notion of the 'competition state'. Cerny clearly accepts many of the arguments of the globalization thesis and his position challenges institutionalist thinking on the grounds that it underestimates the true effects of (particularly) financial globalization on other sectors of state activity. He argues (Cerny: 1997: 607) that a third industrial revolution 'characterized by the intensive application of information technology, flexible production systems and organizational structures, market segmentation and globalization' has entailed, among other things, a fragmentation of 'institutional capacities for political control, stabilization, regulation, promotion, and facilitation of economic activities', and that this revolution has altered the institutional framework of the Keynesian-industrial state. Indeed, because in his opinion nationstates are no longer able to control capital mobility, the tendency over the past twenty years has been for them to conspire willingly in the erosion of their own regulatory powers (Cerny, 1997 and see also Sbragia, 2000). However, for Cerny, this process has not resulted in the decline of the nation-state per se but in its reorganization, the tendency being to enhance supply-side activities at the expense of once-influential demand-side functions, thus effectively reconfiguring its institutional foundations. There is more than a hint of 'convergence' in this formulation, but much depends on perceptions of the stability and power of existing institutions. Cerny (2000: 122-3) plainly believes that the competition state pursues 'increased marketization in order to make economic activities located within the national 
territory ... more competitive in international or transnational terms' and that these goals have been actively pursued through reduced public spending, as well as the control of inflation and the 'promotion of enterprise, innovation and profitability in both private and public sectors'. Scharpf (1994), too, views the process as a form of convergence, characterizing the change as a shift from the various forms of 'positive integration', which typified the postwar CME economies, to the 'negative integration' associated with the autonomously functioning regulatory governmental structures more typical of the LMEs.

There is a need for caution, however, because both Crouch and Streeck, and Cerny, accept a view of globalization more radical than the one proposed here. If, as suggested, nation-states are confronted by an ongoing process in which GEPs and institutional forces are bound into relationships of mutual adjustment, as opposed to the more extreme 'end-state' version proposed by the hyper-globalization lobby, it is unlikely that the nature of the challenge will be such as to undermine existing institutions entirely. Instead, it is more likely that they will have to face the threat of constant attrition, which can 'corrode' hitherto accepted political, social and cultural assumptions, as opposed to the radical transformation of existing patterns of sovereignty and institutional organization. On this reading, pace Cerny and others, there is no reason to assume that state reorganization entails strict convergence around the neo-liberal model, although it is likely to entail 'drift' in this direction. Describing state reorganization as a 'refashioning of the modalities of governance', Jayasuriya (2001: 110) argues, for example, that 'just as there have been a variety of capitalisms embedded within very different systems of bargaining and compromise, it is clear that the emerging systems of negative coordination will also embody different values and principles'. However, these systems will have to 'configure with existing systems of political bargaining and compromise' (Jayasuriya, 2001: 111), the implication being that the politics of state reorganization is not a zero-sum game.

In fact reorganization may take quite different forms, not least because there is little as yet to suggest that the increasing pace of the global economy will result in fully integrated, and thus hegemonic, global markets. Regulation theorists like Hollingsworth (1998), for instance, see less scope for the exercise of institutional power at nation-state level, but nevertheless consider that welfare, tax and training policies are likely to remain within the ambit of a nation-state, the economic institutions and functions of which will increasingly be dispersed across supranational, regional and local levels. In a different way, Boyer (2000: 296-9) notes that, although the financial crisis in Japan and other East Asian countries has 'clearly [shown] that no authority is completely in charge of ensuring its stability' and that 'the bursting of the financial bubble in Japan, uncertain development and near-stagnation in Europe and, above all, the flagrant American expansion of the 1990s have considerably affected the competitive position of [different forms of] capitalism', these changes are unlikely to result in outright neoliberal convergence. In his view, growing inequalities have acted as 'an antidote to the imperfections of collective action' identified by neoliberals in the first place, Boyer (2000: 306) commenting that 'there is nothing like privatization to discover the 


\section{The challenge of globalization}

value which citizens really attribute to public services'. The implication here is that state reorganization could potentially take the form of the revitalization of core 'coordinating' institutions, particularly of course in the CMEs.

Elsewhere much less emphasis is placed on the state's capacity for reorganization of this kind. For their part, Garret and Lange assume the continuation of existing institutional arrangements with changes being kept to the minimum. They are convinced that 'the relationship between changes in economic structure and public policies is contingent upon extant institutional conditions' (Garrett and Lange, 1995: 636) and that path dependent behaviour makes it difficult for governments to pursue change even in circumstances where they believe that a reorganized state would be better placed to derive benefits from the global market. Existing preferences in key sectors will be sufficiently deeply embedded to inhibit governmental efforts to achieve institutional change, meaning that governments' ability to capitalize on the benefits offered by closer integration in the international economy, as these observers perceive them, depends upon an array of purely conjunctural factors. These include prevailing levels of risk-aversity, the length of time remaining in office before voters are able to hold them accountable for their actions and the favourable nature of existing external conditions such as the state of the international economy. In short, Garrett and Lange argue that institutional change is possible - but only at the margin, because it is heavily dependent on endogenous factors outside the control of democratically elected governments.

This view, which is clearly the polar opposite of convergence theory, is broadly endorsed by Kitschelt (1999), who agrees that contingent factors such as the strength and economic predilections of governments, the inclinations of voters and the relative power of key institutions are important. Other reasons for rejecting convergence include the fact that not all sectors of domestic economies are equally vulnerable to the vagaries of the wider global marketplace, the argument being that these more sheltered sectors may form 'local production regimes' of their own, insulated from global economic movements and so can preserve existing institutional configurations and arrangements. Moreover, different sectors of any particular economy are likely to be differently resourced and organized, the point being that 'efficient institutions differ across sectors, regions and countries' (Kitschelt, 1999: 450), and governments will desire to preserve them in order, paradoxically, to remain internationally competitive. These considerations add up to the fact that, although international competitive pressures do indeed exist and tend to take a common form across all advanced industrial countries, they nevertheless 'are likely to be perceived differently by actors in different institutional settings' (Kitschelt, 1999: 440). In this way, production regimes and the social systems associated with them will continue to be characterized by different degrees of divergence, their nature depending, however, on a range of domestically driven factors.

This latter discussion qualifies the wilder excesses of convergence theory but is not intended to lend support to the idea that the effects of GEPs on nation-states are somehow insubstantial. The question is whether their impact is 'direct' or mediated by other factors. As subsequent chapters demonstrate, GEPs are essentially 
'frame-setting'. Because they limit certain economic policy options, the salience of other, contingent, factors increases, forcing governments to maximize economic efficiency and cost-effectiveness in ways which tend to favour market solutions. For example, CMEs like Sweden, confronted by considerably higher levels of capital mobility and demands for tighter budgetary policy, had to adopt certain 'marketfriendly' measures to reduce budget deficits in the mid-1990s, while other countries such as France and Germany currently remain locked in deep political disagreements about the viability of their respective institutional arrangements - particularly where welfare is concerned. LMEs are better disposed towards market solutions, by definition, although it is clear that the countries discussed below are deepening their commitment to the market as a result of GEP-induced constraints.

The general argument here, then, is that, where states are confronted by the challenges associated with GEPs, existing institutions will remain influential, but an endemically unstable economic environment will lead to the sharpening of competition both within and beyond the state as various actors attempt to gain, or retain, influence. Power struggles of this kind can face elected governments with complex dilemmas as they attempt to balance economic and democratic priorities. His convictions about convergence notwithstanding, Cerny $(1997,2000)$ is surely correct to point out that governments in the mature democracies are having to face a deepening democratic deficit as they attempt to reconcile economic and political demands. The need to 'make firms and sectors located within the territory of the state competitive in international markets', undoubtedly an important consideration, nevertheless plays uneasily with the equally important need to respond to voters' anxieties, the concerns of organized labour and the fears of a number of social movements about the social impact of these supply-side policies. As the next chapter demonstrates, this dilemma is played out particularly clearly in relation to contemporary understandings of the role of the welfare state and the changing politics of welfare. 


\section{Globalization and welfare regime change}

Views about the possible impact of 'globalization' on welfare regimes fall into the three broad categories outlined in the previous chapter. Hyperglobalizers argue that growing GEPs associated with increased trade openness and capital mobility have radically affected traditional social and economic arrangements in the advanced societies. By relating these changes to shifts in the institutional foundations of different welfare regimes these observers suggested that pressures to adopt neoliberal social and economic policies can be directly traced back to economic difficulties that have their origins in the global economy. Sceptics, on the other hand, argue that changes in the international economy have at best had a minimal impact on welfare regimes, maintaining that regime change, such as it is, is better attributed to endogenous economic factors such as domestically induced unemployment and low growth, changes in gender relations and household arrangements, and the ageing of populations in the advanced societies. This approach can also hold that institutional factors inhibit the full force of economic pressures, whatever their origins. Finally, the middle way/weak globalization perspective contends that economic change at the global level is increasing, but does not exert the degree of pressure on national welfare arrangements that globalization enthusiasts believe. Commentators favouring this approach point out that welfare regimes are able to accommodate global pressures by adjusting their institutional foundations in ways that do not fundamentally alter their character. In contrast to the globalization thesis, from this perspective there is no 'race to the bottom' spurred by attempts to reduce social spending and levels of protection in order to accommodate market demands for neoliberal solutions. Rather - and in general terms - it is possible to observe an ongoing process of (differential) adjustment to the impact of new economic phenomena, which has recently been characterized by Leibfried and Obinger as 'divergent convergence'. These writers (Leibfried and Obinger, 2001:

5) draw attention to the ways in which different approaches to reform are influenced by a number of factors including 'the partisan complexion of government, the power resources and aggregation capacity of trade unions and employers, the system of interest mediation ... and ... the institutional legacy of the welfare regime'.

To prefigure the argument of this chapter, the 'weak globalization' thesis, as this relates to welfare, suggests that GEPs are increasing in scope and influence, 
and that they constitute an important phenomenon that demands a response from existing welfare regimes, social democratic, continental and liberal alike. To this extent, there is a gathering drift towards a social policy environment in which such pressures are likely to become more rather than less determining over time. The notion of 'drift' depicts the indirect nature of the ways in which GEPs disrupt domestic institutional and political structures, even as they are affected by them. GEPs present important challenges because they play a significant frame-setting role in social reform that 'unsettle' existing arrangements.

\section{Globalization and welfare regimes}

\section{Welfare regimes and the globalization thesis}

Writing about the weakening of social democracy in the modern world, John Gray (1997) is clear that its decline has much to do with the ways in which globalization has undermined the centrepiece of the model - the egalitarian, redistributive welfare state. For Gray (1997: 28), 'economic globalization removes, or weakens, the policy levers whereby social democratic governments sought to achieve goals of social solidarity and egalitarian redistribution'. It is able to do this because pressures for liberal market reforms undermine typical social democratic, welfarist policy options. For example,

full employment cannot be promoted by policies of aggressive deficit financing since that will now be interdicted by global bond markets ... using the tax system to promote goals of income and wealth redistribution is severely constrained by unprecedented international mobility of capital and people.

Furthermore, 'globalization weakens or undermines the bargaining power of organized labour [while] public financing of the welfare state is constrained by dependency on global capital markets, which limit to a narrow range national governments' leverage over interest rates and exchange rates'. According to Gray (1997: 29), the weakening of state institutions by global economic forces is occurring apace whether globalization is defined or measured 'by the magnitude of trade flows, capital or migration, or as a massive extension of processes of marketization of social life that have long been in evidence within national economic cultures'.

These arguments find echoes in the writings of Anthony Giddens (1998, 2000) as well as others like Martin et al. (1997). Of more direct relevance to welfare regimes, however, are the writings of Ramesh Mishra and these will be explored in some detail. Mishra believes that the social, political and economic foundations of postwar welfare regimes have been severely weakened and places the main responsibility for this crisis squarely on globalization, perceiving a convergence of welfare arrangements on the liberal, Anglo-Saxon model. For Mishra (1996: 317, original emphasis), globalization 'appears as an external constraint - not as a matter of political choice at all, but rather of economic necessity - so that nation-states can do little besides follow the dictates of footloose capital in a downward spiral of 
deregulation, lower social spending and lower taxes'. An essential feature of his position is that economic globalization is forcing national governments into policies which have an underlying 'market logic'. In contrast to the 'golden age' of the 'Keynesian Welfare State', which was characterized by full (male) employment, organized trade unionism and high levels of social provision, usually delivered through state-based goods and services, Mishra (1999: 25) believes that the period since the 1970s has been marked by dramatic labour market changes that can be attributed, directly or indirectly, to globalization (see also Reich, 2002). Newly industrializing countries like Japan entered the global economy during the 1960s, bringing cost advantages to mass-produced goods which threatened manufacturing employment levels elsewhere. Just as importantly, 'with increasing capital mobility, freedom to locate production overseas and the use of outsourcing, some of the routine production moved out into the Third World', which also had consequences for full employment strategies. In addition, changing technologies contributed to the phenomenon of jobless growth, which particularly hit the male-orientated manufacturing sector, while the move from manufacturing to service sector employment in the developed societies led to an increase in part-time, non-unionized work often taken up by women (see also Land, 1999).

These changes have led welfare states, 'irrespective of their political complexion', to abandon Keynesian-inspired policies of full employment, progressive taxation and high social spending in favour of liberal supply-side policies, spending cuts and privatization (Mishra, 1996: 323). To be sure, Mishra does not argue that different welfare regimes are adopting identical policies, let alone that they have already converged on the neoliberal model, but his belief that 'Keynesianism in one country' is no longer an option leads him to argue that the social democratic 'left approach', so closely associated with state welfare provision in the postwar era, has fallen victim both to 'real' changes in the global economy and to the increasingly hegemonic market liberal ideology that accompanies them (Mishra, 1999: 102-3).

Mishra's argument is typical of many contributions that regard trade openness and increased capital mobility as an unholy alliance contributing heavily to higher unemployment while simultaneously constraining governments' capacity for economic management, particularly where this involves deficit financing (see also Kurzer, 1993; Sachs and Warner, 1995). Indeed, others less convinced by the globalization thesis overall also endorse the causal logic of this approach. Gilbert (2002: 38), for instance, though more circumspect than Mishra about the precise impact of globalization, nevertheless, argues that 'with the emergence of a wellintegrated global market ... national policy-makers are increasingly being disciplined, and spending on redistributive social benefits is being squeezed by the mobility of capital to go where production costs are low'. It is these changes that inform Gilbert's concept of the marketized 'enabling state' briefly mentioned in Chapter One. This state works on policies and principles established 'on the ideological terrain of the Right - a paradigm shift for the welfare state if ever there was one' (Gilbert, 2002: 180). Scharpf (2000) also argues that increasing international competition in product markets leads to unemployment in the exposed 
sectors and that this in turn reduces the state's capacity to use private sector employment relations as one means of maintaining egalitarian welfare goals. Hostility to higher taxation and deficit financing means that these same factors also prevent the state from shifting the burden onto the formal welfare and tax systems. In these circumstances, Scharpf (2000: 224) concludes, 'all countries are under pressure to increase private sector employment, raise the efficiency of welfare state spending and in particular reduce the employment impeding effects of welfare state financing and welfare state benefits'.

\section{Welfare regimes and globalization - the sceptical vieze}

The economic logic of the hyperglobalist position is contestable. First, as Huber and Stephens (2001) note, the extensive welfare regimes of the Scandinavian countries (indeed the majority of Western European nation-states) developed in highly open market conditions. Not only does this fact indicate that high public spending, deficit financing and other 'Keynesian' policies have always co-existed with economic openness, it also implies that the difficulties experienced by some of the Nordic regimes in the 1990s may not be solely attributable to this factor. A second, and related, matter concerns the extent to which unemployment is caused specifically by factors associated with the international economy. Where increasing trade competition is concerned, Schwartz (2001: 20-1) argues that evidence connecting rising unemployment amongst unskilled labour in the advanced economies directly to corporate relocation to the newly industrializing economies (NIEs) is slight. For one thing, FDI continues to flow disproportionately among the advanced economies as is generally recognized and, for another, 'NIE imports created growth in the OECD that in turn could have provided a window for redistribution towards [unskilled] workers'. More significantly, even if competition from NIEs can explain the weak demand for labour at the low end of the manufacturing labour market, 'it does not provide a sufficient explanation as to why cutbacks are the natural political response to rising unemployment and inequality or why welfare institutions were restructured'.

Turning to trade competition within the advanced economies, Iversen points out that the assumption that trade openness leads to economic insecurity and consequently to welfare regime adjustment might be false. In his view (Iversen, 2001: 50), high export volumes may be associated with lower domestic volatility because 'participation in international trade makes it possible to escape excessive dependence on small home markets', which tend to be more volatile. As Iversen and Cusack (2000: 319) note, the bulk of international trade occurs within product categories that are exposed to similar cycles - the point being that risks are thus diversified across a number of national markets, leading to greater overall stability. Consequently, as the major part of trade the within the OECD is 'intraindustry and occurs across numerous national markets, there is little a priori reason to expect that trade is associated with greater volatility'. Iversen's empirical study found no relationship between the export dependence of manufacturing and a range of volatility measures, including unemployment, in the sixteen OECD 
countries he studied, leading him to conclude that trade openness cannot explain changes in welfare regimes.

With regard to the links between capital mobility and welfare regime change, neither Schwartz nor Iversen - and nor, for that matter, others better disposed to aspects of the globalization thesis like Garrett (1998) - can find proof of a causal relationship here. The lack of unambiguous evidence about interest and exchange rate convergence, discussed in the previous chapter, in addition to the absence of any significant convergence in tax policies, suggests that nation states continue to exercise a degree of autonomy over their economic destinies, which enables them to preserve welfare regime characteristics despite the growing influence of capital markets. There are good reasons why this could be the case. For one thing, as Hay suggests, capital, once it is invested, may become rather more immobile than globalization enthusiasts allow. Outside obviously mobile portfolio investments, other types of FDI, 'once enticed and attracted to a particular locality ... "bed down", acquiring an array of significant sunk costs ... as virtual/immaterial assets are translated into human and physical capital' (Hay, 2001: 51), with potentially significant cost consequences for further relocation.

That the threat of capital flight may be more apparent than real-unless in the exceptional circumstances of extremely large budget deficits (Swank, 2001: 224)gains support from Scharpf, who argues that employment in exposed industries, though in his view declining due to international competition, does not appear to be particularly vulnerable to a regime's overall tax burden. Indeed he argues (Scharpf, 2000: 204) that high-tax Denmark and Sweden, as well as medium-tax Germany and Austria 'have more jobs in the exposed sectors of the private economy than is true of the United States, one of the two countries with the lowest tax burden'. So mobile capital may not actually be that 'flighty'. Indeed it could be the case, paradoxically, that capital actively chooses to locate in high-spending welfare regimes, perhaps because they offer greater long-term social and political stability, or higher productivity ratios, in spite of countervailing pressures emanating from the global economy - this possibility will be considered below.

The main point here is that some observers perceive a distinct gap between pressures arising from economic openness, on the one hand, and welfare regime change, on the other - and this challenges the causal logic of the globalization thesis. With this possibility in mind, it is tempting to go further and argue with Iversen, Paul Pierson, Castles and others that GEPs are so weak as to be virtually irrelevant, if not entirely chimerical. Certainly for Paul Pierson (2001: 82), the budgetary stress with which welfare regimes are currently confronted stems not from 'globalization' but rather from 'a series of "post-industrial" changes occurring within advanced industrial democracies'. Of particular significance here is low economic growth - a phenomenon created not by external factors but by domestic deindustrialization, which is itself the result of technology-led productivity gains and changing patterns of consumption. The principal feature of this perspective is that, although jobs lost in highly productive manufacturing industries have been 'replaced' by rising employment in the rapidly expanding service sector, these latter jobs are simply less productive. According to Baumol's law (1967) productivity in 
the service sector cannot match that in manufacturing because of the greater labour intensity involved in many service industries and partly, too, because wage increases in the traded sector will inevitably filter into services with negative consequences for growth and employment. As Iversen and Cusack (2000: 337) note, 'in laborintensive services, which include many personal social services, a tightly coupled and compressed wage structure will result in rising relative prices and therefore in a slower rate of job creation'. Welfare regimes can be affected by this phenomenon in two ways, depending on their institutional make-up: first, deindustrialization can lead governments to raise the generosity of transfer payments as they 'respond to electoral pressures for insurance against labor-market risks' (Iversen and Cusack, 2000: 336). Second, deindustrialization creates employment effects that lead governments either to stimulate employment by expanding public sector services or to rely on the private sector to soak up surplus labour - contributing to the 'service sector trilemma' identified by Iversen and Wren (1998). Certainly in those nations with traditions of centralized bargaining, 'deindustrialization produces large numbers of workers who cannot find employment in private services... [so] service employment is expanded by increasing the direct provision of government services' (Iversen and Cusack, 2000: 336-7). Sweden, where the social democratic left has traditionally been strong, provides a good example, although as Swedish fortunes during the 1990s demonstrate, there are limits to the extent to which social democratic employment and equality goals can be achieved in an overall context of budget constraint (Iversen and Wren, 1998). Conversely, where bargaining is decentralized, as it is in liberal regimes, then private sector solutions are relied upon. This approach relieves governments of the need to increase the size of the public sector, with beneficial budgetary effects, and frequently leads to higher overall employment levels - however, the 'costs' of deindustrialization are visible in greater wage inequalities and more heavily gendered divisions of labour.

In addition to these processes of endogenous deindustrialization, other domestic 'post-industrial pressures' are also creating difficulties for welfare states, of which perhaps the most visible is population ageing. As Pierson (1998: 550) notes, birth rates are falling and people are living longer in all the advanced industrial democracies with the result that increasing resources need to be found from diminishing numbers of economically active people to pay for those in retirement (see Chapters Six and Seven below). Because pensions are the most expensive item of welfare state expenditure, the current demographic shift constitutes 'a central source of fiscal pressure on national welfare states' (Pierson, 1998: 551) - the problem being that in certain types of welfare regime path-dependent assumptions can lead to significant struggles over changes in pensions arrangements and so to a degree of institutional stickiness.

For sceptics, then, the particular nature of deindustrialization processes, in addition to demographic and other pressures, deny the convergence logic of the globalization thesis. National governments, though not disconnected from the global economy, are more likely to struggle with these domestically driven issues within a national policy discourse and political idiom. While this perspective does not necessarily argue that welfare regimes are incapable of change (the pressures noted 


\section{Globalization and welfare regime change}

here may simply be becoming too much to sustain existing arrangements) reform, if it comes at all, is most likely to be a product of newly emerging domestic political coalitions within regimes themselves (Pierson, 1998). The strength and influence of such coalitions will vary, however, so it is likely that the extent of change will be conditioned by the political capacity of existing institutions (the state, political parties, social movements) either to defend traditional arrangements or at least to 'mediate' attempts to alter them. The nature and character of such attempts will inevitably be regime specific.

\section{Challenging scepticism: tozards a middle way}

How convincing is this argument that pressures on the welfare state are attributable to endogenous processes primarily associated with domestic labour market restructuring, population ageing and institutional stickiness? There is something in this view, to be sure. Taking deindustrialization first, as Held et al. (1999: 187) note, 'manufacturing's share of employment tends to decline at higher levels of development: as productivity rises in manufacturing, progressively fewer are needed to produce a given level of output' - and of course technological advances only exacerbate this process of jobless growth. However, there is a need for caution here as two counter-arguments make clear. First, although sceptics place a good deal of weight on Baumol's law as a major explanatory factor for low growth and higher overall unemployment in the developed economies, it may be that the law 'describes a tendency rather than an absolute condition' (Schwartz (2001: 28). Moreover, as Schwartz argues, the widespread introduction of performance management and other organizational technologies have been successful in increasing service sector productivity, while 'changes to collective bargaining regimes that delink Baumol's progressive and constant sectors [have prevented] rapid crosssectoral transmission of wage gains'. Arguably, then, if low growth and higher unemployment cannot entirely be laid at the door of the transition to a service economy other factors could be playing a role.

Second, even if it is accepted that deindustrialization is essentially an endogenous process, it may be one that is now on the wane. Burgoon's (2001) study of the effects of economic openness on welfare effort notes that, if the impact of deindustrialization is judged over the 1980-94 period, as opposed to the 1961-93 period used in Iversen's study, its influence, though remaining significant, appears to have declined. With trade openness and capital mobility increasing dramatically during the former period, and continuing to do so, it may be that the factors affecting welfare regime change are themselves changing. On this reading, processes of endogenous deindustrialization may have run their course in the majority of the developed economies and welfare regimes are, in all likelihood, beginning to experience a 'second wave' of pressure in which openness of various kinds, increasingly driven by advances in information and communication technologies, plays a larger role. Castells (1996: 238-9) provides support for this view in his contention that, in recent years, a wide range of opportunities has opened up for companies in advanced capitalist nations 'concerning strategies towards labor, both skilled 
and unskilled'. Itemizing five strategies, ranging from downsizing but keeping a skilled labour force in the North, through various forms of subcontracting, to automating or relocating certain tasks and/or reducing wages and working conditions, Castells argues that 'this range of possibilities translates into the actual use of all of them depending on firms, countries and periods of time'. Increasing low-wage competition from the NIEs could be a factor here, at least to the extent that such competition has encouraged producers in high-cost countries 'to automate production or to specialize in "upmarket" industrial products of high technical or aesthetic quality, and in highly productive services' (Scharpf and Schmidt, 2000: 72; see also McKeown, 1999). But the key point is that 'although global competition may not affect directly the majority of the labour force in OECD countries, its indirect effects entirely transform the condition of labor and labor institutions everywhere' (Castells, 1996: 239). Welfare regimes are deeply implicated in this process.

There is some empirical evidence to support these conclusions. Although it is difficult to isolate particular economic explanations of welfare regime change in ways that govern adequately for the influence of alternative factors, Burgoon's study, referred to above, suggests that there is some evidence that economic openness can have a positive effect on welfare effort. Using disaggregated data, Burgoon (2001) argues that, while evidence of an overall effect of economic openness is hard to find, certain elements of openness appear to be correlated with certain elements of welfare provision. He (Burgoon, 2001: 519) is particularly interested in the impact of trade with developing countries, arguing in contrast to Schwartz (2001), that

the sharper wins and losses stemming from developing-country competition should spark stronger demands in industrialized countries for government policies that compensate for the risks of such openness [because] the losers with a concentrated interest in mobilizing action may look to welfare provisions of various kinds - not just to protectionism.

The major losers are likely to be unskilled, low paid workers in the exposed industries (McKeown, 1999), and this group according to Burgoon could be expected to demand greater spending on active labour market programmes, education and training, and other forms of provision explicitly devoted to employment protection and job creation. Importantly, these demands are also likely to be supported by certain producer and investor groups who regard these particular components of welfare as conducive to improving 'economic adjustment, research and development, infrastructure and human capital' (Burgoon, 2001: 523). Burgoon's analysis suggests that there is some merit to this hypothesis, the general picture being one 'of openness having modest and varying consequences for aggregate government spending efforts, negative for general trade, weakly positive for low-wage proportions, and mixed for portfolio and fixed investment' (Burgoon, 2001: 540). Specifically, the data point to the possibility that 'the proportion of low-wage imports tends to have a more 
significant and positive effect on welfare compensation than general openness' and, more especially, that 'low wage, FDI and portfolio openness has a generally positive effect on training and relocation spending' (Burgoon, 2001: 547). Of course, much lies in the detail and like many of those who are sceptical of the globalization thesis, Burgoon notes that 'the findings ... suggest that openness encourages bigger changes in some "worlds" of welfare capitalism than in others'.

Turning briefly to the problem of population ageing, it is worth prefiguring three points made in subsequent chapters in order to provide a counterweight to the sceptical position. First, although the fact that the 'baby boom' generation is approaching retirement is undeniable (as the OECD has tirelessly made clear) and is beginning to exert pressure on existing pensions arrangements, it is not clear that this challenge can be labelled as 'domestic' in any easy sense. For one thing, the alternatives open to governing parties wishing to recast their pensions systems are likely to be limited by spending constraints resulting from market pressures for fiscal rectitude; it is clear that raising taxes or insurance contributions to maintain existing benefit levels is no longer a simple matter. Second, to the extent that GEPs do indeed have an impact on deindustrialization and the associated rise in service sector work, they can be implicated in new patterns of employment that could require different pensions arrangements from those established in the Keynesian era. For instance, many more women now go to work, albeit mainly part-time, and the incidence of self-employment has increased markedly (Bonoli and Gay-des-Combes, 2003), while, the numbers of fully-employed men around whose permanent lifetime employment pensions systems were originally constructed, have declined dramatically. Finally, in so far as many national governments are seeking solutions to their pensions difficulties by incorporating a 'market element' into predominantly state schemes, these systems, along with the savings of the individuals they support, are vulnerable to market instability in a global economic environment that is beyond the capacity of any one national government to control. In this way, with new arrangements frequently entailing a degree of privatization and increasing reliance on the investment decisions of corporate fund managers, the pensions issue is becoming a globally significant phenomenon.

\section{Welfare regimes, institutions and democratic politics}

Having considered the arguments advanced by globalization enthusiasts, the responses of their sceptical critics and some criticisms of the sceptical view, it is plain that neither side is entirely convincing about what it understands as the causal factors promoting welfare state change. Certainly, where the globalization thesis is concerned, Pierson (2001: 99) is surely right to argue that 'simple versions of the globalization story flatten national differences ... [because] if globalization creates a set of overriding imperatives, national characteristics decline in significance'. Too much attention to endogenous economic factors, however, risks losing sight of the global level in spite of sufficiently compelling evidence suggesting that pressures arising in the global economy are likely to condition national policy making, even though indirectly. In attempting to resolve the impasse there is a 
need to steer between the 'one-explanation-fits-all' position of the globalization theorists and the opposing view that GEPs have little influence on welfare regime change. In other words, it is important to explore the limits that GEPs may place on welfare regimes, but just as important to be clear about the nature of 'welfare state limits to globalization' (Rieger and Leibfried, 1998).

One way of advancing this position is to stress again the fact that economic pressures are likely to provoke differential responses from welfare regimes depending on their political and institutional characteristics. Although GEPs can appear as relatively homogeneous entities at the global level, they inevitably fracture as they come into contact with specific political, institutional and cultural environments. Their influence has to be understood in relation to the countervailing influence of the domestic aspects of each regime's global-institutional nexus - for example, structures of industrial relations and the degree of embeddedness of domestic employment patterns, the balance between the exposed and service sectors and between public and private sector employment. In addition, the extent of 'welfare effort' typical of a particular regime, including the proportion of GDP devoted to social spending, the range of, and balance between, 'active' and 'passive' measures for the support of the unemployed, the degree of state support for child care and other care services, together with cultural factors governing attitudes to women working outside the home and part-time working also need to be taken into account.

These considerations indicate that GEPs will be both generally influential and simultaneously regime-specific. Their frame-setting capacity will unsettle all welfare regimes even as the political and institutional supports of each regime either enhance or reduce their overall impact. As Reiger and Leibfried (1998: 366, original emphasis) argue:

The movement toward and the trends in a globalized economy have been triggered, contained, differentiated or modified, weakened or strengthened, and slowed down or speeded up through national structures of social policy and their developments... The crucial variables are the institutional characteristics of social policy. They are the starting and focusing points for new social groups, varying political mobilization, and structural change in interest mediation in the welfare state.

If anything the statement underestimates the influence of GEPs, but it recognizes that they do exist and, equally significantly, that 'politics' and democratic contestation are essential features of global-institutional paradigms.

\section{Stability and change in contemporary welfare regimes}

If 'politics' remains important to the ways in which contemporary welfare regimes are responding to GEPs and other contingent pressures, how are the institutional structures of different regime types politically configured and how do they confront the challenges currently facing them? Swank distinguishes three core characteristics of welfare regimes that either predispose them towards market liberal or (versions 
of) corporatist policy solutions. First, differing forms of interest group representation influence the extent to which groups can rely on continuing social protection in a climate of increasing economic pressure. Swank (2001: 208-9) maintains that the existence of corporatist institutions in the context of economy-wide bargaining 'in which broadly organized and centralized labour movements have regularly exchanged wage restraint for full employment commitments and improvements in social protection' will continue to sustain those nations that have traditionally attempted to balance economic efficiency with comprehensive welfare provision. Countries with more decentralized, pluralist forms of interest representation, on the other hand, are more likely to be characterized by less comprehensive, more contested forms of welfare provision in a policy environment that, when confronted by GEPs, eschews gradual, negotiated change in favour of 'relatively quick and non-trivial retrenchments of the welfare state'. Second, the number of potential 'veto points' within a polity may influence the nature of welfare provision. Where policy making is decentralized, for instance, there may be greater scope for the mobilization of countervailing social forces which can inhibit central government efforts to develop and impose new social policies. As Swank (2001:211) comments, 'institutional structures that disperse policy-making responsibility tend to undercut the formation of coherent national policy strategies by groups and parties' - the upshot being that the decentralization of political authority can be associated with low levels of social spending and fragmented forms of welfare. Finally, Swank (2001:213) points to the significance of the specific nature of social and political support for welfare goods and services. He notes, for instance, how universal welfare systems 'tend to create large cohesive constituency groups organized around relatively generous, universal programmes of social welfare provision', which function at national level. This relatively undifferentiated support base for universal social protection contrasts with more fragmented systems where welfare arrangements are rooted in sectional claims for protection based around particular status groups or social classes.

According to the above analysis, the local impact of global change will differ according to the degree of embeddedness of centralized, corporatist institutions. Where social cohesion and corporatism are weak, political authority decentralized and social democratic parties rarely in government, 'rises in public sector debt and international capital mobility are associated with downward pressures on social welfare provision' (Swank, 2001: 233). Conversely, where social corporatism is strong, left political parties powerful and policy making centralized, 'the effects of fiscal stress and international capital mobility are absent, or they are positive in the sense that they suggest economic and political interests opposed to neoliberal reforms ... have been successful in defending the welfare state' (Swank, 2001: 233). The Nordic social democratic regimes with their historic commitment to universal welfare provision, full employment and centralized bargaining arrangements, stand as examples of the corporatist route, while the USA, Canada and the United Kingdom, joined more recently by New Zealand and Australia, exemplify the neoliberal alternative.

Continental regimes constitute a more complex set of examples. In this diverse group of countries, elements of corporatism are clearly visible but they are usually 
located within decentralized structures of political authority and, occasionally weak, forms of interest intermediation. Not surprisingly, there are differences in the ways that these countries deal with GEPs and other factors, much depending on the particular configuration of social, economic and political forces in each case. The general effect, however, is that continental regimes exhibit little in the way of universal or 'citizen-based' social protection, relying instead on generous insurancebased transfers closely linked to employment history. Because high benefit levels are so dependent on payroll taxes and a fully employed working population, these countries are generally considered to be less capable of adapting to economic and demographic challenges than either their social democratic or liberal counterparts.

These broad descriptions of welfare regime characteristics do much to 'place' the potential influence of globalization as a phenomenon likely to be dealt with differently by differently constituted systems. However, as noted in Chapter One, the systems as described by Esping-Andersen, Swank and others only provide basic, 'ideal-typical' accounts of the nature of the institutional make-up of different regimes. While these institutional supports may have been roughly consonant with postwar regime requirements, evidence provided by the case studies in Chapters Four through Seven suggests that welfare regimes in the OECD are either beginning to adjust their social policies in a market-oriented direction, or, at the very least, are experiencing significant levels of political argument about potential marketization, which are progressively bringing existing welfare arrangements into question. These changes suggest that explanations that consider institutional factors to be capable of effectively offsetting the effects of GEPs need to be probed a little further. If there is a difficulty, it lies in the conviction that welfare regimes and the institutions that underpin them will consistently 'conform to type' in the face of global economic pressures. But is this in fact the case? Might it be that as the states within the clusters outlined here experience continued and persistent pressures for 'adjustment', their institutional supports will progressively weaken? In consequence, could 'traditional' forms of welfare provision erode as regime-specific institutions start to fracture? An indication of the accuracy or otherwise of this possibility can be gained by taking a closer look at the changing nature of core elements of the production regimes with which welfare regimes in the developed democracies are so closely associated. Changes in patterns of industrial relations that alter the balance of power between employers and employees are likely to have significant implications for employment policies and levels of welfare provision. In addition, shifts in the nature and levels of political support for established welfare arrangements provide a further indication as to whether contemporary welfare regimes may be living on 'borrowed time'. Finally, some assessment needs to be made about the causal impact of global forces on these changes.

\section{Change in the social democratic universe}

One of the points made by Soskice in his discussion of 'divergent production regimes' is that coordinated market economies (CMEs) contain institutional frameworks that tend to develop 'long-term cooperative relations, between one company and another, between companies and employees, and between companies 
and their owners' (Soskice, 1999: 106). Until the 1980s, the 'industry coordinated economies' of many European nations could be divided into the 'centralized egalitarian' systems of Scandinavia, characterized by 'egalitarian, centralized wagesetting procedures' and the 'flexibly coordinated' systems of countries like Germany, 'in which average wage increases are coordinated across industries but in which companies contain considerable room for maneuver' (Soskice, 1999: 124). In Soskice's opinion, a number of factors, of which GEPs are one, have forced acrossthe-board changes as coordinated institutional frameworks have 'increased considerably in the flexibility they allow individual microeconomic agents'. The Scandinavian model, in particular, has experienced significant changes, moving rather closer to the German model, at least in terms of employer autonomy.

Soskice's argument seems to apply most obviously to the Swedish case. As Swenson and Pontusson (2000) have argued, it is widely recognized that centralized bargaining broke down under the weight of international pressures in the 1980s (see also Lash and Urry, 1987). In a context of rising demands from employers for a more liberal direction in economic policy and substantial welfare state restructuring, Social Democratic governments abandoned devaluation as their preferred means of maintaining Swedish competitiveness in favour of a hard currency policy and increased central bank autonomy. The ill-timed 'stabilization policy' coincided with the global economic upheavals resulting from the loosening of capital controls and led to Swedish multinational companies swiftly increasing their outward investment (Swank, 2002: 135). Rapidly rising unemployment and severe economic crisis were the inevitable results (Benner and Vad, 2000: 419). These changes struck at the heart of Sweden's established postwar pattern of economic management and fundamentally challenged the relationship between the social partners on which it was based - with obvious results for Swedish industrial relations. Two factors were particularly important. First, the interests of private and public sector unions began to diverge as those in the exposed sectors became aware of the threat to jobs posed by public sector wage increases and, second, this loss of cohesion within organized labour facilitated employers' demands for an end to centralized wage bargaining.

The strains of sustaining the solidaristic wages policy in the face of employers' desires for more decentralized bargaining practices in an effort to improve firms' international competitiveness led initially to sectoral bargaining rounds in the late 1980s followed by employer withdrawal from centralized bargaining in 1990, which involved the removal of over six thousand business representatives from the various institutions associated with the bargaining process (Blyth, 2001: 14). While these changes should not be taken to suggest a complete collapse of corporatist arrangements, not least because sectoral bargaining has continued and the trade unions remain powerful, particularly in the web of institutions that support Swedish economic performance and social welfare arrangements, there is nevertheless a sense that something has changed. In Traxler's (1997: 172) opinion, 'the system became unsustainable after liberalization of the financial markets because further support for competitiveness through devaluations became impossible' and the focus consequently shifted to wage restraint. Others concur with this view that Sweden 
experienced severe economic difficulties following financial deregulation in the 1980s (Clasen and Gould, 1995; Stephens, 1996; Jochem, 2000), some even arguing that "Sweden represents one of the most obvious instances of "paradigmatic realignment" or "regime change" among OECD countries over the last 10 to 15 years' (Iversen and Pontusson, 2000: 1-2). To be sure, the Swedish economy improved markedly in the later 1990s but this was partly because first Bourgeois, and subsequently Social Democratic, governments pursued tight monetary and anti-inflation policies in an environment of decentralized wage bargaining - and at the expense of the traditional goal of full employment (Benner and Vad, in Scharpf and Schmidt 2000).

Whether these changes directly resulted in a 'transformation' of the Swedish universal welfare state - and indeed whether they were a direct result of global economic pressures - is by no means clear. The specific examples of labour market policies and pensions will be discussed below - but here it is important to note in general fashion that Swedish governments of both political colours attempted to curb spending on core welfare programmes throughout the 1990s and that the process of retrenchment was made easier by organized labour's relative disarray and the growing power of employers. Benefit levels, though remaining generous, were cut, waiting periods lengthened and eligibility criteria tightened, while certain services were decentralized and/or privatized - health care being a core example (Gould, 2001: 74-5). As Timonen (2004: 85) notes, these changes have begun to have an impact on those most vulnerable to welfare state withdrawal, who include new groups - young people, immigrant populations, lone parents and large families. Importantly, too, the trade unions proved unable to resist new employment laws introduced by the Social Democrats in the mid-1990s, which went some way to 'flexibilizing' the highly controlled labour market. The fractured character of organized labour was visible during the negotiations, with unions disagreeing both among themselves and with the Social Democratic government about the nature of employment protection (Gould, 2001: 150-1). To be sure, the unions did succeed in defeating more radical proposals for labour market flexibility coming from the Association of Swedish Industry and endorsed by the Bourgeois parties; they also remained important actors in the delivery of certain employment-related services such as active labour market policies. Nevertheless, if the tone is one of 'adjustment' rather than 'transformation', the direction, however gradual, is towards greater marketization.

Concentration on Sweden, often treated as par excellence the embodiment of social democratic corporatism, needs to be balanced by a brief consideration of the fortunes of other Scandinavian nations. With the exception of oil-rich Norway, the other two Scandinavian countries, Denmark and Finland, experienced severe economic difficulties in the 1980s and 1990s respectively. To take the Danish case, the crisis began to come under control in the mid-1980s when Centre-Right governments adopted a hard currency policy as well as placing stress on exchange rate and price stability together with reforms to curb public sector spending. Industrial relations have changed markedly in recent years, starting in the late 1980s. The '1987 declaration of intent' saw Danish unions agreeing to keep wage 
increases below the level of Denmark's trading partners while subsequent years saw a trend towards 'centralized decentralizaton' in wage bargaining (Benner and Vad, 2000: 439-40; Bjorklund, 2000: 159). According to Due et al. (quoted in Benner and Vad, 2000: 440) this process has meant a transformation of national bargaining

from a large number of trade unions and employer organizations to a few, broadly based bodies capable of concluding framework agreements. This centralization is accompanied by a decentralization of competence to make decisions on wages and working conditions for a single workplace at local level, thus allowing maximum flexibility when filling in the details of these framework agreements.

By the late 1990s decentralization had expanded further. Although the social partners continue to be committed to an organized labour market at one level, it is the case nevertheless that 'as more and more employees negotiate salaries, pensions, special bonuses, etc, with their employers on an individual basis, a gradual challenge to centralized decentralization in both the private and public sector is emerging from outside the system' (Benner and Vad, 2000: 440). In Bjorklund's (2000: 159) words, 'central agreements at the industry level have gradually become less binding on individual firms' and, to this extent, bargaining processes are becoming more 'supple' (Rhodes, 2001: 167) with corporatist structures loosening accordingly.

These changes were accompanied by reforms to the Danish welfare system that, in Scandinavian terms, are far-reaching. The 1990s saw both Conservative and Social Democratic governments cutting taxes, reducing benefits, tightening eligibility criteria and increasing means-testing, albeit in the context of continuing generosity in comparison to other welfare regimes (Swank, 2002: 143-4) - a bipartisan approach to welfare that has continued into the new century. The CentreRight coalition government, led by Anders Fogh Rasmussen, that came to power in 2001 and gained a second victory in February 2005 differs little in social policy terms from its social democratic counterparts, although its enthusiasm for neoliberal adjustment appears to be becoming more pronounced (Aarsland, 2005). In contrast to Sweden, however, where union resistance was more than residual, Danish governments have broadly enjoyed the backing of both trade union leaders and employers in their efforts to reorganize the Danish economy and welfare state. Union support can be attributed to the recognition that the Danish export sector, dependent as it is on a large number of small- and medium-size enterprises, is not well-linked to expanding market areas, particularly in the new technologies, nor easily able to compete in a global marketplace increasingly dominated by large corporations. Anxieties about unemployment dampened wage demands and accepted the need for industrial restructuring in a 'liberal' direction, which recently has stressed the importance of 'framework conditions' - increased skills training, infrastructural change and tax reductions - with the private sector as 'the main engine of growth, employment and welfare' (Benner and Vad, 2000: 442). 
Is there a sense in which these changes and their knock-on effects for welfare arrangements can be attributed to GEPs? To the extent that Danish politicians and labour market actors are clearly aware of the ways in which the growing world economy can create pressures for a small, open economy such as Denmark's, such awareness has contributed towards political demands for the development of market-friendly policies in the 1980s and beyond. However, this context of global economic pressure has been accompanied by certain domestic factors which have strengthened the trend towards marketization - while others have worked in the opposite direction to balance these 'neoliberal' changes according to the prevailing logic of the universal welfare state. On the first count, Centre-Right policies in the 1980s were aided by the relative absence of veto-points in the Danish system, which means that key negotiations about budgets tended to be conducted among a small group of party leaders with 'the content of the compromise ... often unknown to the public until the very last moment' (Goul Andersen, 2002a: 1567). For example, central government proved quite successful at imposing fiscal restraint on localities, particularly at the height of economic stress in the 1980s (Schwartz, 1999: 13). A further factor is that the social partners have proved reluctant to oppose the changes in bargaining practices mentioned above, with the result that wage restraint generated higher employment levels. Moreover, acceptance of increased labour market flexibility and low employment protection also bolstered employment - although support for the unemployed remained comparatively generous. On the second count, the prevailing logic of universalism has meant that 'the well entrenched Danish moral consensus favoring the welfare state strongly conditioned efforts at change [which] had to be sold as welfare preserving cost containment, not a gutting and rebuilding' (Schwartz, 1999: 15). In this social democratic environment, characterized by cross-class support for existing arrangements, Centre-Right coalitions have had to cut their neoliberal cloth to suit enduring universalist ends - at least until very recently. In sum, then, prevailing global economic conditions set the parameters within which Danish governments and the social partners have been forced to operate, but they have not directly dictated precisely how key actors would respond to these pressures, nor the content of the policies designed to ameliorate them.

\section{Continental regimes in changing times}

Unlike countries in the social democratic cluster, it is less easy to characterize the Continental regimes of continental Europe as systems that are essentially similar. These countries vary a good deal in terms of population size, the nature and size of their economies and their political structures. Of particular note for present purposes are the variations in industrial relations practices among these states, which display markedly different degrees of union strength and social partnership. Two key similarities stand out, however. As Scharpf and Schmidt (2000: 104) have pointed out, all the continental systems are involved in the various processes of European integration, including financial market integration. Each participates in European Monetary Union, for example, and so currently operates under the 
tight monetary constraints imposed by the European Central Bank. Moreover, as mentioned, their welfare institutions are broadly 'Bismarckian', employing the social insurance-based, male breadwinner model as the central means of social protection. Despite Esping-Andersen's (1996a) conviction that the particular institutional makeup of continental welfare regimes militates against reform, it is possible to discern a general, if embryonic, drift in a neoliberal direction as existing welfare and production regimes are confronted by new economic and political challenges.

Taking Germany first, it is clear that there is now an extensive history of governmental attempts to 'adjust' the German social market model. The West German economy was amongst the first to adopt a hard currency policy in the wake of the economic difficulties associated with the collapse of the Bretton Woods exchange rate system and oil price rises of the 1970s, with the Bundesbank pursuing a tight monetary policy throughout the 1980s and 1990s. This stance meant that West German governments had to achieve and maintain cost efficiencies in the public sector, particularly in relation to welfare provision - and the successes and failures here are very much the story of the GDU governments led by Helmut Kohl which enjoyed an unbroken period in office between 1982 and 1998. Pre-unification, the healthy state of the German export sector and the stable nature of industrial relations meant that it was possible to conduct a restrictive macro-economic policy in the prevailing context of capital liberalization and increasing trade openness without trenching too much on social provision - though at the cost of higherthan-average unemployment. To be sure, measures were taken to control health costs in the mid-1980s and the 1989 pension reform tightened eligibility and benefit levels but, in general terms, the German welfare state was not subjected to extensive cuts and, indeed, was even modestly expanded in certain areas - child benefits being one example. Unification with the German Democratic Republic in the East altered the picture substantially, however. The decision immediately to extend the West German welfare system eastwards to offset the effects of industrial collapse and rapidly rising unemployment effectively entailed a huge expansion of welfare effort, the costs of which were borne mainly by rises in Western insurance contributions derived in the main from payroll taxes (Fuchs and Schettkat, 2000; Swank, 2002: 178).

There is some evidence to suggest that GEPs have played a part in the fortunes of the German economy in the 1990s, if only because they have exacerbated the deleterious effects of unification. As Swank (2002: 182) notes, increasing exportoriented modernization combined with 'accelerating European Community trade integration increased the already high trade openness of Germany' - and to these factors may be added significant outward flows of FDI in search of cheaper labour costs, which may have directly caused additional problems for a system increasingly characterized by high levels of unemployment. With resources being diverted to the social and economic development of the Eastern Länder, it is not surprising that employers and politicians began to voice concerns about the viability of the social market model, which appeared to be being sustained by persistent rises in payroll taxes and contribution levels at a time when the German export sector 
needed to become more competitive. Nevertheless, once again, these global pressures provide a backdrop and context which 'frames' political debates about reform rather than acting as direct economic agents of change. For one thing, in the absence of unification, it is likely that the West German economy would have proved to be more robust in the face of global competition and European integration than it turned out to be having taken on the economic deadweight of the Eastern Länder. Moreover, it is worth noting that policies for the reform of the social market economy, particularly in relation to the welfare state and labour market, did not emerge in any sustained manner during the early and mid-1990s, when concern about German uncompetitiveness was growing. Indeed welfare reform has really only been on the political agenda since the late 1990s, which suggests no direct cause-effect relationship.

The dangers of globalization have been used, however, to underpin employer and Centre-Right-led demands for the reform of the German model. Calls for welfare reform, particularly for a greater degree of marketization in service provision and cuts in benefit rates, came from these sources during the 1990s, with employers becoming increasingly vociferous in their demands for changes in the industrial relations arena where nascent shifts in favour of decentralized bargaining had begun to erode the power of the trade unions. This latter issue is worth pursuing further because the challenge to union power is clearly a significant indirect effect of the political deployment of globalization arguments.

The German industrial relations system is characterized by the legalized absence of the state from industrial bargaining practices, which may have served to loosen existing sectoral bargaining structures over the past decade. In an economic context which encourages new decentralized forms of business organization as well as departures from traditional methods of financing within the social market model (Hall and Soskice, 2001: 61), German companies have proved able to manipulate the parameters of social partnership in their favour. In this connection, Rhodes and van Appeldorn (1998: 417) note that 'German companies and unions are now agreeing patterns of flexible working that were unthinkable just five years ago, and many of these are reached locally with company works' councils'. Changes of this kind have been directly reinforced by the consequences of reunification. High unemployment levels in the eastern Länder have meant that employers there have been reluctant to develop traditional West German forms of collective bargaining - and indeed relatively few employers in the East are organized in the manner of their Western counterparts (Fuchs and Schettkat, 2000: 221). Far from West German insitutions being exported eastwards as the trade unions had originally hoped, the scale of Eastern unemployment has led to demands for greater wage flexibility, which have spilled over into the West. As is often the case, these issues are particularly clear in the metal industry where, in the light of the collapse of East German markets and the ensuing productivity gap between East and West, many Eastern firms have found it easier to stay out of Gesamtmetall, the employers' association, and instead to bargain directly with individual employees (Thelen, 2000: 144). As Fuchs and Schettkat (2000: 229) make clear, the acceptance of 
these 'opening clauses in the East was a signal for employers to abandon collective bargaining or to ignore agreements - even though the unions were prepared to accept a moderate, flexible policy on wage levels and working hours'.

There are currently signs that politicians may be growing more sympathetic towards employer aspirations for a reform of the system. Although during the 1990s both the Germany's political parties were apparently content to negotiate changes towards greater flexibility, decentralized bargaining and wage restraint consensually through tripartite talks - to little effect (Ebbinghaus and Hassel, 2000: 51) - there is currently a much greater willingness to support employers' demands in more forthright fashion. With the more vociferous employers demanding a 'German Thatcher' (Gow, 2003: 1) and an end not simply to job protection but to the entire social market model (Gow, 2004), Chancellor Schroeder's new Agenda 2010, introduced in May 2003, goes a long way towards recognizing the validity of these objectives. For example, the Agenda explicitly endorses the easing of employment laws and the further relaxation of rules on collective bargaining in addition to cuts in the levels of unemployment and other welfare benefits, including pensions (The Economist, 5.6.03). Significantly, too, a key justification for these changes, which were endorsed by the SPD and came into force early in 2004, is that 'globalisation is not an "option"; it is a reality' and that modernization is necessary if the social market economy is to be saved from the inegalitarian ravages of 'uncontrolled market forces' (Schroeder, 2003: 1). In this sense, globalization provides an economic justification for a shift of political focus aimed at securing a greater space for neoliberal policy alternatives. Of course, only time will tell whether Agenda 2010 represents an unequivocal step towards neoliberalism or a defensive move aimed at retaining the core characteristics of the social market model. This issue will be further addressed in Chapters Five and Seven.

The French case echoes the German story to the extent that here, too, there has been a degree of drift towards neoliberal policy alternatives over the past twenty years or so. The manner of drift differs, however, as does the role played by GEPs. In the French case, the marked departure from demand-led policies by Francois Mitterrand's Socialist government in 1982, characterized above all by the dramatic expansion of social protection, testifies to the increasing difficulties associated with trying to run 'Keynesianism in one country'. Falling confidence in the domestic business sector combined with a deteriorating balance of payments forced changes which entailed significant welfare retrenchment and a turn towards 'businessfriendly' industrial restructuring. With financial liberalization proceeding apace during the 1980s, eligibility rules were tightened, benefit levels reduced and health budgets capped, while taxes and social insurance contributions were increased. Significantly, though, the election of a Gaullist government led by Jacques Chirac in 1986 did not lead to the predicted radical shift towards neoliberalism, his plans for an overhaul of the entire social security system being met by strong union and popular opposition (Swank, 2002: 192). Indeed this pattern of government attempts to implement far-reaching reforms to the welfare system meeting with strong opposition from public sector unions and other interest groups, typified French social politics throughout the 1990s and into the present century. 
In one sense then, the core of the French welfare regime has not been greatly changed: despite reductions, benefits remain generous, there is a continuing, if increasingly politically contested, emphasis on 'solidarity' and a combination of continuing high unemployment and domestic demographic pressures make it difficult to reduce social spending. Moreover, the social insurance basis of the system remains - although it has progressively been hedged around by meanstested benefits and other measures designed to reduce the salience of the contributory principle and cater for the increasing numbers who do not qualify for contributory benefits (Gilbert, 2002: 144). In another sense, however, much has altered. Where industrial relations are concerned, as Ebbinghaus and Hassel (2000: 50) make clear, over the past twenty years union-employer bargaining has become increasingly decentralized in the private sector, leading to 'market-driven, employerimposed wage settlements at workplace level against the will of the unions' (Ebbinghaus and Hassel, 2000: 50; see also Clift, 2004: 102). These changes have led to greater labour market flexibility, lower rates of taxation on employers, lower service sector wage levels, less job protection and greater compulsion for the unemployed to find work, as Chapter Five demonstrates. Whether GEPs can be held directly responsible for this shift of emphasis is doubtful, however. It is true, as Swank (2002: 199) acknowledges, that financial liberalization and the reform of the 'overdraft economy' through a turn to price and exchange rate stability during the 1980s 'contributed to economic policy reversal and the shift from welfare state expansion to cost control and revenue raising' - but economic pressures arising from European Monetary Union have clearly been a factor here, as much as distinctly global challenges, while demographic issues continue to contribute to French difficulties. Moreover, the defensive political-institutional response has been marked, particularly among the public sector unions where the financing of health and pensions are concerned - changes in these areas remaining essentially pathdependent. Even so, although current levels of retrenchment hardly amount to neoliberal convergence, it appears that the French welfare system is beginning to drift in that direction.

The Italian case is distinguished by the late turn towards continental welfare structures, which really only emerged during the 1970s. Welfare state expansion consequently coincided with the economic downturn associated with the collapse of the exchange rate system and the rise in oil prices, which resulted - not surprisingly - in a declining balance of payments and rising inflation. Some efforts were made to tackle these difficulties during the 1980s. With the lira in the European Monetary System from 1979, a restrictive monetary policy was pursued by the newly independent Bank of Italy while unions and employers agreed, at least in principle, to greater labour market flexibility, and welfare spending was tightened. These initiatives did not succeed in lowering unemployment, however, while high levels of social spending continued to contribute to Italy's budget deficit, which stood at over 10 per cent of GDP throughout the 1980s (Swank, 2002: 205). A marked change occurred in the early 1990s, since when a number of attempts have been made to reform key elements of welfare provision. Three factors are particularly important. First, GEPs played at least a contextualizing role, as did 
other supranational pressures associated with European integration. For example, the liberalization of capital controls in 1988 and Italy's increased openness to global capital markets, as well as rising FDI outflows, produced pressures for labour market changes and the reduction of public debt. This latter issue was particularly pertinent in the wake of Italy's ratification of the Maastricht Treaty in 1992 as the Treaty demanded that all signatories must conform to strict European public spending targets. Second, a specifically domestic political pressure occurred in the form of the national emergency created by the scandals of Tangentopoli (Ferrera and Gualmini, 2000: 199). The investigations into widespread political corruption involved the 'turnover of the entire national political class' and contributed to the ensuing fiscal and monetary crisis that effectively paralysed the country. Third, in the wake of this crisis, the new government led by Giuliano Amato initiated moves designed to stabilize the Italian economy in general and its industrial relations system in particular. As Ebbinghaus and Hassel (2000: 52-3) note, a key feature of the Italian case is the reduction of employer-union hostility and the move towards stable industrial relations based upon the unions' willingness to drop automatic wage indexation in return for extensive reforms to the bargaining system. These reforms, implemented in 1993, reduced the hold of Italy's three main union confederations, which had historically divided on ideological lines. Driven partly by demands from autonomous unions and partly by employers' desires for 'a strong institutional link between bargaining agreements at the national and plant levels', the reforms consisted of national-sectoral level agreements, which set out wage norms in the medium term, and a system of plant level bargaining that allowed union representatives to negotiate wage bonuses on the basis of productivity increases (see generally, Thelen, 2001: 90-1).

As to social policies, GEPs combined with these new forms of 'concertation' to produce changes, mainly in the areas of pensions and health policies. As detailed in Chapter Seven, 'the 1992-5 pensions reforms represented major breakthroughs with respect to the institutional legacies of the past' (Ferrera and Gualmini, 2000: 192), although these changes, together with others, were only achieved through a consensual and dialogic process during which governments were forced to make significant concessions which reduced the impact of the reforms. Nevertheless, some progress was achieved - and this in distinct contrast to the first Berlusconi government's attempt to short-circuit negotiations with the trade unions over an explicitly neo-liberal pension reform package which backfired and resulted in the government's dramatic downfall in late 1994, in the wake of intense opposition from trade unions and the public at large. This clear resistance to the attempt to shift the Italian polity towards market solutions - resistance which has re-emerged during the second Berlusconi administration - suggests that the nature of the reforms implemented by the Amato and Dini governments was essentially incremental. Where globalization is concerned, economic pressures constrained Italian governments and cut out certain policy options, particularly perhaps in the late 1980s and early 1990s. But EMU has also played a significant part and GEPs cannot be said either solely or directly to have caused welfare reforms. As discussed below, these are best understood as the product of a combination of domestic 
political factors, including pressures arising from the need to reorganize the complex and fragmented Italian welfare system itself, though in circumstances framed by international and European economic constraints.

Turning finally to the Netherlands, changes here have been more marked than in other Continental countries, leading some observers to go so far as to label the Dutch welfare regime as 'post-productivist' (Goodin, et al., 2001). In historical perspective, however, as van Kersbergen (1995) has demonstrated, the pillarized, confessional nature of Dutch politics created a typical 'breadwinner style' welfare system characterized by generous, insurance-based transfers as the respective pillars developed their own designs for social improvements in the context of a general acceptance of the family as the focal point of social life. These arrangements survived subsequent depillarization and the decline in family ideology during the 1960s, 'the prevailing high benefits [becoming] the norm when differentiation in the schemes was eliminated' (van Kersbergen, 1995: 135). Generous welfare spending was maintained both by the new cross-confessional Christen Democratisch Appel (CDA) in the 1970s and later by the social democrats under Wim Kok both parties effectively marginalizing neoliberal resistance to high social expenditure. However, although rapidly rising social spending initially appeared to be economically sustainable in the late 1960s and early 1970s, largely due to the discovery of North Sea gas reserves, a number of difficulties emerged in the wake of the economic turbulence created by the oil crises of 1973 and 1979. The impact on the exposed sectors of the economy led to a severe employment crisis unemployment rose to 15 per cent in 1984 - a major consequence of which was the acknowledgement on the part of the trade unions that the constant pursuit of higher wages was counter-productive in terms of both economic growth and employment.

The Wassenar agreement, concluded between trade unions and employers in 1982 just as Ruud Lubbers' new Christian democrat-conservative liberal coalition came to office, signalled a recognition from both sides of industry that 'higher profits were required for the higher level of investment essential to job growth' (Hemerijck et al., 2000: 216). For Martin Rhodes (2001: 182), this agreement was the key feature of the ensuing 'Dutch miracle', which represented a return to corporatism following the breakdown of arrangements in the wake of the economic crises of the 1970s. This was a new 'competitive corporatism', however, with 'a considerable degree of decentralization in wage bargaining that is compatible with intensified competitive restraints'. Because Wassenar also involved an austerity package that saw salaries, benefits and the minimum wage frozen, and public sector wages cut in 1983-4, in addition to a hard currency policy which pegged the Guilder to the Deutschmark, it may be regarded as a significant factor contributing to the extensive institutional change subsequently experienced in the Netherlands.

These basic features of social and economic policy have persisted. The pact was updated and renewed in 1993 in the shape of the 'New Course' agreement between the social partners, which introduced even more flexibility and decentralization, while reforms in the welfare sector saw an attack on the widespread abuse of disability benefits in addition to cuts in mandatory insurance provisions and the 
privatization of sickness allowances. Moreover, as Cox (2001: 484) reports, 'the wage indexation of benefits was adjusted so low that it is virtually insignificant'. Wim Kok's Labour-led coalition government continued these reforms throughout the 1990s, further attacking sickness and disability programmes, and launching new initiatives, particularly in the area of labour market flexibility (Levy, 1999: 261). Here, as Chapter Five records, initial scepticism about flexibility, particularly from the unions, has been turned on its head by the greater institutional willingness to accept change and also by the 'contingent' factor of increasing female employment. With many more women entering the labour market, the traditional male full-employment model has explicitly given way to one which recognizes the importance of part-time work (with appropriate social benefits) and the work-life balance. In what is effectively a clear shift in political and institutional discourse, labour market flexibility has come to be regarded favourably by politicians, employers and unions, while 'flexicurity' has proved politically popular because it provides high levels of insured employment. Although it is certainly the case that part-time work is heavily concentrated in the female workforce, which hardly makes for genuine independence for women, there is at least the possibility of mixing careers and family life, owing to the recognition of the importance of publicyfunded social care arrangements (Knijn, 2004: 63).

To be sure, there is little direct relationship between GEPs and the current Dutch attachment to part-time working and a constrained welfare state. Even so, as Green-Pedersen (2004: 143-4) argues, the Netherlands, in common with neighbours like Denmark, had to develop macroeconomic policies which met the demands of the financial markets for low inflation and limited budget deficits before proceeding with welfare state reforms. With these changes achieved, further reforms associated with labour market and pensions policies have been attained through political 'adjustment' - although as subsequent chapters make clear, adjustments have taken a liberal direction and the process is by no means complete, particularly where pensions are concerned.

\section{Embracing change: liberal democratic regimes}

As already intimated, those countries that broadly endorse the market model are also those which accept the 'logic' of GEPs with the greatest alacrity. Reasons for the undoubted deepening of neoliberal policies in these regimes have much to do with the institutional predisposition against forms of corporatism, which characterize their business systems in particular, and their institutional make-up more generally. In broad terms, the nature of companies' market strategies, industrial relations structures and perceptions of the state's role in economic management are premised upon the inability, but also the ideological unwillingness, to coordinate capital and labour. Weak associational relationships among firms together with the weak central coordination of organized labour lead to extensive decentralization in product markets and industrial relations, where bargaining mainly takes place at plant level. As King and Wood argue, these features have certain implications for LMEs in a context of increasing GEPs. For example, 
because growing trade openness and capital mobility compromise Keynesian full employment strategies they weaken 'the power of trade unions and [increase] the centrality of firms' competitiveness in economic performance' (King and Wood, 1999: 379). Significantly, though, in order to ensure the viability of their economies in the absence of coordinating institutions, governments have to support these decentralized competitive strategies by developing increasingly market-friendly policies - at the cost of social protection. It is in supporting these strategies that the move towards the 'competition state' (Cerny, 1990; Evans and Cerny, 2003), or Schumpeterian workfare state (Jessop, 1994, 2002) is at its most visible.

With respect to the United States, the marked neoliberal shift that started at the end of the Carter presidency is clearly observable. Confronted with high unemployment and inflation on coming to office in 1980, Ronald Reagan initiated a series of measures - tax cuts, 'welfare' retrenchment, cuts in social insurance benefits and increased insurance contributions, deregulation and labour market reforms - that began the process of 're-liberalizing' the US economy. This was indeed a process. Despite the contemporary rhetoric, the Reagan years did not produce the level of economic reform or the degree of retrenchment in social spending that conservatives had hoped, mainly because a Democrat-dominated Congress supported by the trade unions successfully opposed the full extent of proposed cutbacks and were also able to mitigate the impact of Republican welfare legislation in the late 1980s. However, because the Clinton presidency broadly continued with welfare retrenchment, this time with a Republican-dominated Congress demanding ever more radical changes, the outcome by the beginning of the new century has been one of the purest neoliberal welfare models on the globe (see Chapter Four).

In terms of causation, in the US context the relative weight of global economic, political/ideological and institutional factors is hard to ascertain. Taking GEPs first, although the world's largest economy, this feature alone has not immunized the US against a range of challenges that threaten to undermine American economic hegemony. These were particularly evident from the late 1970s and throughout the 1980s, a period during which the USA experienced significant deindustrialization and declining living standards. To some extent, the magnitude of the problem depends on the spin put on it, and some commentators attach more weight to falling shares of world trade, rapidly increasing budget and trade deficits, increased competition, particularly with Japan, and the perceived shortcomings of American management than others (see Coates, 2000: 26-32). What seems incontrovertible, however, is the fact that the USA became more vulnerable to GEPs as a result of falling levels of national saving and the consequent need to turn to foreign capital as a major source of domestic investment. As Krugman (1998: 85) acknowledges, during the 1980s the USA became 'a massive net importer of capital - initially by selling foreigners large quantities of bonds, and increasingly, by attracting foreigners eager to buy controlling interests in American businesses'. These developments are particularly important in the US context because the extensity of corporate welfare - company-provided health care insurance, corporate pensions and so on - is such that for many individuals 'foreign trade is a directly 


\section{Globalization and welfare regime change}

relevant factor in their personal social security' (Rieger and Leibfried, 2003: 153). Their vulnerability is particularly acute because, as Rieger and Leibfried go on to say, failures in corporate welfare are not adequately compensated for by publicly funded income or service support. In these circumstances, it is not surprising, first, that the USA has become increasingly protectionist and, second, that social policy has been adjusted to conform to the perceived needs of the market.

Political factors facilitated the movement in this direction. With the bulk of federal spending, such as it is, tied up in popular 'middle-class' programmes such as old age pensions and medicare (the costs of which are set to rise markedly as a result of population ageing), political attention shifted to the less powerful 'undeserving' poor. Here a combination of neoliberal and neoconservative ideological initiatives succeeded in linking 'welfare' (i.e. social assistance in the American context) spending with a range of social problems and pathologies achieving extensive reform as a result (see for example Murray, 1984). Although, as Krugman (1998: 96) argues, the resulting cutbacks could produce only 'pocket change compared with the size of the deficit problem', suggesting that there was little formal or direct connection to globalization arguments, there is no doubting the effectiveness of this domestic ideological onslaught on core aspects of US social policy, conducted against the backdrop of global economic uncertainty. Importantly, too, certain elements of the US' institutional structure work to cement the neoliberal understanding of the role of social policy. For instance, the degree of decentralization in the US political system, with state governments having independent tax-raising powers, increasingly extensive control over welfare budgets and a good deal of legal autonomy, works against attempts to coordinate opposition to cuts in social spending. As Swank (2002: 228) notes, decentralization works to fragment 'pro-welfare state actors and coalitions and [has] promoted antistatist orientations, conflict and competition within the American political system'. This degree of institutionalized fragmentation has allowed many state governments to pursue the liberal supply-side solutions held by business and political elites to be conducive to greater economic competitiveness.

Other elements of the political system do not encourage even this level of potential opposition, however. Organized labour in the USA is weak in comparison to that in many Western European countries. Although American trade unions have traditionally supported welfare initiatives, not without effect during the postwar period, they came under sustained attack during the Reagan years, finding themselves 'hard pressed to protect [their] most immediate interests in wages, jobs and labor legislation' (Pierson, 1994: 160). Certainly union membership fell markedly during the 1980s - a trend that has since continued (Bureau of Labor Statistics, 2004) - and this lack of influence, together with other factors such as low voter turnouts at elections (with the active electorate coming from higher income groups), and a diverse system of interest group representation that favours the business lobby and 'coalitions of the wealthy', makes it difficult for low-income groups, especially minority ethnic populations, or their supporters to develop coherent strategies capable of attracting a significant cross-section of opposition opinion. 
If decentralization fragments opposition in the USA, the high degree of centralization and effective absence of veto-points in the UK gives elected governments a wide degree of discretion over policy making. Ironically, both the establishment of the welfare state in Britain in the late 1940s and its subsequent restructuring since the early 1980s owe much to the fact that governments with large parliamentary majorities can effect radical changes if they are minded to do so. This constitutional feature alone, however, can hardly account for the turn towards market liberal alternatives in British social policy since Mrs Thatcher's Conservative Party won office in May 1979 - other factors, both global and domestic, need to be taken into consideration.

Judged from the perspective of the postwar 'golden age', the UK was by no means a typical liberal regime, but a 'hybrid' which displayed continental and social democratic, as well as neoliberal, characteristics. Benefit structures, developed under the insurance system originally devised by William Beveridge (1942) and introduced by the Labour government's Social Insurance Act in 1946, had many of the features of the Bismarckian employment-based breadwinner model. Replacement rates were considerably less generous than continental models, however, mainly because (excepting the brief experiment with earnings-related benefits in the late 1970s) unemployment and sickness benefits, as well as old age pensions, were based on the principle of flat-rate contributions for flat-rate payments, designed to provide incomes at about 25 per cent of the average male industrial wage. The system also mimicked Bismarckian arrangements in so far as it was designed to protect individual contributors (as opposed to all citizens) against the major risks of unemployment, sickness and old age, while the 'citizenship' element took the form of means-tested, tax-financed social assistance for those not eligible for contributory benefits (see Glennerster, 1995). These measures, together with a newly created National Health Service (arguably the only truly 'social democratic' element in UK welfare) and a free system of compulsory primary and secondary education made up the core of the UK's postwar welfare regime.

These arrangements did not survive the recession of the early 1970s. The UK experienced increasing difficulties in the wake of the move to floating exchange rates and the oil price rises of 1973 as the new phenomenon of 'stagflation' hit the economy and industrial militancy spiralled. In the UK's case, the quasi-corporatist solution in the form of the 'social contract' between a minority Labour government and the trade unions briefly held wages and inflation down in the mid-1970s but, in the absence of a properly institutionalized social partnership, ultimately fell victim to a combination of employer hostility and the inability of the Trade Union Congress to control the sectional demands of its more militant members. This latter shortcoming had dramatic results. Throughout the 1980s and much of the 1990s, Conservative governments under Margaret Thatcher and her successor, John Major, progressively reorganized UK industrial relations to reflect employer demands for a low-cost, flexible labour force suited to the conditions of what they perceived as an export-dependent economy in an increasingly competitive global market. Trade union rights were abrogated and unemployment was allowed to rise to over 12 per cent, its highest level since the 1930s. As Wood (2001: 395) 


\section{Globalization and welfare regime change}

comments, 'the effect on unionization rates in Britain [was] catastrophic - TUC membership fell from 12.2 million in 1979 to 6.9 million in 1995'.

With the unions on the defensive, Conservative governments turned their attention to the labour market, where greater flexibility was the key objective. To this end, nationalized utilities were privatized and elements of low-paid welfare state services such as hospital catering and cleaning, and residential care for older people, contracted out to private sector companies. Also, wages and working conditions were progressively deregulated, particularly for younger employees, with a consequent decline in income levels for low-paid workers. To bolster these initatives and encourage individuals to take up employment, eligibility rules for benefit receipt were continually tightened, with specific attention being paid to unemployment benefits and the requirement that claimants should 'actively seek work'. Complementary moves saw old age pensions virtually privatized and core services reorganized to mimic the workings of the market - the National Health Service and education being the two clearest examples (Bartlett et al., 1998).

In asking whether GEPs played a role in this turn to market liberal welfare solutions, the answer is a qualified 'yes'. The UK's economy has always been open to international influences and the fact that the country suffered periodic currency crises throughout the postwar era suggests that the (declining) domestic economy was indeed vulnerable to global pressures. More recently, of course, rising trade flows and extensive financial liberalization have led to greater economic integration with global markets. As Swank (2002: 233) has noted, 'the integration of British and international markets [has] increased significantly [with] ... total flows of FDI, portfolio investment, direct bank lending, as well as trade flows, [averaging] 60 percent of GDP in the 1990-5 period' - higher than in the majority of OECD countries. However, to argue that these factors alone are solely responsible for welfare state retrenchment in the UK, as governments seek to strip away inhibitions to greater competitiveness, would be to go too far. At least two further domestic factors have contributed to a 'mix' that has clearly itself contributed to the extensive changes, aspects of which will be detailed in Chapters Four and Five.

First, structural explanations suggest that there was little option but for UK social policy to shift towards neoliberalism. According to King and Wood (1999), the economic challenges of the 1970s and 1980s made the turn towards markets inevitable because, as suggested, the UK is institutionally indisposed towards forms of economic governance such as corporatism, which privilege 'organized' relationships between labour and capital. As King and Wood (1999: 379) point out, weakened unionism in the wake of the failure of full employment policies left employers in a powerful position to insist on the market-friendly policies they regarded as essential for increased competitive performance. This institutional factor is complemented by another which specifically concerns the nature of the UK welfare state. Because UK social policy has always contained certain neoliberal components - for example, a high degree of means-testing, ungenerous replacement rates and high levels of occupational pensions in addition to other forms of occupational and fiscal welfare (Titmuss, 1963) - these embedded precedents made the UK susceptible to policy changes that sought to reinforce and build upon them 
while eroding those collectivist elements of welfare which had come to be regarded as both inefficient and expensive.

Turning finally to the Antipodes, both Australia and New Zealand differ from other liberal states in that they have a history of 'wage earner' welfare with its own institutional and political characteristics (Castles, 1986). Of particular significance here, however, is the way in which increasing GEPs conspired to undermine the foundations of the wage-earner model, leaving governments in both countries in the early 1980s facing rising unemployment and a growing budget deficit as traditional economic policies based upon 'import substitution' failed. These policies aimed to maintain employment by using profits made in the export-oriented sectors to fund increased employment in the service sector. With the arbitration courts the core apparatus for wage setting - awarding high wage increases to both sectors, exposed parts of these economies were forced to demand increased protection to remain competitive. The system held together during the postwar years partly because export markets held reasonably steady and partly, too, because employment policies discriminated against Aboriginal peoples and foreign labour in favour of white Australian men, thus restricting the demand for jobs (see Schwartz, 2000: 82-3; Huber and Stephens, 2001: 173). However, by the mid-1970s it was becoming clear that the export sectors in both countries could not make sufficient profits in an increasingly competitive global market to be able 'to fund a volume of consumption and capital goods imports consistent with the socially defined standard of living' (Schwartz, 2000: 83). In much the same way as in the UK in the 1970s, the initial reaction was a turn to incomes policies in an effort to contain wage rises and inflation. To compensate for rising unemployment and falling wages, both Australia and New Zealand shifted social policy from its 'informal' role as a complement of their respective egalitarian wages policies to a 'formal' one in which the core elements of welfare - health care, social security and so on - were properly institutionalized as a 'social wage'.

At this point the policy choices of the two countries diverge, Australia being the focus of discussion here. Utilizing the spirit if no longer the letter of the wageearner model, Australian Labor governments successfully sought a corporatist relationship with the trade unions which was sustained through a series of 'Accords' from the early 1980s to the early 1990s. The main feature of the Accords was organized labour's agreement to allow governments to pursue economic liberalization in return for a degree of social protection (Saunders, 1999: 497-8). This they did. On the one hand, Australia witnessed a marked decentralization of the wage system with the Keating government in particular encouraging bargaining at enterprise level. On the other hand, a range of social reforms saw important innovations in health and childcare in the context of an approach to social policy that tightened eligibility criteria for benefits and pensions, introduced means-testing for some benefits and encouraged individuals 'to be "active" recipients of welfare' (Johnson and Tonkiss, 2002: 8). In the words of Johnson and Tonkiss (2002: 10), Australian Labor governments produced a 'peculiarly economic kind of social contract [that] was seen to rest on the assumed common interest of wage earners, welfare recipients and business in economic growth, in the context of a welfare 


\section{Globalization and welfare regime change}

system strongly oriented towards waged work'. Since the mid-1990s, however, in the 'post-Accord era', National coalition governments have taken welfare state restructuring much further in a neoliberal direction, particularly in relation to labour market and pensions policies. They have also presided over the further decentralization of industrial bargaining and consequently a marked weakening of the Australian labour movement.

Before moving on to consider labour market and pensions policies in the above countries in more detail, it is important briefly to take stock of the discussion so far. The core contention is that GEPs are significant constraining factors in a process which is witnessing marked, if varying, degrees of change in 'mature' welfare regimes. In most cases, they play an indirect or 'contextualizing' role in welfare regime change. However, much depends on the particular configuration of institutional factors ranged against them and, of course, the nature of other contingent issues with which welfare regimes have to deal. Broadly speaking, GEPs are more influential in regimes with liberal economic and social arrangements because these are institutionally predisposed to embrace the logic of 'globalization' and attempt to absorb the impact of increasing trade openness and capital mobility even at the cost of certain radical institutional adjustments. Conversely, regimes with highly institutionalized and embedded systems of economic and social governance supported by a range of core social and political actors are less likely to want to accommodate GEPs in this manner. However, while each of the countries considered here is faced with the need to deal with these pressures by making (at least) incremental adjustments to its welfare policies, a key issue is whether the core institutional supports in social and continental systems can remain sufficiently well embedded to limit the extent of the neoliberal turn. The following chapters will consider this matter in the context of an examination of labour market and pensions policies in the countries under review. 


\section{Towards workfare? Changing labour market policies}

Maintaining 'full employment' in conditions where deindustrialization has removed many of the traditional male, blue-collar jobs, where women are entering the workforce in increasing numbers, and where budgetry constraints make it difficult to reduce the problem by increasing public sector employment constitutes a significant challenge for many welfare regimes. Is it feasible, in the light of these developments, to formulate labour market policies that can lead to greater employment opportunities without eroding the institutional structures and assumptions on which any particular welfare regime is founded? To answer this question, this chapter will first examine the changing nature of labour markets and employment in selected OECD countries before moving on to consider how liberal welfare regimes have attempted to use labour market policies to deal with the difficulties involved. Taking these regimes as examples of extensive change, Chapter Five will then consider the labour market measures that social democratic and continental regimes are developing to bolster employment and assess the impact of these policies on their institutional make-up.

\section{Changing labour markets}

What factors have contributed to the far-reaching changes that have occurred in labour markets in OECD countries over the past thirty years? We have already seen that GEPs set the context for change in a number of ways. While deindustrialization and the dramatic rise of the service sector are not purely a consequence of global economic pressures, these changes need to be understood against the unforgiving backdrop of increases in trade openness, capital mobility and the technological advances that have set a new competitive tone for the exposed sectors of the developed economies. In response, employers have come to demand greater 'flexibility' from their workforces, this demand frequently being synonymous with 'downsizing' as companies subcontract work and make increasing use of parttime, casual, and often female, labour (see Castells, 1996). At the same time, low wage competition from developing countries appears to have increased the pressures created by domestic deindustrialization by reducing the demand for unskilled labour, particularly in textiles and associated goods. The resulting wage inequalities, reduced working conditions and unemployment have come to be regarded as 


\section{Towards workfare?}

endemic features of deindustrialized, service-oriented economies in which governments appear to be faced with a trade-off between 'equality' - the attempt to maintain wage levels and generous social protection - and 'employment' - the desire to maintain employment levels even where jobs are low-paid and/or parttime (Esping-Andersen, 1996a; Iversen and Wren, 1998). Here the traditional Keynesian strategies for dealing with this tension - tight incomes policies accompanied by devaluation - employed in particular by Scandinavian and Continental regimes, have proved less useful in an economic climate dominated by free capital movements where the 'rational expectations of investors [mean] that the negative effects of (fear of) inflation or devaluations, especially increasing interest rates, come before positive effects' (Goul Andersen and Halvorsen, 2002: 5). The resulting marked shift towards hard currency policies and balanced budgets in the 1980s subsequently led to greater concentration on supply-side measures designed to improve competitiveness.

These changes naturally affect existing labour market structures, but they are also accompanied by other social and economic phenomena which contribute to increasing pressure on traditional labour market policies. Where labour markets are concerned, much depends on how a range of factors common to the advanced economies are accommodated by regimes that hold rather different views of the challenges posed by the global economy. Five factors are particularly significant and are characterized by Sarfati (2002) in the following terms:

- High unemployment, albeit with regional and national variations.

- The differential role of the services sector in different national economies.

- The dramatic rise in female employment and labour participation.

- Changes in family composition.

- The diversification of forms of employment.

These 'postindustrial' phenomena are well known and have been widely discussed, particularly in relation to changing class structures (Esping-Andersen, 1993, 1999; Castells, 1996; Klausen, 1999), but certain aspects are important for present purposes because they bear directly on the changing nature of labour markets and labour market policies - in a variety of welfare regimes. It is worth noting, for example, that high unemployment has affected all the advanced economies at different times since the 1970s, with, in many cases, long-term unemployment taking up an increasing proportion of total unemployment in the 1980s and 1990s (see Table 4.1). Unemployment rates decreased in the late 1990s, to be sure, as European nations began to increase employment in their service sectors - a feature of the US economy since the early 1980s. As Sarfati (2002: 17) explains,

the difference in employment rates, particularly between the United States and the major European Union countries, can almost entirely be explained by the higher employment in services in the United States, where the services sector accounted for 90 per cent of net job growth. 
Table 4.1 Growth of long-term unemployment as a percentage of total unemployment in OEGD countries

\begin{tabular}{lrrrrrrrr}
\hline & 1979 & 1985 & 1989 & 1991 & 2000 & 2001 & 2002 & 2003 \\
\hline Australia & 18.1 & 30.9 & 23.0 & 24.9 & 29.1 & 21.2 & 22.1 & 22.5 \\
Canada & 3.4 & 10.3 & 6.8 & 7.2 & 11.2 & 9.5 & 9.7 & 10.1 \\
Denmark & 36.2 & 39.3 & 25.9 & - & 20.0 & 22.2 & 19.7 & 19.9 \\
France & 30.3 & 46.8 & 43.9 & 37.3 & 42.6 & 37.6 & 33.8 & - \\
Germany & 28.7 & 47.9 & 49.0 & - & 51.5 & 50.4 & 47.9 & 50.0 \\
Italy & 51.2 & 65.8 & 70.4 & - & 61.3 & 63.4 & 59.2 & 58.2 \\
Japan & 16.8 & 13.1 & 18.7 & 17.9 & 25.5 & 26.6 & 30.8 & 33.5 \\
Netherlands & 35.9 & 60.7 & 49.9 & - & - & - & 26.7 & 29.2 \\
New Zealand & - & - & 14.7 & 21.2 & 19.2 & 16.8 & 14.4 & 13.3 \\
Sweden & 6.8 & 11.4 & 6.5 & - & 26.4 & 22.3 & 21.0 & 17.8 \\
UK & 29.5 & 48.6 & 40.8 & - & 28.0 & 27.8 & 23.1 & 23.0 \\
USA & 4.2 & 9.5 & 5.7 & 6.3 & 6.0 & 6.1 & 8.5 & 11.8 \\
\hline
\end{tabular}

Source: adapted from OECD, 1993: 87 and OECD 2004a: 315.

Within Europe, service sector expansion has increased fastest in Scandinavia and the UK, 'with the difference that in Scandinavia growth has been particularly strong in social services and the public sector whereas in Britain much of the growth took place in the predominantly private-sector service occupations (Klausen, 1999: 268) (see Table 4.2). As is well known, the rise of service sector jobs is closely associated with the entry of large numbers of women into labour markets in the advanced economies, although, as Klausen's comment implies, the structure of this sector varies depending on the regime in question. In general, Scandinavian countries, and the Netherlands, have been favourably disposed towards integrating women into the post-industrial workforce, and have attempted to support female employment by maintaining large public and social services in addition to nearuniversal access to child care. Women are heavily, though more precariously, employed in private sector distributive services and 'personal services' like domestic work, hotels and catering in liberal economies such as those of the UK or the USA - particularly the latter. In contrast, female participation rates in continental states like Germany, Austria, France and Italy, which have been slower to deindustrialize, have tended to lag behind social democratic and liberal nations, although female service sector employment has nevertheless increased over the past decade (see Table 4.3).

The turn to services is part cause, part consequence, of marked changes in household structures since the 1970s. Alongside other factors such as advances in labour saving technologies, which have reduced domestic working time (Gershuny and Miles, 1983), the increase in services has effectively created a new employment sector that, among other things, has 'increasingly [absorbed] what are essentially menial household job functions' (Esping-Andersen, 1993: 22). If the up-side of this phenomenon has been that many women are now free 'to pursue sustained employment and career development' and that double-income families have greater 
Table 4.2 Employment in services as a percentage of civilian employment

\begin{tabular}{lccccc}
\hline & 1970 & 1988 & 1991 & 1996 & 1999 \\
\hline Australia & 55.6 & 67.9 & 71.2 & 72.4 & 73.4 \\
Denmark & 50.7 & 67.1 & 66.6 & 69.0 & 70.0 \\
France & 47.2 & 63.0 & 65.3 & 69.4 & 71.0 \\
Germany & 42.0 & 56.1 & 54.9 & 61.6 & 62.6 \\
Italy & 40.3 & 57.7 & 59.2 & 60.8 & 62.2 \\
Netherlands & 54.9 & 68.8 & 69.9 & 73.8 & 75.9 \\
Sweden & 53.5 & 66.7 & 68.6 & 71.0 & 72.3 \\
UK & 52.0 & 64.8 & 66.6 & 70.7 & 72.4 \\
USA & 61.1 & 70.2 & 71.8 & 73.3 & 74.4 \\
\hline
\end{tabular}

Source: adapted from OECD, 2001a.

Table 4.3 Female labour force as a percentage of total labour force

\begin{tabular}{lcccccc}
\hline & 1970 & 1988 & 1991 & 1996 & 1999 & 2003 \\
\hline Australia & 32.2 & 40.3 & 41.6 & 42.8 & 43.1 & 44.6 \\
Denmark & 38.6 & 45.7 & 46.5 & 45.8 & 46.5 & 46.5 \\
France & 35.7 & 43.1 & 43.7 & 44.7 & 44.9 & 46.4 \\
Germany & 35.9 & 39.9 & 42.2 & 42.8 & 43.1 & 45.3 \\
Italy & 28.8 & 36.3 & 36.9 & 37.0 & 38.0 & 38.3 \\
Netherlands & 23.5 & 38.3 & 39.7 & 41.7 & 42.9 & $43.6 *$ \\
Sweden & 39.5 & 48.0 & 47.9 & 47.8 & 47.6 & 48.3 \\
UK & 35.3 & 42.5 & 43.1 & 44.0 & 44.4 & 45.0 \\
USA & 37.2 & 44.5 & 45.0 & 45.9 & 46.3 & 46.8 \\
\hline
\end{tabular}

Source: adapted from OECD 2001a and OECD 2004b.

Note: $* 2002$

access to leisure time and consumption, the down-side is that certain social groups - predominantly women and those from minority ethnic groups - can end up trapped on the margins of employment. This is not of course to sanction the traditional postwar model of the nuclear family over other types of family structure and functioning, which, after all, vastly underplays the social importance of unpaid domestic labour, but it is to recognize that the consequences of the expanding service sector may be less than optimal for many of those involved.

The economic shift towards service sector employment in the 1960s and 1970s occurred simultaneously with changes in attitudes to marriage and traditional gender roles, this combination of economic and socio-cultural factors being implicated in increasing divorce rates and rising numbers of single parents, as well as mounting numbers of people either choosing, or finding themselves having, to live alone (these phenomena being particularly visible in Northern Europe, the USA and Canada). Because these types of household are more vulnerable to poverty, owing mainly to the fact that they are more likely to be employed in lowpaid service sector work, or to be without work entirely, there are knock-on effects for traditional patterns of welfare provision. Significantly, too, the diversity of employment associated with the service sector has meant that many people, 
especially the large numbers of women employed in distributive and personal services, tend to work either casually or part-time and on low wages (see Table 4.4), the point being that even those who participate in the labour market may need forms of welfare support, outside traditional benefit arrangements, to keep them there. The general point, however, as Sarfati (2002: 37) observes, is that

these changes in occupational structures and job profiles are liable to adversely affect the viability of existing social protection systems, which were created in the context of a completely different set of parameters (full lifelong employment of male workers in large manufacturing establishments).

Of course, the direction of causality implied by Sarfati's statement can be inverted and it is important to appreciate that social policies in general, and labour market policies in particular, are themselves a factor in labour market change. As EspingAndersen (1993: 19) argues, because social policy 'directly and powerfully determines ... some of the principal mechanisms by which [labour] markets "clear" ' - for instance, 'the welfare and behaviour of the family, the commodity status of labor and the organization of the market' - it inevitably influences the nature and structure of labour markets. For example,

welfare state institutions [can] dictate the choice of non-entry; either via the provision of a social wage option, or via ... tax or service treatment of households. Women with small children are capable of paid employment only if they have access to child care facilities and enjoy rights to paid absenteeism.

(Esping-Andersen, 1993: 20)

More specifically, labour market policies can influence entry into employment, employment levels, levels of job mobility, and, to an extent, who is employed. Active labour market policies (ALMPs), to which particular attention is paid here, can provide education and training programmes, job creation schemes and other supply side measures designed to ensure that the jobless remain connected to the world of work, while the balance struck between 'active' and 'passive' policies might affect tax levels and thus employers' capacity to create jobs, as well as wage structures and industrial relations more generally.

\section{Active labour market policies in contemporary welfare regimes}

As Chapter Three indicated, the structures of production regimes in the advanced democracies are altering in ways that permit greater flexibility of employment and, in certain cases, the emergence of new forms of industrial bargaining. These changes form the backdrop to shifts in labour market policies across the advanced economies which in some cases have been dramatic. In general terms, the most visible change, irrespective of regime type, has been the increased attention paid to various forms of ALMP, characterized most obviously by greater efforts to 'guide' 
Table 4.4 Part-time employment as a percentage of total employment and women's share in part-time employment

\begin{tabular}{|c|c|c|c|c|c|c|}
\hline & \multicolumn{3}{|c|}{$\begin{array}{l}\text { Part-time employment as a percentage } \\
\text { of total employment }\end{array}$} & \multicolumn{3}{|c|}{$\begin{array}{c}\text { Women's share in part-time } \\
\text { employment }\end{array}$} \\
\hline & 1990 & 2001 & 2003 & 1990 & 2001 & 2003 \\
\hline Australia & 22.6 & 27.2 & 27.9 & 70.8 & 67.8 & 67.2 \\
\hline Denmark & 19.2 & 14.7 & 15.8 & 71.1 & 66.0 & 64.2 \\
\hline France & 12.2 & 13.8 & 12.9 & 78.6 & 79.6 & 80.0 \\
\hline Germany & 13.4 & 18.3 & 19.6 & 89.7 & 84.6 & 83.3 \\
\hline Italy & 8.9 & 12.2 & 12.0 & 70.5 & 72.6 & 74.7 \\
\hline Netherlands & 28.2 & 33.0 & 34.5 & 70.4 & 76.3 & 76.0 \\
\hline Sweden & 14.5 & 13.9 & 14.1 & 81.1 & 72.7 & 70.8 \\
\hline UK & 20.1 & 22.7 & 23.3 & 85.1 & 79.8 & 77.3 \\
\hline USA & 14.1 & 12.8 & 13.2 & 68.2 & 67.5 & 68.8 \\
\hline
\end{tabular}

Source: adapted from OECD, 2004a: 310.

the unemployed into work and also by their emphasis on education and training, particularly for the young unemployed. Certain countries have attempted literally to 'activate' unemployed individuals by tightening eligibility rules, withdrawing benefits and, in some cases, coercing them into a job. Despite the fact that the effectiveness of such policies is open to question (Martin, 1998), these alternatives to 'passive' forms of welfare provision have been enthusiastically supported by both the European Union, through successive versions of the European Employment Strategy (EES), and the OECD. In the former case, the Essen European Council in 1994, and particularly the Amsterdam Council and the Luxembourg Special European Council (the Luxembourg 'Jobs' Summit), both of which met in 1997, agreed that social protection must not act as a disincentive to work. To this end, the 'Employability' pillar of the EES (one of four, the others being entrepreneurship, adaptability and equal opportunities) contains principles and goals which include a 'preventive approach' (creating employment through activation strategies) as well as the improvement of education and training systems, and the inclusion of disadvantaged groups in the labour market (CEC, 2001: 8). Such changes also include reform of the Public Employment Services (PES) in each country with a view to ensuring a more coherent approach to the job search and allocation process, particularly at local level.

Much of this strategy conforms to OECD employment priorities. For much of the 1990s, the OECD promoted ALMPs in preference to passive policies, which were regarded as a work disincentive (OECD, 1994, 1998a), continuing to argue in the 2002 Employment Outlook (OECD, 2002: 9) that "a "rights and responsibilities" approach is needed, which increases employment opportunities and the financial returns to working, but also obligates benefit recipients to actively search for work or take steps to improve their employability'. Indeed the Organization (OECD, 2002: 9) remains convinced that 'making work pay policies can play a constructive role as a component of a more employment-oriented social policy'. As this and 
the next chapter demonstrate, different states have interpreted such policies in different ways, with regimes differing to greater or lesser degrees between two broad approaches. First, 'work first' (WF) approaches look for rapid moves into work on the part of the unemployed and, while a certain amount of education and training assistance may be provided (often by private sector agencies), the emphasis is squarely upon intensive counselling and job search, frequently underpinned by a system of penalties for those who fail to comply with programme requirements. Second, human capital $(\mathrm{HC})$ approaches develop policies that stress the importance of education and training as the best means of 'securing sustainable transitions to work' (Theodore and Peck, 2000: 85). The main objective, as Theodore and Peck (2000: 85) note, is to ensure 'substantial "front-end" investment [which] will not only prepare participants more comprehensively for work, but [by] raising levels of human capital will actually broaden the range of jobs open to welfare recipients'. In broad terms - and with some exceptions - while regimes can exhibit examples of both perspectives, active labour market policies in liberal regimes tend to accentuate the work first philosophy in policy initiatives that more closely resemble 'workfare' alternatives, while social and continental regimes veer towards the human capital model.

Activation policies apart, adjustments to passive policies in the shape of benefit cuts, and changes to eligibility criteria and the length of benefit entitlement, feature in the efforts of a wide range of regimes to combat unemployment and increase their participation rates. Expenditure on 'in-work' benefits such as tax credits and benefits to employers, in contrast to passive spending on unemployment benefits and social assistance, has been historically less popular in Europe than in the USA, with the partial exceptions of the UK and the Netherlands, but there is a growing trend in this direction. Is there evidence here of a convergence of labour market policies among the developed economies, broadly speaking? The answer to this question is both 'yes' and 'no'. On the one hand, the across-the-board rise in interest in ALMPs, retrenchments in benefit levels, tightened eligibility criteria and other efforts designed to keep individuals in work (or to make work a more attractive prospect) are notable changes that contrast with the traditional passive-protectionist approaches to unemployment which characterized the postwar period. In this regard even the briefest reading of the European Commission's report on Employment Policies in the EU and in the Member States (CEC, 2001) indicates a general movement in the direction of 'activation' and associated policies, in addition to others designed to reduce tax burdens on business and encourage labour 'flexibility', part-time working and so on. On the other hand, much depends on context, and, as suggested, the nature of activation policies varies both among and within regime types, as do other measures designed to stimulate employment. Clearly, such measures have to be considered alongside broader aspects of social and economic policy such as tax policies, public sector employment strategies, approaches to female employment and governments' willingness to intervene in wage setting through low or minimum wage strategies, as well as access to child care services - in other words, the panoply of policies deployed by different countries in their efforts to negotiate the trade-off between 'equality' and employment. 


\section{Towards workfare?}

What follows examines the development of labour market policies in liberal regimes. In view of their looser institutional make-up, these regimes have proved readier to develop WF approaches to ALMPs that are aimed at reducing spending on passive benefits while simultaneously promoting the workforce flexibility that they believe the global market requires.

\section{Labour market policies in liberal regimes}

Liberal welfare regimes are less committed than their social and Continental counterparts to 'equality' and the extensive social spending that such a commitment entails. Aware of the need to remain globally competitive in order to attract inward investment to flexible labour markets, these regimes are reluctant to raise taxes to fund social spending, preferring to let the market set wage levels, particularly in their expanding service sectors, and use ALMPs to bolster employment at the bottom end. Significantly, too, because the market is believed to offer individuals the best chance of income security, less attention is paid to alternative policies designed to enhance social cohesion and associated forms of collective responsibility found in other types of regime. Because liberal regimes are less heavily institutionalized than others they are able to alter existing welfare arrangements with somewhat greater ease. In two of the examples discussed here - the USA and Australia - existing preferences for market solutions have facilitated radical changes in the direction of loosening controls over the labour market and furthering forms of WF activation. The Australian case is particularly interesting. Here a declining 'wage earner' regime initially adopted a version of corporatist industrial relations and social policies in an effort to offset the social costs of liberalization in the economic sphere. Recent changes, however, suggest that corporatism Australianstyle is firmly on the wane, Australia adopting an uncompromising neo-liberal WF approach where employment policies are concerned. The UK presents a slightly different picture. Change has been extensive, to be sure - and in the context of an across-the-board alteration in welfare policy. Nevertheless, certain elements of UK labour market policy border on an HC approach, though one more than tinged with a WF mentality. Before considering Australia and the UK, it is important to begin with the clearest case of a shift towards a WF version of active labour market policy: the USA.

\section{The USA}

In the US context 'welfare' has a different meaning. Unlike the situation in Northern and Western Europe, or in the UK, where the term is frequently used generically to apply to the full range of publicly provided goods and services, including social insurance and social assistance, 'welfare' in the USA applies strictly to the latter. Unemployment insurance, 'social security' (which refers to insurance-based old age and disability pensions) and Medicare are regarded separately from 'welfare'. In the absence of an egalitarian social policy tradition, however defined, this separation between benefits that are regarded as 'deserved', because of their contributory nature, and 'handouts' to the poor, who are conceived as largely 
'undeserving', is particularly rigid. The result is that the core sources of 'welfare'Aid to Families with Dependent Children (AFDC) and its much changed successor, Temporary Assistance to Needy Families (TANF) - are, as their titles suggest, stigmatized and contested forms of support intended solely for very poor families with children. Stigmatization is particularly marked because those uninsured individuals on means-tested benefits who are considered 'deserving', such as older people and those with disabilities, are treated separately through the Federal Supplemental Security Income programme. Only 3 per cent of the total amount spent on income maintenance is devoted to 'welfare' (Evans, 2001: 8), but this area is the focal point of labour market policy in the USA. In common with other liberal regimes, unemployment benefits, which are administered at state level in the USA, have strict eligibility rules and, like those in the UK, run for only 26 weeks, during which time unemployed individuals must be seeking work or registered with the State Employment Service. As Rosch (1998:1) notes, 'in the USA [there] does not exist any kind of unemployment benefit, it is only a temporary short-term earnings-related benefit' and it is up to the individual concerned 'to search for a new job and to accept one if it is offered to him or her'. Once the insurance period is exhausted, those who remain unemployed join those on 'welfare', both groups constituting the core targets for a liberal regime intent on enforcing the work ethic (see Karger, 2003).

That so much political and ideological attention is given to welfare and the resources spent on it demonstrates the strength of the conviction expressed by politicians of the two major political parties, as well as by large sections of the American public, that individuals who can work, should do so, virtually irrespective of their domestic circumstances. It is this principle that lies behind the growing belief among Democrats and Republicans alike that even potentially vulnerable individuals such as single mothers with young children should be employed because the market is considered to be the best source of income and also because work is believed to develop self-discipline. As Hillary Clinton (quoted by Deacon, 2001: 9) puts it, 'I think getting up and going to work ... and having to make difficult decisions about who cares for your children that every other working mother has to make is a necessary step toward learning how to be self-sufficient'.

On one view, it is moral concerns of this nature, as much as the economicallyinduced imperative of reducing high unemployment, that have driven the US reform agenda and brought labour market policies and 'welfare reform' into ever closer proximity. While many European countries, as well as Australia and New Zealand, have experienced periods of high unemployment and reduced passive spending in favour of ALMPs in response, the USA has consistently seen unemployment rates lower than those of European Union countries over the past twenty years - enjoying rates of less than 4 per cent in the latter part of the 1990s. Of course, this figure masks wide variations, with unemployment among African American and Hispanic populations, though declining, nevertheless running at a rate twice as high as the figure for the white population and ' 50 per cent higher than the overall rate' (Evans, 2001: 8). Moreover, as Gray has commented, the USA does not compare quite so favourably with others when all forms of nonemployment and high rates of incarceration are taken into account. As he (Gray, 
1998: 113) makes clear, 'over a million people ... would be seeking work if American penal policies resembled those of any other western country'. Even so, these comparatively low levels of joblessness - sustained by a strong private service sector - suggest that the need to reduce open unemployment per se has been less of a driving force behind the dramatic changes to the US welfare system since the mid1990s than the perceived need to enforce preferred forms of behaviour among certain sections of the poor - predominantly those in minority ethnic populations. Certainly the highly charged ideological debates about the role and nature of 'welfare', which preoccupied social liberals and neo-conservatives alike during the 1980s and early 1990s, are considered a key source of change according to many observers (King, 1995; Schram, 1995; Deacon; 2000; Peck, 2001). There is little doubt that during the course of these debates right wing critiques of welfare spending, initially expressed in the writings of major neo-liberal and conservative thinkers like Charles Murray (1984) and Lawrence Mead (1986), and subsequently reflected in policies developed during the Reagan and Clinton presidencies, gained the upper hand. It is the degree to which these critiques have become so influential that indicates the extent of the institutional shift away from what were, by US standards, the rather more generous 'commercial Keynesian' (Skocpol, 1995: 217) attitudes towards welfare associated with the postwar period.

The core conviction here is that the dramatic increases in passive benefits like AFDC, which characterized the Johnson and Nixon administrations in the 1960s and early 1970s, led to 'dependency' among poorer social groups and that this, in turn, resulted in a range of social ills including rising divorce rates, increasing numbers of never-married mothers, absent fathers and a general decline in family values - all culminating in the emergence of a largely racialized 'underclass' cut off from the rest of society both culturally and economically (Murray, 1984). Although different strands of thinking can be found within this broad critique Deacon (2001) points to fundamental differences of approach between Murray and Mead, for example, while William Julius Wilson (1987) has a very different take on the issue - there is no doubt that the basic idea that welfare spending actively creates dependency made dramatic headway in policy terms. Peck (2001: 84-8) shows how, once the Republican Party had gained control of Congress in 1994, key figures like Newt Gingrich and Alfonse d'Amato were able to capitalize on the (relatively small) gains made during the Reagan years to change the basis of welfare 'discourse' in ways that effectively demonized traditional social liberal welfarism and replaced it with the hard-edged logic of 'workfare'. Clinton, if not initially a crusader for welfare reform, changed his tone in the lead-up to the 1996 presidential election. By this time, as Peck (2001: 87-8) states, 'workfare was no longer one of the "wedge issues" that differentiated the candidates in terms of policy substance' because 'conservatives and liberals [had] found common cause - and a common language of reform - in the issue of "welfare dependency".

The undoubted power of neo-conservative ideology notwithstanding, it is hard to imagine that the increasing influence of these ideas on government policies just at the time that the US economy began to experience the effects of the intensified global competition discussed in Chapter Three is entirely coincidental. Indeed, as Rieger and Leibfried (2003: 208) comment, 'the changed framework conditions 
of the market economy [led] to welfare state institutions suddenly being seen in a different light and to their programmes' benefits being measured by different standards'. With employment shifting away from its postwar base in manufacturing towards less secure service sector jobs by the early 1980s, solutions to the prospect of rising un- or under-employment were held to lie less in traditional forms of social protection than in an outright endorsement of a free market in labour where 'private insurance, entrepreneurially provided social services and transfer systems employing strong income incentives are considered far more suitable to the new Zeitgeist of frugal state budgets and deregulation' (Rieger and Leibfried, 2003: 211). As intimated, the changes in the nature of employment in the USA do not appear to have resulted in the kind of open unemployment rates experienced in parts of Europe. However, private service sector work in the USA is distinguished by 'the proliferation ... of "non-standard" forms of employment: part-time jobs, temping, self-employment and multiple job-holding' with 'as many as 4 million workers ... in 1997 [reporting] that they wanted full-time employment but could only find part-time work in which by then 30 per cent of all available employment was of this non-standard variety' (Coates, 2000: 250).

In view of the prevailing commitment to market solutions - and taking account of the sustained political assault on assumptions that the state should be powerful enough at least to play a major role in the shaping of macro-economic strategy it is not surprising that the USA has moved to shore up employment at the bottom end with an increasingly rigorous supply side-oriented, WF labour market policy.

Turning to welfare reform itself, the thrust of change has been twofold. First, welfare payments have been progressively restricted in terms of both eligibility and value; second, however, in-work benefits have noticeably increased. These changes were introduced during Reagan's presidency in the 1980s, the most obvious examples of his administration's efforts to curb welfare spending coming in the form of the Omnibus Budget Reconciliation Act (OBRA) early in the first term and the Family Support Act (FSA) of 1988. OBRA restricted access to AFDC, cut welfare payments and began a process of decentralization that gave individual states incentives to develop welfare-to-work programmes (Peck, 2001: 91) - a process that gained added impetus with the passing of the FSA. This latter piece of legislation reflected a compromise between Republican desires for radical reform and the limits of what could be obtained from a Democrat-dominated Congress. Passive benefits were increased, for instance, in the form of the extension of AFDC to two-parent families, while the FSA built on demands from the National Governors' Association for an extension of the 1981 welfare-to-work reforms by accelerating the move towards workfare. Stringent participation rates on welfareto-work programmes were required in order for states to qualify for federal funding (King and Wood, 1999: 389). Differences about the 'rehabilitative' or 'deterrent' functions of workfare still persisted at this stage, however, with social liberals favouring a human capital approach and demanding increased spending on training and counselling (Pierson, 1994: 123).

In retrospect, these changes look decidedly moderate in comparison with subsequent events. Once the Republicans had gained a majority in Congress, the way was clear for an altogether more dramatic and radical overhaul of the US 
welfare system, which came in the form of the Personal Responsibility and Work Opportunity Reconciliation Act (PRWORA) of 1996. As Holcomb and Martinson (2002: 1) put it, 'the new legislation set the course for a work-oriented welfare system designed to provide temporary financial support for needy families, and gave the states unprecedented fiscal and policy authority to carry out its goals'. These observers also make it clear that 'work first' was the dominant - indeed the universal - approach taken towards workfare, although there is wide variation among states and localities over the details of specific programmes. Before briefly discussing the kinds of workfare programmes that have emerged across the USA since 1996, it is important to note that PRWORA effectively abolished the 'right to welfare' as this phrase is commonly understood. Deacon (2001: 1) notes that the original obligation placed upon states 'to pay something to people whose income and resources fell below the limits defined by the federal government' has been removed (see also Holcomb and Martinson, 2003). PRWORA specifically states that the Act 'should not be interpreted to entitle any individual or family to assistance under any state program' (quoted in Deacon, 2001: 1-2). The core social assistance programme created by PRWORA - TANF - only guarantees eligibility for welfare payments for a maximum of five years (Florida, Massachusetts and Wisconsin have adopted more restrictive time limits). Moreover, a range of associated conditions prevent, inter alia, states from using TANF allocations for payments to a family that includes an adult who has claimed welfare for a total of five years, or to single mothers who are under eighteen and not living with their parents or at school. As Wiseman shows, tough participation requirements are imposed by PRWORA, actual levels depending on family category. For instance, 'in 1997, on average, $25 \%$ of single parents were to be participating for at least 20 hours per week in any of nine work activities'. Participation rates for two-parent families were more demanding - rates for the 'non-exempt parent [rising] from $75 \%$ in 1997 to $90 \%$ in 2002, and through the five year period 35 hours per week of activity are required for meeting the participation standard' (Wiseman, 2000: 232).

Of course, as these comments suggest, the key objective of PRWORA is to instil a WF mentality among the unemployed - 'activation', American-style. States take a dual approach to this goal involving benefit cuts and sanctions regimes, on the one hand, and the linking of payments to participation on work programmes, on the other. Many states operate rigorous sanctions policies, which either cut or entirely remove benefits where individual recipients fail to comply with stated work requirements. The nature of these sanctions depends on the particular state in question: as Holcomb and Martinson (2002: 6-7) note, thirty-six states 'impose full-family sanctions for noncompliance', eighteen initially reducing the grant before terminating it in cases of additional noncompliance and the remaining thirteen imposing full sanctions immediately. The characteristics of the work programmes themselves vary widely with much depending on local social and political conditions. There are certainly 'more' or 'less' radical initiatives under the general rubric of PRWORA. For example, Florida's WAGES programme (1996-2000) permitted only a three-year lifetime limit on benefit while requiring adults to work or 'engage in work activities' (Jonas, 2001: 16) under threat of immediate sanctions 
for non-compliance. Wisconsin's W-2 programme contains similar features being premised on the notion that 'welfare recipients should be required to participate in employment or employment-related activities in return for their benefits' (Theodore and Peck, 1999: 494). In both these cases, welfare administration was decentralized, with Florida creating twenty-four regional boards charged with the task of meeting programme goals and Wisconsin opening the public system of welfare administration to competitive bidding from for-profit and non-profit organizations. Perhaps the most influential programme, however, has been the GAIN project at Riverside, California. The chief characteristic here, according to Theodore and Peck (1999: 493), is a "'hard" welfare-to-work' model, which enforces 'rapid entry into the wage-labor market at whatever wage and under whatever conditions' (Peck, 2001: 171). To this end, job search is given priority over education and training. This is essentially a 'strict regimen of supervised daily vacancy searching and cold calling' (Peck, 2001: 179) with targets being set for the number of calls to be made in a day amd the number of 'job leads' generated. In a process which Peck labels 'Riversidization', other areas such as New York, and indeed other parts of California, abandoned approaches which placed greater emphasis on human capital development in favour of 'work first'. On the other hand, more socially liberal initiatives continue to exist, as Holcomb and Martinson (2003: 147) note in the case of Portland, Oregon. They argue that this programme has 'substantially increased participation in education and training programmes particularly post-secondary education and training - and placed a strong emphasis on job quality while maintaining an employment focus'. The Portland programme has produced a 21 per cent increase in employment, a 22 per cent reduction in time spent on welfare and higher earnings for participants over time - figures which compare favourably with Riverside.

These examples aside, there is no space here to enter into a detailed account of the effectiveness of the various US welfare-to-work initiatives. It is not the purpose of this chapter to provide an analysis of this kind, although it is worth noting with Peck and Theodore (2001: 434 original emphasis) that

the matrix of successful and innovative programmes in the US remains extremely sparse ... programme quality remains highly uneven, progress in raising employment and wage levels has been incremental at best, while ... the aspiration of underwriting sustainable transitions from welfare to work remains just that, an aspiration.

Nevertheless, there is no doubt that the general impact of PRWORA, and particularly the new approach to welfare payments contained in TANF, has been to cut welfare rolls, and thus passive spending, dramatically, while unquestionably adding to the numbers of those in some form of work. It has been estimated, for example, that 76 per cent of TANF spending was on cash benefits in 1996, this figure falling to only 41 per cent by 2000 (Holcomb and Martinson, 2003: 137). Significantly, too, welfare caseloads fell 50 per cent between 1996 and 2002. Of course, it is not surprising that spending on benefits has fallen in view of the rigorous 
eligibility criteria; nor is it surprising to learn that the numbers of welfare recipients reporting income from paid work has increased from 7 per cent in the early 1990s to 33 per cent in 1999 (Weil, 2002: 2), given the near-universal emphasis on work programmes. The real issues are twofold. First, is it the case that those leaving welfare enter sustainable employment, which offers a secure income? Here, as Peck and Theodore intimate, the evidence hardly supports an affirmative answer. Loprest (2002: 21) reports that 'of those who left welfare between 1997 and 1999, 22 per cent were back on welfare ... in 1999'. Just as importantly, 52 per cent of those leaving welfare in 1999 had incomes below the poverty level (Loprest, 2001). On the other hand, those who do manage to gain employment are likely to benefit from the Earned Income Tax Credit (EITC) the value of which has been vastly expanded in recent years to 'make work pay', although it is not clear that these inwork benefits really help to lift the low-paid out of poverty (Besharov and Germanis, 2001: 77). Less is known about those whose time on benefit expires because they are relatively few in number owing to the fact that the five-year limit on welfare payments adopted by the majority of states has only recently expired - and states are permitted to extend payments beyond the TANF limit in 20 per cent of cases. Those who fall through the net may not necessarily be without benefits altogether because they may be eligible for alternative forms of support such as food stamps and housing, which 'are often more valuable than the basic welfare payment' (Besharov and Germanis, 2001: 74). However, it is hard to pretend that individuals who become ineligible for TANF are not vulnerable to extreme poverty. Moreover, they tend to come disproportionately from minority ethnic communities, be poorly educated and in worse health than others (Loprest, 2002: 25; Weil, 2002: 5) underlining Loprest's (2002: 26) opinion that 'economic hardship among disconnected families is acute'.

Second, the success or otherwise of welfare reform, at least judged by the numbers of people able to sustain employment, is only now being properly tested in a period of economic slowdown. During the initial phase of reform, in the midto-late 1990s, the US economy enjoyed sustained growth, which inevitably had a beneficial effect on welfare rolls. An economic downturn can be expected to affect adversely those with less formal education and fewer skills who tend to inhabit less secure areas of the labour market. While some may be eligible for unemployment insurance in the short term, Nightingale (2002: 114) points out that 'many unemployed people, especially low-wage workers, do not qualify for benefits' because 'some do not have enough quarters of work to qualify [and] some have left their jobs under conditions that disqualify them for benefits'. Any sustained downturn is likely to result in rising welfare caseloads as well as an increase in the number of poor families who are no longer eligible for TANF.

This brief assessment of what is undoubtedly a radical example of a workfare - and WF - approach to welfare reform and activation needs one qualification. As the policy has unfolded since 1996, it has become clear that its obvious success in terms of cost-effectiveness has meant that the federal funds that states originally had to devote to passive welfare spending are now available for increasing investment in existing welfare-to-work initiatives. Greater amounts of funding have led 'some 
states ... to broaden their focus on work by providing post-employment services to improve job retention and by incorporating strategies to improve individuals' skills and earnings potential' (Nightingale, 2002: 109). Paradoxically, it may be that an $\mathrm{HC}$ approach is developing from within the WF perspective, particularly because some states may be beginning to realise that those left on welfare rolls face more serious barriers to employment than those already working. Obviously it is too early to tell how far this process may go in terms of ultimately substituting a human capital ethic for the work first approach, but, in view of the uncompromising nature of change under PRWORA to date, this nascent shift away from so-called 'tough love' is unlikely to do more than blunt the hardest edges of what remains the most radical case of market liberal 'activation' in the OECD.

\section{Australia}

As discussed in Chapter Three, Australia's history as a 'wage-earner' welfare regime has been explored by Castles $(1986,1996)$ in some detail. The crucial issue, however, is that this type of regime became increasingly unsustainable as the exposed sectors of the Australian economy began to encounter stiff global competition in the late 1970s. Faced with the prospect of economic decline but with a strong trade union movement used to receiving favourable treatment over wage levels, Australian Labor Governments set out to alter the institutional foundations of the wage earner state by developing a market-friendly form of corporatism in the shape of the Accords. While the Accords set a certain 'negotiated' tone to change - change occurred nevertheless. Indeed, as Schwartz (2000: 105) makes clear, 'the Hawke-Keating governments used the Accords to decentralize collective bargaining while still preserving minimum wages, to remove trade protection and encourage more manufactured exports, and to generate robust part-time employment as lower barriers to trade destroyed unsustainable jobs'. Since the Australian Labor Party's (ALP) fall from power in 1996, John Howard's Liberal-National coalition has continued policies of economic liberalization including the decentralization of collective bargaining and, significantly, a radical decentralization of labour market policies, which had already seen a dramatic orientation towards activation under the ALP in the 1980s and 1990s.

The first Accord, agreed in 1983, succeeded in stimulating investment while containing wages, which fell from a peak of 64.6 per cent of GDP in the late 1970 s to 60 per cent. With employment gains made from lower wages and rising productivity the unemployment rate fell from 10 per cent in 1983 to 5.7 per cent in 1989. Deep recession in the early 1990s, however, saw unemployment hit 11 per cent and led the ALP to formulate a more systematic approach to labour market policy. To this end, the 'Working Nation' White Paper was published in 1994 and proposed 'a strategy which combined an expansion of labour market programmes with reforms to the benefit system which, with continued economic growth would effectively end long-term unemployment' (Finn, 1999: 56). The core component of this strategy was the 'Job Compact' which, as Finn (1999: 56) notes, was 'effectively a job guarantee, under which all the long-term unemployed, or 


\section{Towards workfare?}

those at risk of long-term unemployment, would be offered a temporary job or training place' - the object being to reconnect the unemployed to the labour market. Associated measures included a Youth Training Initiative and comprehensive case management for the long-term unemployed. On the benefits side, Australia has no insurance system to protect against unemployment but rather pays the unemployed through - not ungenerous - means-tested, flat rate social assistance funded by general taxation. Eligibility for this benefit was increasingly targeted (Saunders, 1999) and progressively tightened from the 1970s, with job search requirements being incorporated in the late 1980s and early 1990s. Indeed, starting with younger age groups, unemployment benefit was progressively withdrawn from 1988 and replaced by different benefits (e.g. the Newstart Allowance) targeted at different age groups, each of which emphasized the importance of job search. Under the Working Nation strategy, enhanced work activity tests strengthened search requirements with regulations also being introduced to encourage claimants to take part-time or casual work. Moreover, the numbers falling subject to the activity test were increased when, in a marked shift from earlier cultural assumptions associated with the wage earner ethic, spouse dependency was ended. In Shaver's (1999: 594-5) view, Australia has made strong headway towards the feminist goal of 'economic individualism' - although she points out that allowances for nonemployed spouses with dependent children (under 16 years of age) remain rather more generous than elsewhere. This tendency to protect the position of nonemployed spouses is a feature of the Liberal-National Coalition government's conservative approach to social policy. Shaver states, in this regard, that the Government 'reshaped ... allowances to reflect a conservative preference for traditional family structures' by introducing a Family Tax Initiative which gives 'very substantial added support to single-earner families with children under five'.

Despite what appeared to be initial success in the shape of falling numbers of long-term unemployed, Working Nation fell subject to the kind of problems that often affect programmes of this kind. For example, it became clear that employers were unwilling to take on the long-term unemployed, the result being that the Compact moved away from a reliance on subsidized work with employers to intensive training and work placements. In an effort to improve the quality of placements, the newly created Employment Services Regulatory Authority (ESRA) began to outsource case management to private and community providers (Webster and Harding, 2000: 21), but, because the system became dominated by the need to find placements quickly, this pressure 'led to fewer placements into sustained regular employment than might have otherwise been achieved' (OECD, 2001b: 80). In addition, the reformed benefits system was characterized by lack of clarity about eligibility rules, the ambiguous status of part-time and casual work, and the inevitable anomalies that ensued. Indeed, as Finn (1999: 65) reports, Department of Social Security (DSS) staff had "themselves become "increasingly concerned" that the system was becoming "too complex and riddled with anomalies to be administered" and were demanding "a major restructuring and simplification"'.

'Simplification' arrived in 1996, in the form of Howard's Coalition government, which among other things, abolished the DSS. The government announced radical 
changes to Australian labour market policy, including a substantial reduction in spending and a clear turn towards the 'work first' model. Borrowing from policies established by some of the federal governments, particularly Victoria, a fully 'contestable' employment service was to be created 'with the government no longer a direct provider, but rather a purchaser of services determined through competitive tendering' (OECD, 2001b: 89). To this end, the Commonwealth Employment Service (CES) was abolished in 1998 and the majority of employment services were contracted out to over 300 members of the newly created Job Network. The system, which covers a wide range of services, is coordinated through Centrelink, a one-stop shop which provides information about benefits and placement providers, and also assesses eligibility for labour market assistance. A key feature of the new arrangements is the relative absence of job creation and training programmes targeted at the long-term unemployed. In their place the Coalition government has substituted measures designed to provide training within, or at least associated with, employment relationships - a reworked version of the traineeship system in the form of 'New Apprenticeships' is one example (OECD, 2001b: 273-4), and Work for the Dole is another. Otherwise the emphasis remains firmly on job seeking: for instance, job matching services for all those on unemployment (and other) benefits, who are entitled to self-refer with up to six Job Network providers suggested by Centrelink; job search training for those unemployment beneficiaries assessed by Centrelink as 'job ready' (Webster and Harding, 2000: 24); and, for the longerterm unemployed, Intensive Assistance (IA), where eligible jobseekers are referred by Centrelink to placement providers with a view to receiving intensive support in their search for employment.

Taking these changes as a whole, it is clear that Australian labour market policies have progressively tightened over time, continuously developing towards the current position in which increased responsibility to find salvation through work is placed upon unemployed individuals in a highly decentralized 'unemployment market'. Although, as Chapter Five will discuss, there are certain broad points of similarity with developments in social and Continental regimes, which have instituted one or other version of active labour market policy, supported by associated benefit reforms and an increased sense of 'obligation', the WF approach has obviously been applied more stridently in the Australian case and this has contributed to the clearest difference between Australia and alternative regime types: Australian governments have pushed the 'contractualist' model of welfare virtually to its limits. As Ramia and Carney (2000: 63) make clear, 'the Australian context now embeds case management within a broader employment services regime, consisting of various public and private organisations which "negotiate" with unemployed people in a complex of contracts, administered predominantly according to private sector principles'.

This model permeates not just Australian employment policy, but the industrial relations system too, where direct bargaining between individual workers and their employers has been encouraged by the Coalition government. The point, of course, is to distance the state from direct contact with activities which are considered to be the responsibility of individuals themselves, while nevertheless ensuring 


\section{Towards workfare?}

compliance with the general requirement to seek work above all else. Whether or not this approach is effective in terms of maintaining and improving participation rates it is too early to tell. Younger workers apart, where employment rates are amongst the highest in the OECD, Australia performs around the OECD average for the 25-54 age group and lower than average for older workers of 55-64 years (OECD, 2001b: 60-2). Even so, long-term unemployment remains high at 22 per cent of the total unemployed and this may prove to be a difficult problem to solve. Having witnessed a steeper than average decline in the male full-time workforce during the 1980s, Australia's employment structure is distinguished by a large private service sector and high rates of part-time and casual employment. The potential difficulty with the Australian version of the 'active line' is that the WF approach is less committed to social inclusion than $\mathrm{HC}$ approaches - even, as in the case of France, where these latter policies clearly exist in tandem with a number of WF policies. For instance, it appears that the Jobs Network may not always provide equitable access to available services, 'particularly for indigenous jobseekers' and there are further issues about 'balancing quality of service and flexible delivery' (OECD, 2001c: 102). There is some suggestion, then, that the move to contestability had more to do with cost reduction (Webster and Harding, 2000: 33) than with improving standards of service delivery and employability - a characteristic that can be observed in the radical changes made to employment policy in the USA.

\section{The United Kingdom}

The changes to labour market policy in the UK over the past twenty years have been amongst the most marked in the mature welfare democracies. Progressive moves towards these new arrangements were stimulated by the impact of deindustrialization, which was at least partly induced by GEPs (see Allen and Massey, 1988) and saw (largely full-time, male) manufacturing jobs decline from 44 per cent of the labour force in 1966 to just under 27 per cent by 1991, while poorly paid (largely part-time, female) service sector jobs increased (Allen and Massey, 1988; Glynn and Booth, 1996). High unemployment rates throughout the 1980s and early 1990s, together with falling union membership, fostered flexibilization while, in a manner typical of liberal regimes, alterations to the benefits system from the mid-1980s onwards saw its transformation from a system of social protection to one which progressively reinforced the supply side imperatives of the new labour market policy (Jessop, 1994).

Beginning in the mid-1980s - and much influenced by debates about welfare reform in the Reagan White House (Deacon, 2000) - the Thatcher governments reduced benefit levels and subjected the unemployed to a regime that increasingly stressed the ills of welfare dependency and the importance of taking personal responsibility for 'actively seeking work' (King, 1995). The result of these changes, as Clasen (2002: 67) states, was that 'by 1994, the UK had no regulation of working time or wage levels, no legal protection for those hired under fixed-term contracts and no right of representation at the workplace'. Moreover, 'policies made it harder 
for jobless people to qualify for contributory benefits, excluded certain groups from benefit eligibility, introduced reduced rates for younger claimants and lowered the number of unemployed claiming benefits'. The apogee of these Conservative efforts to furnish UK employment policies with a clear supply side logic came in the form of the Jobseeker's Allowance (JSA), introduced in October 1996. The title is instructive: the contributory component of unemployment benefit was reduced from one year to six months, at which point claimants are shifted to a means-tested 'allowance' paid on the basis that claimants are actively 'job seeking'. This latter element was enhanced by a new stress on activation, hitherto neglected in government policy. Claimants were required to sign 'Jobseekers' Agreements', which committed them to a specified and agreed job search stategy and their efforts to find employment were monitored more closely, individuals being obliged to visit Jobcentres fortnightly 'when staff would review their jobsearch activity and provide advice' (Trickey and Walker, 2000: 189). In addition, the JSA made greater use of welfare-to-work programmes, forty-two of which were running before 1997, mainly connected with 'education, training or jobsearch assistance' (Trickey and Walker, 2000: 189).

If there is an irony in the UK case, it is that successive Conservative governments never fully implemented the strict US-style workfare regime that their critique of welfare dependency seemed to demand (Peck, 2001: 297-8). Instead they concentrated largely on the rhetoric of welfare dependency and personal responsibility for finding work, and less on developing a dedicated infrastructure to enforce job seeking. In contrast, it was the incoming New Labour government, which won a 179-seat majority in the House of Commons at the May 1997 General Election, that created a more comprehensive system of employment support, combining both WF and $\mathrm{HC}$ approaches to labour market policy. This (for Labour) radical new perspective had taken time to mature, being one instance of the Party's marked ideological (and institutional) shift from its democratic socialist past (see Ellison, 1994, 1997; Shaw, 1996; Hay, 1999) to a more market-friendly, 'postThatcherite' position (Driver and Martell, 1998) by the mid-1990s. Gathering coherence in the wake of the sharp recession in the early 1990s, when unemployment once again rose to over 10 per cent of the workforce, the new proposals developed by the Labour-appointed Commission on Social Justice (1994) were endorsed by Tony Blair after his election to the leadership. They focused particularly on work as an obligation of citizenship in the context of a 'right', not so much to work per se but to an opportunity for employment. In essence, this developing vision - some would say 'sleight of hand' - conjured by New Labour's 'third way' rhetoric was of an enabling state providing the chance of work but requiring its citizens to take that chance as and when offered. The supply side impetus is unmistakeable. As Labour's Chancellor, Gordon Brown (1999: 37) has written, 'we operate in a global market in capital and credit where billions of pounds flow in and out of Britain each day', this context providing, in his view, the raison d'etre for a switch away from demand-led social protection to an approach to welfare that privileges paid employment. According to Brown (1999: 41), what is good for the individual - inclusion in society through access to paid work - is also for the good of the 


\section{Towards workfare?}

economy, which needs to utilize and develop 'the skills of the whole workforce' if the UK is to become a global competitor. These ideas have been echoed by Blair who argues that the government's task is to encourage 'fair but flexible labour markets' and to increase 'the employability of our people through education and skills, and an active employment service' (quoted in Finn, 2003: 115-16).

The New Deal for the Young Unemployed (NDYP) - the first and arguably most successful of New Labour's New Deal measures - typifies this general policy approach. Utilizing the basic framework of the JSA regime, the NDYP offers an increased degree of support to jobseekers through the medium of personal advisers, who provide careers advice as well as guidance about job search techniques and information about available job opportunities. Those who have not manged to obtain unsubsidized employment after six months on JSA are required to take up work in one of three NDYP schemes: a subsidized employment option, employment with the Environmental Task Force or full-time education and training. There is no option simply to draw benefit without undertaking some kind of work-focused activity. This WF approach has been further enhanced during New Labour's period in government most obviously via the institutional changes made to the Employment Service. Following pilot projects designed to test the efficacy of a 'single work-focused gateway' to the benefit system (ONE pilots), the government decided to establish a new 'Jobcentre Plus' regime. This built on the idea of the 'single gateway' by bringing the Benefits Agency and the Employment Service together under one roof (CEC, 2002a: 16), with services being delivered either by public, not-for-profit and for-profit agencies in designated local areas, each working to centrally defined performance measures (Stafford, 2003: 156). Effectively, as Finn (2003: 122) makes clear, claimants - or customers - having contacted Jobcentre Plus through a call centre, are then interviewed by a benefits assessor before seeing a 'personal adviser whose task it is to assess employability and provide employment assistance', this process taking place within one local office. Significantly, it is this emphasis on employment services and administration rather than training and skill enhancement that defines British governments' (and specifically New Labour's) approach to active labour market policy. As Clasen and Clegg (2003: 374) make clear, the reform of these services accounted for well over 40 per cent of 'active expenditure' in the late 1990s.

The New Deal ethos has been extended to other social groups, notably the long-term unemployed. However, lone parents and people with disabilities are also encouraged to think of work as a possible option, and voluntarily to join a New Deal programme following a compulsory work-based interview. This attention to other sections of the community is a distinguishing feature of the New Deal, which some observers regard as beneficial. For Millar (2002) this indicates that the government is attempting to address the general issue of worklessness as opposed simply to dealing with those on the unemployment register. Others, conversely, are wary of policies that focus exclusively on paid work (Levitas, 1998), while Stafford (2003) notes the creeping degree of compulsion in the treatment of lone parents and disabled people.

A core feature of New Labour's approach, which underpins the JSA and various 
New Deals, is not simply the desire to encourage work, but to 'make work pay' and here, once again, the American influence is discernible. Like the EITC, the value of which was substantially increased by the Clinton administration, the Working Families Tax Credit (WFTC) that replaced Family Credit in October 1999 was intended to supplement the incomes of those with children who are in low-paid employment and who work for sixteen hours or more per week. Importantly, the money was paid directly to the employed person and incorporated credits for 70 per cent of childcare costs as well as credits for children and adults in receipt of disability living allowance. In April 2003, this arrangement was itself replaced by a series of new tax credits - the working tax credit, child tax credit and childcare tax credit (Bennett, 2004: 46) - with both the first and last of these being paid as in-work benefits. Although the sums paid are not overgenerous, WTC explicitly rewards those who work and, in this way, clearly contributes to New Labour's efforts to activate the workless and unemployed. Indeed, the fact that WTC, unlike WFTC, covers certain groups of able-bodied, childless individuals indicates a desire to ensure that those on low incomes are provided with the incentive to stay in employment. In pursuit of an integrated approach to welfare provision, other policies have been developed to support these work-oriented measures. The government's Childcare Strategy, for instance, has created over 484,000 new childcare places, with the objective of providing 'a childcare place for each lone parent entering employment by 2004' (CEC, 2002a: 8). More generally, the childcare tax credit is paid to all those with young children who receive WTC and is clearly primarily designed to encourage mothers to seek - and to stay in - work.

This growing reliance on ALMPs and associated policies is significant because it illuminates wider issues about the ideas and principles that inform New Labour's vision of welfare. On the face of it, UK policy-makers appear to have adapted US attitudes to welfare dependency to the British situation - and much has been made of this connection by some observers. Deacon (2003: 65) points out, for example, that 'Americanisation has served to heighten New Labour's preoccupation with the problem of welfare dependency' and, to this extent, 'the British debate is less dominated by economic considerations than it otherwise would have been and more concerned with the issues of individual responsibility and personal behaviour'. And, to be sure, the current stress on duties and obligations and the equal stress on the 'conditionality' of benefits (Dwyer, 2000) provide unambiguous evidence of trans-Atlantic policy transfer. However, it is important to be clear that UK labour market policy may be becoming less concerned with individual responsibility and behaviour. Conservative governments embraced this dimension of welfare reform with enthusiasm without doubt but, as the statements from Gordon Brown and Tony Blair quoted above suggest, New Labour has shifted the emphasis to incorporate a distinctively economic rationale for employment and 'social inclusion'. That the current government's key target group is the young unemployed, followed closely by the long-term unemployed, in contrast to the US stress on lone parents, suggests that the policy focus is essentially 'economic' and 'skills-based' rather than purely 'moralistic' (Stafford, 2003). Programmes like the Employer Training Pilots and, more specifically, the Modern Apprenticeships scheme, which is intended 
to 'prepare young people for an economy requiring a high level of skills' (CEG, 2002a: 12), provide further evidence of this HC focus. In this way, US-inspired policies are being given a different slant in the UK context - the slant being attributable to an identifiable 'European' dimension in UK labour market policy. This mixed approach accords with New Labour's conviction that the New Deals and associated programmes can act as vehicles for reducing welfare dependency and simultaneously strengthening social inclusion in the context of a global economy. In Levitas' (1998) terms, these objectives mean that UK labour market policies operate on a dual logic. First, they exhibit a 'moral underclass discourse' (MUD), derived from the US conservative critique of welfare via British Conservative governments while, second, attempting to embrace a 'social distributionist discourse' (SID) that owes much to European anxieties about the consequences of social exclusion in economies that are increasingly vulnerable to the play of market forces.

There is a real ambivalence here. While much of New Labour's rhetoric revolves around a moralized communitarianism, which certainly invokes a WF vision of citizen duty and responsibility to the 'community' (see Mandelson and Liddle, 1996: 102), the New Deals also appear to embrace elements of the HC dimension in their recognition of the importance of skills training, personal guidance and particularly the need to develop employment services to facilitate job search. However, the balance between these two perspectives is hard to sustain in view of the open, flexible and business-friendly nature of the UK economy. At its base, New Labour's apparent concern for social inclusion is embedded in a view of economic policy that makes a virtue of flexibility, low job protection and low pay - in other words, a view that accepts that the trade-off between employment and 'equality' should favour the former. While it is possible to maintain the belief that any form of paid employment is more likely to be inclusive than lack of employment and possible benefit dependency, the onus is on governments to ensure that work is actually available and the 'opportunities' offered to jobseekers genuinely capable of leading to sustainable jobs. In the absence of such guarantees, the extent of 'inclusion' derived from poor jobs is unclear.

This review of the recent changes to labour market policies in liberal regimes illustrates how extensive the shift away from earlier practices has been. Although these regimes differ from one another in many respects - not least of course in their very different histories of welfare state development - they nevertheless share a number of characteristics that have allowed them to alter social and economic policies to accommodate perceived market demands with relative ease. As Hall and Soskice (2001: 57) point out, the looser institutional configuration of liberal regimes mean that 'in the face of more intense international competition, business interests in LMEs are likely to pressure governments for deregulation, since firms that coordinate their endeavours primarily through the market can improve their competencies by sharpening its edges'. The real issue, however, is that liberal regimes do not possess the institutional depth in countervailing areas of economy and society to offset demands of this kind. To be sure, 'organized labor will put up some resistance, resulting in mild forms of class conflict. But because international 
liberalization enhances the exit options of firms in LMEs ... the balance of power is likely to tilt towards business' (Hall and Soskice, 2001: 57). Even in the UK, where attachment to welfare state institutions was embedded more deeply than in other liberal regimes, the absence of more tightly institutionalized, non-market forms of coordination means that path-dependent behaviour among welfare state supporters is more widely dispersed and less deeply entrenched than in other regime types. Conversely, as Wood (2001: 250) points out, employers are not only used to maintaining competitive advantage through well-tried market-oriented strategies but have to do so because they would otherwise be 'faced with enormous collective action problems in the absence of institutions and practices of coordination'.

While it may be possible to take a sanguine view of these developments in purely economic terms, it is more difficult to do so when confronted by the effects of - in this instance - the WF turn in labour market policy. In each of the countries discussed above, this trend has contributed to growing wage inequalities even as employment rates have held up in comparison with other regime types. And of course the effects of these inequalities are experienced more acutely by some social groups than others. Minority ethnic groups suffer disproportionately from unemployment, under-employment and low wages, for example (Quadagno, 1994; Craig, 2002), while women from both minority ethnic and majority white populations also experience poorer quality, lower paid jobs than males. Because, these populations in particular lack coordination and are 'institutionally fragmented' in liberal regimes - having no concerted base within organized labour and possessing no alternative institutional mechanisms for voicing their demands they cannot easily combat the atomizing processes fostered by means-testing and the privatized, decentralized forms of welfare delivery that characterize many welfare state programmes. 


\section{Labour market policies in social democratic and continental regimes}

The discussion in Chapter Four suggested that liberal welfare regimes have made extensive changes to their labour market policies, particularly over the past fifteen years or so. They made these changes in response both to a perceived rise in global economic competition and a number of other associated factors primarily concerned with employers' responses to service sector expansion, most obviously their demands for greater flexibility within the workforce. These policy shifts are not too surprising in view of the 'disorganized' character of welfare institutions in liberal regimes. A further issue, however, is the extent to which similar changes are occurring in those regimes in which welfare institutions are more closely coordinated, both in terms of popular subscription to existing arrangements and the ways in which institutional relationships, particularly those among the state and the social partners, work to perpetuate them. What follows examines current developments in labour market policies in social and continental regimes, beginning with the latter.

\section{Continental regimes}

A good deal has been said about the character of continental welfare regimes in previous chapters. However, it is worth repeating the fact that, as van Kersbergen and Hemerijck (2004: 172) comment, these regimes have

always promoted a passive or reactive social policy which was characterised by the readiness to moderate the harmful outcomes of the imperfect market mechanism by transferring considerable sums of money to families in need, without changing the logic of the market itself.

This reluctance to intervene directly in market processes is also reflected in the equal reluctance to tamper with the existing social structure. Welfare policies in the continental states have never been egalitarian as such, which is not to say that they are ungenerous. Rather they are used to preserve social divisions - and indeed to reproduce them 'well into retired life' (van Kersbergen and Hemerijck, 2004: 172). Unsurprisingly, then, active labour market policies have not been a marked feature of these regimes, the emphasis being placed instead on 'compensation' for 
breadwinners' loss of income. Of course, the parallel stress on the traditional family and the familial role of women as cornerstones of the social architecture not only helped to perpetuate the male breadwinner model of welfare throughout the postwar period, but also compounded it by condoning high male wages and job protection. As Levy (1999: 242) has noted, high wages dampen job creation, particularly in low-productivity services and, in addition, rising unemployment can only be dealt with by generous early retirement or disability programmes premised upon prior social insurance contributions. This reliance on social insurance as the main means of funding the core risks of unemployment, sickness and old age places a heavy burden on employers and employees alike, both of whom face rising payroll taxes during economic downturns - the result being selfdefeating as the costs of employment increase. It is this kind of vicious circle that led Esping-Andersen (1996a) to speak of 'Euro-sclerosis' and the innate conservatism of the continental model, his prognosis being that this model has 'an inbuilt tendency to eat the hand that feeds it' (quoted in Levy, 1999: 242).

Esping-Andersen's dictum may no longer be entirely accurate, however. Continental regimes are currently struggling with the unenviable logic of their welfare systems, to be sure, and there is also little doubt that many of these regimes seem to be institutionally 'stickier' than either their liberal or social democratic counterparts. Nevertheless, an examination of labour market policies in contemporary continental regimes lends credence to the view that this judgement may be premature, at least in certain instances. What follows surveys changes in labour market policies, and particularly the use of active labour market policies to enhance the work relationship, in Germany, France, Italy and the Netherlands. These countries have been chosen either because, like the Netherlands, they constitute examples of a capacity for change, or because, like Germany, France and Italy, they provide an insight into how continuing institutional hindrances to labour market reforms are beginning to be addressed by greater emphasis on the duties of the unemployed in the context of labour market flexibilization.

\section{Germany}

The original 'home' of Bismarckian social insurance, the postwar West German welfare regime was distinguished by generosity towards those - mainly men whose insurance contributions entitled them to a range of benefits at high replacement rates. Based on the principle of 'subsidiarity', the West German system was designed to ensure that 'welfare' was achieved through a combination of informal (female) care at family level supported financially by the male wage packet or, in cases of unemployment, sickness and old age, benefits derived from insurance contributions based on employment record. Outside this system, less generous tax-financed, means-tested social assistance is available for those either lacking a work-based contribution record or whose entitlement to insurance benefits has been exhausted.

As indicated, systems of this kind are vulnerable to economic downturns because rising unemployment quickly undermines the contribution-benefit relationship. 


\section{Labour market policies}

In addition to this systemic difficulty, the German welfare regime also proved susceptible to another: the temptation, particularly in view of the (then) Bundesbank's hard currency policy, for both federal governments and Länder to make savings by cutting their contributions to the social budget, thus forcing employers and employees to shoulder an increasing share of the burden of social protection through higher workplace contributions. As Manow and Seils (2000: 143) point out, Federal government support for the social budget fell by 5 per cent between 1970 and 1997, while Länder support fell by 3 per cent. Meanwhile, insurance contributions rose by 7 per cent over the same period. This practice was not seriously questioned until very recently because the social insurance system was broadly accepted by the social partners, particularly the trade unions, whose members have proved reluctant to give up the prospect of generous benefits and pensions.

The weaknesses of this combination of a contribution-based system of social protection, a hard currency policy and an industrial relations system historically linked to the social insurance principle were exposed during the process of reunification following the collapse of the Berlin Wall in 1989. Conducted against the backdrop of a seemingly immoveable Bundesbank, which rigidly stuck to a high-valued Deutsche Mark, the political decision to reunite East and West Germany as rapidly as possible led to severe economic dislocation, the effects of which continue to be felt. Dramatically rising unemployment in the East - the result of the brutal exposure of the old communist economy to global market forces and an unrealistic conversion rate for the East German currency - was met by the decision to use social insurance fund resources, as opposed to general taxation, to finance the process of economic and social restructuring in the eastern sector. In view of the fact that West German industry was itself beginning to feel the effects of international competition by 1990, the twin burden on the insurance funds inevitably led to higher contribution rates from both employers and employees - which in turn resulted in growing wage militancy, higher non-wage labour costs and thus increasing unemployment. Moreover, it became more difficult to disguise both the level and costs of unemployment through the traditional route of early retirement: the costs of early retirement programmes increased enormously as employers 'resorted to [them] simply to pay workers to stay at home at the state's expense' (Wood, 2001: 388). This situation was further exacerbated because avenues into lower paid service sector employment were blocked. For one thing, Germany's service sector has remained comparatively small because the rigidly structured patterns of social and industrial relations associated with the social market economy do not easily permit the kind of flexibility associated with service sector employment. For another, rising employer contributions could not be offset by lower wages because wage levels are not permitted to fall below the minima set for unemployment benefit and social assistance. As Manow and Seils (2000: 156) make clear, 'one consequence is that many low-productivity jobs become unprofitable and are either replaced with more capital-intensive production methods or are not created in the first place. The upshot is poor job growth and below-average employment in the German service sector'. Due to this coalescence of factors, unemployment has literally become institutionalized in post-unification Germany, with the East regularly recording rates which are 10 per cent higher than those in the West. 
Faced with these multifarious challenges, it is not surprising that both CDU and SPD governments generally failed to ensure that German labour market policy effectively counters the rising trend in joblessness. Indeed, in contrast to the emphasis placed on activation policies in the Scandinavian countries (and, in different fashion, in Australia or the USA), labour market policy has been decidedly cautious until very recently. Caution has taken the form of incremental moves away from the idea that the state had prime responsibility for avoiding unemployment. Initially the Kohl administrations restricted benefit eligibility, encouraged job search and weakened employment protection in small firms, while the Schroeder Red-Green coalition government elected in 1998 concentrated on working with the social partners to increase part-time working, flexible working and job creation (Evans, 2001: 15-16), in addition to tightening unemployment compensation payments. Where ALMPs are concerned, this minor tinkering was supplemented by new vocational training and job creation measures, which were initially used in Eastern Germany in the early 1990s 'as a bridge over the "troubled water" of the transformation process' (Blien et al., 2002: 6). However, there is some reason to doubt the effectiveness of these early attempts at activation, as Wurzel (1999) has noted. Participation in employment provision and training schemes fluctuated during the 1990s, with the schemes being cut back for budgetary reasons in middecade. Significantly, too, figures for one of the new Länder - Saxony-Anhalt show that 'in the eight years from 1990 to 1997, only about a third of training scheme participants in work provision schemes went on to employment' (Wurzel, 1999: 3).

Of course, such criticism should not be taken as an indication that these policies were universally unsuccessful - and, as with the other examples discussed here, the key concern here is less about efficacy per se and more about the extent to which activation has become a significant feature of a general move towards workfare-style policies as a solution to persistent unemployment. In the German context, much depends on the nature of the claimant, the benefits involved and the locality in which benefits are being claimed. In this regard, the principle of subsidiarity that pervades German social policy has contributed to a highly decentralized system of employment services with institutions arranged at national, federal and local levels. As Voges et al. (2000: 72) make clear, 'this multiplicity of actors means that there is a great heterogeneity in how, and to what extent, unemployment provision programmes are implemented'. Some claimants primarily those who are insured and receiving unemployment benefit and unemployment assistance benefit through locally based federal employment offices - 'are relatively well placed to access support in the form of job creation opportunities' (Voges et al., 2000: 75). However, the monitoring of job search activities is not systematic and 'the underlying approach of [Public Employment Service] offices is not to enforce job search but to leave it to the claimant' (Evans, 2001: 35). Others, conversely, are less well served. For example, uninsured claimants in receipt of tax-funded social assistance have worse placement prospects than their insured counterparts, though, here too, the monitoring of willingness to work and subsequent placement activity varies among local authorities. Where social assistance claimants are concerned, the 'Help Towards Work' (HTW) programmes run by 


\section{Labour market policies}

local authorities are primarily intended to provide a 'workfare' element, with 'work testing' being a core component of the schemes. In practice, however, HTW is implemented differently in different localities, programmes varying greatly in terms of target groups, types of employment offered, the length of employment, sanctions imposed and the organization and delivery of the programmes themselves (see Voges et al., 2000: 87-96). This degree of diversity implies an absence of generally accepted criteria against which the achievements, or otherwise, of HTW programmes can be evaluated - the suggestion being that lack of systematic evaluation is likely to hinder a more coherent approach to policies designed to tackle unemployment at the more 'vulnerable' end of the labour market.

This situation is beginning to change, however. Recently there have been signs of a growing awareness in political circles of how ill-matched German labour market policies are to prolonged economic recession. Although local and Federal job placement services have been 'continuously reorganized to increase performance' (Blien, et al., 2002: 9) in recent years, a much more radical reorganization is now under way in the aftermath of the discovery of apparent mismanagement of job placements by the Federal Employment Service, which came to light in early 2002. In response to this incident, the government established the Hartz Commission (named after its Chairman, Peter Hartz, Head of the Personnel Executive Committee at Volkswagen), charging it with the task of producing recommendations for the modernization of German labour market policy and the reduction of unemployment. The Commission reported in August 2002 and - surely correctly - argued that the government's responsibilities for the unemployed should be brought together under one organizational structure. Specifically, 'the administration of social [assistance], unemployment benefits and unemployment assistance will become the responsibility of local employment offices' (The Economist Intelligence Unit, 19.8.02: 1). In addition, the Commission recommended that job centres be introduced throughout the country and child day care facilities be expanded to facilitate female employment; further, temporary employment and employment at home should also be promoted. These recommendations, which are broadly aimed at bringing the unemployed into more systematic contact with available jobs, are complemented by others geared towards tightening benefit entitlements and imposing greater penalties on those who turn down offers of work. In the Commission's view, for example, entitlement to unemployment benefit should be reduced from three years to one - with those moving to means-tested social assistance even having their children's savings taken into account in the calculation of claims. Moreover, young unemployed people should be expected to accept jobs anywhere in Germany or risk losing benefits.

The Schroeder government has broadly supported the Commission's recommendations - and all the more so in the aftermath of the September 2002 general election and rising levels of voter dissatisfaction in the face of increasing unemployment. Under the Job-Aqtiv Act 2002, tougher rules have been imposed on the unemployed including the implementation of Hartz's proposal that claimants refusing offers of work should be penalized. Moreover, the employment service has been reorganized with new 'personnel service agencies' to place unemployed people into temporary work being created in the non-profit and private sectors. 
Restrictions on private job agencies have been removed and, since 2002, they no longer require a licence to operate - these agencies also being permitted to 'charge a fee of between 1500 and 2500 euros if they successfully find a job for an unemployed worker' (Bleses and Seeleib-Kaiser, 2004: 65). These measures have been accompanied by other employment enhancing policies. For example, older unemployed workers whose unemployment benefit is not yet exhausted are being encouraged to take jobs at a lower monthly income for the duration of the remaining benefit entitlement measures, while employers providing work for those over 55 years of age, who have not previously worked for them, are rewarded by reductions in their unemployment insurance contributions (see Bleses and Seeleib-Kaiser, 2004: 65-7).

It is true, of course, that these measures are still in the process of being implemented and to condemn them for failing to produce desired results would be premature. However, there is as yet little indication that they are having the anticipated impact on German unemployment rates. In May and June 2003, unemployment fell slightly, but rose a little to a standardized rate of 9.8 per cent in October 2004 (OECD, 2004b). The apparent intransigence of these figures suggests that the claim that the reforms will yield a 50 per cent fall in unemployment, as the Hartz Commission and government predicted, is open to question. So, while in Gray's (2004: 180) view, these changes indicate that labour market policy 'is dissolving into an extreme form of workfarist benefit system, with employment agencies as placement agents', with 'the emerging German model of workfare [being] the European form that perhaps comes closest to the US model', they may not be enough in themselves to stimulate higher employment. It is partly for this reason that the trade unions are currently calling for greater attention to be paid to the creation of additional new jobs, while simultaneously sticking to their institutionally ordained role of demanding greater job protection for those already in work - a sort of rearguard action in a struggle which has seen the state increasingly reluctant to intervene in the marketplace and, at the most, being prepared only to 'enhance and enable market solutions' (Bleses and Seeleib-Kaiser, 2004: 125).

As Chapter Three suggested, Germany currently faces challenges both from GEPs and, more directly, from the consequences of reunification, the effects of which are mutually reinforcing. The political decision to reunite with the East was taken at a time when global pressures on (West) German industry were mounting with the result that there was little economic leeway for the accommodation of the internal challenges that reunification inevitably posed. With labour market reform now firmly on the agenda as one means of cutting spending and the increasing recognition that new working practices are necessary to develop competitiveness, the trade unions, for all their opposition to extensive change, appear to be making compromises - at least on a case-by-case basis. That managements at DaimlerChrysler and Siemens have succeeded in gaining agreements from their respective workforces to work for longer hours with no extra pay in order to save jobs being moved abroad is indicative of the kind of decisions that unions may be faced with in other parts of German industry in the near future. Again, the fact that in October 2004 Volkswagen workers had to vote on a proposal to reduce labour costs by 30 per cent over six years, while the recent decision by General Motors to cut 


\section{Labour market policies}

approximately 8,000 jobs in their German car operation citing 'the pricing environment and competitiveness of the market [which] do not allow us to grow fast enough to offset the cost base we have today' (The Guardian, 14.10.04) as key reasons, are further instances of the pressures with which established institutional structures and expectations are increasingly having to deal.

It may be that Germany is approaching a 'tipping point', which will see substantial institutional changes both to core elements of its welfare system and also to the infrastructures that support them. Although countervailing factors such as the profound disparity between West and East (Hutton, 2004: 2; The Observer, 5.9.04), which necessitates the continuing flow of resources into the East German Länder, mean that there will no seismic shift in existing welfare arrangements for fear of destabilizing the East, there is now evidence from monthly public opinion polls that Schroeder's plans for welfare reform are finally beginning to strike a chord with the electorate (Traynor, 2004). This nascent endorsement of reform by voters, combined with the fact that the trade unions appear to be increasingly on the defensive, suggests that core institutional actors are beginning to question the key institutional assumptions which underpinned the German welfare regime for much of the twentieth century.

\section{France}

In a similar manner to the German system, French labour market policies are insurance-based, 'with a strong reliance on both the contributory principle and the principle of subsidiarity' (Enjolras et al., 2000: 42). However, although France has not had to contend with anything as dramatic as reunification, the country has struggled to adjust to the pressures imposed by global competition and, just as importantly, EMU. The challenges for labour market policy have been severe. French unemployment rose continuously throughout the 1970s and 1980s from a level of 3 per cent in 1974 to 10.5 per cent in 1987. Even higher levels - 12.5 per cent - were experienced in the mid-1990s with a gradual decline thereafter; currently, as of October 2004, the French unemployment rate stands at 9.5 per cent (OECD, 2004b). Although key indicators such as the levels of long-term or young unemployed have declined since the mid-1990s nadir, the French labour market, and by extension French society, have a number of characteristics that make it, if not impervious, then certainly institutionally resistant to change. For one thing, like other continental states, long-term unemployment has remained high (rising as high as 43 per cent of total unemployment at the end of the 1990s) while, perhaps more than elsewhere, labour market participation 'has been highly concentrated on intermediate age groups' (GEC, 2002b: 6) owing to policies that have encouraged young people to stay in formal education and those over 54 years of age to take early retirement. In 2001, for example, nearly 80 per cent of the 25-54 age-group were in work in comparison to only 62 per cent of the 15-64 age-group, suggesting much higher levels of inactivity at either end of the employment cycle.

These trends are beginning to change. As part of its participation in the European Employment Strategy, France is committed to reducing levels of youth 
unemployment as well as to increasing participation rates among older workers these issues having to be dealt with at the same time as pressures to increase employability in general, and women's entry into the job market in particular, are mounting. Taken together, these factors have encouraged successive governments to alter employment policies in ways designed to achieve higher overall participation rates. However, the process of reform has not been smooth, with successive governments attempting to strike a difficult balance between the traditional imperative for socially inclusive policies to protect the most vulnerable and increasing demands from employers for market-friendly measures such as lower payroll taxes and benefit levels, as well as reduced employment protection and greater flexibility. This process is ongoing, but the clearest outcome to date has been a discernible fragmentation of French labour market policy as governments attempt to push beyond the parameters set by traditional social insurance solutions while nevertheless recoiling from the prospect of root-and-branch reform.

The insurance system itself - Union interprofessionalle our l'emploi dans l'industrie et le commerce (UNEDIC) - was originally created in 1958 to protect against unemployment in the private sector. Administered by the social partners, it was entirely separate from state social security provision and has remained so. However, owing to rising unemployment in the early 1990s, the traditional method of maintaining insurance protection - raising employer and employee contributions - was acknowledged to be counter-productive, contributing both to further unemployment and increasing pressure on the insurance fund. One strategy to offset this trend was the reform of unemployment protection in 1992 in the shape of the introduction of a new benefit, the Allocation Unique Dégressive. With the impetus coming mainly from employers, changes were made to eligibility criteria and benefit levels, a key feature being that full entitlement (75 per cent of earnings) lasted for only six months with reductions thereafter. A condition of benefit receipt is that claimants 'must actively seek work, must enrol at the State employment exchange office and must accept jobs where the wage is above $30 \%$ of the wage they earned in their most recent job' (Enjolras et al., 2000: 48-9). If they are still unemployed at the point of benefit exhaustion, claimants become eligible for a means-tested 'solidarity benefit', the discretionary and locally administered Allocation de Solidarité Specifique (ASS). Not surprisingly, the numbers claiming ASS rose dramatically to 467,000 in the earlyto-mid 1990s. Significantly, however, as many as 700,000 individuals, the majority of them under 25 years of age, failed to meet the eligibility criteria for ASS and so fell outside the system altogether - the point being that fully one-third of the unemployed were neither catered for by social insurance nor by ASS.

Recognition of the increasing gap between what the social insurance system could provide and the needs of the growing numbers of those falling outside this system led to the development of new forms of income maintenance. Generally speaking, in the context of a discernible shift away from the 'passive' forms of protection associated with the social insurance model towards activation, there has been a two-fold policy response. First, the late 1980s saw an attempt to enhance social inclusion, through the Revenu Minimum d'Insertion (RMI), while, in the earlyto-mid-1990s, more clearly market-oriented initiatives were developed in an effort to create jobs. Since that time, French governments have oscillated - at least in 
terms of political rhetoric - between the two poles of 'inclusion' and 'liberalization'. Beneath the rhetoric, however, it is possible to detect a drift towards the latter pole, even where policies have been framed in terms of inclusion.

Support for social inclusion was clearly the intention behind the tax-financed RMI introduced by Michel Rocard's Socialist government in 1988. Until that time, a comprehensive system of income support for those lacking entitlement to social insurance did not exist, so the 'universal' right to means-tested assistance, albeit only for all those over 25 years of age, was clearly a major advance on existing provision. The 'insertion' aspect of RMI is particularly important. Recipients have a 'right', through an 'insertion contract' agreed between the individual and local 'commissions for insertion', to various services designed to facilitate their social integration. Employment is an obvious example, but health, housing and vocational training are others (see generally Enjolras et al., 2000: 50-1). Here, however, party political differences and tensions between the social partners (and between the social partners and the state) ensured that the path of reform was hardly smooth. Differing perceptions of the nature of the contract provide an example of the tensions between social inclusion and 'liberalization', which broadly mirror human capital and work first approaches to labour market policy. From the outset, socialists stressed the individual's right to insertion and cash assistance, while their opponents argued that benefits should be conditional on the individual taking up these opportunities for reintegration. As Enjolras et al. point out, despite a ministerial circular of 1989 attempting to clarify the position by indicating that the insertion contract was intended as a means of allowing for each RMI recipient 'to assert the right to insertion' (quoted in Enjolras et al., 2000: 51), confusion remained with expectations about 'rights' and 'conditionality' varying according to local practice. In the meantime, the cash element of RMI is now going to over 1 million households and the benefit is 'increasingly [functioning] as a safety-net for the long-term unemployed', who fall outside the social insurance system (Palier, 2001: 66).

RMI is significant because it represents an attempt to resolve the difficulties created by reliance on social insurance provision without relying solely on the market. Whether a safety-net benefit of this kind can really increase social inclusion is a moot point, but perhaps the major feature of the policy is that it deliberately excludes support for the young unemployed. This large group is not included in RMI because of government fears that receipt of the benefit and associated insertion opportunities, in the absence of any previous work experience, may induce welfare dependency. Instead, activation was regarded as particularly important for the under-25s with an emphasis on vocational training and work experience. More than others, this group has been subjected to HC-oriented, but nevertheless 'workfare-style' policies in the sense that 'absence of entitlement, plus the presence of work programmes constitutes a kind of workfare policy for young people in need of financial help' (Enjolras et al., 2000: 53). Since its inception in 1998, for example, over 350,000 young unemployed have entered the Nouveaux Services emploisjeunes programme, which provides young people with a five-year work programme designed to enhance their vocational skills by providing subsidized employment at local and community levels. The long-term aim is 
that at the end of five years, those jobs which are clearly addressing a continuous and long-term need will become permanent, with the funding provided locally, and where this is not the case the young people involved will have by then acquired recognized skills of interest to other employers.

(Pisani-Ferry, 2001: 5)

Alongside initiatives of this kind, France has also implemented key elements of the EES, notably the development of individualized 'guidance' services for both the young and long-term unemployed by the National Employment Agency. As Pisani-Ferry (2001:4) has observed, employment policies for these groups are now 'moving in the direction of a much more finely-tuned monitoring of the situation of jobseekers so that they can rapidly be offered jobs or training' - and this largely irrespective of party politics.

If these measures display an ambivalence about the importance of social inclusion as a goal of French labour market policy, the 'liberal turn' that gained increasing influence during the 1990s can certainly be construed as a clear shift in favour of the market. The process began with the Balladur government in the early 1990s, although the policies associated with it have been employed by Socialist as well as right-of-centre administrations. The core features of this approach involve a typical agenda of cuts in social insurance contributions accompanied by tax cuts, the objective being to relieve pressures on employers in the hope they will be encouraged to increase their labour forces. Both the Balladur and Juppé governments, for instance, 'exempted employers from paying social taxes on low wages' (Ughetto and Bouget, 2002: 95) in an effort to encourage higher employment amongst the unskilled. Following orthodox economic policies designed to keep the French budget within the guidelines set for monetary union, these governments are associated with regressive tax policies and the cuts in insurance entitlements (see Levy, 2001: 281). In certain respects, Lionel Jospin's Socialist government, which came to power in 1997, adopted a similar approach, assisting low-wage employment creation by further reducing social security contributions on lowskilled work. Moreover, in a move reminiscent of recent policy initiatives in liberal regimes, an earned income tax credit (PPE), intended to support those employed on low incomes, was introduced in 2001 - and if a rigorous privatization policy is added to the mix, it seems reasonable to suggest that low-end private sector service employment has been given a significant boost.

Taken together, these sustained efforts to lower labour costs and encourage low-wage, unskilled employment have led to a situation in which 'most hiring is now carried out for insecure jobs' (Ughetto and Bouget, 2002: 96). It has been estimated, for example, that permanent, full-time jobs now account 'for a much smaller proportion of total employment than they did ten or twenty years ago and the proportion of "atypical" jobs (fixed-term contracts, temporary agency work ...) increased from 16\% in 1990 to close on 25\% in 2000' (Pisani-Ferry, 2001: 4). This liberal approach may offer 'activation' of a kind, to be sure, as the unemployed take up the large number of unsubsidized jobs that have been created, especially in the private sector. However, this form of liberalization has also contributed to 


\section{Labour market policies}

an unbalanced labour market, which combines 'precariousness with unemployment' (Ughetto and Bouget, 2002: 93) and hence threatens the logic of inclusion.

It was in an effort to retain at least an element of the social inclusion principle that the Jospin Government attempted to complement its activation policies towards the young unemployed with more obviously 'inclusive' measures towards the labour market in general. For example, the Government took a decidedly more dirigiste approach to working time in the later 1990s in the form of the 35-hour week - the objective being the attainment of higher levels of employment without further increasing reliance on low-wage, dual labour market strategies. Although a good deal of initial 'persuasion' had to take place to allay employers' anxieties about the costs, by the end of 2000 approximately 56 per cent of employees in businesses with more than ten employees were working thirty-five hours - and recent estimates suggest that the policy has contributed to the creation of over 200,000 new jobs (Pisani-Ferry, 2001: 2-3). Again, the Government supported the trade unions in their attempt to prevent the implementation of the proposed Plan d'Aide au Retour a l'emploi (PARE), much favoured by the main employers' association, MEDEF. The original provisions of the PARE were decidedly 'liberal' and WF in character in so far as they required the unemployed to accept whatever jobs or training they were offered - thereby acknowledging that benefit was no longer a social right driven by the logic of inclusion, but a status conditional upon the acceptance of an offer of training or employment. Union objections to this workfarist conception of unemployment provision provided an opportunity for Jospin to reject it and jettison the element of compulsion in favour of voluntary acceptance of the PARE. Essentially, unemployed individuals would sign a PARE contract based on its perceived advantages to them - one being that unemployment benefits are paid at a constant, rather than diminishing rate throughout the period of unemployment (see generally Ughetto and Bouget, 2002: 98-9).

In contrast, the rightward turn in French politics following the general election in June 2002 witnessed a renewed trend towards liberalization. The incoming Prime Minister, Jean-Pierre Raffarin, made his intentions clear within weeks of his election victory. In his general policy address delivered to the French National Assembly, Raffarin promised to reduce social insurance charges and taxes - including an across-the-board 5 per cent income tax cut - because 'we simply recognize that it works. It creates jobs' (Raffarin, 2002: 17). To this end, he argued (Raffarin, 2002: 18) that 'we must trust creators and entrepreneurs, all those who can create employment [for] what benefits employment, benefits us all'. This stress on the need to stimulate private sector employment, coming, as it did, at a time when France was once again entering a period of economic slowdown, is indicative of the Centre Right's willingness to reduce the rigidities associated with the insurance system, even if such policies compound the inequalities associated with a dual labour market. Moreover, the Raffarin government supported this line of policy with a more rigorous approach to unemployment - particularly youth unemployment. According to Raffarin (2002: 17), the young unskilled unemployed should be offered a 'social reinsertion contract', which would provide a guaranteed minimum income in return for a commitment to take up offers of jobs or training - terminology 
notwithstanding, the proposed arrangement resembles MEDEF's original proposal for PARE in key respects.

The general point, however, is not that liberal policies are about to be uniformly applied in crude fashion - this is unlikely, not least because the institutional infrastructure of social insurance presided over by the social partners remains largely in place. It is a paradox, nevertheless, that, despite the apparently high degree of institutional embeddedness, the social partners' hold over employment policy is gradually being whittled away - not by a direct assault on the social insurance principle but by stealth as the growing numbers of uninsured unemployed are dealt with in different ways. As Clasen and Clegg (2003: 373) make clear, 'France's institutional expression of occupational solidarity is objectively in crisis, unable to respond to the diversification of labour market trajectories'. The system's continued survival is bought at the cost of 'abandoning its one-time quasi-universalist pretensions [and] casting the net of its coverage ever less wide [which] has left France with an ever more fragmented and complicated system of provision for the unemployed'. These developments do not make France a 'workfare state' on US lines, although the tendency to label activation policies targeted at those without insurance as a form of 'solidarity' is surely something of a misnomer. But the ambivalence about, and tension between, social inclusion and liberalization that have characterized recent French labour market policy, are likely to continue in an economic environment which appears to favour the latter but in a political environment where governments face clear electoral costs if they push for far-reaching institutional change. To surmount this impasse will be difficult. In terms of labour market policy, it may be that France - now with a new right-of-centre prime minister - will tackle the issue by allowing 'passive' social insurance to wither further as policies focus increasingly on market-led job creation, easier redundancy procedures and means-tested social assistance for uninsured individuals. However, as Hutton (2004: 1-2) comments, pressures for swifter, more radical change are mounting as the economic costs of institutional stasis become ever clearer.

\section{Italy}

In the words of Dell'Aringa (2000: 1), 'Italy has one of the "worst" labour markets in Europe'. This judgement refers to the fact that Italy suffered - indeed continues to suffer - from a number of structural and institutional labour market rigidities which conspire against reform. Although some changes have occurred in recent years, it is clear that Italy continues to face severe difficulties in its attempts to adjust labour market policies better to conform to the demands of the global market.

The difficulties are plain to see. To a greater extent than the other countries discussed here, the Italian labour market is heavily segmented in terms of territory, gender, age and skills. Moreover, there is a legacy of rigid regulation, especially in relation to job protection and 'flexibility', that has proved particularly damaging. Taking these issues in turn, despite the state's efforts to promote employment at regional levels, the historic divide between North and South persists. In labour market terms this means that 'in the South there is an abundance of workers and 


\section{Labour market policies}

a shortage of jobs, while in some zones of the North the situation is exactly the opposite (Franzini, undated: 4). In 1999, for example, the unemployment rate of 6.5 per cent in the Centre-North contrasted markedly with the South's rate of 22 per cent (Franzini, undated: 4). According to Chiesi (1999: 3) 'regional differences turn out to be the most important variable that can explain differences between unemployment rates', to the point where 'two separate labour markets seem at work during the nineties'. This territorial dimension is accompanied by marked gender differences, Italy's female unemployment rate of 14.4 per cent in 2000 being well above the European average and contrasting with the male rate of 7.4 per cent. Age differences are also evident with employment rates of 29 per cent for men and 21 per cent for women of 15-24 years-old in 1999 contrasting with rates of 84 per cent and 49 per cent respectively for those aged between 25 and 54 . Employment rates also drop significantly for those over 54 , standing at 40 per cent for males and only 15 per cent for females in 2000.

Accompanying these structural problems are other features of the Italian labour market that have contributed to Italy's persistently high levels of unemployment. For instance, although Italy has a higher share of jobs than the European average in agriculture, 'industry in the strict sense' (Franzini, undated: 5) and public administration, the country lags behind others in areas ranging from construction through transport and communications to services. Moreover, rates of selfemployment and 'atypical work' are higher than the European average, while the amount of irregular work in Italy's extensive informal economy is estimated to be as high as 15 per cent of the total of those employed - the figure possibly being as much as 20 per cent in the South.

The factor that compounded these difficulties, at least until the early 1990s, was the extreme degree of regulation, which, to make matters even more complex, was (and to some extent remains) differentially institutionalized across the Italian labour market. As Ludovici (2000: 273) points out, labour market regulation was generally accepted by the social partners but really only covered 'core dependent workers and family heads by the strict regulation of employment relations and the use of public resources to support labour hoarding'. Essentially the system was designed to protect the insured industrial elite against the perceived 'risk' of flexibility, particularly in the form of fixed-term contracts and part-time work. Although characterized by high contribution levels, it was in the interests of both trade unions and companies to perpetuate this system because, from the union viewpoint, it protected the incomes and employment conditions of unionized industrial workers while, so far as firms were concerned, it excused them from having to bear the costs of temporary lay-offs but nevertheless afforded high internal flexibility. There were some broader advantages to the arrangement. For example, it smoothed potential industrial conflict between the social partners and also provided generous protection in the form of the contribution-based cassa integrazione ordinaria (ordinary redundancy fund) and the cassa integrazione straordinaria (extraordinary redundancy fund), thus allowing companies in the industrial sector to restructure at little cost. However, because the system covered so few employees (about 40 per cent of total employment), it reinforced the segmented nature of the 
labour market and contributed to the growth of the 'underground economy' at a time when growing global competition was beginning to highlight Italy's economic weakness. Moreover, because the redundancy funds bore the brunt of the costs of restructuring in the industrial sector, benefit levels elsewhere were less generous. Unemployment benefit, for instance, covers those on open-ended employment contracts who are made redundant, provided they have accumulated 53 weeks of contributions in the previous two years - but replacement rates are only 40 per cent of the average industrial wage, which is low by the standards of continental regimes.

Over the past decade, Italian governments, in concert with the social partners, have made efforts to alter labour market policies in ways designed to reduce labour market segmentation and, by introducing greater flexibility, increase Italian economic competitiveness. The result, as Ludovici (2000: 274) makes clear, has been a gradual turn away from the rigid system of the past - although, the path of reform has been far from smooth. Attempts at reform began in earnest in the early 1990s with the unions' acceptance of the fact that greater flexibility was required if unemployment rates were to be lowered. To this end, the Guigni income agreement of 1993 saw constraints on fixed-term and part-time contracts reduced, while the 1997 'Treu Package' eased regulations on job protection and atypical contracts, albeit in the context of a 'strong regulative approach, all premised on concertation with the social partners' (Ludovici, 2000: 280). Alongside these developments greater flexibility over wage determination has seen a moderate shift away from national level bargaining for each industry towards a combination of national and firm-level bargaining - the latter allowing companies to take account of local factors such as their financial viability and productivity rates. Meanwhile, some progress has been made in reducing contribution levels in an effort to lower labour costs.

Progress has been slow, however, and 'one-sided' to the extent that flexibility measures in the shape of a relaxation of regulations on temporary, part-time and atypical employment were not accompanied by reform of the public employment service or the active measures required to link jobseekers with work until very recently. Italy's Impact Evaluation of the European Employment Strategy (CEC, 2002c: 1) noted that, despite significant growth in employment since 1995, "we are still far from a solution to the traditional problems of the Italian labour market'. The key drawbacks remain those discussed above and the document makes it clear how difficult it has been to make progress towards those EES goals which stress activation and PES reform. The document (CEC, 2002c: 29-30) records, for instance, the difficulties encountered in decentralizing responsibility for ALMPs to the regions and provinces. It comments that 'the network of employment services has long been in a situation of uncertainty' and that 'this is all the more serious in a phase in which services are called upon to undertake new tasks in line with European policy'. Of particular note is the acknowledgement that circulars to regional offices requesting them to plan interviews with 'young unemployed people and adults' were not acted upon because 'the request was poorly formulated and ... based on an unreliable system of procedures and administrative information in a phase 


\section{Labour market policies}

characterized by the disorientation of the sector'. This verdict does not suggest that the requirements for well-targeted labour market and training measures, in addition to the 'rapid revision of the social protection system', noted by Ludovici (2000: 296) are close to fulfilment. Indeed recent developments suggest that institutional constraints in the labour market are likely to ensure that the pace of reform remains slow.

Significant in this regard is the reception of the 'Biagi Law' implemented by the Centre-Right Berlusconi coalition during 2003. The law contained the majority of the proposals made by a labour law expert, Marco Biagi (murdered by the Red Brigades in March 2002), in a 2001 White Paper and aimed to improve the efficiency of job placement services, as well as to increase labour market participation by extending existing flexible labour contracts and reforming the PES by ending its public monopoly and allowing employment consultants, temporary work agencies, universities and joint bodies created by the social partners to provide employment services. The social partners expressed conflicting opinions about this legislation. Employers' associations such as Confindustria, not surprisingly, signalled broad approval, as did two of the three major trade union associations. The Communistled Cgil confederation was more cautious, however, with the result that negotiations about the law were protracted. Key arguments in negotiations within the commercial sector, for example, turned on the determination of wage increases and the degree of flexibility permitted within companies allied to this sector. As Eironline (2004: 6) records, 'the talks ... were long and difficult' and it appears that, although they ultimately produced agreement among the social partners, both wage levels and 'flexibility' continue to be regulated to a greater degree than is now the case elsewhere in the continental universe. The suggestion, of course, is that the intractable problems associated with the Italian economy combine with, and are compounded by, institutional, path dependent assumptions and practices in ways that prevent far-reaching labour market reform. While these factors would certainly hinder any attempt to impose the workfare-style solutions noted elsewhere, policies of this kind are not on the Italian agenda. The current issue is whether Italy can discover a satisfactory 'middle way', which combines HC approaches to activation and labour market flexibility with robust - and egalitarian - practices supported by the social partners that are capable of encouraging wider participation among all sections of the population and all regions of the country.

\section{The Netherlands}

In contrast to the Italian case, the Netherlands stands as an example of a regime that has reformed labour market policies better to meet the combination of changing global demands for more flexible patterns of employment and domestic pressures for labour market change arising from, for example, the rise in the numbers of women seeking work. With the Wassenar and subsequent agreements between the social partners effectively resolving hitherto divisive issues of macroeconomic strategy by the early 1990s, employers and trade unions have since worked together to reduce unemployment. Employers gave up their previous opposition 
to shorter working hours while the unions accepted flexible working time patterns and part-time working as a solution to worklessness. Moreover, both sides also accepted the need to develop active labour market policies (Hemerijck et al., 2000). Importantly, agreements have also been reached on key distributional issues such as levels of social security contributions, low wages and training.

These measures, initially helped by the global upswing in the mid-to-late 1980s, have resulted in a steady improvement in the Netherlands' economic and employment position. The gradual fall in the standardized unemployment rate to 4.5 per cent in 2004 was achieved in the context of strong economic growth, wage moderation and industrial peace, accompanied by a successful job creation strategy, which displayed a growing emphasis on paid work and ALMPs. Two points worth noting here are, first, the dramatic surge in female participation rates, particularly in part-time work (CEC, 2002d: 12; Visser, 2002; Zijl et al., 2002) and, second, the political decision to end the misuse of the disability benefits system, which had become a backdoor method of reducing labour supply that masked the true extent of unemployment (Hemerijck and van Kersbergen, 1997). Both factors, in their different ways, encouraged governments in the 1980s and 1990s to reduce traditional passive forms of insurance-based social protection in favour of greater attention to employment opportunities and active labour market policies in a context of increased 'citizen obligation' and employer responsibilities (the latter relating particularly to sickness and disability benefits). As van der Veen and Trommel (1999: 294) argue, a paradigm shift took place in the Dutch approach to social security in the early 1990s which 'can be typified as a reversal from thinking about social policy in terms of rights and duties to thinking about it in terms of incentives and disincentives'.

On the face of it, existing criteria for the payment of unemployment and social assistance benefits already included stringent conditions: the insured unemployed had to accept suitable employment and those receiving social assistance were expected actively to look for work, accept suitable jobs and so on. Before the mid1980s, however, these criteria were applied only loosely and much of what has happened over the past fifteen years has been a tightening of existing requirements for benefit receipt (Abrahamson and van Oorschot, 2002: 5). Nevertheless, a number of fundamental changes involving the stricter selection of recipients for unemployment benefits and tougher activating strategies have complemented the closer enforcement of conditions. Where social assistance is concerned, for example, all entitlements for individuals under 21 years of age were eradicated following the Social Assistance Act of 1996 - a move that built upon the 1992 Youth Employment Act (YEA) which removed the benefit entitlement of those aged between 18 and 22 and instead substituted minimum job rights (Spies and van Berkel, 2000; Lødemel, 2004). This focus on activation has sharpened in recent years. In 1998, following the creation of the EES, the YEA was merged with 'previously noncompulsory training and employment programmes for older long-term unemployed people through the Jobseeker's Employment Act (JEA)' (Spies and van Berkel, 2000: 105). According to research commissioned by the Dutch Ministry of Social Affairs and Employment (Zijl et al., 2002: 37), the JEA, which clearly echoes the 


\section{Labour market policies}

UK's Jobseekers' Allowance and associated New Deals, 'contains a comprehensive approach for the young unemployed' in that 'within six months they are offered a route leading to employment'. All those who become unemployed are offered guidance at an early stage and a range of opportunities - education, application courses and work experience - to enhance employability. Different pathways to work are available depending on distance from the labour market, skills and so on, these ranging from subsidized work opportunities with regular employers to municipal work placements, which can become permanent subsidized jobs for those deemed unable to proceed to employment in the open labour market.

It is clear, however, that these 'opportunities' are backed by an increasingly rigorous sanctions regime. Van der Veen and Trommel (1999: 304) point out that, from 1992, 'with respect to the choice of jobs, clients [were] no longer free to refuse work beneath their level of qualification', which indicates an initial tightening. However, the Social Assistance Act further increased job search obligations for benefit recipients - single mothers, for instance, are now expected to become active in the labour market when their children reach the age of five. Moreover, a further Act of 1996, the Law on Penalties and Measures, aimed to motivate those reluctant to work by intensifying 'the sanctioning policies of social security administrations', penalties now being 'nationally prescribed per type of misbehaviour and administrations [being] policed on their implementation' (Abrahamson and van Oorschot, 2002: 5). At the margin, Spies and van Berkel (2000: 123) suggest that a WF, workfare element has been introduced into Dutch employment policy. They locate this specifically in the subsidized employment offered particularly to young people by municipalities, arguing that many of the jobs on offer are 'second rate' and 'partly superfluous', and that this pathway is distinguished by a requirement to work rather than to be willing to work.

To appreciate the true significance of these changes to labour market policy, it is important to see them as part of a wider process of reform that has seen a marked reduction in public agencies' direct involvement with the unemployed. As Abrahamson and van Oorschot (2002: 3) argue, 'only few activation measures are aimed at the unemployed individuals themselves', the majority involve a range of initiatives including payroll tax reductions and wage subsidies for employers designed to encourage them to take on unemployed (particularly long-term unemployed) people. In addition to these measures, the Netherlands has mirrored recent shifts in the delivery of services to the unemployed developed in the United Kingdom and Australia. In the same manner as these liberal regimes, the role of the PES is being redefined and public employment agencies are gradually withdrawing from frontline 'service delivery', the work placement function in particular being decentralized and made 'contestable' - that is, taken over by competitive, private sector provision. Paradoxically, however, decentralization and privatization are accompanied by an increased level of central state control and surveillance, which has led some observers to characterize the Dutch system as one of 'managed liberalism' (van der Veen and Trommel, 1999: 309). Unquestionably, too, the administrative role of the social partners has been reduced following the abolition of the old corporatist industrial insurance boards, although they continue to play 
a role in the Central Employment Board, which oversees the running of the PES (Finn, 2000: 51-2). The main obective, as Finn (2000: 52) states, is for central government to consolidate "patterns of cooperation and partnership ... through the "Jobs and Income Collaboration Project", which requires the PES to enter into agreements with the municipalities and insurance organizations'. The aim is to develop 'a "one counter system", creating a national network of "Centres for Work and Income"'. Of course, much of the administration of the system is carried out at municipal level with local authorities charged with the task of developing and purchasing the services they deem necessary to supply coherent and flexible forms of provision for the unemployed. 'Supply' itself comes increasingly from private companies, which, by 2000, were responsible for 15 per cent of 38,000 'routes' towards work started by unemployed adults (Zijl et al., 2002: 37).

Whether these reforms to Dutch employment policy can be described as effective is not the point here. To be sure, just as in the cases of Denmark and Sweden considered below, there are signs that the 'activation' element per se is no panacea for reducing unemployment, much depending on the type of activation in question (see Sianesi, 2002: 25-6). Van Oorschot (2002: 412) has observed, for example, that the 'Dutch miracle' of strong job growth and falling unemployment in fact 'contains less employment growth than suggested by the number of people in paid work, and it conceals a high degree of hidden unemployment'. Activation remains of key significance, however. Supported by a clear stress on 'obligation' and a range of measures directed towards encouraging employers to play their part in the new world of flexible, part-time employment, it symbolizes the palpable shift in Dutch policy away from its traditional corporatist roots. In some ways these reforms echo the Danish case, where there has been a marked change in favour of activation, although the balance between the HC and WF perspectives in Dutch policies has tilted further in favour of the latter.

\section{Social democratic regimes}

Changing labour market policies in both Denmark and Sweden demonstrate a shift towards activation in the former case and a tightening of existing practices in the latter. The Danish case provides a clearer example of neoliberal drift, partly because activation has been used directly to combat the increasing difficulties associated with passive labour market policies. In Sweden, of course, ALMPs have always been a feature of labour market policy, but there has nevertheless been a 'refocusing' around a tougher interpretation of 'activation' in recent years.

\section{Denmark}

As Rosdahl and Weise (2000: 159) make clear, high unemployment in Denmark during the 1980s and early 1990s meant that large numbers of people of working age were receiving state assistance in the form of unemployment benefit, sickness benefit, social assistance of early retirement pension, which contributed to high levels of social spending. Indeed, between the early 1960s and the mid-1990s, 'the 


\section{Labour market policies}

number of people receiving these benefits consistently increased alongside high and increasing unemployment' - the total reaching 13 per cent in 1994. Although Conservative-Liberal governments had made some efforts to reduce spending on 'passive' benefits for the unemployed - mainly by reducing benefit levels for the young unemployed - in the late 1980 s, the unemployment benefit system with its generous, tax-financed, 'passive' provision was left largely untouched. Goul Andersen (2002b: 66) has commented, for instance, that

access was easy, since only one year of membership and six consecutive months of (normal) employment was required to achieve full entitlements. Duration was very long (some 8.5 years) because entitlements to 2.5 years of unemployment benefits could be prolonged twice for another 2.5 years if the individual took part in a job programme. The compensation level of 90 per cent, which is very favourable to low-income groups ... was maintained [and] the works test appears to have been rather liberal.

The point, as many observers note, is that the Danish system offered little incentive to seek work at a time when it was becoming clear that employers' demands for greater flexibility and productivity were potentially being undermined by traditional passive-protectionist measures.

In response, the Social Democratic coalition government that came to power in 1992 embarked on a range of initiatives that saw a tightening of eligibility rules for benefit receipt combined with much greater attention to an 'active line' designed to enhance labour market participation. These new measures had their origin in the report of the Labour-market Commission - the Zeuthen Report - set up by the Conservative coalition before it left office, the stress on activation being progressively increased in line with further recommendations from the Social Commission, and particularly the Welfare Commission, during the 1990s. The Zeuthen Report recommended that the skills and qualifications of employed and unemployed alike needed to be raised to match the changing demands of the marketplace, in addition to other reforms to the unemployment benefit system. It was particularly influential because 'the representation of the central labour-market organizations ... served to legitimize the conclusions and recommendations' (Torfing, 1999: 14). Prefiguring the EES by some years, the Labour Market Reform Act of 1993, according to Torfing (1999: 15) 'constitutes a decisive break with the passive safety-net model, not because it lowered the generous unemployment benefits, but because it implied a much more aggressive attempt to get people back into the labour market'. In this regard, the training programmes, employment projects and so on, which had been part of Danish labour market policy at least since the 1970s, were not only transformed and enhanced, but increasingly came to be understood less as a social right than as a duty.

Goul Andersen sees this emphasis on duty developing in three phases. First, the maximum unemployment period of seven years included an activation phase for the final three years - not in itself particularly demanding because, as Goul Andersen (2002b: 70) acknowledges, 'seven years is a long time and it took only 26 
weeks of ordinary employment to become entitled to another seven-year period'. However, the 1993 Act required that all the long-term unemployed should have an individual plan of activation developed with the support of their local employment office and tailored to individual needs and abilities, and this 'social right' increasingly became a duty in subsequent phases. Indeed, the second stage of reform, commencing in 1996, saw the unemployment period cut to five years with a 'right and duty' to activation after two and eligibility to benefit now requiring a 52-week period of ordinary employment. Furthermore, the activation policy was also applied to those receiving social assistance and penalties could be imposed where offers of work were rejected: for example, in cases where an unemployed person rejects a fair offer of activation a month's benefit would be forfeited. This phase also included the introduction of youth measures which gave those under the age of 25 with no formal training or education a 'right and duty' to an 18months training course after six months of unemployment. Finally, from 1999, following negotiations with trade unions and employers' associations, the unemployment period was cut to four years, 'consisting of a one-year benefit period with the possibility of activation according to a regional needs assessment and a three-year activation period with a right and duty to enter labour market programmes involving up to full-time participation during the entire period' (Maerkedahl, 2000: 265). Where those under 25-years-old were concerned, the initial benefit period was six months, with a 'right and duty' to a three-and-a-half year activation period thereafter, irrespective of whether the individuals involved had received formal training or education.

What principles underpinned these changes? In one sense, as Torfing (1999) notes, successive reforms during the 1990s introduced elements of Bob Jessop's (1994) 'Schumpeterian Workfare State' into the Danish welfare regime, with the neoliberal connotations that accompany this supply side model. Indeed, the growing stress on duty together with the fact that individuals who rejected offers of work or training could face benefit withdrawal was suggestive of the increasingly rigorous treatment of the unemployed according to WF principles in the USA. According to Maerkedahl (2000: 264), however, the governing principles of the new ALMP were less focused on workfare per se than on other objectives more typical of the inclusive nature of the Danish welfare regime. The fact that activation plans are tailored to individual needs, for example, frequently containing an education or training element designed to enhance opportunities of future employment suggests a concern about social integration which corresponds better to the HC than to the WF model. Significantly, too, the involvement of the social partners in the fourteen regional labour market councils and the National Labour Market Council is indicative of the negotiated, consensual nature of Danish labour market policy. This approach is also visible in the recent creation of Local Committees for Preventive Labour Market Measures. These 'coordination committees' involve social partners and non-state actors, together with municipalities, in the development of 'socially targeted employment activities' (Ploug, 2002a: 54), the point being to widen the ambit of activation policies to embrace a true 'social policy' dimension by including those on social assistance. So, as Torfing (1999: 17) 


\section{Labour market policies}

puts it, Danish ALMP has not concentrated on the typical workfarist 'solutions' of benefit or wage reductions, but has focused instead on improving skills and the work experience of the unemployed, and thus stressed education and training as opposed to work-for-benefit, in order to develop 'empowerment rather than control and punishment'. In short, while there is undoubtedly an ever-stronger emphasis on the duty to work, this has to be set alongside Denmark's continuing commitment to generous levels of 'passive' spending and the 'communitarian notion of work as the core of citizenship and social integration' (Goul Andersen, 2002b: 71).

Outside the focus on ALMPs, surely the core feature of Danish labour market policy, Danish governments also introduced complementary reforms in the 1990s designed to increase participation rates in other ways. If Denmark is not especially defined by the move to part-time working as a means of increasing participation, as has happened in the Netherlands for example (Ploug, 2002b: 47-8), there has been a concerted attempt to offer incentives to stay at work for 60-year-olds - a group not significantly affected by activation policies. In 1999 new rules governing retirement were introduced which made early retirement a less attractive option. Ploug (2002b: 19) notes that now 'there are clear incentives to postpone early retirement at least to the age of 62 ', with a tax free premium calculated according to the number of hours worked being payable to those who decide to postpone the end of their working life still further. Another aspect of Danish governments' efforts to create an inclusive labour market with high participation rates is the high level of female employment, which already comfortably exceeds the Luxembourg benchmark for 2010 (CEC, 2001: 46). While a gender gap persists where wages are concerned, as well as in the stark pattern of vertical and horizontal job segregation, Denmark follows Sweden in its commitment to high employment rates regardless of gender.

Nevertheless, this principle of employment being a core citizenship 'right and duty' needs to be set against two further features of labour market policy which could, in time, compromise the apparently solidaristic nature of Danish labour market policy. First, although the tax system is not used as a central policy tool, employers' social contributions are low and company taxes were reduced in 2001. Employers therefore do not have to contend with the prospect of high labour costs in their calculations about the size of their workforce, which, while it encourages employment, will also encourage flexibility. Second, this stimulus to labour market flexibility needs to be understood in the context of the low levels of employment protection in Denmark. Taking account of the 2005 general election result, it is possible that the balance struck in the 1990s between a liberal, flexibilized employment structure and policies that continue to stress social solidarity may be beginning to tip in favour of the former. Significantly, during the 2005 election campaign, trade unions voiced fears about the impact of 'globalization' on Danish employment levels and the need for stronger labour market measures relating to better training, employment opportunities and job protection. Their concerns may be justified: as Eironline (2005: 2) reports,

in 2004, more than one enterprise per month on average moved a location in Denmark with more than 100 employees to a low-paid country outside Europe 
or to another of the group's undertakings in another European country, typically the eastern European countries.

It is a possibility, however, that with immigration issues playing a pivotal role in the election campaign, the returning Liberal-Conservative government will maintain the liberal drift of labour market policies while using restrictions on immigration to protect 'Danish jobs'. The new coalition depends for its overall majority on the anti-immigration Danish People's Party, which increased its vote in February 2005, so the recent trend towards much tougher controls seems set to continue.

\section{Sreden}

ALMPs have a long history in Sweden, dating originally from the public works programmes of the 1930s. In the postwar period, labour market policies have been administered by a semi-autonomous board - Arbetsmarknadsstyrelsen (AMS) - founded in 1948 and consisting of representatives from trade unions and business. The modern version of active labour market measures originated in the 1950s with the Rehn-Meidner model. This model aimed to combine tight monetary and fiscal policies, and a solidaristic wages policy with an ALMP that would help to reduce structural unemployment by increasing labour and skills mobility among companies and regions, and acting counter-cyclically to maintain full employment during economic downturns (Benner and Vad, 2000; Gould, 2001; Huber and Stephens, 2001). In its initial stages, the main objective of Swedish labour market policy was the limited one of ensuring a high level of labour mobility, albeit at the price of 'individual hardship for workers forced to move, undergo retraining or "volunteer" for early retirement' (Esping-Andersen, 1985: 231). However, what Calmfors et al. (2002: 4) refer to as 'generally rising ambitions in employment policy' resulted in the use of ALMPs to hold down open unemployment during recessions. In this sense, ALMPs in Sweden gradually came to be treated as measures of social integration rather than purely as economic tools to ease pressures in the labour market.

In retrospect, the 'Swedish model' as originally conceived by Rehn and Meidner had barely begun to function as planned before it encountered the economic crises of the 1970s. Since that time it has proved increasingly difficult to maintain full employment and universalistic welfare provision in the context of an open economy dependent on multinational corporations and thus vulnerable to global economic fluctuations. Initially, before Sweden opted for a hard currency policy prior to joining the European Union, governments had maintained economic stability through successive currency devaluations, which kept Swedish industry notionally competitive and employment levels high. However, although this option, in conjunction with efforts to contain public spending and wages during the early and mid-1980s, proved fairly successful in the short term, it masked a number of problems including Swedish industry's increasing uncompetitiveness and the imbalance of employment between the public and private sectors. This latter factor refers to the dramatic growth of public sector employment in the late 1970s and early 1980s, which was not only costly but also altered the operation of the collective 


\section{Labour market policies}

bargaining system as sheltered public sector unions sought settlements that 'undermined the flexibility of real wages that had characterized Swedish wage politics in the 1960s and 1970s' (Wood, 2001: 401). As mentioned in Chapter Three, by the early 1990s Sweden was confronted by an overweening public sector, rising wages, weakening competitiveness and declining exports as private firms began to make the most of the opportunities afforded by financial liberalization and invested abroad. With growth declining, open unemployment rose to 8 per cent of the labour force - a figure which virtually can be doubled if those on active labour market schemes are included. As Clayton and Pontusson (1998: 77) point out, this level of unemployment threatened the foundations of Swedish welfare universalism, which 'in large measure ... derived from the universalism of employment in Sweden', because of the ineligibility for certain key contributory benefits (e.g. sickness benefits) that lack of work entails.

Unlike Danish governments, Swedish politicians did not overstress activation during the unemployment crisis of the early 1990s - indeed, as unemployment rose through 1990, numbers on ALMPs actually fell in relation to 1989 levels. Following the employers' disengagement from AMS in 1991, the Bourgeois government (1991-4) paid little attention to ALMPs as a solution to the crisis, preferring instead to concentrate on containing the generosity of passive measures, where expenditure was rising rapidly, by cutting employers' insurance contributions and replacement rates for unemployment insurance, as well as introducing more rigorous eligibility criteria for unemployment benefits. At this point, according to Gould (2001: 142), 'fears were ... expressed about whether AMS could continue to perform an effective role'. On their return to power in 1994, the Social Democrats responded to these anxieties by using ALMPs to provide programmes for the young, the hardto-employ and the rising numbers of long-term unemployed. A 1995 proposal, $A$ More Effective Labour Market Policy, stated that labour market measures should primarily be targeted at the long-term unemployed 'and other vulnerable groups' such as immigrants and refugees (quoted in Gould, 2001: 145). Meanwhile, more expensive AMS schemes such as labour market training were contracted out to private or municipal providers and 'new cheaper schemes such as Ungdomspraktik (Youth Training) and ALU (Working Life Introduction) were introduced and expanded' (Gould, 2001: 142). After 1995, the municipalities were given a greater role in provision for the young unemployed, with Youth Training being replaced by Working Place Introduction (API). Active provision was further extended for the long-term unemployed, who were provided for by both AMS and municipal support. The municipalities now had the ability to use AMS resources to remove individuals from social assistance into labour market programmes (Gould, 2001: 143-5) - something they welcomed because it eased the pressure on their social assistance budgets caused by unemployment.

These changes introduced an approach to activation that, over a period of time, reinforced arbetslinje or the 'work line'. The abolition of both relief work and the two work practice schemes - ALU and API - in 1998, alongside the continuation of labour market training, support for the self-employed and a new emphasis on ICT training can be seen as measures designed to make LMPs more efficient and 
increasingly 'employment oriented'. Finally, the last five years have seen greater attention being paid to individual advice and guidance for the unemployed with a view to increasing the chance of effective work opportunities. Of particular importance here is the 'activity guarantee', targeted at those in danger of becoming longterm unemployed. As Levy (2004) comments (see also Bjorklund, 2000), one of the weaknesses of the Swedish system lay in the fact that the unemployed could claim unemployment benefits on virtually a permanent basis owing to the fact that six months attendance on a training programme entitled them to a further two years' benefits. The activity guarantee broke this cycle by requiring claimants after their first 100 days of unemployment to be 'active' for eight hours a day 'with "activity" defined as a job, a training programme, a public internship or some other kind of structured routine outside the home' (Levy, 2004: 202). A further effect of the guarantee has been to energize not only the unemployed but the authorities who now are required to monitor the activities of unemployed people more closely. One consequence, as Levy (2004: 202) notes, has been that 'claimants can no longer receive unemployment benefits while holding a job under the table, since they must account for their actions eight hours a day'. He goes on to state that 'recent Swedish statistics reveal a sharp drop-off in the unemployment rolls at the 100-day mark'.

The use of ALMPs during the 1990s is interesting. There was a considerable turnover of initiatives within the general framework of schemes either run directly by, or contracted through, the AMS. As Calmfors et al. (2002: 6) make clear, with the exception of labour market training, 'all other programmes have either been instituted during the period and/or ended during it'. If there is a good deal of debate about the effectiveness of these programmes (Calmfors et al., 2002; Kvist, 2002; Plougmann and Madsen 2002; Sianesi, 2002), the main object here is to understand the 'direction' that active labour market measures have taken. Are Swedish ALMPs moving towards the 'workfare' solutions, or do they retain a more Scandinavian, social democratic character typically associated with the human capital model, albeit in more challenging economic circumstances?

There is little evidence of any wholesale endorsement of the kind of US-style workfare policies discussed in the last chapter. Indeed, Plougmann and Madsen (2002: 14) have even commented that 'during the 1990s policy makers of Denmark and Sweden were locked into the universal welfare state regime and made no serious attempt to follow ... OECD recommendations [i.e. towards greater flexibility]'. In general, Swedish activation measures in the 1990s were aimed primarily at the young and long-term unemployed, and maintained continuity not so much with the initial objectives of the Rhen-Meidner model - the facilitation of employment and skills mobility - but those goals subsequently applied to it, which focused on maintaining the connection with employment as a means of offsetting the costs of Sweden's generous passive unemployment benefits. Within this focus it is clear that ALMPs have shifted from mass training programmes towards individualized strategies for training and employment, which are more rigorous in their demands on the unemployed. As Calmfors et al. (2002: 4) note, 'by making payment of unemployment compensation conditional on accepting 


\section{Labour market policies}

regular job offers or placement offers in ALMPs from public employment offices, active labour market policy has been used as a work test for the recipients of unemployment compensation'. While this 'test' carries none of the conservative moral rhetoric associated with the dangers of 'welfare dependency', which characterizes welfare-to-work programmes in liberal regimes, the Swedish regime has been tightened accordingly, albeit within an HC-led approach.

So the system itself has not been significantly transformed, but it is worth noting that the changes have nevertheless dented the generous image of Sweden's universalist welfare state. In addition, the greater incidence of decentralization and particularly the contracting out of certain labour market programmes to private providers is further evidence of this trend. On the other hand, unlike Denmark, where employment protection legislation has been relaxed considerably, Swedish governments have broadly retained the country's strict legislation bending only a little, in 1996, to allow a new form of employment which permitted employers to take on individuals for between one month and a year with the option of terminating the contract at that point or taking them on permanently (Gould, 2001: 150). While this approach to employment protection can have negative consequences for employment levels and thus place additional pressure on labour market policies, there is no evidence of a general desire to 'flexibilize' the labour market. In fact, Swedish employment rates rose in the late 1990s, although they have fallen back recently, with open unemployment currently standing at 5.8 per cent (a further 121,000 people are engaged in labour market programmes - Swedish Bureau of Statistics, 2004). There is nothing here, then, to indicate a retreat from social democratic principles as these have been understood by Swedish governments in fact, as Kvist (2002) and others (Hvinden et al., 2001) acknowledge, it is the case that the changes discussed above have not led to any significant departure from the Nordic ideal type. To date, then, changes have been ones of incremental adjustment - the abiding image being the continued commitment to full employment as a key force for social integration and 'welfare', as well as economic prosperity. Even so, the direction of adjustment is worth noting. Drøpping et al. (1999: 157) refer to a 'new direction in Nordic policy discourse', while Plougmann and Madsen (2002: 4) write of 'rational political adjustments aimed at adapting the social institutions to the new global economic and social conditions of the 21 st century'. Underscoring

both comments is the shift of policy focus towards the duty to work - and of course this represents a turn, however nascent, in a 'liberal' direction, which could act as a precedent in time to come.

The Italian case apart, this discussion of changes to labour market policy in social and continental regimes indicates that these countries are beginning, however slowly, to lean towards neoliberal or 'market-led' outcomes. It is important to be cautious about generalizations of this kind, however, and clearly there are significant differences among the regimes considered here in terms of historical context, institutional environment and consequently the manner in which budgetary constraints are perceived and managed. If labour market policies in Germany and France are changing, the process is by no means smooth - and, in view of its 
contested nature, it is perhaps not surprising to discover that the spread and application of new initiatives can be uneven. Social democratic Denmark and the continental Netherlands regime, both of which faced severe economic difficulties in the 1980s, have adjusted their labour market policies in a market-oriented direction - to the point where it is legitimate to ask how much further these processes can be taken before the solidaristic character of these regimes is seriously undermined. Sweden, meanwhile, has 'refocused' labour market policies to accommodate contemporary demands - the extent of 'drift' at this point, at least, being minimal. 


\section{Population ageing, GEPs and changing pensions systems}

Retirement pensions are at once the most 'national', 'institutionalized' and globalized of all areas of social policy - an assertion that this chapter and Chapter Seven will attempt to justify. The object here is to examine how pensions systems in different regimes are changing in response to a range of factors, exogenous and endogenous, the growing demands of which appear to be compromising the traditional, institutionalized bases of income security in later life.

Amongst the first pieces of social legislation in many cases, pensions systems emerged for a variety of reasons. In united Germany they were amongst the measures adopted by Bismarck to counteract growing socialist revolutionary fervour in the rising working class, in Sweden universal pensions were adopted in 1913 as a result of an alliance of convenience between poor farming and industrial workingclass interests (Baldwin, 1990). Again, in the USA, a form of old age pension for those (loosely) defined as veterans appeared in the wake of the Civil War (Skocpol, 1995: 52). Postwar systems extended protection in old age considerably further and more systematically. In their different ways, developed welfare states ensured that pensions did not simply protect special interest groups or mitigate poverty but, instead, 'defended the social standing attained in competitive labour markets' (Rieger and Leibfried, 2003: 76). Irrespective of the particular system, pensions provision extended well into the middle classes, with populations in many welfare regimes enjoying generous replacement rates as a result of earnings-related arrangements either directly provided, or regulated, by the state. These systems were indubitably national in so far as they evolved within national frameworks of welfare and usually built upon arrangements dating from the later nineteenth or early twentieth centuries (Flora and Heidenheimer, 1981; Baldwin, 1990).

In the contemporary world these systems, and the institutional structures and assumptions that underpin them, face at least three common challenges. First, the fact that populations are ageing across OECD countries is likely to have consequences for existing pensions provision because, in the absence of reform, costs will inevitably rise, thus placing additional pressure on social budgets and economic competitiveness. This issue will be discussed below, but whether or not the ageing problem is as significant as some believe, there is little doubt that this perceived 'crisis' has altered attitudes to pensions provision in all welfare regimes and stimulated efforts to find alternatives to traditional arrangements. Second, 
and rather differently, changing patterns of employment have challenged the fundamental assumption on which postwar pension systems in the great majority of OECD countries were based - that fully employed male breadwinners would be the contributors to public schemes, which would subsequently maintain both them and their spouses in retirement. As discussed in preceding chapters, labour markets have changed to the point where the fully and permanently employed male breadwinner is becoming an increasingly rare species. Women have entered employment in large numbers, unemployment continues at high levels in some countries and, of course, with the trend towards various forms of 'flexibilization', the nature of work itself has become increasingly diverse. Pensions arrangements in developed welfare systems certainly need to take account of those individuals, predominantly female but also members of minority ethnic populations, who lack a consistent employment record and, owing to the rising incidence of divorce and non-marriage, cannot be expected to rely on a spouse's contribution record to provide for them in later life.

The third challenge arises at the global level. Both demographic and labour market changes will involve extra costs in what are already the most expensive items on countries' social budgets (see Table 6.1). But, in an economic environment characterized by hard currency, anti-inflation policies and tight social spending, national governments are unwilling to relax their (often hard-won) restrictive macroeconomic policies, preferring instead to contemplate changes, which, in some cases, were unthinkable even a decade ago. Indeed these cost pressures have contributed to a growing recognition in certain regimes that pensions arrangements require radical reorganization rather than simple 'adjustment'. While it would be incorrect to attribute what in some instances is extensive institutional change to globalization in any direct manner, once again GEPs appear to set the parameters for national policy making. Moreover, where pensions are concerned, it is possible to go further and argue that, particularly in LMEs, the growing influence of large pensions funds is beginning to have a profound effect on the quality and extent of provision. As subsequent sections of this chapter discuss, with personal private and occupational arrangements growing in importance, the impact of pension fund resources on global financial flows is increasing. And, indeed, because what has

Table 6.1 Old age pension spending as a percentage of GDP in selected OECD countries, 2000

\begin{tabular}{lr}
\hline Australia & 3.0 \\
Denmark & 6.1 \\
France & 12.1 \\
Germany & 11.8 \\
Italy & 14.2 \\
The Netherlands & 5.2 \\
Sweden & 9.2 \\
UK & 4.3 \\
USA & 4.4
\end{tabular}

Source: adapted from Visco, 2001: 21 
come to be termed the 'Anglo-American model' of finance (Clark, 2003), with its in-built short-termism, individualized returns and antipathy to 'social contract', dominates the investment strategies of the large funds, these practices are beginning to infiltrate social and continental welfare regimes in ways that are starting to challenge existing fiscal-institutional arrangements (Reich, 2002; Clark, 2003).

The discussion in this chapter proceeds as follows. Arguments about the impact of population ageing on pension reform need to be considered in some detail. This factor more than any other is responsible for the current preoccupation among governments and global agencies like the OECD with the need to reorganize existing pensions arrangements. Following consideration of this issue, the implications of labour market changes will be noted more briefly before the discussion moves on to examine the changes currently occurring in the financial sector. Finally, changes to pensions arrangements in the three liberal states will be discussed, with developments in social and continental regimes being taken up in Chapter Seven.

\section{The debate about ageing}

\section{International institutions and pressures for change}

As Jackson (1998: 15) notes, concerns about population ageing and its social effects tend to rise and fall according to the pattern of demographic changes and economic conditions. There were two main periods during the twentieth century in which fears of a declining population came to the fore. The first occurred in the 1930s during the recession with anxiety focusing on the possibility that economic depression could worsen because of the dwindling demand resulting from slow population growth. Interest abated during the postwar years because the baby boom meant that 'the populations of developed countries were no longer ageing as quickly as had hitherto been expected [and] along with the rise in population growth came a rise in economic growth rates to unprecedented levels' Jackson, 1998: 15). Current concern about population trends, which constitutes the second, contemporary, period of interest began about twenty years ago and can be related directly to the uncontroversial fact that the baby boomers born in the late 1940s and 1950s are approaching retirement age (Gauthier, 1996). Crucially, the issue is not simply one of population ageing and lower mortality rates among older people, but of 'replacement'. Fertility rates that were declining in the first half of the century, but which were reversed in the years following the Second World War, have again resumed their downward trajectory, the effect being to increase old age dependency ratios (OADR) in the majority of OECD countries as the proportion of the working population declines in relation to those in retirement (Table 6.2).

As Christopher Pierson (2001: 91) puts it,

at its most primitive, the key argument in relation to ageing societies is that at some point in the next fifty years in all developed and many developing countries the costs of supporting a growing elderly population out of current production of a much smaller active workforce will place on the latter a burden which is either unsustainable or ... politically unacceptable. 
Table 6.2 Old age dependency ratios in selected OECD countries

\begin{tabular}{lrrrrrr}
\hline & 2000 & 2010 & 2020 & 2030 & 2040 & 2050 \\
\hline Australia* & 21.0 & - & 25.0 & - & 43.0 & 45.0 \\
Denmark & 24.1 & 27.6 & 33.7 & 39.2 & 44.5 & 41.9 \\
France & 27.2 & 28.1 & 35.9 & 44.0 & 50.0 & 50.8 \\
Germany & 26.0 & 32.9 & 36.3 & 46.7 & 54.7 & 53.9 \\
Italy & 28.8 & 33.8 & 39.7 & 49.2 & 63.9 & 66.8 \\
Netherlands & 21.9 & 24.6 & 32.6 & 41.5 & 48.1 & 44.9 \\
Sweden & 29.6 & 31.4 & 37.6 & 42.7 & 46.7 & 46.1 \\
UK & 26.4 & 26.9 & 32.0 & 40.2 & 47.0 & 46.1 \\
USA* & 22.0 & - & 28.0 & - & 38.0 & 38.0 \\
\hline
\end{tabular}

Source: adapted from Maré and Pennisi, 2003: 198.

Note: *estimates from OECD, $2001 \mathrm{~d}$ : 4.

With OADRs rising, the fear is that the variety of arrangements designed to increase security in old age and put in place by all the developed economies in the early postwar period cannot be sustained economically - one key anxiety being that the 'intergenerational contract' which underpins much welfare funding will collapse as those in employment attempt to protect their consumption patterns at the expense of the older generation. Details will be provided below, but suffice it to say for the moment that the great majority of state pension systems developed around 'payas-you-go' (PAYG) principles where the payments made by economically active generations (roughly those between 20 and 65 years of age), through general taxation and/or payroll taxes of one kind or other, furnished the pensions of those in retirement. The implicit 'bargain' was that these active cohorts would themselves be supported in later life by succeeding generations. In so far as international organizations such as the World Bank (1994) and OECD (1996, 1998b, 2000a) are warning of a looming 'crisis', their fears are based on the apparently incontrovertible fact that the contributions of a shrinking working population will be insufficient to sustain large numbers of economically inactive older people, together with the further observation that the costs of providing public support for the latter group will not only escalate, but, in doing so, will 'crowd out' private and voluntary alternatives to state-provided security in old age.

So far as the World Bank is concerned, the 'crisis' is already in full swing. Averting the Old Age Crisis (1994) argues that current forms of provision for older people are out of control and require immediate reform. Noting that the OADR is set to rise from 19 per cent in 1990 to 37 per cent in 2030 in the OECD as a whole and that in certain countries - Japan and Germany for example - the rise will be considerably greater than this average, the Bank has recommended reforms designed to ameliorate these looming difficulties. Perhaps not surprisingly, in view of the Bank's neoliberal leanings, the main suggestions for change focus on running down extensive PAYG systems in favour of a 'three-pillared' (or 'tiered') arrangement, which contains a mix of private and public provision. The first, 'public' pillar is comprised of a flat-rate means-tested element (effectively a safety net payment), paid for out of general taxation, and indexed to either wages or (preferably) prices. 
This pillar would be accompanied by a second that would be compulsory but 'occupational' (i.e. financed through recognized private pension funds) and also 'fully funded' through employers' and employees' contributions. Finally a third pillar would be voluntary, comprising the personal private pensions of those choosing, and able, to enhance their financial position for retirement.

These recommendations are largely echoed by the OECD, which has now published three significant reports on the ageing issue - one essentially speculative and exploratory (OECD, 1996), one programmatic and recommendatory (OECD, 1998b) and the final report assessing the policy progress so far made by OECD countries (OECD, 2000a). If the tone is milder than the World Bank's, the OECD is equally clear about the problem. Ageing in OECD Countries (OECD, 1996: 9) argues that time for action is short:

in many countries, a window of opportunity exists in which to address both short- and long-term policy goals in ways that are mutually reinforcing. Further, unless action is taken soon, problems are likely to be much worse after 2010 in most member countries as the heaviest effects of ageing populations begin to be felt.

Although the UK and Ireland are partial exceptions, and 'the seriousness of the problem varies from country to country depending on the timing and size of the demographic transition' (OECD, 1998b: 32), the OECD argues that all countries will experience a dramatic rise in public debt as a direct result of demands on old age pensions in ten to fifteen years time with potential knock-on effects on national saving rates and economic growth as large cohorts of older people draw down accumulated assets. The worst affected nations, according to this view, will be Japan and Germany, which face a 6 per cent decrease in fiscal balances by 2030, with Europe as a whole facing an average decline of 3 per cent.

The Organization's response to the problem is multi-faceted, requiring both short- and long-term measures. On the one hand, a general approach to 'active ageing' is recommended (OECD, 1998b: 14) in which 'a high degree of flexibility in how individuals and families choose to spend their time over life - in work, in learning, in leisure and in care-giving' is promoted. Public policy can foster active ageing by 'removing existing constraints on life-course flexibility' and, in particular, encouraging the adoption of policies such as lifelong learning or medical interventions 'that help people maintain autonomy as they grow older'. On the other hand, of course, specific recommendations for the reform of existing pensions systems are made, the emphasis being upon 'a mix of tax-and-transfer systems, funded systems, private savings and earnings' (OECD, 1998b: 19). The main objective is to bring contributions and expenditures on pensions into line - and certainly to reduce the significance of public PAYG arrangements in favour of fully funded occupational and private alternatives. Arguing that payments from 'first tier', publicly funded basic pensions do not have a significant impact on the incomes of the majority of retirees, who rely more heavily on either PAYG earnings related schemes or fully funded private and occupational pensions, perhaps 
supplemented by income from property and elsewhere, the OECD (1998b: 5861) recommends two specific measures. First, tax financed public pensions should be means tested so they can be targeted at those most in need and, second, PAYG systems should be shifted away from 'defined benefit' (DB) arrangements, where the retirement income remains fixed and the risk of varying rates of return to pension assets is borne by employers and/or the state, towards fully funded 'defined contribution' (DC) systems, where there is a strong link between an individual's pension contributions and subsequent level of provision. The latter approach transfers risk to the individual but, according to the OECD, can provide older employees with more flexibility over the timing of their retirement in addition to providing greater choice over how they might use their 'fund'. From the societal viewpoint, a shift to DC funding is considered to be a means of cutting back on incentives to early retirement in current public pensions systems, which certain European countries have explicitly used to combat unemployment, while also being consonant with the increased health of the 'young old'. On this latter point, the argument is that a retirement age of 65 no longer accords with the capacity of many older people to remain economically active. In addition, increased life expectancy rates suggest that retirement at 65 means that individuals now draw down their pensions for longer than preceding generations, thus adding to funding difficulties (Table 6.3).

Two further recommendations concern two rather different dimensions of change, but both are regarded as significant features of a fully developed approach to the ageing problem. First, the OECD perceives a need to strengthen the financial market infrastructure with a view to ensuring that regulatory reforms give pension funds greater choice in asset portfolio management and thus provide support for growing numbers of fully funded private pension schemes (or schemes that have come to include an element of 'partial funding'). Although the assets held by pension funds (shown as a percentage of GDP in Table 6.4) have grown considerably over the past decade or so, the OECD (2000a: 74) believes that the continuing 'low level of assets to GDP in some countries is a good indication of the scope for further growth of pension fund assets in ageing countries with relatively underdeveloped pre-funded systems'. The issue is particularly important for those who favour occupational and personal private arrangements. They argue that private solutions of this kind need to make up a much greater proportion of pension funding because the better management of funds, in terms of both beneficiaries' rights and the financial security of the schemes themselves, can not only be expected to improve fund performance but also might be required to protect savings ratios as the baby boom generation begins to sell off its financial assets. These issues will be taken up below.

Second, the OECD recognizes that ageing populations present major challenges to health and social care systems, arguing that health problems tend to increase markedly after the age of 75 with 'a constant period of disability of about two to four years on average [to be] expected' in the final stage of life (OECD, 1998b: 90). Health care expenditures are predicted to increase when the baby boom generation hits the 'fourth age', with expenditure on long-term nursing care, for 
132 Population ageing, GEPs and changing pensions systems

Table 6.3 Life expectancy at birth (years) in selected OECD countries

\begin{tabular}{lcc}
\hline & $1970-5$ & $2000-5$ \\
\hline Australia & 71.7 & 79.2 \\
Denmark & 73.6 & 76.6 \\
France & 72.4 & 79.0 \\
Germany & 71.0 & 78.3 \\
Italy & 72.1 & 78.7 \\
Netherlands & 74.0 & 78.3 \\
Sweden & 74.7 & 80.1 \\
UK & 72.0 & 78.2 \\
USA & 71.5 & 77.1 \\
\hline
\end{tabular}

Source: adapted from UN Human Development Report, 2004.

Table 6.4 Pension fund assets as a percentage of GDP in selected OECD countries

\begin{tabular}{lcc}
\hline & 1990 & 1998 \\
\hline Australia & 17.0 & 55.4 \\
Denmark & 14.6 & 21.5 \\
France & - & $6.0^{*}$ \\
Germany & 3.1 & 3.3 \\
Italy & 3.5 & 3.2 \\
Netherlands & 81.0 & 85.6 \\
Sweden & 1.7 & $2.7 *$ \\
UK & 55.0 & 83.7 \\
USA & 44.9 & 86.4 \\
\hline
\end{tabular}

Source: OECD, 2000a: 74 .

Note: * 1997.

example, set to increase by 50 per cent. The challenges are complex, however, as countries struggle to balance trends towards deinstitutionalization and community care, frequently driven by cost considerations, with demands from informal carers - mainly women - for adequate remuneration and recognition of the high personal opportunity costs particularly in terms of paid employment. Reforms differ markedly from country to country, but the OECD again stresses a mix of public, private and informal solutions in the context of closer coordination between health and long-term care agencies, and a decentralization of responsibility for service provision.

\section{An ageing crisis?}

The ageing crisis identified by the World Bank and the OECD is, unsurprisingly, the subject of some dispute, with debate falling broadly into three parts. First, there is an extensive demographic literature which addresses the ageing issue, with some observers (Gee, 2000; Wilson, 2000) challenging the more dramatic elements 
of the time bomb theory. While this theme is plainly important - and some consideration will be given to it here - it is not a central focus of the present discussion. Of the two remaining positions, the first relates to those who are not only critical of the ageing thesis, but (consequently) critical of many of the recommendations for pension reform advanced by the World Bank and the OECD. A key element of dispute concerns the reasoning behind recommended moves away from PAYG systems and arguments about the drawbacks of alternative forms of pension financing (Barr, 2003). Finally - and most relevant for present purposes - a further literature largely accepts that there is indeed an 'ageing problem' of some kind, but is more concerned with how welfare regimes are dealing with it in terms of policy change. This perspective is mainly interested in the politics of pension reform and its impact on welfare regimes.

Such is the weight of official and academic interest in the 'problem' of population ageing that it is worth briefly examining the basis of the issue in a little more detail. While there is no doubt that populations in Western nations are growing older, primarily as a result of declining fertility rates but also declining mortality rates among older people, there is some doubt about the severity of the problem. Debate tends to focus on the nature of the indicators used to estimate the scale and impact of demographic change. For, example, although the World Bank and the OECD make much use of OADRs, there is reason to be cautious about this method of measurement. Jackson (1998: 19) argues that the notion of 'dependency' is complex and certainly not unique to old people - indeed 'old age is neither a necessary nor a sufficient condition for being physically dependent'. Rather than being an 'objective' measurement, OADRs are socially constructed because they are artefacts of statutory retirement ages as opposed to 'measuring' a physical incapacity to work. If retirement ages were raised in OECD nations, OADRs would decline accordingly - and vice versa. A further factor is the apparent assumption that the two populations measured by OADRs - those between 20 and 66 and those aged 66 and over - are either fully employed, in the case of the former group, or completely inactive, in the case of the latter. Current unemployment levels across the OECD gives the lie to the idea that all those who should be economically active actually are so, while the suggestion that those over 65 are inactive ignores not only the fact that some individuals continue in formal employment past that age, but that many important informal activities are carried out by older people which could usefully be viewed as economically productive. In this regard, Gee's (2000: 11-12) comments that 'an elderly woman who is the primary care giver for an ill husband, a homemaker, and a volunteer worker at a local arts organization is considered to be dependant/non-provider/economic drain [or that] an elderly woman who looks after her grandchildren two or three days a week so that her daughter can profitably work outside the home, is considered a dependant', clearly suggest that there is more to the notion of 'dependence' than OADRs take into account.

If the construction and use of OADRs is problematic, long-term projections about the likely demographic structures of OECD countries in 2030 are equally so. Bonoli (2000: 16) notes that World Bank and OECD population projections 


\section{Population ageing, GEPs and changing pensions systems}

assume that fertility rates will remain constant until 2005 and that they will then increase and converge in 2030, but argues that these rates may be more volatile than expected. Recent fluctuations in fertility rates in the Nordic countries, particularly Sweden, seem to relate to contingent factors like family-friendly social policies, which could be positively related to higher rates in the early 1990s, and economic recession along with the retrenchment of welfare provision, which could be a possible reason for the falling rates of recent years. As Bonoli (2000: 17) makes clear, population projections to about 2015 are relatively reliable because 'the ratio between the above-retirement-age population and the working-age population is not going to be affected by changes in fertility for the next fifteen to twenty years'; beyond this date, however, they become less useful.

These points are important because, as the World Bank and OECD literature indicates, OADRs and long-term population projections make up the core basis of the argument for a restructuring of pensions systems. However, even if these figures turn out to be more accurate than some believe, other factors in addition to these strictly demographic variables need to be considered. Changes in labour force participation rates (LFPR) and levels of economic growth may be significant, for instance, because they directly impinge on the amount of resources available for transfer to an ageing generation. Indeed, the international agencies' case for a move away from public PAYG systems to fully funded arrangements is based on assumptions that worsening age profiles in developed economies will be accompanied by LFPRs that remain constant at 2000 levels and growth rates that increase at an average of 1.5 per cent per annum. Their argument is that low participation and low growth will not provide working populations with sufficient employment and incomes, or governments with sufficient political support, to raise taxes and/ or insurance contributions to ensure adequate pensions as OADRs rise. These projections might be over-pessimistic, however. For one thing, they are firmly grounded in prevailing assumptions about balanced budgets - although some analysts maintain that there is no overriding need for governments to balance specifically the pension budget at all (see Jackson (1998: 128). In any event, LFPRs will almost certainly rise as women continue to enter employment in increasing numbers and labour markets are likely to become tighter and better balanced in the wake of the baby boom generation's passing. If the gathering policy shift away from early retirement in certain countries is added to the mix, together with the possibility that greater numbers may choose to work past official retirement dates, the effect on predicted LFPRs could be substantial. It is worth pointing out in this respect that estimates of participation rates are sensitive to fairly small variations so, as Christopher Pierson (2001: 105) notes, 'the consequences of an aged dependency ratio of 3:1 will be quite different where the labour force participation of the 15-64 group is at 80 per cent rather than 60 per cent.'

Low growth is a more complex issue but in fact it is not clear that the OECD's estimated growth rates for the developed countries are particularly relevant to the ageing problem per se. Of greater import is the balance between state and nonstate provision in old age, and the degree of political willingness to sustain pension levels for ageing populations. For certain countries - the UK, for example - the 
maintenance of provision at present levels has not been considered particularly problematic from a fiscal standpoint because only a small percentage of public pensions are PAYG and earnings related, and the basic state pension is currently indexed to (low) inflation as opposed to wages. (Of course, these assumptions entirely ignore the social costs of this approach, which are discussed below.) In other cases - those with established social insurance systems, for instance - where pensions are PAYG earnings related and usually indexed to wages, a vicious circle can develop whereby low economic growth leads to lower wage growth, making it difficult to fund the (guaranteed) incomes of increasing numbers of pensioners and consequently necessitating higher income or payroll taxes, which in turn can lead to more unemployment, falling wages and so on. In this situation, as Chapter Seven makes clear, various forms of 'reorganization' may be required, running through the curtailment of early retirement options and/or the extension of the retirement age, to other measures such as channelling tax revenues into dedicated retirement savings. Whatever the precise policies chosen, however, the point is that future levels of spending on pensions are unlikely to be a function of economic growth alone. Indeed, as Fougère and Mérette (1999: 421-2) have suggested, population ageing could even change existing forms of economic behaviour in ways that offset the problem and contribute to growth.

These critical observations about the working assumptions behind the World Bank and OECD perspectives are not intended to imply that the ageing problem is insignificant. This is far from the case, but, as Bonoli (2000: 19) notes, projections 'are too uncertain to give a reliable measurement of the actual size of pension expenditure at any given time', which creates a difficult environment for governments and future pensioners alike. While it is true that pension spending will rise over the next thirty years in the majority of developed economies and that some countries will experience a noticeable impact on their public finances in the absence of significant reform, it may be as much the climate of uncertainty as the imminent explosion of the 'time bomb' to which governments are responding in their endeavours to alter existing pension arrangements. This general scenario is hardly a 'crisis', however, because countries are by no means lacking in policy options to offset the worst consequences of population ageing. The more interesting issues concern what steps different countries are taking to adjust existing pension arrangements, the potential politico-institutional barriers to these efforts and the ways in which GEPs work to restrict particular policy choices.

\section{GEPs in the pensions universe}

The various issues discussed above need to be understood in the light of GEPs for the simple reason that, pensions perhaps more than any other area of welfare, involve a tangible link between the sources and mechanisms of funding, and global financial markets. Inevitably, the basic distinction between LMEs and CMEs referred to in previous chapters is particularly relevant where pensions are concerned. In liberal economies, state pension entitlements tend to be universal but ungenerous with additional entitlements coming from a mixture of occupational 


\section{Population ageing, GEPs and changing pensions systems}

and personal private sources. Outside state provision, coverage can be patchy because employer-sponsored pensions are vulnerable for a number of reasons, discussed below. Provision for those in public sector occupations tends to be both more generous and more stable (because public sector occupational schemes are generally well funded) but many others, particularly those low income groups in the private sector, either do not - or cannot - save adequately for retirement. The result is marked inequalities in old age, with large numbers of pensioners living on inadequate state incomes and others with private and occupational pensions dependent on market fortunes. Social and continental CME systems, by contrast, are more generous in terms of replacement rates, which is not to say that they are superior in every respect. Whatever their precise arrangements, however, these European systems are increasingly encountering problems. In addition to the tighter macro-economic climate towards which GEPs have contributed, the push towards financial market integration in Europe, symbolized in this instance by the recent EU Pensions Directive, is beginning to impact upon the traditional financial practices associated with the social market model in the European Union. A recent verdict on the Directive concludes, for example, that 'the protection of employees about potential losses when transferring pensions savings to another member state [has] a low priority compared to internal market provisions which aimed at improving above all capital mobility' (Larsen and Daguerre, 2003: 45), while Clark (2003: 6) attributes this privileging of capital to 'the Anglo-American model of economy, finance and the welfare state [which] poses a serious threat to the perceived integrity of Continental European traditions'.

At the core of the Anglo-American model, so far as pensions are concerned, is the growing might of pension funds, which operate in a liberal financial environment characterized by short-termism and deregulation. Governments in liberal regimes have increasingly come to rely on the private sector to fund and resource desired growth in occupational and personal pensions, with the result that the financial assets resulting from 'how we pay for the maintenance of a large and growing proportion of the population as defined by a certain stage in life' (Minns, 2001: 33) have vastly increased. Minns (2001: 26) estimates that the total amount of worldwide pension assets in 2000 was over $\$ 12$ thousand billion $(£ 8.5$ thousand billion) amounting to almost 43 per cent of world GDP. This figure represents a significant proportion of the total capital invested in world financial markets and, with large pension funds investing as much as 30 per cent of their assets overseas, they are clearly deeply involved in international financial flows (Minns, 2001: 29). The main point is that

the pension/stock market model shifts a major responsibility for the production of pension and social security benefits onto the market, albeit underwritten by the state through tax subsidies. By doing so, it gives the financial institutions and capital markets ... greater influence over economic and social outcomes ...

(Minns 2001: 185). 
This influence can take the form of direct intervention by funds in the operations of other companies as described by Reich (2002: 80), with the threat of disinvestment or hostile takeovers being used as a means of ensuring that enterprises maximize share prices even if this entails job losses or relocating to countries with lower labour costs. But it can also take a different guise. As private arrangements of one kind or other come to be regarded as viable alternatives (or supplements) to state pensions, so the financial institutions involved exercise greater control over the future prospects of their policy-holders. Policy-holders find it difficult to counter this influence in an economic climate that has weakened the power of corporate interests like private sector trade unions, which used to monitor closely the behaviour of 'their' pension funds (Blackburn, 2003: 158). In addition, in something of a self-fulfilling prophecy, the desire for swift returns 'skews investment towards large companies' and, certainly in the USA and the UK over the past twenty years, away from 'companies that made things' (Blackburn, 2003: 184) - which contrasts with attitudes to investment and saving in many European countries.

This turn to the market initially appeared to deliver high returns in the bull years of the 1990s. However, recent stock market difficulties have led to considerable problems and many analysts have been forced to revisit the optimistic assumptions about the shift from public pensions arrangements to private alternatives. As John Thompson (2002: 2) states, 'since early 2000, the capital markets have been undergoing a serious reversal [and] the major equity exchanges have lost 35-50 per cent of their value while losses have been much larger on specialised "growth" exchanges where technology companies dominate'. The scale of reversal has not been helped by the fact that some companies took 'pensions holidays' during the boom years, while others, in an attempt to take advantage of bull market conditions to increase fund values, invested unwisely in high risk equities. Substantial underfunding has been the inevitable result. Unsurprisingly in these circumstances, there has been a quickening of a longer-term trend towards converting DB into DC schemes, thereby limiting future employer liability for poor market performance. A recent survey in the UK, for example, found that in 2002 'fewer than half of surveyed final salary schemes are still open to new members, and that a third of the sponsors of surveyed occupational schemes were reviewing arrangements' (Curry and O'Connell, 2002: 33). Well-known UK companies such as Sainsbury's, Marks and Spencer, HSBC, British Telecom and GlaxoSmithKline are closing their DB schemes to new employees in favour of DC plans. Furthermore, The Economist (25.9.03) has estimated that over 900,000 people have seen their DB plans closed down 'and their employers substantially reduce their contribution to the alternative (defined contribution) plan, sometimes by as much as half'. There are also growing numbers of companies which face pension shortfalls so large that they are closing their schemes and offering, at best, token coverage - with obvious results for those who rely upon them.

So, with many companies, including some in continental Europe as well as the UK and USA, closing DB occupational schemes, there is good reason to believe that the occupational solution offers no easy panacea for the future. This is not to say that occupational schemes are unviable, however. The point is that where these 
schemes are DC, they are likely to provide a lower value of pension than properly and responsibly managed DB schemes. This problem is related to liberal capitalism's endemic short-termism, the need for quick returns meaning that the investment strategies underlying DC schemes are not designed to guard effectively against long-range risks. As Blackburn (2003: 163) states, the funds focus on 'pooling risk among a cross-section of the population at a given point in time', with the result that individuals have 'flattened and foreshortened protection at a time when "event risk" and global turbulence are growing' (see generally Blackburn, 2003: 163). In contrast, well-managed DB schemes, particularly in the public sector, have not relied so heavily on investing in equities and have accumulated significant assets, which better places them to absorb future shocks.

If to these difficulties are added others created by the labour market changes of the past thirty years or so, the picture becomes more serious still. Blackburn (2003: 160) argues that the rise of 'short-term contracts and part-time employment [have] spread in ways that did not favour pensions coverage'. Many of those contributing to either occupational or personal schemes cannot afford to pay sufficient amounts to produce a viable income in retirement - and, particularly in the USA, there has been a tendency 'to dip into the fund between jobs'. Where personal schemes are concerned, these are markedly skewed towards better-off groups with an equally

distinct slant towards white men. These schemes can also be expensive because of the costs associated with product marketing, fund management and the constant need to track contribution histories. If factors such as these are placed in the context of the growing reluctance on the part of many governments to provide tax-financed or PAYG public pensions it is clear that governments need actively to manage the complex and diverse pressures with which they are faced. To understand how different regimes are dealing with the challenges currently confronting them it is necessary to turn to a more detailed account of each case. To what extent are embedded assumptions about 'security in old age' beginning to fragment as politicians attempt to alter existing arrangements? The remainder of this chapter will deal with liberal regimes, which are generally distinguished by their enthusiastic endorsement of occupational and personal private alternatives.

\section{Liberal systems}

Despite the obvious similarities in terms of coverage and generosity, the pension systems of liberal regimes are actually quite diverse. Referring to the USA and the UK, for instance, Paul Pierson (1994: 54) notes that, although these countries are often grouped together as liberal welfare states, 'they represent near opposites in pension development'. The late-nineteenth century veterans' pensions notwithstanding, Roosevelt's New Deal provided the USA with what is effectively a 'Bismarckian', contribution-based, earnings-related social insurance system - in addition to occupational and private provision. These arrangements contrast with the UK's state pension, which pays flat-rate benefits in return for flat-rate contributions, in addition to an array of voluntary occupational and personal private schemes. The differences are viewed as sufficiently marked by some 
observers to merit a new typology of pensions systems, which in contrast to EspingAndersen's regime typology, treats the USA as an example of the continental, social insurance model and the UK as a 'Beveridgean' system, lacking proper secondtier arrangements (Hinrichs, 2001). Dissimilarities should not be pushed too far, however. Both these systems are wary about placing too much reliance on the state as the guarantor of security in later life and, currently, both appear to be contemplating extensive reorganizations of their pension systems. Already possessing high degrees of private provision, the issue for governments on both sides of the Atlantic is not so much whether to push for further privatization, but what type of private provision to endorse. Interestingly, these difficulties are not mirrored in the Australian case. While Australia certainly stands as an example of significant market-oriented change, with its basic 'age pension' now being supplemented by a mandatory private superannuation scheme, the development of this policy and the institutional changes required for its implementation are quite different from its US and UK counterparts.

\section{The United States}

Retirement provision is the one area of social policy where the USA has, according to at least one observer, developed 'a truly "modern" welfare state' (Myles, 1989: 265). The US system is often referred to as a 'three-legged stool' comprising individual retirement savings, private pensions and 'Social Security' - the latter being the social insurance element of this three-tier structure. The Social Security programme dates to Roosevelt's Social Security Act of 1935, which took the first steps towards the creation of a universal earnings-related, PAYG social insurance system - Old-Age Survivors and Disability Insurance (OASDI) - designed to provide income security in old age. Although it took over thirty years to achieve a system sufficiently generous to provide replacement rates which compared favourably with continental systems, major benefit increases under the Johnson and Nixon administrations saw the income position of older people vastly improved. Myles (1989: 274) states, for example, that the result of these changes was 'a real increase in benefits (i.e. net of inflation) of 23 percent in just three years [while] of equal importance was the fact that ... legislation [in 1972] added indexing against inflation'.

Undoubtedly, Social Security is the 'foundation' component of the three tiers. The system covers 96 per cent of the workforce, is the major source of income for two-thirds of retired Americans and provides the sole source of income for nearly 30 per cent of those aged over sixty-five (Fleming quoted in Blackburn, 2003: 379). Even so, the scheme does not treat beneficiaries with complete equity, being distinctly gendered and racialized. O'Connor, et al. (1999: 115) note for instance, that 'over 99 per cent of male Social Security beneficiaries make claims as workercontributors' while, although the number of women only eligible for 'auxiliary' entitlement (i.e. through marriage) is falling, it remains the case that 'women's growing propensity to engage in paid labour is not yet reflected in individual entitlement to benefits'. Again, divorced women who have undertaken unpaid 
domestic labour and who consequently have limited work histories can lose significant amounts of benefit under the present system. Where minority ethnic groups are concerned, African Americans and Hispanics depend more heavily on Social Security as a source of income in old age than does the white population (Tanner, 2001), although these groups also receive lower levels of benefit owing to higher rates of unemployment and thus erratic contribution histories (Quadagno, 1994; Tanner, 2001). These factors are important because they bear upon the nature of proposed reforms discussed below.

The other tiers of the US system are considerably less universal than Social Security. Private pension coverage is not extensive, with 53 per cent of the workforce having no private pension and 32 per cent having no savings specifically set aside for retirement (Social Security Administration, 2004). Women enjoy less protection from private pensions and savings than do men, while retired members of the white population receive a greater proportion of retirement income from private pensions and savings than those from minority ethnic populations. Inevitably, too, those on lower incomes have much lower coverage than those with high earnings - Economic Policy Institute (2003) analysis of data from the March 2001 Current Population Survey indicating that 18 per cent of individuals in the poorest quintile had private pension coverage in 2000 compared to 73 per cent of those in the wealthiest quintile.

Although these patterns tell a familiar story with regard to the ways in which welfare regimes tend to treat marginal and minority groups, they are particularly prescient in the US case because these groups are likely to be amongst the most affected by the proposals for reforming retirement provision currently under consideration by the Bush administration. These proposals, considered below, are the latest of many attempts to reform Social Security over the past generation or so. The impetus for reform has changed over time, shifting from a preoccupation with cutting social spending and limiting budget deficits in the Reagan years (Pierson, 1994: 65-7) to a much more defined assault, on the part of many Republicans, against what is perceived as a dangerously egalitarian, anti-market retirement programme. Underpinning this critique is a genuine concern - shared by both political parties - that the Social Security system cannot survive without far-reaching reorganization. Although the rate of population ageing in the USA is not as dramatic as it is in some other countries, the looming prospect of a doubling of the retired population and the reduction of the OADR by a third over the next thirty years has concentrated minds and led to concerted efforts to produce reform proposals designed to curb Social Security spending without significantly reducing benefit levels and so damaging the most coherent 'leg' of the US system. The most commonly discussed reforms focus, first, on Social Security itself and, second, on private occupational pensions, with current recommendations strongly favouring the introduction of private individual accounts (IAs) within the Social Security system in addition to the strengthening of existing occupational provision outside it.

Owing to the extent of coverage, Social Security reform is currently a hot issue in the USA, with fears being expressed about the prospective rise in the numbers of older people as baby boomers retire. Penner (2002: 1) estimates that numbers 
of OASDI beneficiaries are set to rise by 65 per cent between 2010 and 2030, 'while the working population will rise less than 8 per cent'. Meanwhile, 'the number of taxpayers per beneficiary will fall from 3.4 in 2001 to 3.1 in 2010 and 2.1 in 2030'. Importantly, also, the system itself becomes more expensive year on year due, first, to the fact that Social Security benefits are linked to wage levels and, second, to increasing life expectancy. According to President Bush's bipartisan Commission on Strengthening Social Security (CSSS) (2001: 64) the fiscal problem will worsen considerably between 2016 and 2038 as tax revenues fail to compensate for the demands placed on the Social Security Trust Fund. Although this situation may be sustainable in the short term, because the Fund can redeem bonds to make up the shortfall (so long as the US Treasury is prepared either to borrow, tax or cut spending elsewhere to redeem them), forecasts suggest that the Fund will be exhausted by 2038.

These projections can be contested, of course, as can the policy lessons to be drawn from them. One issue is whether Trust Fund exhaustion in 2038, as opposed to 2075 , as originally forecast is really an issue. For one thing, the projection is based on a 1.5 per cent growth rate, which is on the low side, and, for another, the contribution increases built into it are comparatively low. As Blackburn (2003: 380) points out, 'even the 18 per cent payroll tax envisaged for 2075 would be slightly below the contribution paid by Swedish employees today'. Moreover, other policies, such as the extension of the retirement age, could also influence OADRs and contribute to a reduction of Social Security's benefit commitments. Nevertheless, there is little doubt that the tone of debate in the USA, particularly over the past decade, has not been about whether reforms should be implemented but rather about which measures to adopt. Straight cuts in benefits of the kind contemplated in the early years of the Reagan Presidency are no longer regarded as viable because there is no desire to stimulate the storm of public protest that ensured the failure of Reagan's proposals. Instead, argument turns on whether, as a matter of principle, the integrity of the system should be preserved - the implication being that reform should leave it as the leading (indeed only) instance of a 'solidaristic policy' in the US welfare universe - or whether Social Security should be reorganized on lines that reflect a greater market logic.

This debate is ongoing. During the 1990s, although Clinton seriously entertained the idea of giving Social Security a greater market orientation by allowing the Trust Fund to buy into equities, with the hope of boosting returns, this proposal was eventually dropped in the face of criticisms from the political right about potential state interference in the stock market. Ultimately, the Clinton-Gore position became one of 'Social Security first'. This approach was committed to protecting the 'investment' of contributors while relying on the (then) predicted ten-year budget surplus to underpin the programme (Blackburn, 2003: 390). Bolstered by a robust defence of the DB PAYGO approach by one-time World Bank Chief Economist, Joseph Stiglitz, the policy, had Gore been victorious in the 2000 Presidential election, would have been to use the surplus to 'pay down the Federal Debt' (Birnbaum quoted in Blackburn, 2003: 411) and then channel the resulting interest savings into the Social Security account. Such a strategy would 


\section{Population ageing, GEPs and changing pensions systems}

have been popular with trade unions and those in low paid employment who always stand to gain by the retention of long-range $\mathrm{DB}$ provision.

In the event, George Bush's first election victory put paid to this strategy, although it should be acknowledged that the rapid elimination of the budget surplus would anyway have had significant implications for its viability. To date, the three possible strategies for reform outlined by the CSSS are the only policy options under consideration. Unsurprisingly, in view of the strong pro-market make-up of the Commission, each of the proposals involves an element of 'privatization' in the form of IAs. In the Commission's view (Commission on Strengthening Social Security, 2001: 27), 'the Social Security system would be strengthened through personal accounts regardless of the level of benefits promised, and the level of revenues committed to, the Social Security system'. A core component of the reasoning here is the conviction that the 50 per cent of US households that currently save nothing each year, in addition to others who hold no appreciable financial assets, will effectively be forced to save at least something. Quoting a paper by Moore et al. (Commission on Strengthening Social Security, 2001: 28), the Commission states that individuals involved in trial programmes of IAs reported that this type of asset-building led to greater feelings of security. More important, perhaps, is the Commission's anti-DB bias, which approves of the conclusion reached by other researchers (see Commission on Strengthening Social Security, 2001: 29) that 'individuals with personal defined contribution accounts would voluntarily choose to save more than individuals with a defined benefit plan'. This feature is particularly significant bearing in mind that the CSSS wants Social Security reform to contribute to national saving - something which it believes can only come about through the introduction of IAs and not 'through the Social Secuity system as currently structured or through government investment of the trust fund in the stock market' (Commission on Strengthening Social Security, 2001: 29).

Despite the clear preference for Social Security reforms which incorporate IAs, no final decision has been taken about how to proceed. One reason for the apparent slowness, no doubt, is the simple enormity of the task of shifting such a deeply institutionalized system onto a different track. Social Security, after all, is the USA's one genuinely social programme that benefits the majority of citizens, however ungenerously, in ways that cannot be described as providing 'handouts' for the undeserving. In consequence, the programme has largely avoided head-on assaults of the kind that conservatives have launched at 'welfare'. Even so, it is unlikely that the US's neoliberal regime, particularly once conservative Republicans had increased their influence in Congress in the early 1990s and a conservative President was installed in the White House, would have baulked at radical reform had it not been for another factor that affected perceptions of the safety and stability of private occupational pension provision. Stock market decline in 2000-1 took much of the shine off optimistic predictions about the market's capacity to act as a partial substitute for stable PAYGO arrangements. More particularly, the collapse of Enron in December 2001, followed closely by the equally dramatic demise of Worldcom, focused the impact of market failure on the retirement prospects of 
individual employees in no uncertain terms. Enron employees, for instance, not only lost their jobs but also saw their 401 (k) DC occupational schemes, which had a significant percentage of contributions invested in Enron itself, collapse with the company. These individuals were left heavily dependent on Social Security.

While by no means all enthusiasm for occupational pensions has been dimmed as a result, the Enron debacle nevertheless points up the weaknesses in the arguments of those who advocated the extension of this form of retirement provision. The criticisms of 401 (k)s levelled by many observers (Minns, 2001; Blackburn, 2003; Gale and Orszag, 2003; ) are especially pertinent. They acknowledge that DC plans in general, including $401(\mathrm{k}) \mathrm{s}$ (the most popular DC schemes the take-up of which outstrips DB schemes), can provide a more flexible form of retirement provision, allowing employees to customize their arrangements with choice over contribution rates, some choice over where to invest, and the ability to decide when to withdraw funds and in what form to take the withdrawal (Gale and Orszag, 2003: 9). However, $401(\mathrm{k}) \mathrm{s}$ are also associated with lower accrual rates, the burden of risk attaching to the employee and low take-up among poorer groups of employees, and these difficulties require attention if occupational schemes are genuinely to complement Social Security provision.

These criticisms are telling - but, despite misgivings in some circles, occupational pensions will continue to be regarded as a core component of the pensions system. Meanwhile, Social Security is likely to be reformed in the direction of IAs even if the combination of institutional and market difficulties means that this move will have to be carried out with due regard to existing assumptions and expectations. Reform in this direction conforms to prevailing preferences for market solutions, despite the obvious risk that diverting resources into IAs will reduce revenues for the payroll tax system and so compromise existing Social Security benefit levels (Penner, 2002: 4). In this respect, Bush's key instruction to the CSSS that 'modernization must not change Social Security benefits for retirees or near-retirees' will help to ensure that the forces of popular dissent that undermined Reagan's proposals will have no compelling reason to oppose new reform proposals, the calculation apparently being that younger generations of workers - those who feel more at home in the individualized financial world of the 'new economy' - will baulk less at the proposed changes. As Reich (2002: 238) acknowledges, 'the old systems of social insurance were designed for large and stable groups of people who didn't know what sorts of risks they faced individually'. But the emergence of new practices where employment law has little purchase on 'the growing numbers of contract workers, contingent workers, freelancers, e-lancers, commission-sales workers, managerial and professional workers, and everyone else selling their services directly in the new economy' means that younger citizens are becoming used to 'selfservicing', seeking private solutions to their increasingly individualized needs.

Where occupational and personal private pensions are concerned, the turn towards self-financing hardly seems propitious in the wake of Enron and market difficulties more generally. However, despite the problems associated with $401(\mathrm{k})$ pensions and the lack of personal pension take-up, there is little reason to suppose that these forms of provision will be altered in any radical manner. Unsurprisingly 


\section{Population ageing, GEPs and changing pensions systems}

in view of the USA's liberal economic character, current debate focuses on how to extend private provision and encourage private saving in those groups that have little or no pension provision outside Social Security. As Gale and Orszag (2003: 31-7) make clear, there are ways of reducing the risks that Enron so dramatically exposed. DC schemes such as 401 (k) could be 'adjusted' to take greater account of the need for workers to have clearer information and advice about investments, and to ensure that employees can diversify their portfolios after they are vested so further extending the flexibility of these schemes. Moreover, the percentage of assets invested in employer's shares could be strictly limited, while the balance of risk could be 'redistributed' towards the employer, and incentives for saving increased, if greater use was made of Cash Balance Plans, which also have the advantage of limiting employees' access to their funds before retirement age.

\section{The United Kingdom}

Until the early 1980s, the UK was regarded as a 'hybrid' system so far as pensions - and indeed other elements of welfare provision - were concerned. The hybridity stemmed from the mix of funding mechanisms which characterized pensions arrangements from Edwardian times. The first old age pension was means tested, non-contributory and funded from general taxation. However, due in part to a process of 'policy learning', with ideas being imported from Germany in particular, as well as to the central contribution of William Beveridge from 1910 onwards, the insurance principle became firmly embedded in ideas about how core risks could best be collectively avoided. Following the recommendations of the Beveridge Report (1942), the first Attlee government created a comprehensive National Insurance system designed, inter alia, to provide flat-rate pensions in return for flatrate contributions. While this policy undoubtedly reflected contemporary optimism about the ability of such a system to 'end poverty', the government's understandable decision to include large numbers of retirees and near-retirees in the scheme irrespective of their lack of contributions - meant that the state pension had to be supplemented with means-tested benefits from the outset. In fact the contributionbased state pension was never sufficiently generous nor sufficiently redistributive either to prevent poverty in the poorest groups of retirees, without additional meanstested National Assistance, or to foster greater income equality between the retired and working populations (Hills, 2004). Morover, not only did the breadwinner character of the national insurance system mean that married women were dependent on their husbands' pensions, but the lack of generosity led those who could afford to do so to pay into occupational schemes, subject to generous tax concessions, which added both to the inequality of provision and the overall complexity of the system (Titmuss, 1963).

The only attempt to develop more coherent arrangements came in the shape of the State Earnings Related Pension Scheme (SERPS), legislation being passed by a minority Labour government in 1978. A second-tier, PAYG publicly-funded system of this kind had been much debated within Labour circles from the mid1950s (Ellison, 1994) and, despite the protracted progress, SERPS was regarded 
as something of an achievement. Had the policy been successfully instituted, it would have provided employees with complete contribution records and lifetime average earnings with approximately 33 per cent of their final gross earnings (Bonoli and Palier, 2001: 67). But the SERPS experiment was short-lived. Throughout the 1980s Conservative governments, citing future demographic pressures and the need to 'roll back' state spending as major reasons, whittled away at the basic state pension (benefits were linked to prices, not wages, in 1982) while also encouraging moves towards greater second tier occupational and personal private provision. In 1986, for example, SERPS was changed from 25 per cent of earnings during the best twenty years of employment to 20 per cent of average career earnings; this reform also allowed employees to opt out of SERPS entirely and into the private pensions market. As Bonoli and Palier (2001: 68) report:

the 1986 reform resulted in a massive outflow of some 5 million employees from SERPS into private pensions. The lowering of SERPS benefits, the general lack of support for state provided pensions, and the aggressive marketing by private insurance carriers persuaded many to turn to the private sector for their pensions.

On the face of it, both the de-linking of the state pension and the downgrading of SERPS passed relatively smoothly at the time. There was certainly 'uproar in the Commons' (Timmins, 1996: 376) over de-linking and both employers, and trade unions, vociferously objected to the Conservatives' initial proposal to abolish SERPS completely. In fact, on this score, the 1986 legislation was regarded as something of a retreat on the part of the Thatcher government (Pierson, 1994: 60). With the advantage of hindsight, however, what is noteworthy is not so much the fact that SERPS survived (though fatally damaged) but that so many people decided to opt out when the chance came. In this regard, as Pierson (1994: 63) writes, 'the reforms of the basic state pension and SERPS represent a dramatic change in pensions policy [having] significant repercussions for income distribution, the roles of the state and private sector in pension provision, and the evolution of state finances'. Unlike Reagan's experience - and certainly unlike Australia's shift towards compulsory private superannuation, discussed below - the reform process in the UK was neither inhibited by embedded popular expectations about future benefits, nor, conversely, positively endorsed by strong unions keen to see the state pension complemented by alternative forms of provision. Rather, outside the fairly thin layer of academic experts and (disorganized) institutional interests, the complex and poorly institutionalized UK pensions system was ill-understood. Few members of the public claim to have a good understanding of pensions issues with comprehension about 'the interactions between state and private pensions being problematic, as people's beliefs about what the state will provide affect their decisions about what they should add privately' (Hills, 2004: 362).

In retrospect, it is ironic that Conservative governments believed that, by effectively abolishing SERPS, they had insured the UK's pension system against future shock. This complacent attitude, based on the simplistic belief that the only 


\section{Population ageing, GEPs and changing pensions systems}

issue of concern is population ageing, has given way in recent years to a recognition that the UK has an inadequate pensions system and that there is little to suggest that tomorrow's pensioners will enjoy security in old age (Whitehouse, 1998). One aspect of this inadequacy is that an already ungenerous basic state pension (BSP) is set to reduce further in value over time. The Pensions Policy Institute (Curry and O'Connell, 2003: 4) estimates for example that the BSP will fall from its current value of 17 per cent of national average earnings to roughly 12 per cent by 2039 . Two other factors are also important. First, the private pensions industry clearly mis-sold its products during the late 1980s and the 1990s with the result that many individuals who opted out of SERPS (and in some cases their occupational schemes) into personal pension plans now risk pension shortfalls on retirement. Although these plans drew tax concessions from the state, they did not fully compensate for the loss of the employer's contribution - and many plans were simply less wellmanaged than established occupational schemes, with administration charges frequently being high. In consequence personal private pension take-up stalled in the mid-1990s, with fewer than 15 per cent of employees having individual pensions. Second, private occupational pensions have a much higher take-up and, in the case of many public sector schemes, can provide good benefits on retirement. However, as noted above, women cannot always make full use of occupational alternatives because of the need for more career breaks or because of their greater presence in the low paid service sector where DC schemes predominate. Moreover, DB schemes in the private sector are becoming increasingly unstable. A recent survey by the National Association of Pension Funds has estimated that 10 per cent of final salary schemes closed to new members in 2000 - this figure rising to 19 per cent and 26 per cent in 2001 and 2002 respectively (Pensions Commission, 2004: 85). Though it is hard to be certain, the Pension Commission estimates that 'the evidence suggests that active membership of open private sector DB schemes has so far fallen by 60 per cent since 1995' (Pensions Commission, 2004: 85).

So, with a declining BSP, patchy take-up of personal pensions (which tend to be bought by the already well off) and an occupational sector rapidly retrenching on the generous schemes of the 1980s and 1990s, the New Labour government faces serious and continuing challenges. All the more so, in fact, because patterns of takeup indicate that the better off are to be found in good occupational and personal private schemes, while lower paid individuals, including a disproportionate number from minority ethnic groups, in addition to women, will have to rely on the BSP and means-tested supplements. It is interesting, then, that in its first term of office the government rejected radical reform in favour of yet more incremental additions to the existing forms of provision - and this despite having charged, Frank Field, its first Minister of State in the Department of Social Security to 'think the unthinkable'. Field's recommendation that the UK should pursue compulsory pre-funded second tier pensions - but with responsibility for fund management entrusted to trade unions, 'friendy societies' and other social agencies (see Blackburn, 2003: 298-300) - was rejected outright, with reasons differing among different sections of the Labour Party. 'Old' Labour critics, perhaps simplistically, wanted a large increase in the BSP and its reconnection with earnings, while ministers, on the other hand, appeared reluctant 
to become too deeply mired in disentangling the existing mix preferring a gradualist approach designed to tip the balance between public and private provision in favour of the latter. As the Green paper Partnership in Pensions (Department of Work and Pensions, 1998) made clear, the objective was to ensure that, over a fifty-year period, the UK reversed the public/private pensions mix from its current ratio of 60-40 in favour of the former to the exact opposite, where private provision accounts for 60 per cent of total provision.

Outside the BSP (which is now supplemented by a means-tested Pension Credit), the declining value of which will continue, New Labour's strategy is to support the very poorest earners through a compulsory state second pension (S2P), with the result that 'the emerging system [will] mimic something not unlike a flat rate pension of more than 25 per cent of average earnings' (Hills, 2004: 363). Meanwhile, others are being encouraged to pursue private methods of supplementing the BSP. The difficulty is to persuade those on low-to-average incomes to invest in their retirement by individually saving more. With their low administrative costs, stakeholder pensions, introduced in 2001, were intended to encourage the lowerpaid and self-employed, who do not have access to occupational schemes, to do precisely this. However, at the present time, take-up has been poor and, ironically, seems to have attracted a different group of contributors to that envisaged - welloff individuals who wish to take advantage of the low charges associated with stakeholder pensions to buy provision for spouses or young family members.

Lacking a clear strategy to ensure higher rates of private saving and conscious of the need to control public spending, New Labour has followed Bush's example of appointing an independent commission to examine the whole area of pensions provision. The Pensions Commission, chaired by Adair Turner, Vice-Chairman of Merrill Lynch, has, to date, produced one volume (Pensions Commission, 2004), of two, that recommends three possible alternative policies. First the voluntary system could be subjected to a major revitalization, second, significant changes could be made to the state system, and/or third, 'an increased level of compulsory private pension saving beyond that already implicit within the UK system' (Pensions Commission, 2004: xviii) could be introduced. With the UK's Chancellor, Gordon Brown, already ruling out the second option (Elliott, 2004) for fear of the impact on public spending, it appears that one private solution or other will be adopted. Whether the UK will take the mandatory Australian route remains to be seen.

\section{Australia}

Over the past twenty-five years, Australia has gone further than others in its efforts to reorganize retirement arrangements. In essence, Australian governments have created a system that continues to afford basic pension cover - the age pension (AP) - through the state while promoting a radical shift towards mandated private occupational pension arrangements. As Harris (2004: 2) puts it, 'countries like Australia and the UK have moved towards encouraging individuals to save on an individual retirement basis so offsetting the rapid ageing of each of their corresponding populations'. In fact, Australia's population is not ageing at the rate of 
some other countries in the OECD - though the numbers of those over 65 are set to rise from the current figure of 12 per cent to 24 per cent by 2051. It is clear, however, that both political parties believe that the requisite action to offset future difficulties has been taken (Bishop, 1999) - and that these difficulties are as much economic as demographic.

At the present time, the main sources of pension income are the AP, with over 80 per cent of Australians receiving at least some benefit from this asset-tested source, together with age-related individual private pensions and home ownership - the latter being a particularly important source of security in old age in Australia where 82 per cent of those aged 65 or more own their homes outright (Bishop, 1999:14). The objective of Labor governments in the 1980s and 1990s was to offset the anticipated fiscal impact of an ageing population by progressively reducing state spending on the AP and substituting mandatory superannuation for all Australians. Following an initial agreement in 1985 to adopt a system of employerfunded, second-tier occupational pensions, the 1992 Superannuation Guarantee, required employers to contribute approximately 3 per cent of wages into superannuation funds (which are usually industry based) or face a penalty - the Superannuation Guarantee Charge - for failing to do so. Employers' contributions, which rose to 9 per cent of wages in 2002-3, must be fully vested and fully funded in an approved private fund, with benefits remaining in the fund until the retiree has reached the 'preservation age', which is due to be raised from 55 years to 60 years of age between 2015 and 2025 (OECD, 1999: 110). According to the OECD (1999: 117), 'the replacement rate relative to expenditure in the final working year will be a little over 80 per cent [of the average industrial wage] in 2032. This compares with a replacement rate of a little over 40 per cent in 2032 for a full-rate age pension alone'. The OECD also notes that replacement rates are inversely related to earnings due to progressive income tax rates and the means and asset testing of the age pension.

The new system has advantages and disadvantages. There is no doubting its success in extending superannuation to the vast majority of Australians, including working women, 86 per cent of whom were covered in 1993 (O'Connor et al., 1999: 135). Moreover, the redistributive dimension, together with the diversity of provision among the $\mathrm{AP}$, home ownership and compulsory superannuation, suggests that Australia is as well placed to meet future challenges as its politicians appear to think. As to disadvantages, one potential difficulty is the level of means testing involved in the system. Involving a 'tall poppy' test, which 'measures whether income and assets are above a limit set each year' (Curry and O'Connell, 2003: 8), the full guaranteed AP at 25 per cent of average earnings is not particularly generous, but, even so, in order to qualify for this full amount, individuals with limited assets may choose to spend them. As Blackburn (2003: 271) states, 'means testing discourages savings greater than the mandatory amount, or can lead some to spend until their savings come in below the threshold'. Women could be particularly affected here because many have limited employment records, which leaves them more dependent on available assets and state support. Where superannuation is concerned, arrangements are excessively complex, owing to the intricate system of tax concessions, and too closely bound up with the financial services industry 
(Shaver, 1997). On the latter issue, it is not clear that accumulated occupational pensions assets will be deployed in the best interests of employees because the majority of funds are managed on DC principles with risks therefore being borne by contributors, not employers. Furthermore, with a high proportion of the $\mathrm{A} \$ 439$ billion pension assets invested in equities there is the ever-present danger that the funds may not yield adequate incomes in old age if markets fail to perform. A further problem relates to the fact that the funds themselves differ widely. Blackburn (2003: 271) comments that, as elsewhere, the large public sector funds manage their assets effectively, incurring only modest administration charges but there are also 'large, private retail suppliers who manage a mass of small or individual schemes and whose charges are high' - one consequence being that the sums available from superannuation assets will vary among retirees with similar contribution profiles.

Whatever the potential disadvantages of these arrangements may be, in 'institutional' terms the shift from reliance on the AP to mandated superannuation was managed successfully. Australian Labor governments moved from a singletier, state-funded pension system to a two-tier model dominated by occupational schemes funded through the private sector seemingly without difficulty. How did they implement these institutional changes without greater political disagreement? The short answer is the Accord process, discussed in previous chapters. One aspect of this quasi-corporatist series of agreements between the Australian Labor Party (ALP) and the Australian Confederation of Trades Unions (ACTU) was union acceptance of wage reductions in return for greater security for vulnerable groups through a rising social wage and associated benefits. In this regard, the 1985 Accord saw union agreement to restrain wages in exchange for the 'employer funded mandatory second tier pension [which] secured pension benefits without requiring government spending' (Schwartz, 2000: 118). There is no question that the trade unions favoured this arrangement - and largely because, in Australian conditions, it was perceived not so much as a move towards outright 'privatization' but as the extension of earnings-related pension provision to union members. Prior to the reform, superannuation had typically covered only white collar, middle-class employees amounting to approximately 40 per cent of the workforce. Women and minority ethnic groups were underrepresented, as were blue collar male workers. Moreover, in an economic environment of increasing budget constraints, wage increases were becoming more difficult to obtain. In consequence, the ACTU came to see that 'deferred savings benefits may be an alternative to simply striving for an increase in workers' net pay' (Harris, 2004: 3). There is also the highly important fact that, from the outset, the unions were represented on the trustee boards of the roughly 1,500 schemes that make up the 'Super' - indeed some schemes were initiated by the unions themselves.

Other factors are also important. The transition to superannuation was less painful than it had been in other countries - Chile for example - that had adopted a similar pensions strategy because insurance and financial services institutions, which had dealt with voluntary superannuation for many years, were already well established (Harris, 2004: 5). Just as significantly, it is likely that the ills that have affected organized labour in all the developed welfare regimes also played a role. 
Their part in the Accords, notwithstanding, Australia's strong union movement was beginning to weaken by the 1980s. Membership fell from 46 per cent of all employees in 1986 to 31 per cent a decade later and this difficulty, coupled with the ongoing decline in heavy manufacturing, 'reinforced the union's (sic) enthusiasm to support ... retirement reforms as they felt that they were in effect increasing their profile and relevance for existing and potential members' (Harris, 2004: 5). Of course, the Accords themselves were made possible partly at least by the sustained period of ALP rule between 1983 and 1996, as well as by the fact that the ALP and the ACTU were able to neutralize a weaker, and considerably more divided, business opposition. Certainly length of time in office contributed to the ALP's ability to develop the requisite skills needed to balance 'the competing interests of public sector/unskilled workers and private sector/skilled workers', the Accords leading to employment gains and other advantages that reduced the likelihood of 'public-private and sheltered-exposed cleavages' (Schwartz, 2000: 122). Beyond these factors, a number of wider institutional components of the Australian political system may have worked to ensure that the process of change was fairly smooth. Shaver (1999: 597) points out that Australian incrementalism, as opposed to the rather more brutal form of welfare state reorganization adopted in New Zealand, for example, is a product of a 'federated structure, bicameral parliament, and compulsory preferential voting systems [that] serve to moderate the speed of change'.

It is clear from the above discussion that pensions arrangements in the three liberal economies examined either have changed, or are in the process of changing, markedly. While the bulk of the reforms in the Australian case were both consensual and agreed a decade or more ago, neither the USA nor the UK have yet finally decided how best to reorganize their systems. Although in each case the preference is for private solutions of one kind or other, which is in keeping with regime type, the mandatory nature of the Australian superannuation system has something in common with developments in social democratic Denmark and the continental Netherlands regime. These countries have more generous basic state pensions, to be sure, but it is important to be aware that the drift towards privatization in the pensions arena is not confined to liberal regimes. A further feature worth noting is that the 'ageing problem' in these regimes is modest when compared to countries like Germany and Japan. The real issue, tackled by these countries in slightly different ways, has been to avoid resorting to expensive public funding of pensions arrangements in an economic climate that is no longer conducive to PAYG solutions. Latecomers to second-tier arrangements like the UK and Australia have not faced quite the same level of institutional stickiness initially faced by the USA - though for different reasons - although it appears that opposition to pension reform in the USA is less extensive than it used to be. Of course, while it may prove possible to 'solve' the public finance problems that PAYG systems encounter, as Myles (2002: 151) argues, privatization does not remove larger economic challenges. It is just that 'the economic costs of supporting the retired will increasingly occur off budget'. On this reading, the levels and extent of income security in retirement could become 
Population ageing, GEPs and changing pensions systems 151

increasingly opaque as outcomes are controlled by loosely regulated corporations operating on Anglo-American financial principles, any notion of a redistributive bias in old age provision being accordingly lost. 


\title{
7 Pensions policies in continental and social democratic regimes
}

\begin{abstract}
While it is not surprising, in view of their institutional make-up that liberal regimes increasingly look to the private sector as a major source of income provision in retirement, the issue in this chapter is whether or not changes of this kind are crossing the regime barrier and developing in countries with more closely coupled institutional structures. To anticipate the argument somewhat, the evidence indicates that they are - although this is not to suggest that social and continental systems are 'catching up' with their liberal counterparts. Rather, what seems to be happening is that each of the countries examined below is leaning towards liberal solutions at least to the extent that various forms of 'privatization' have either been implemented or are being actively contemplated. In addition, definite adjustments are being made to existing PAYG social insurance arrangements, usually in the form of increased contribution periods and/or later retirement. Efforts to contain contribution levels are also a core feature of pension reform, particularly in the continental countries, and can be expected to lead to reductions in pension income as the baby boom generation enters retirement.
\end{abstract}

\section{Continental regimes}

This grouping contains the largest number of countries, distinguished by arrangements grounded in PAYG social insurance contributions paid by those in employment and often originating in policies adopted in the latter years of the nineteenth or early part of the twentieth centuries. The real issue in these cases is the difficulty many governments are experiencing in attempting to control the effects of expensive PAYG policies, which are deeply embedded elements of their production and welfare regimes. Nowhere is there evidence of a wholesale transformation away from public, unfunded social insurance principles towards private pension provision. In countries like Germany and France, however, where governments are actively contemplating far-reaching policy adjustments, the threat of change to established pension systems is producing extensive political disagreement between governments of all political persuasions and institutionalized interests concerned both about the loss of anticipated income in retirement and their continuing ability to exercise a degree of control over pensions arrangements. Pressures are mounting on the institutional infrastructures of continental pension regimes, in other words, and these are particularly visible in government attempts 
to break - or at least to 'adjust' - the link between contributions and benefits, and also to introduce alternative personal private and occupational forms of retirement provision.

\section{Germany}

Social insurance continues to be the operating core of the German welfare regime. It is the key institutional principle, with financing through insurance contributions extending to all the major areas of German welfare provision. With regard to old age pensions, from 1957 the system has operated on an earnings-related, DB PAYG basis. Unlike the earlier Bismarckian arrangements, which provided a contributionlinked, but relatively ungenerous pension, the 1957 reforms saw West Germany move to a true wage replacement system with replacement rates of over 70 per cent. Contributions were paid by employers and employees, with the state also providing a federal grant. The earnings related component preserved certain elements of Lebenstandardsicherung, or status maintenance, that had characterized the German system from its earliest days, a persisting feature of this architecture being that pensions are not state-administered but organized through occupationally segregated schemes charged with paying benefits at levels consonant with preretirement living standards (Hinrichs, 2003: 6). Outside this earnings-related tier, there was only means-tested social assistance for those (mainly women) lacking an employment record - so, post-1957, West German arrangements became essentially a 'one-tier' affair (Hinrichs, 2003: 6).

For thirty years or so, no significant reforms to the system were considered, largely for path-dependent reasons, the key principles of the system being broadly accepted by political parties and the social partners alike. So, while it is possible to discern a gradual drift away from the 'classic' earnings-related breadwinner model - key features of this incremental process being the gradual elimination of the differences between white- and blue-collar pension schemes, and the equally gradual extension of pension coverage to non-waged groups such as the self-employed, houseworkers and students (Leisering, 2001: 172) - this shift towards greater equity (particularly for women) did not fundamentally threaten the nature of the model itself. More recently, however, the system has been severely tested as a result of a growing recognition among politicians of Germany's deteriorating demographic situation - more than a third of the German population will be over 60 by 2030 but also as a consequence of the stresses and strains of the unification process. If these difficulties are set in the context of GEPs, the issues that currently face Germany are plain to see. As Hinrichs (2003: 2-3) points out, in Germany 'as the "social insurance state" par excellence', insurance contributions make up a larger share of GDP than anywhere else in the OECD - 18.6 per cent in 2001, or roughly 43 per cent of total public revenues. Such high costs on labour risk high unemployment rates as employers in exposed industries automate where possible, while in service sector areas potential job creation is impeded. High labour costs also contribute to low inward investment that has further consequences for employment, particularly in the East, where the economic fallout associated with the collapse of inefficient ex-communist industries continues. 


\section{Pensions policies in continental and social democratic regimes}

The first signs of serious difficulty were visible - at least to some - before the Berlin Wall came down and the unification process began. The incoming Kohl government postponed the scheduled adjustment of pensions from January to July 1983 and also raised the contribution rate in September of that year, while by 1987 the government had begun to draw up a more comprehensive plan for reform (Aust et al., 2002: 8-9). However, an announcement by the Association of German Pension Insurance Bodies (VDR) in 1988 that their financial reserves were low and deteriorating because of declining contributions and rising pension claims, lent some urgency to the process and encouraged the CDU/FDP coalition government to introduce a bill with provisions, inter alia, to increase women's retirement age to 65, restrict male early retirement, and shift the base of calculation of yearly pension growth from gross to net wages (Meyer, 1998). Although the bill was criticized by the SPD opposition, the Greens and the trade unions (not least because it contained little that was of benefit to women), as was traditionally the case with legislation of this sort extensive debate among the contending interests saw a consensus develop around 'a compromise which reflected the main criticisms [containing] the retrenchment measures of the first bill, but ... [improving] regulations to protect the income for people on low wages and interrupted employment careers' (Meyer, 1998: 200). The ensuing 1992 Pension Reform Act did not tamper with the nature of the system itself (Hinrichs, 1998: 20) but did decrease the rate of contribution rises over time and made early retirement a less attractive option by imposing benefit reductions of 3.6 per cent for each year under the official retirement age - this latter arrangement to begin in 2001. However, even before the Act was passed rising unemployment and the rising costs of unification were taking their toll on the once-healthy German economy. Indeed, such was the extent of economic slowdown that Germany experienced difficulties in meeting the fiscal demands for EMU, facing deficits exceeding 3 per cent of GDP in 1993, 1995 and 1996 (Bonker and Wollman, 2001). With respect to pensions and other 'insured' elements of the German welfare state, the fact that the major costs of unification fell upon social insurance funding, as opposed to general taxation, meant that pressure on the insurance funds increased, with contribution rates rising throughout the 1990s.

This deteriorating situation, together with additional pressures associated with population ageing, triggered further efforts to reform the pensions system, which to all intents and purposes are ongoing. As the basis of the system itself increasingly came into question, the late 1990 s were characterized by growing political disagreement between the GDU-Liberal coalition and the employers, on the one hand, and the SPD and the trade unions, on the other. The latter opposed further reductions in benefit for early retirees and also opposed proposals for the accelerated increase (from 60 to 65) in the retirement age for women, for example. Significantly, the SPD refused to participate in the 'pension reform commission', set up by the government in 1997 (Hinrichs, 1998: 21). The core issues, however, which appeared in legislation between 1996 and 1999 were the continuing effort to reduce contribution rates over time coupled with further attempts to close off opportunities for early retirement, for instance by making access to disability pensions more difficult. 
Moreover, the proposed introduction of a 'demographic factor', which took account of increased life expectancy for those over 65, was intended to reduce the value of pensions over a period of years (Meyer, 1998: 202).

Far from reneging on the policies pursued by the Kohl governments, as initially expected, the SPG-Green coalition has kept up the pace of reform. Although the Schroeder administration initially suspended the introduction of the demographic factor and the measures relating to invalidity pensions when it came to power in 1998, it rapidly changed course. Indeed the proposals from the SPD-Green coalition based on the policies outlined in Chancellor Schroeder's Neue Mitte in 1999 and introduced in the policy document Future 2000, went beyond the CDU position in their attempt to curtail the scope of the social insurance model. Ironically, in 2001, the government reintroduced the demographic factor and also a moderated version of the disability pension reform (Hinrichs, 2003: 12). Other changes are equally significant. Upper limits have been placed on contribution rates which must not exceed 22 per cent by 2030, with the result that the German ratio of wages to net benefits will fall from 67 per cent in 2015 to 64 per cent by 2020 (Blackburn, 2003: 261). Also an element of 'privatization' has been introduced in the form of voluntary pension provision - Riester-Rente funds - which are intended to encourage individuals to supplement the inevitable shortfall in public pension provision following the cuts in contribution rates through private pension plans. Tax relief is available on up to 4 per cent of the gross income that can be devoted to private or occupational schemes.

Although, as one observer puts it, the new funds 'will change the role of private pensions, since in the long run they will become a necessary component of income, if the living standard is to be maintained during retirement' (Sailer, 2002: 1), the issue is complex. Take-up has been low, for example, with only 12 per cent of employees investing after the first eighteen months (Hinrichs, 2003: 14; Financial Times, 11.7.02)-a difficulty that appears to be due in part to the problems associated with modifying existing contracts (Sailer, 2003: 81). On the other hand, occupational schemes, always a feature of the German pensions landscape, have grown rapidly because the government has reduced vesting periods, improved portability and given employees the legal right to invest part of their wages in schemes which are not controlled by their employer ( Leinert and Esche, 2000; OECD, 2001d; Sailer, 2002). Current figures suggest that 42 per cent of all employees in the private sector have access to occupational schemes compared with just 29 per cent in April 2001 (Investment and Pensions in Europe, 2003: 23). Taken together, the development of the Riester-Rente funds and the increase in occupational schemes point to the de facto emergence of second tier pension provision in Germany.

To what extent do these changes constitute a major shift in German pensions policy? Certainly observers like Hinrichs (2003) and Hering (2003) believe there has been a significant 'paradigm shift' in postwar arrangements, although Hinrichs (2003: 19) argues that the changes '[do] not imply that basic programmatic structures are completely thrown out'. This is an important observation because it implies that successive incremental decisions can result in extensive, systemic change as it were 'from within' an existing model without the actual collapse of the model itself. As van Kersbergen (2000: 29) has written, 


\section{Pensions policies in continental and social democratic regimes}

incremental changes - commonly taken as signs of the resilience of welfare states - can at a certain point in time result in a more fundamental transformation when, as a consequence of the accumulation of small measures, a social programme ceases to offer the level of protection for which it was originally designed.

In the German case, over a decade of incremental changes to the social insurance system has by no means resulted in its destruction - but serial adjustments have brought pension arrangements to a point where further, and different, forms of provision can now be contemplated. The fact that the Riester-rente funds could not only be advocated as serious policy proposals but also accepted as such in a welfare regime with deeply embedded interests, practices, assumptions and expectations is indicative of the distance travelled since the early 1990s. It is hard to imagine that, whatever its objective merits, this particular policy would have been considered at that time (see Aust et al., 2002: 13).

This process of change is by no means complete and it is clear, for example, that movements in the financial arena are likely to have an impact on pensions arrangements in the medium-to-long term. Significantly, one signal that the Riester option is unlikely to be abandoned despite low take-up has come recently from the Rürup Commission, established under Schroeder's Agenda 2010. The Commission not only proposed further cuts in PAYG contribution rates, including the abolition of non-contributory credits for time spent in education, but also suggested that the Riester funds should be made compulsory if they do not take off 'voluntarily' within two years (Investment and Pensions in Europe, 2003: 23). This attachment to market-oriented alternatives is also evident in further developments which suggest that the financial assumptions underpinning the traditional German social market model may be at increasing risk. For instance, the German government has made important financial market reforms in the past few years, which have included measures to simplify stock market access for issuing companies and also 'regulations on delisting and a number of deregulation measures' (OECD, 2000a: 78). Moreover, in the business world, large corporations, particularly those operating in the USA and UK, are becoming increasingly familiar with Anglo-American financial systems and accounting standards - particularly the different management practices that characterize these systems - that contrast markedly with the German model of co-determination. In Clark's (2003: 127) view,

the large German firms (their management and principal shareholders) and the federal government have put in place institutions and policies consistent with the imperatives of global finance ... and have done so in order to remake the distribution of power within large firms and to enhance managers' shares of market-defined corporate value.

Employer-sponsored occupational pensions are an intrinsic part of this process, Clark's (2003: 127) point being that 'these institutions may have been thought properly to belong in the sphere of co-determination and the social market [but] these embedded commitments are being revalued in terms of global finance'. 
While Clark (2003: 139) is quick to point out that 'bonuses and stock options are not the most important issues in German corporate governance', it is the case nevertheless that, in large companies, managers are becoming impatient with the risk aversity embedded in co-managed pension institutions, and excited by the possibility that pension fund assets (often unfunded as in the direktsuzagen plans) can be manipulated in ways that facilitate 'maximization strategies' designed to produce short-term returns. The likelihood that they will be able to pursue such strategies is of course enhanced by two factors. First, union-based opposition to change in the German pensions system is beginning to wane as the unions themselves becoming less powerful. As Rieger and Leibfried, (2003: 228) note, organized labour represents a decreasing number of workers. Second, as mentioned in the last chapter, approval of more aggressive financal management is evident in the tone of the EU Pension Directive, which clearly privileges capital mobility over social protection in its attempt to develop cross-border sustainability for occupational pensions (Larsen and Daguerre, 2003). At the very least, in view of these considerations, German citizens may be forced to look - however reluctantly - to a 'rebalancing of the "public/private mix" of pension income ... and a longterm convergence of different schemes' (Hinrichs, 2002: 25), as private (personal and occupational) alternatives become increasingly significant elements of pension provision.

\section{France}

The distinguishing feature of the French pensions system is its complexity. Different professional categories are covered by different schemes while 'each social group aims at preserving its own advantages' (Mandin and Palier, 2003: 1). In contrast to Germany, there is no sense of 'design' in the early development of the French system, with the state playing a relatively minor role in an administratively and financially decentralized framework of provision controlled by the social partners. During the postwar period, the state acted as guarantor of last resort, ensuring the financial integrity of the various schemes, but the 'design and implementation of the ... social security system was a contested and protracted process of accommodation' (Clark, 2003: 67). What emerged over the twenty or so years following the Second World War was a set of PAYG arrangements which saw a series of statesponsored institutions - the régimes général for private sector employees and the régime spéciaux for public sector workers - each administered by jointly managed regional caisses, joined by myriad private and occupational arrangements known as régimes complémentaires. As Clark (2003: 67) puts it,

at one level the rules and regulations regarding coverage, minimum and maximum benefits, and contribution rates were the responsibility of the state ... however the caisses were initially responsible for collecting contributions, setting benefits and distributing benefits in accordance with 'local' circumstances and national legislation 


\section{Pensions policies in continental and social democratic regimes}

the point being that 'embedded in this system were multiple and overlapping jurisdictions'. In this environment the state found it difficult to assert its authority and, indeed, it has only been over the past ten years or so that French governments have made concerted efforts to establish greater control over the system.

The impetus for reform is closely associated with the 'usual suspects'. France's population is ageing faster than the OECD average, with nearly a quarter of French people predicted to be over 65 by 2030 - and importantly 7 per cent of these being over 80. Labour market changes have seen a marked trend towards early retirement as a means of dealing with the impact of deindustrialization. The LFPR for men aged between 60 and 64 fell from around 70 per cent to less than 15 per cent between the late 1960 s and the late 1990s, for instance, with rates also falling for men aged between 55 and 59. As Clark (2003: 63) notes, 'it is now rare for French men and women over 60 years to be working and contributing to social security institutions'. On the economic front, the strict fiscal regime for EMU laid down by the Maastricht Treaty and the later introduction of the Euro have obliged governments of all political persuasions to control inflation and public spending deficits (Bonoli, 2000: 130-31). Despite these difficulties, however, the move away from social insurance principles has been politically difficult and ultimately rather less pronounced than in Germany. Lack of clear progress is partly attributable to trade union reluctance, particularly in the public sector, to recognize the shortcomings of the PAYG system, although the sheer complexity of French social security has also been a factor - and one that has caused significant political disagreement. In addition to the problem of fragmentation, a further instance of 'complexity' was the practice of making the resources of the contributory schemes available for more general purposes. As Bonoli (2000: 125) argues,

governments faced with rising social problems ... tended to use the social insurance system to achieve their social policy objectives. Instead of duplicating social insurance schemes for those unable to build up a sufficient contribution record, it was decided to extend social insurance entitlements beyond the core of actual contributors.

Where pensions are concerned older people, particularly women, who had paid insufficient contributions to be entitled to an adequate pension were nevertheless deemed eligible for a means-tested minimum pension - the minimum vieillesse - but paid out of the social insurance budget.

This habit, indulged by governments of all political colours, of using social insurance in this way increasingly came to be resisted by the trade unions, which, though weakly organized by European standards, have always been able to mobilize popular resistance to what can be easily portrayed as undue state interference. Even during the 1980s, before governments began to push for radical pension reforms, the unions were already trying to defend the integrity of the social insurance system by only accepting increases in insurance contributions (at this stage brought on more by the rising incidence of early retirement than predictions of population ageing) as a means of maintaining benefit levels so long as 
governments introduced 'tax-financed benefits for those who did not contribute and [shifted] ... the financing of some non-contributory benefits from contribution to taxation' (Palier, 2001: 64-5). By the later years of the decade, however, it had become clear that policy makers no longer believed that adjustments of this kind were sufficient to sustain expected levels of pension provision without further changes being made to the system itself.

The first attempt at institutional reform, by the Balladur government in 1993, restricted changes to the private sector general scheme (the régime général), where union density was weakest, indexing pensions to prices rather than earnings and extending the qualifying period for a full pension from 37.5 to 40 years (Bonoli, 1997b). As a peace offering to the unions, not only were there extensive negotiations prior to implementation but the government also pleased them by entirely separating the contributory and non-contributory systems, and removing the noncontributory minimum vieillesse from the insurance scheme (Bonoli, 2000). This degree of care in negotiating the reform was successful and the measures were adopted in 1994. Their impact on long-term pension expenditure has been regarded as generally positive, recent estimations suggesting that contribution rates will have to rise by between 2.7 and 7.2 percentage points by 2010 as opposed to the 10 per cent originally predicted (Palier, 2001). For Mandin and Palier (2003: 7), the Balladur reform signifies 'a major break with the past' because the new measures effectively entail a drop in retirement income. Thus private employees who, prior to the reform, could look forward to receiving 50 per cent of their wages in pension income will in fact receive approximately 33 per cent once the system is fully embedded in 20 years time. Again, the new 40-year contribution period will mean that many employees will have to work after 60 but, because 'this does not correspond to the possibilities of the labour market', the actual effect will be to lower pension levels.

The successful passage of the Balladur government in pension reform (if not always in other areas of public policy - see Levy, 2001), contrasts markedly with the Juppé government's subsequent attempt to restructure the French social security system, as a number of commentators have made clear (Bonoli, 1997b, 2000; Merrien and Bonoli, 2000; Levy, 2001; Palier, 2001). In this instance, the government felt able simply to ignore the trade unions and pressed ahead with plans to bring the public sector into line with the reformed private sector, the increase in the contribution period from 37.5 to 40 years being a key example of the desire to harmonize arrangements between the two sectors. The Government's prevailing popularity, strong parliamentary majority and good relationship with the right-of-centre President, Jacques Chirac, led ministers to conclude that union recalcitrance could easily be surmounted. In the event, however, strong opposition to the Juppé Plan from organized labour, in the shape of damaging public transport strikes in November and December 1995, forced the government to withdraw its proposals. The example is an interesting one. For one thing, the substance of the Plan was by no means purely about retrenchment - and indeed the Socialist parliamentary opposition preferred to attack the government on the basis of its approach to the policy process rather than on the policy details themselves, with 
which it broadly agreed (Merrien and Bonoli, 2000). That said, the trade unions viewed the Juppé Plan very much as an attack on them, partly because the 40-year contribution period was not popular, but, more significantly, because they feared that Juppé wanted to undermine social insurance principles through the greater use of tax financing - the proposal to shift a proportion of health insurance financing from contributions to taxation being an example of this intention (Bonoli, 2000: 144). This inversion of the earlier tendency to use insurance funds to pay non-contributory benefits not only jeopardized existing arrangements but, by diluting the insurance principle, also threatened a key bastion of trade union power. It is hardly surprising, then, that the unions regarded the Juppé Plan as an example of unwarranted state interference (Myles and Pierson, 2001).

Pressure for reform persisted in spite of union hostility. The socialist Jospin government, which came to power in 1997, took matters further in two ways, both of which signalled a desire, however tentative, for further change. First, the government continued quietly to increase the tax-funded elements of welfare provision. Palier (2001: 71-2) points to the growing role of the Contribution Sociale Généralisée (CSG) which, in contrast to social insurance contributions is levied on all types of personal incomes including 'wages (even the lowest ones), but also capital revenues and welfare benefits'. C.SG was first introduced in the early 1990s but increased from 1.1 per cent under Balladur to 7.5 per cent under Jospin. This tax now provides 'more than one-fifth of all social protection resources and [pays] for more than one-third of the health care system' (Palier, 2001: 72). Second, and less convincingly, although the Jospin government did not itself embark on extensive reform, it made a point of gathering expert advice about possible future arrangements, which its successors have utilized. In 1999 Jospin requested the Commissariat Général du Plan, headed by Jean-Michel Charpin, to produce ideas for pension reform and the ensuing Charpin Report recommended major changes to the system. A key proposal argued that the contribution period ultimately should be raised to 42.5 years for both private and public sector employees, which would effectively entail increasing the retirement age in France from the current age of 60 to 65. Additionally, the report urged the government to establish a central reserve fund to provide an alternative form of saving and hedge against population ageing through investing in equities on the global financial market (Clark, 2003: 45). The Taddéi study, meanwhile, addressed the apparent contradiction between increasing the retirement age and the persistent problem of early retirement, and argued for a 'progressive transition from full activity to retirement, with a combination of revenue from employment and retirement income' (Mandin and Palier, 2003: 10). Less 'progressively' perhaps, the Teulade report for the Conseil Économique et Social was clearly less convinced than others about the accuracy of the demographic projections, and suggested that the contribution period be reduced to the original 37.5 years, a public reserve fund created to support the PAYG system, and the state's role in relation to non-contributory pension rights enhanced. Meanwhile economic policy should concentrate on growth and increasing productivity (see Mandin and Palier, 2003: 10-11). 
Jospin remained cautious. He adopted the Teulade proposal for a public reserve fund to underpin the PAYG system, to be resourced from a proportion of the proceeds of inheritance tax and other exceptional revenues, although there is little evidence of sustained progress here presumably due to the change of government in 2002. Mandin and Palier (2003: 10) note that, with the exception of a first donation of €3.049 billion, 'after 2001, no more money has been put into the reserve fund'. Before leaving office, Jospin also tried to extend the contribution period for public sector workers to 40 years but retreated in the face of hostility from the public sector trade unions. A simultaneous attempt by the employers' association, MEDEF, to lengthen the contribution period for those in the régimes complémentaires to 45 years was also successfully blocked by the trade unions.

Jospin's successor, Jean-Pierre Raffarin, inherited this impasse but proved more able to tackle it. Despite a series of strikes in May and June 2003 that threatened to disrupt the process, Raffarin pressed on and in the summer of 2003 the French parliament passed legislation raising the contribution period in the public sector to 40 with a 'life expectancy' increase that will see the period extended to 41 years in 2012 and 42 years by 2020 (The Economist, 3.9.03: 2). In this way, private and public sector contribution periods have now been harmonized. But does Raffarin's apparent success here indicate that France is beginning to move away from the path-dependent disagreements of the past? This is by no means clear. Natali and Rhodes (2004: 18) argue that Raffarin, with a more cohesive executive than Juppé had enjoyed, proved willing to negotiate and compromise with the social partners ultimately forging a trade-off which 'consisted of a mix of cost containment measures, benefit improvements (e.g. more generous indexation), concessions to particular categories of workers, equity improving provisions and a consolidation of the unions' co-management role'. Movement, to be sure, but through a process of bargained reciprocity, the conditions for which may not always pertain. Moreover, as The Economist (26.6.03) notes, the Raffarin reforms are less ambitious than Juppé's proposals of the mid-1900s - and, indicatively, they were only passed following an appeal for 'social solidarity' from Chirac, which was explicitly based on preserving the social insurance system. It may be that, as Natali and Rhodes (2004: 19) suggest, further reform will follow Raffarin's example - 'building consensus, neutralizing opposition and seeking trade-offs' - but it is equally likely that this painstaking process will be overtaken by developments of a rather different kind, particularly as younger generations, less schooled in the arts of social partnership, become increasingly attracted by the perceived benefits of more individualized solutions.

There are signs that more extensive change may be emerging, as it were, 'from within', as a brief examination of the role of the pension reserve or capital funds demonstrates. Funds of this type initially surfaced in the form of the Loi Thomas, which allowed large private companies to create voluntary savings schemes for their employees. Although the law was passed by the Juppé government in 1997, it was blocked by the incoming Jospin administration and repealed in 2001. Indicatively, however, the Socialists did not object to the idea of non-state pension funds in principle, but wanted to see them 'democratized' in a manner that allowed 


\section{Pensions policies in continental and social democratic regimes}

them to be established, and contribution levels agreed, not unilaterally by employers but through the normal channels of social partnership and collective bargaining. To be sure, Jospin shortened the vesting period and allowed contributors to draw on the funds after ten years, thus reducing 'the likelihood that they [would] serve as a supplement or alternative to public pensions' (Levy, 2001: 274), but no amount of tampering with funds of this kind can disguise the fact that they are new instruments designed for investment in capital markets. Once the precedent was set, it was perhaps inevitable that this 'private' means of bolstering the PAYG system would be increasingly exploited by employers and younger employees. Undoubtedly, as Clark (2003: 72) reports, there is rising interest in individual retirement accounts particularly by younger workers who are less certain that state pension provision will suffice on retirement. Palier (2000) has made it clear that ever-rising payroll taxes are no longer considered a viable method of financing pensions, not least because of the implications for employment, the result being that people are beginning to look elsewhere. In Clark's (2003: 72) view, there has been a marked growth in 'savings, equities and pension-related assets' which he regards as 'evidence of an implicit defection; those individuals who can afford to purchase such products do so while acting with the majority to limit increases in the public pension contribution rates'. This interest in the potential of private alternatives has a peculiarly French twist, however. While some large companies and younger workers may be excited by the prospects offered by the increasing power of global finance, politicians and trade unions are more cautious about being sucked into the 'global casino economy' (Blackburn, 2003: 242). Thus in 1999 Chirac voiced his anxiety that French economic interests were being jeopardized by the growing encroachment of foreign investments, while Jean Peyrelevade, president of Crédit Lyonnais, also warned that the power of the Anglo-American pension funds was privileging short-termism and the needs of 'rentier interests' over those of ordinary working people (Blackburn, 2003: 225). These sentiments appear to have hit a paradoxical chord within French labour. As Mandin and Palier (2003: 12) note,

members of the social-democratic party as well as trade unions' representatives are ... becoming less reticent to the introduction of pension funds, but they ... justify this evolution by anti-American arguments [rather] than by economic arguments. They underline the necessity [of developing] French pension funds to reinforce the power of French companies to face international competition.

While unions like the CFDT and CFTC appear to endorse these opinions, they are by no means universally held - the CGT, for example, continuing unequivocally to support the public PAYG system. Despite growing interest in new forms of pension funding, it is important to be clear that there is 'not yet a consensus among the players in the pension reform debate about the characteristics of these savings schemes' (Mandin and Palier, 2003: 12), the consequence being that developments in this direction are unlikely to be rapid. 


\section{Italy}

If the German and French examples suggest the beginnings of a trend, however embryonic, towards greater private provision of pensions, movement in this direction has been less marked in Italy. Like France, the Italian pensions system was extremely fragmented in the postwar period, with different occupational groups being covered by different schemes. Fragmentation continues to characterize the system today with three main paying agencies 'and a plethora of formally autonomous funds operating within the agencies [and] direct government intervention dwarfed by the amounts administered through the agency system'

(Rostagno and Utili, 1998: 13-14). In Italy, too, governments continue to be faced by deeply entrenched principles and practices in a system of social insurance that, until recently, paid very generous pensions to males with long employment records in core sectors of the labour market - organized on a DB formula and paying up to 80 per cent of earnings (Ferrera and Gualmini, 2000). This imbalance is a further example of the gender and geographical inequalities, discussed in Chaper Five, that characterize the Italian welfare regime. A further imbalance is the limited scope of non-pension-system social protection. Rostagno and Utili (1998: 8), refer to the fact that 'the portion of the social budget needed to meet entitlements arising from the mandatory pension system is between 10 and 20 percentage points higher in Italy than in major partner countries'. Indeed these observers make it clear that Italy's main public response to emerging welfare challenges - women's labour market participation, demands for child care, changes in family structures - has been 'the traditional reliance on derived pension rights', with governments failing to develop comprehensive policies for family support or a minimum income scheme.

Matters are also complicated by the fact that Italy has an ageing population combined with improving longevity rates, which places additional pressure on pensions even as these other challenges are increasing. The OECD estimates that 30 per cent of the Italian population will be over 65 by 2030 - about 10 per cent above the expected OECD average. This difficulty is compounded by the marked trend towards early retirement, which is more pronounced than elsewhere, The Economist (9.10.03) noting that fewer than three people in ten over the age of 55 'holds a (legal) job'. Each of these factors places additional pressure on Italy's expensive but inefficient pensions system.

Confronted with the need to cut back on social spending in order to conform to EMU criteria and offset wider international pressures, and with little space to resort to tax increases in an already overtaxed fiscal environment, Italian governments began to cut pension spending from the early 1990s. Pension reforms were introduced throughout the decade, particularly focusing on pension income and early retirement. While spending on pensions still remains above the EU-15 average at 15.1 per cent of GDP (Ambrovici, 2002), the changes to the Italian system have been successful to the degree that they have restrained 'a sector which has been historically hypertrophic' (Ferrera, 2000: 176). With regard to the reforms themselves, an initial phase (the Amato reforms of 1992) saw the retirement age for men and women raised (from 60 to 65 years and 55 to 60 years respectively), and 


\section{Pensions policies in continental and social democratic regimes}

both the minimum period for pension contributions and the reference period for calculating average earnings lengthened. The package was comparatively moderate, however, particularly because few immediate savings were likely to be achieved owing to the extreme length of the transition period and the fact that contribution rates remained 'excessively high' (Hamann, 1997: 11). A year after these reforms, further changes introduced reformulated supplementary pensions arrangements, establishing public second tier provision which had been 'relatively underdeveloped ... on account of the entrenched and generous nature of public social insurance and of the rules governing severance payments' (Ferrera and Gualmini: 2000: 191). Despite these efforts, continuing increases in social spending led to mounting concern from the EU and other international agencies about the level of public debt. Against this background, in 1994-5 the first Berlusconi government attempted to drive through pension reforms without reference to the trade unions and met with a degree of opposition that not only prevented an overhaul of the pensions system but led to the early demise of the government itself. In the judgement of Ferrera and Gualmini (2000: 191), Berlusconi's attempt to implement changes to seniority pensions 'would effectively have led to their disappearance' - a case of going too far, too fast.

These initiatives were followed in the mid-1990s, by the Dini reforms that, crucially, moved pension entitlement from a PAYG, DB system to one that, like Sweden, depends on a 'notional defined contribution' arrangement that takes greater account of actuarial considerations. Unlike Amato, a flexible retirement age was introduced, with an age threshold of 57 for pension entitlement, rules between private and public sector employees were standardized, and survivors' benefits graduated according to income (Ferrera, 2000; Natali, 2004). With benefits indexed to prices, the new system was projected to result in a decrease of retirement income from the current average gross replacement rate of 80 per cent to 70 per cent in 2030 and 65 per cent by 2040. Though far-reaching to the extent that the reform tackled the large disparities among different groups of workers, while reducing benefits overall, the transition period is exceptionally long, only taking immediate effect for individuals beginning work in 1996 and new retirees having their pensions calculated partially according to the new system from 2013. As Hamann (1997: 13) makes clear, 'only from 2036 onwards will all new pensions be calculated entirely on the basis of the new system'. With benefits levels still more generous than those expected in Germany or France, the growing awareness of the long-term economic effects of this problem led the government to seek further advice about pension reform.

In 1997 the Onofri Commission was appointed to investigate Italian social spending in the round, but its recommendations for the further reform of pensions were unequivocal. Taking account of the economic constraints imposed by EMU, and recognizing that insurance contribution rates were much too high, the Commission recommended cuts in contribution levels, increases in the minimum retirement age and a redirection of social spending away from pensions to provide resources for active labour market policies and minimum incomes for the worst off. However, the policies that emerged from this process, implemented in the 
1998 budget, were more cautious because they were watered down following negotiations with the unions. For instance, the government failed to persuade the unions of the benefits of speeding up the phasing in of the Dini reforms, while it also made concessions on the retirement age, exempting blue-collar workers from the increased age threshold for seniority pensions - thus reducing the overall significance of the reform package. With the system's inherent generosity not being directly addressed, scope remains for continuing debate and, indeed, arguments about the pensions system have become increasingly virulent in recent years with no real progress being achieved.

Since Berlusconi returned to power in 2002, his attempts to force the pace of change, particularly in relation to the retirement age, have generally met with popular hostility, although there has been somewhat greater consensus over the Government's attempts to develop private pension funds and enhance the role of capital markets. The drive to raise the retirement age to 65 for men and 60 for women by 2008 has been the most contentious issue and a focal point of popular and trade union protest. According to Rhodes and Natali (2003: 1), this initiative is particularly ill-judged because the reform will almost certainly be withdrawn during the scheduled review process due in two years or so - the verdict of these observers consequently being that 'the reform is more virtual than real'. As Rhodes and Natali (2003: 2) argue, the better strategy at this point would be to engage 'unions and employers in broader reforms to Italy's perverse and poorly performing welfare system'. Indeed, in the absence of such an approach, Italian pension reform will remain caught between the understandable reluctance of those who benefit from the generous PAYG arrangements to see their retirement incomes reduced, or working lives lengthened, and the mounting economic and social costs of inaction.

Where 'privatization' is concerned, recent policy proposals reflect the spirit, though hardly the letter, of the changes that have either been made, or are being contemplated, in Germany, France, Sweden and elsewhere. Generally speaking Italian pension fund assets, at 2 per cent of GDP, make up a considerably smaller percentage of GDP than those of comparable countries. One means of enhancing fund assets within second-tier provision, which is currently being contemplated, is to divert the proceeds of severance pay (Trattamento di Fine rapporto - TFR) into pension funds. TFR comes from the 8 per cent of employees' wages that is set aside by the employer and paid as a lump sum on retirement - it is essentially a form of forced saving for employees, and a source of low-cost financing for companies. Since 1993 efforts have been made to transform the proceeds into a source of pension fund income and the latest reform aims 'to transform the entire severance pay accumulated from 1999 up to 2002 into shares and/or bonds issued by the firm which are then transferred to the pension fund joined by the firm' (International Reform Monitor, 2004: 7). As the International Reform Monitor (2004: 4) observes, 'this reform is intended to create and develop a private system of pension funds giving more fiscal incentives to savings invested in pension funds, especially compared to other forms of long-term financial investment'. Boeri (2003) estimates that the transfer of the total stock of TFR would add assets worth roughly 14 per 


\section{Pensions policies in continental and social democratic regimes}

cent of GDP to Italy's pension funds, with stocks for the 1999-2002 period adding approximately 6 per cent, so providing a considerable boost to the pensions industry. However, despite the fact that government and trade unions appear to agree about the benefits offered by the reform, there appears to be little movement towards implementing it owing to companies' reluctance to see this source of capital removed unless adequate compensation is provided. Consequently, while some commentators regard the proceeds from TFR as the potential 'missing pillar' in the Italian pension system (Boeri, 2003), whether or not they are likely to form the basis of properly constituted arrangements for occupational pension provision remains to be seen.

\section{The Netherlands}

In some contrast to the previous cases examined in this section, the Netherlands initially developed a pension system which was much influenced by the Beveridge vision of comprehensive, universal pension cover. Postwar Dutch reformers wanted a system of this scope but also one that provided more generous retirement incomes for all citizens, based on prior earnings and residence. Unlike Beveridge, however, the state pension - the Algemene Onderdomswet (AOW) - was intended to be more than basic provision as the relatively high contribution levels (17 per cent in 2001) indicate. The resulting level of generosity from the AOW meant that the Dutch did not adopt public earnings-related second-tier provision in the postwar period, so the growth of private employer-sponsored schemes as a substitute is not surprising. Clearly these features hardly make the Netherlands a typical example of continental pension provision, although there is nevertheless a sense in which the country does conform to certain continental regime characteristics. For instance, the ubiquity of occupational pensions and their close relationship with the AOW mean that, taken together, they mimic the high contribution-high benefit, earnings related arrangements found in Germany, France and Italy. More indicatively perhaps, occupational pensions contain early retirement options, which again reflects trends in these countries, but in the Dutch case, the state has successfully managed to shift a substantial element of pension income to the private sector, 'thereby discounting its looming social security obligations' (Clark, 2003: 145).

Pension arrangements in the Netherlands, then, combine a contributory state pension with private occupational schemes, the latter enjoying rapid growth in the 1980s, resulting in almost 90 per cent of employees being covered (Myles and Pierson, 2001: 315). Although the Dutch population is ageing at rather above the OECD average (OECD, 2000a: 186) certain measures, in addition to the increased reliance on occupational schemes, have been taken to diffuse a potential pensions crisis. First, as Chapter Five indicated, labour market changes - particularly the entry of women into employment - have been explicitly encouraged, which is expected to improve the LFPR as baby-boomers enter retirement. Second, all political parties have agreed that extra revenue from general taxation should be put into a special, interest-earning fund to meet age-related pension expenditure after 2020 (OECD, 2000a: 37). Such a move will produce higher yields because 
the revenue base is not restricted to employees. Third, with regard to occupational pensions, which, unlike in Denmark, has been organized on the more expensive DB model, 'unions and employers are quietly negotiating a change from a final to middle wage system, and the replacement of collective early retirement schemes ... with a funded time-saving system' (Hemerijck et al., 2000: 224). This shift of emphasis is expected to reduce the amount of benefit payable on retirement sufficiently to enable employers and pension funds to meet their obligations - as they must do under a DB scheme. These consensually agreed arrangements are expected to ensure that pensions in the Netherlands are better adapted to the ageing problem than is the case with many European welfare regimes. It is certainly the case that Dutch governments have not had to make the marked adjustments noted elsewhere in this chapter.

Are there, then, any emerging problems on the Dutch pensions horizon? On the one hand, no, because the Netherlands appears to have incorporated successfully the financial competitiveness associated with Anglo-American capitalism and the social market features of European corporate governance - providing according to Clark (2003: 143), 'a beneficial mixture of pension institutions'. The 'compromise' between the two systems is embedded, first, in the relative generosity of the AOW, which remains essentially a 'citizens' pension' and, second, in the institutional structure of occupational pensions arrangements. With respect to the latter, the compromise takes the following form. Because the boards of sector-wide and corporate pension plans are legally independent and responsible for the management and investment strategies of the schemes, they have a capacity to operate autonomously in the global financial market. Yet, because pension provision is organized on a corporate or sector-wide basis, with pension boards managed by the social partners according to established processes of collective bargaining, there is little inter-firm competition with administrative costs lows and contribution rates, and pension benefits, being similar within each sector (although not necessarily among them). In this way, the worst ills of 'Grey Capitalism' (Minns, 2001; Blackburn, 2003) are avoided with 'the national institutions of social solidarity properly [regulating] the risks of selection bias and moral hazard' (Clark, 2003: 152 and see Clark generally, 150-2).

On the other hand, pressures on these solidaristic elements of the Dutch system are growing. For one thing, Dutch governments have increased the market accountability of sector-wide pension funds by requiring that performance is assessed against 'the industry average and deviations measured according to standardized Z-scores' (Clark, 2003: 150). Although in the solidaristic world of sector-wide funds it may be possible to offset consequent competitive pressures, this move is nevertheless significant because it plainly introduces a greater market element into investment decisions. Of equal importance is the recent decision to introduce, from 2006, a new financial assessment framework (Financieel Toetsingskader - FTK) which requires pension funds and life insurers to match assets more closely to liabilities. The new framework demands that funds no longer value liabilities according to a fixed discount rate but instead according to a mechanism that is more sensitive to prevailing capital market rates, which will make liabilities more 
volatile. A recent Rabobank International report (2004: 8-9 www.rabotreasury web.com) estimates that, in consequence, 'the present value of liabilities could increase by no less than 20\%', which in turn will lead to 'a change in the cover ratios of Dutch pension funds and probably lead to increased demand for inflationlinked bonds'. Assuming that a shift into bonds will result in lower returns on assets, Rabobank forecasts that contribution rates are likely to rise. These changes may accelerate moves from DB to DC plans as funds attempt to match the risk profile of their assets more closely to their liabilities.

Whether or not these changes will undermine the solidaristic elements of pensions arrangements in the Netherlands remains unclear. While governments have introduced them in order to conform to the liberalizing impetus of the EU Pension Directive, some efforts are being made to preserve aspects of social solidarity. According to IPE (www.ipe.com 4.11.04) a model currently under discussion will separate pension funds into two entities - 'the pension fund board will set policy while a market-driven company will be in charge of asset management and administrative affairs [which] is expected to compete for new business on the free market'. An advantage of this arrangement is that it could act to break up potentially monopolistic behaviour on the part of fund boards, which currently can 'operate financial firms from their administrative offices using boards of directors drawn from the fund's own board of directors' (Clark, 2003: 157) - effectively risking the capture of decision making and asset allocation by entrenched interests. Nevertheless, the counter-risk is that large corporate and sector-wide funds will become increasingly drawn into the activities of the global market for financial services with all the temptations that this implies. As this process advances it is hard to see how fund boards, however attached to the principles of social solidarity they may be, will be able successfully to incorporate the dynamic, competitive characteristics that their market-led arms will have to develop without ultimately losing sight of the principles themselves.

\section{Social democratic regimes}

If this volume was primarily concerned with the accurate categorization of pensions systems, then Sweden would be placed in a 'Beveridgean early second tier' group, while Denmark, though also 'Beveridgean' in origin by virtue of its commitment to a universal basic state pension, is best understood as a 'latecomer' that failed to develop public second tier provision during the postwar period (Hinrichs, 2001; Myles and Pierson, 2001). This basic difference in pensions arrangements means that these countries have little in common in this area apart from the traditional social democratic commitment to a fairly generous universal 'citizens' pension'. While both face similar challenges in terms of population ageing, the pressure on public budgets and the growing influence of global finance in the form of the increasing turn towards the liberalization of financial practices, their approaches to dealing with them have been, of necessity, very different. Swedish governments have been faced with the need to reconstruct their embedded second tier arrangements - literally to alter course in mid-stream - while Danish administrations 
have had to deal with a more gradual, but marked, shift towards private occupational pensions, with the potential implications for principles of social solidarity that this entails.

\section{Denmark}

In common with that of other OECD countries, Denmark's population is ageing. Although the rate of ageing is not particularly dramatic - Denmark's OADR is expected to rise in line with the OECD average over the next forty years - it is the case nevertheless that, if existing trends continue, there will only be 2.5 employees for each older person by 2030 compared with 3.5 employees in 1960 (OECD, 2000a: 148). As discussed in Chapter Three, following a difficult period in the 1980s, the Danish economy strengthened during the 1990s and the commitment to welfare spending has remained strong - particularly where health and old age pensions are concerned (Goul Andersen, 2000). Indeed, Danish public spending has remained 60-70 per cent higher than the OECD average since 1980 with spending overtaking Swedish levels in the late 1990s. With a healthy balance of payments and falling debt, Denmark is now the second wealthiest country, after oil-rich Norway, in the Nordic group (Marklund and Nordlund, 1999: 23). Within this overall framework of welfare generosity, however, a number of adjustments have been made, not so much in terms of immediate retrenchment, but rather by way of a reorganization of key areas of provision in anticipation of future fiscal difficulties. Where the basic state pension is concerned, the core change has been the dilution of Denmark's generous tax-financed, universalistic pension system, which, since 1994, has been affluence-tested. Higher earners now receive only a portion of the basic pension, while the highest earners may receive no pension at all (Kvist, 1997: 235). Conversely, the poorest retirees are eligible for a meanstested supplement to a maximum value of about half that of the affluence-tested element (Pensions Policy Institute, 2003: 10). About 50 per cent of pensioners' gross incomes derives from the folkepensionen, although this figure is declining owing to the dramatic rise in occupational provision. A further element of the public system is the Labour Market Supplementary Pension (ATP), a fully funded, DC scheme which covers all wage earners and, since 1996, the bulk of social security claimants as well. ATP, however, is only intended to provide a very modest flat rate supplement to the basic pension. It is targeted primarily at low earners and has long been regarded by the trade unions as furnishing middle income earners with low replacement rates. As Kvist (1997: 27 my emphasis) states, although 'the national old age pension and ATP together provide low income groups with comparatively high replacement rates ... high income groups do not have the same income compensation as in many other European countries'. This feature is important, not least because these state systems afford a high level of gender equality in old age - Denmark being amongst the most generous of European states in this regard (Ginn, 2004: 130).

While low earners have benefited from the relative generosity of publicly provided pensions, the most dramatic change in the Danish system has been the 
rapid development of occupational and private schemes, intended to provide better replacement incomes for middle and higher earners. DC occupational schemes date back to the late 1960s when plans were created for public employees as compensation for the removal of tax-financed PAYG arrangements for civil servants (Ploug, 2002b: 5). These early developments were compounded by the gradual expansion of occupational plans throughout the 1970s and early 1980s - an important precedent for more decisive moves in this direction towards the end of the decade. The occupational, or 'Labour Market', pensions that emerged in the early 1990s are fully funded, DC schemes with contributions set as a percentage of wages according to collective agreements between employers and employees. Since they were first introduced in 1991, these industry-wide schemes have grown to cover over 80 per cent of the labour force - effectively inverting the traditional dominance of public sector pension provision. As Benner and Vad (2000: 450) point out, annual occupational pension income rose faster than income from public pensions between 1983 and 1993 - the former rising by 6.2 per cent per year compared with a 1.6 per cent annual increase for the latter. Despite fears that inequalities among older people may increase and that rising private pension income could lead to the emergence of a dual pension system, changes to date have not led to benefit cuts for any group and the value of pensions has gone up. Even so, with low income earners apparently not benefitting to the same degree as those with occupational provision, who enjoy beneficial tax advantages, for example, this nascent division between public and private pension funding is likely to become more marked in the future.

Turning to the political and institutional processes that have driven this movement towards the marketization of old age pensions, these have been broadly consensual. At party level, Denmark's political system is strongly oriented towards coalition governments - Conservative dominated in the 1980s and Social Democrat for much of the postwar period and for the greater part of the 1990s. Although during the 1980s the Conservative-Liberal coalition was prepared to concede to the demands of the Danish trade union confederation (LO) for a generous taxfinanced minimum pension, it was not prepared to give way to union calls for a state superannuation scheme on pre-reform Swedish lines - something the LO had been demanding for years (Overbye, 1996). Lack of progress in this direction, with the Conservative-Liberal coalition first promising to negotiate with the LO, then retracting the promise while nevertheless continuing to discuss occupational pension arrangements separately with public sector unions, eventually led trade unions representing skilled workers - particularly the powerful metalworkers - to break ranks with the LO in 1990 and negotiate a separate DC occupational pension arrangement with employers (Overbye, 1996: 81). This move was facilitated by the earlier decentralization of wage negotiations in 1987. As Overbye makes clear, the Danish LO is a weaker organization than its Swedish or Norwegian counterparts, despite high union density, the consequence being that the general trend towards decentralization observable in the Nordic countries was more marked in Denmark. Industry-wide occupational pensions became increasingly popular in the early 1990s with the Social Democrats effectively being forced to accept them, 
the arrangements themselves being 'negotiated in corporatist consultation with unions or with professional organizations in a particular field' (Cox, 2001: 482).

Two points are worth noting here. First, the general market-oriented thrust of pension reform in the 1990s was confirmed and strengthened in the recommendations of the 1993 Social Commission appointed by the Conservative coalition to review the existing welfare system. Faced with something of a fait accompli, the Commission concluded that individuals should take greater responsibility for their own pension savings and advocated 'making the public system a less central component of total pension income and replacing the receding public scheme with more vigorous incentives for private pension savings' (Cox, 2001: 481). This approach was endorsed by the Social Democrat-led coalition that came to power in 1993, its policy outcomes being clearly visible in tax reforms and the continuing expansion of DC occupational pension schemes. Second, the consensual nature of the process owes much to the Danish system of industrial relations, which, in the 1990s, was increasingly characterized by the form of 'organized decentralization' discussed in previous chapters. This system almost certainly facilitated the expansion of occupational pensions on an industry-wide basis (although schemes can be company based, collective agreements between the social partners are more common with over 600,000 white- and blue-collar workers participating). Indeed, such is the coverage of these schemes that, in 1997, the Danish government felt it unnecessary to make them mandatory for all workers.

There is one further issue here, which has already been mentioned in connection with the continental regimes discussed above. The fact that the Danish system has become so dependent on occupational provision means that it is no longer just a system of pension provision but also a financial industry which is becoming increasingly exposed to the global financial market. While the same can be said for all systems that have a high ratio of pension fund assets to GDP (Denmark's ratio is among the highest in the EU), the point is that these systems are becoming participants in global financial practices organized on the Anglo-American model. Standing to one side of EMU, Denmark is less subject to the embryonic, though not uninfluential, pressure for financial liberalization coming from this quarter but the Danish pensions landscape appears to be changing nevertheless. In fact, something of a sea-change took place in 2000 with the introduction of the Taxation and Pension Investment Returns Act. This legislation removed a set of arrangements so complex that 'only the large domestic fund managers ... were able ... to provide a full service to pension funds' (Broby's website for active asset management, 2002: 1). The new Act has resulted in 'foreign fund managers ... rushing to send bright young marketers to what they see as a new and under-developed market'. While occupational schemes continue to be managed by the social partners - and domestic fund management is sophisticated - the expectation is that the industry-wide pensions sector will 'see an increase in investments in equities [and the] increase will ... be in foreign equities'. One example of this turn is ATP - the first-pillar fund - which decided to invest $€ 3$ billion into private equities in 2002 (Altassets 2002: 2). With greater global market exposure, and markets themselves currently volatile, Denmark is likely to accede to the growing pressure to conform to more 


\section{Pensions policies in continental and social democratic regimes}

transparent standards of pensions governance - indeed this debate began in earnest in the summer of 2004 (Mercer: 2004: 2). How new forms of governance will affect the role of the social partners and the 'solidaristic' dimension of Danish pensions provision remains to be seen. As discussed above, the current situation in the Netherlands suggests that solidaristic institutions, however well embedded, may be vulnerable to the increasing influence of the Anglo-American standards and practices that dominate the global financial market.

\section{Sreeden}

The first tier of the postwar Swedish pension system was comprised of a basic flat rate pension, the origins of which date to 1913. A supplementary pension was added to the basic pension in 1976 for those with low incomes. Benefit levels were calculated in relation the the 'base amount' (about 20 per cent of the average industrial wage), with the basic pension paying about two base amounts. Over time, the supplementary pension came to increase the value of the basic pension by about 50 per cent. Following what, for Sweden, was a period of bitter political disagreement about the potential nature of second tier provision (Esping-Andersen, 1985), ATP - the earnings related component - was introduced in 1960. Benefits were calculated on the generous basis of the best fifteen years of earnings and, at the point of start-up, the system was fully funded. With the funds devoted to the financing of housing, however, the system quickly became a typical PAYG scheme with the consequence that it became vulnerable to the problems associated with population ageing. Not only did the generosity of pension provision appear to encourage early retirement - by the 1980s 50,000 new cases of early retirement were being granted each year (Stahlberg, 1995: 46) - but projections about the ageing of the baby boom generation suggested that pension payments could not be sustained on the existing DB basis. Low economic growth throughout the early and mid-1990s added to these problems, making it difficult continually to raise employer and employee pension contributions. As discussed in Chapter Five, falling GDP and a rise in unemployment from under 2 per cent in the late 1980s to over 8 per cent in the early-to-mid 1990s encouraged first Bourgeois, then Social Democratic, governments to adjust existing patterns of welfare provision, including old age pensions.

Changes to the Swedish pension system agreed during the 1990s have been substantial. At first-tier level, a new Guaranteed Pension (GP) pays benefits originally provided by the combined basic pension and supplementary pension to those whose eligibility for income related provision is restricted (Eitrheim and Kuhnle, 2000). Payment of the full GP is conditional on forty years residence in Sweden, payments being reduced by $1 / 40$ for each year under the stipulated limit. However, this arrangement was considered to discriminate against minority ethnic groups, which had disproportionate numbers of individuals with neither full contribution records from employment, nor sufficient years of residence to trigger sufficient levels of GP. To correct this problem, in 2003 a new payment - the äldreförsörjningsstöd (AFS)

- became available to all persons over 65 'resident in Sweden who have no pension 
or such a small pension that they cannot manage their upkeep in any other way' (Timonen, 2003: 5). For others qualifying on the residential criterion, the GP is 'affluence tested' rather than 'means tested' in the strict sense: although earnings related income is taken into account, additional income from private assets or other sources is disregarded.

Outside this reorganization of the basic pension, the core of the reforms relates to the extensive changes made to the earnings related element. The details are complex but essentially the earnings related tier takes the form of a 'notional defined contribution' (NDC) system with contributions based on a 'defined contribution rate' applied to earnings and recorded on individual accounts (Palmer, 2000: 5). Unlike typical DG schemes there is no advance funding, with contributions paid into the system being used to finance current pensions on a PAYG basis, which are administered through four independent buffer funds. Nevertheless, the value of an individual's account is a claim on a future pension and in this way pension provision is effectively 'fully funded'. Pension levels are based on total lifetime contributions (as opposed to the best fifteen years income under the old system), with contributions being divided equally between employees and employers, and balances further enhanced by 'interest payments' indexed to wage growth or an 'approximation of the internal rate of return in the system' (Settergren, 2001: 3; see also Myles and Pierson, 2001: 323). These arrangements reduce the salience of the connection between contributions and earnings without actually severing it, meaning that the incentives to seek and maintain employment - the core advantage of DC systems - are retained. Significantly, the fact that, in the new system, employees will be subjected to a payroll tax is expected to 'increase public awareness of the costs of retirement' (Anderson and Meyer, 2004: 152).

Four other features make the system more flexible than its predecessor. First, the NDC system automatically adjusts to financial pressures caused by population ageing because 'for any given amount of accumulated capital, a benefit is less at a given retirement age the greater the length of life expectancy' (Palmer, 2000: 11). With life expectancy projections made available well in advance, the idea is that individuals can adjust decisions about work and retirement to accord with anticipated pension provision. Second, although the earnings-related pension is no longer calculated on the fifteen best years of income, which is likely to disadvantage women, free pension rights have been made available for parents with child care responsibilities, which will mainly benefit women in particular, in addition to others, such as those on disability benefits, who have not accumulated sufficient earnings related entitlements. The system automatically credits 'the parent with the lowest earnings in the year(s) in question' with child-care pension rights, the 'earnings' being calculated according to the most favourable of a range of computations, each targeted to specific types of recipient (Palmer, 2000: 16). Third, the age of retirement has been made more flexible: the basic pension can be claimed at 65 but the earnings-related pension can be claimed at 61 with benefits being adjusted according to the exact age of take-up and becoming more generous towards the new 40-year ceiling.

The fourth point is the most interesting in view of the past universalist and 


\section{Pensions policies in continental and social democratic regimes}

solidaristic character of the Swedish welfare regime. A compulsory private funded element, or 'pension reserve', has been introduced. Of the 18.5 per cent of gross income paid by the employer and employee as pension contributions, 2.5 per cent will go into one of (now) 650 or so privately managed funds, chosen by the individual concerned. The majority of these funds invest in equities with about 50 per cent investing primarily in overseas equities. So long as they do not opt for the default fund, which is entirely managed by the government for those who do not wish to make active investment choices, individuals are permitted to change funds at any time and do so through the auspices of a public clearing house that acts a 'broker' between individuals and the funds themselves - there is no direct communication between investors and fund managers in the new Swedish system, a feature that, by preventing unnecessary competition for clients, reduces administrative costs.

This private component is at once less and more than it appears. On the one hand, the extent of these arrangements is considerable with 'the number of investment plans vastly exceeding what is available in other countries that have introduced individual accounts or 401 (k) plans' (Sundén, 2004: 3). Investment in the privately managed funds is at the individual's own risk and there are no guarantees on returns. To this extent, free market conditions apply for those not opting for the government's default setting and, indeed, 'most participants have lost money in their accounts because of the fall in the stock market and many are starting to question the reason for managing their own pension fund' (Sundén, 2004: 7) - this feature being largely responsible for the marked decline in those opting actively to manage their individual accounts. On the other hand, the total contributions to these funds are comparatively small in relation to the public NDC element and risks are also offset by other retirement assets such as DC occupational pensions, which provide roughly 10 per cent of retirement income and cover the majority of employees (OECD, 2000b).

With these points in mind, it is clear that pension reform in Sweden has significantly changed previously existing arrangements. In general terms, individuals have to work longer to achieve a full pension, with pension value being contingent on factors such as life expectancy and market performance, which will make individual decisions about retirement considerably more complex. It is not clear that women, particularly those who are single mothers, will fare better under the new arrangements because, since they tend to earn less, they are hit harder both by high progressive taxation whilst in employment and the effects of lower pension contributions once they have retired. On a more positive note, it is generally accepted that the new system will be more equitable among social classes than the old ATP arrangements, which privileged middle-income groups once the system had matured (Gould, 2001: 95-6). With respect to the privately managed element, it seems a little dramatic to argue that it 'represents a shift from public sector to private sector control' (Timonen, 2001: 42) - particularly because a majority of new entrants to the scheme are declining to choose funds for themselves and thus opting for the general pooled fund run by the state (Blackburn, 2003: 258). It is more likely that the majority of Swedes would concur with Kuhnle's general observation (2000: 225) that, 'although the Nordic countries are now more open 
to private initiatives in the fields of health services, social care services and social insurance than before ... no political party (and very few voters) favour a deconstructed welfare state', the point being that Swedes themselves do not perceive the changes made so far as likely to do significant damage to universalist principles (see Hajighasemi, 2003).

The one flaw in this judgement is that the market element in the new arrangements could increase over time with the result that the system could gradually become more market-oriented. To be sure, the current situation with individual accounts hardly suggests that Swedes are becoming avid private investors but, even so, Gould (2001: 97) points out that the incidence of personal private pension insurance rose from 5 per cent of employees in 1984 to 25 per cent by 1996 and, equally significant may be the marked rises in the equity portions of Swedish pension funds in 2000-1 (Investment and Pensions in Europe, 2003: 33). The 2001 Report of the Third Swedish National Pension Fund (AP3) made it clear, for example, how fund managers have reorganized investments away from the previous reliance on Swedish treasury bonds to 'a global, well-diversified portfolio with a considerably higher proportion of equities than previously' (Third National Pension Fund, 2001:3). Perceptible changes such as these could result in further adjustments away from the public character of the Swedish pensions system in time to come (Myles and Pierson, 2001; Green-Pedersen and Lindbom, 2002), particularly because it appears that the institutional constraints on any putative move towards the market are now less than they used to be.

This much is evident from the manner in which pension reform in Sweden was achieved. Although, in contrast to the current situation in many continental countries, the process was highly consensual, the role of the trade unions was less prominent than has historically been the case in Sweden and the SAP was plainly prepared to compromise on certain important issues. Anderson and Meyer (2002: 235) note, for instance, that unlike earlier pensions investigations, 'the working group excluded members of the interest groups, such as the trade unions'. Although 'the influence of the SAP in the reform process [was] substantial' (Anderson and Meyer, 2004: 152), these observers state that the Party had to concede, for example, over the switch to the visible individual contributions, something that the unions opposed. Gould (2001: 93) also comments that the Social Democrats 'put the agreement above pressure from their own rank and file', citing the retreat from the desire on the part of both the SAP and the unions to retain PAYG and a greater degree of redistribution as evidence of the left's willingness to compromise. Most telling of all is the fact that Social Democratic agreement was gained for the 'pension reserve', which was a key demand of the bourgeois parties, and strenuously opposed by both the Party membership and the trade unions.

In the event, even though five of the seven Swedish political parties and over 80 per cent of MPs supported the reform, the context of the compromise is important. There was a general recognition that the old arrangements had to be reformed if Sweden was to retain a viable pensions system in a colder economic climate. This near-universal agreement about the need for reform meant that typical pathdependent sticking points such as the need to maintain near-retirees' expectations, 


\section{Pensions policies in continental and social democratic regimes}

though complex, were not allowed to subvert the reform process. The concern to protect existing entitlements certainly contributed to the shared view that there should be a reasonable transition period before the new system's full introduction (see Palmer, 2000: 18-19) and also, despite some misgivings on the part of the Social Democrats, to the agreement that the public savings (AP-funds) accumulated during the build-up of ATP (i.e. to compensate for the decline of private saving in the wake of the earnings related reform) should be used to ease what could otherwise have been a significant double payment problem. Outside these technical considerations, it is worth noting once again, the fact that the trade unions, though important players, were only able to influence decision making at one remove, their relative weakness contributing to the particular character of the new system as finally agreed in 1998.

Taking these points together, it is hard to imagine that Sweden would have embarked on reform at all had it not been for the combination of recession and worrying predictions about population ageing. The deviation from the 'path', though slight as yet, is understandable in view of the fact that more typical reforms - raising contribution levels, taxes and so on - could not realistically be contemplated, particularly from the economic perspective of the early-to-mid 1990s. Whether or not the reformed system will be pushed towards further 'privatization' remains to be seen - but the fact that the main left parties and trade unions do not have quite the influence they enjoyed in the past suggests that such an outcome is at least plausible.

Both this and the preceding chapter have produced sufficient evidence to indicate not only that pension systems in different regimes are changing, but that reforms are reorganizing existing arrangements in ways that, however implicitly, reflect market imperatives. It is important to be clear that these developments do not have to be characterized as a 'race to the bottom'. It should be evident from the case studies that different countries are moving at different speeds, with policies emerging from different contexts in ways that are inevitably affected by 'local' institutional assumptions and embedded practices. In many instances - especially the continental countries considered here, though with the exception of the Netherlands - processes of change have been, and continue to be, extremely sticky. Faced with disruption to deep-rooted expectations about levels of security in old age, and with organized labour in particular fearing the loss of erstwhile influence, it is not surprising that governments of all political persuasions in these countries have had to employ consensual strategies of corporatist bargaining and the 'logic of trade-offs' (Natali and Rhodes, 2004) to achieve change. Elsewhere, in social democratic regimes, the pace of change has been both more decisive and swifter. Social democratic states have embraced reform in ways designed to preserve solidaristic, egalitarian principles even as they become more exposed to the market. However, the key question for these regimes is whether the speed of change can be controlled as the institutional structures on which bargaining and negotiation depend come under increasing pressure. It is when confronting issues of this kind 
that the role of GEPs needs to be brought into what otherwise can appear to be essentially 'domestic' problems.

Without wishing to characterize the Anglo-American model and the financial power of the pension funds that embody its core practices as an uncontrollable leviathan, it is important to acknowledge that the model represents a clear challenge to many European welfare regimes confronted by the need to reform their pension systems. While certain countries - Denmark and the Netherlands - with longer histories of private occupational pension arrangements are prepared to see their large pension funds become more deeply engaged in the global financial market and to adjust their systems accordingly, others are more ambivalent. Although governments in Germany, France, or (differently) Sweden, may well perceive the benefits to be derived from reducing the state's commitment for funding security in old age, and while large corporations also see distinct advantages in, inter alia, forms of accounting that more accurately depict the relationship between assets and liabilities, and provide wider opportunities for investment and growth, organized labour and those individuals who are retired, or within sight of retirement, are understandably more defensive. It is in the clash between this 'domestic' ambivalence and defensiveness, and the domestic impact of global financial imperatives, permeated of course by a range of contingent factors - unification in Germany, the timing of elections, constitutional norms and so on - that pension reforms need to be understood.

To date, it is not the case that European governments are simply buckling under the weight of Anglo-American financial logic. 'Parametric' reforms - essentially incremental adjustments - continue to dominate actual legislation and of course public first and second tier pensions systems continue to be the core sources of security in old age in the majority of EU countries. Even in the Swedish case, surely the clearest example of systematic change, it is possible to represent the key reforms as an 'adjustment' of existing practices and principles, albeit a radical one. But the argument above suggests that in many instances parametric reforms are being accompanied by others, or ideas for others, which, if fully implemented would be 'paradigmatic' - shifting pensions provision away from established mechanisms and principles. The market orientation inherent in these policies and proposals symbolizes the declining institutional force of organized labour and the solidaristic principles embedded in conceptions of social partnership, which have hitherto characterized social democratic and continental regimes. With pressure for greater penetration of the European pensions market increasing from within and without, it is hard to be sure that these solidaristic alternatives, whether in the form of public PAYG systems or occupational arrangements managed by the social partners, can survive indefinitely. 


\section{Conclusion

\author{
Welfare regimes in a liberalizing \\ world
}

If there is a single 'conclusion' to this book, it is that 'globalization matters' - but that the impact of GEPs inevitably differs depending on institutional context. The institutional foundations of the mature welfare regimes are in flux partly because a range of contingent factors - some concentrated in one country, others such as population ageing having a wider impact - have challenged the capacity of postwar welfare systems to deliver the appropriate goods and services to the right populations in a cost-effective manner and this has in turn challenged prevailing assumptions about the role and nature of welfare itself. But these factors have not emerged in an economic and political context where the resources or political will exist to develop new goods and services, and new forms of delivery, by recourse to higher taxation and insurance contributions, and/or an increased role for the state. By themselves contributing to a global economic environment conducive to tighter budgets, GEPs constrain available options by raising the political and economic costs to national governments of pursuing 'tax and spend' strategies. In this way they 'condition' and 'frame' decision-making and policy outcomes within the globalinstitutional nexus.

This is not to say, however, that the consequences of constraint are necessarily manifested in spending cuts. As Castles (2004: 15) argues,

over nearly two decades, in which the welfare state crisis has been the leitmotif of informed social commentary, and welfare state reform an ostensibly major concern, many Western governments, welfare state structures, and priorities, at least in so far as these may be revealed by spending patterns, have remained much as they were in the early 1980s.

Contemporary welfare state politics, then, are not 'about' cuts as such. Indeed, it is possible that welfare systems may actually increase spending in certain areas in response to changes - both high unemployment and population ageing in (slowly) reforming pensions systems can lead to higher spending, for example. Moreover, normal processes of political debate and electoral competition will mean that 'reforms may incorporate some programmatic expansions in exchange for cutbacks elsewhere, rather than simply dismantling social benefits' (Pierson, 1998: 557). Nevertheless, the policy changes examined in this book indicate that, however gradually, welfare regimes are adopting policies which contain elements - sometimes 
merely traces - of 'liberalization' as the power of traditional institutions declines and governments are confronted with the hard-edged logic of GEP-induced constraints. This term does not simply refer to 'retrenchment' understood in spending terms so much as to structural changes in the organization of welfare provision which, in one way or other, are loosening existing institutional arrangements

Two matters will considered by way of conclusion. First it is important briefly to summarize the changes considered in the previous four chapters in order to provide a 'qualitative snapshot' of change in the examples studied. Second, in view of the fact that many regimes are 'recalibrating' welfare provision in ways conducive to greater liberalization, it is also important to consider what limits there might be to this process. In European welfare regimes in particular, which, after all, are the core foci of potential 'regime change', there is every reason to be clear about the potential of newly emerging institutions to contain the 'liberal turn'.

\section{The extensity and limits of neoliberal logic}

The evidence of neoliberal drift discussed in previous chapters is not tantamount to the 'race to the bottom' that many observers predicted in the 1990s. Liberal regimes themselves have, not surprisingly, embraced neoliberal logic more swiftly and willingly than have social and continental states, which have approached 'recalibration' more cautiously and in different ways. How far these latter countries will travel is unclear, but, in view of GEPs and the distinctly neoliberal trajectory of the EU, in some cases it could be 'quite far'. It is not possible to 'measure' neoliberal advance with any precision, but with key institutional structures weakening and the influence of important collective actors on the wane, much will depend on the ways in which recalibrated social policies in the different regimes either do, or do not, enhance two significant dimensions of liberalization: 'individ' ualization' and 'conditionality'. These features are present in all 'reorganizing' welfare systems, but how they are configured indicates the strength of neoliberal drift.

The concept of individualization as this term has been applied to analyses of contemporary post-industrial or 'post-modern' societies is by no means restricted to social policy. In Bauman's (2001: 49-50) 'individualized society', for example, "the "public" is colonized by the "private"; "public interest" is reduced to curiosity about the private lives of public figures, tapering the art of public life down to a display of private affairs and public confessions of private sentiments' - and 'the prospects of the individualized actors being "re-embedded" in the republican body of citizenship are dim'. In more empirical terms, Putnam (2000) charts the decline of 'social capital' in the USA, understood as the engagement of individuals in the life of their communities, and the corresponding rise of disengagement and individualization - expressed in the metaphor of 'bowling alone'. If the main theme is community decline, individualization is an integral part of a process that leads Putnam (2000: 27) to conclude that 'we have pulled apart from one another'. Beck and Beck-Gernsheim (2003: xxi-xxii) come closer to explicit social policy issues when arguing that individualization is rooted in the growth of an institutionalized 
individualism in which 'central institutions of modern society - basic civil, political and social rights, but also paid employment and the training and mobility necessary for it - are geared to the individual and not to the group'. They go on to state that 'insofar as basic rights are internalized and everyone wants to or must be economically active to earn their livelihood, the spiral of individualization destroys the given foundations of social existence'. While, on this view, it is possible that the process of individualization might in time lead to the development of an 'ethic of "altruistic individualism", , the term nevertheless remains closely connected, as both cause and consequence, to the growing inequalities in post-industrial societies.

Where welfare provision is specifically concerned, Ferge (1997: 23) has referred to 'the individualization of the social' as 'the withdrawal of social commitments and ... by implication ... the rejection of the importance of an integrated society'. For her, this shift is part of a wider transformation from the 'old paradigm' of the twentieth century, rooted in 'the modern "European" social state', to a new postindustrial, or post-modern, paradigm defined, inter alia, by rising inequalities, the rejection of collective responsibility and increased international competitiveness. This understanding very much accords with hyperglobalizers' views about the likely trajectories of welfare regimes, with the weaknesses that this rather general, one-dimensional perspective entails. Nevertheless, Ferge's approach usefully describes the features that need to be taken into account when considering the extent of neoliberal drift in contemporary welfare regimes, although it needs to be complemented by a rather different understanding of individualization that has more to do with the ways in which 'social policy is becoming a branch of the doit-yourself industry' (Klein and Millar, 1995: 304). The point here is not to try to decide whether the state or the market is the best vehicle for delivering social policies, but to ask 'to what extent, and under what conditions, it is desirable to promote individual decision-making in social policy - whether in a State or a market system of welfare production' (Klein and Millar, 1995: 307). For these observers, the promotion of individual choice and decision making can certainly be desirable where DIY social policy is framed by adequate public regulation in the context of an 'enabling state' which attends both to redistributive issues and social investment.

Taken together, these two varieties of individualization can be used to throw light upon the nature of contemporary social policy change in different regime types - but 'conditionality' further illuminates matters. Two types of conditionality are relevant here. First, the degree to which policies demand 'specific performance' under threat of penalties demonstrates that they are less concerned about citizenship as a social right than about the desire to enforce particular forms of individual compliance. Benefit penalties for refusing offers of employment are a case in point (Dwyer, 2000). Equally, means tests are best understood as a 'condition' - in other words, individuals have no right qua citizens to social goods and services. Second, conditionality can also be understood rather differently as a 'technology' which induces individuals to 'condition themselves' - but supported by an enabling state that promotes the DIY welfare policies that make self-conditioning feasible. Certain labour market policies, for example, activate the unemployed in ways that do not simply provide jobs under threat of sanctions but also encourage the unemployed 
to regard work and training as a means to a range of opportunities, including higher standards of living, a pension and so on - a life plan in other words. Individual interviews and guidance about job opportunities are an instance of how the unemployed can be trained to self-condition and this process is also evident in certain pensions policies. As previous chapters have shown, with the private/ occupational element of pension provision increasing in the majority countries, some states support individuals in their retirement planning by permitting a degree of individual choice in pensions schemes, retirement ages and so on - but in the context of regulation and generous public provision in old age - while others 'encourage' individuals to act as responsible private consumers in the pensions market with a minimum of guidance and only modest levels of publicly-funded provision.

In certain circumstances, individualization and conditionality can be advantageous, but as Lewis and Bennett (2004) point out, different policy logics apply in differently institutionalized regimes, the nature of these phenomena varying accordingly. For example, while women may generally benefit from individualizing measures that provide greater access to the labour market and the entitlements pension rights, sickness benefits and so on - associated with employment, they will benefit even more where these policies are accompanied by publicly provided forms of social care that reduce unpaid domestic obligations. Naturally, neoliberal drift will be more pronounced and rapid where privatizing and marketizing strategies produce highly individualized and conditional social policies relatively unfettered by concerns about social cohesion or the putative enabling role of the state. Conversely, in those regimes where individualization and conditionality are accompanied by a recognition of market limitations and a continuing commitment to public welfare the pace of liberalization will be slower.

\section{Liberal regimes}

There is a good deal of diversity among the liberal regimes examined in this book, but, because private and market alternatives to state provision have been expanded in each case, interpretations of individualization and conditionality can be extreme. Recent changes to labour market policies in the USA, where an explicit workfare agenda now dominates policy making, are an obvious example. Here the 'work first' regime is both robust in terms of the compliance it demands from both men and women as independent labour market actors and uncompromising in the penalties levied either for non-performance or, uniquely, for literally running out of time on benefit. Means testing is rigorous. Even where pensions are concerned, bearing in mind that US retirement provision has a significant social insurance dimension, potential solutions to the forecast overspend on pensions are understood in terms of private individual accounts for the insured and a greater concentration on personal private and occupational schemes - particularly 401 (k) plans. In both cases the turn towards full funding through IAs and occupational DC arrangements places the responsibility for retirement provision and the burden of risk on individual employees. It is hard to see social policy in the USA as anything but highly individualized, on the one hand, and 'conditional' in the punitive sense of the term, on 


\section{Conclusion}

the other. Lacking a developed 'enabling state', labour market and pensions policies are not consistently, or coherently, underpinned by training and skills strategies for vulnerable populations, nor does the Federal Supplemental Security Income Program provide a generous 'citizens' pension' for those older people lacking sufficient insurance contributions or other forms of retirement income.

Elsewhere in the liberal universe social policy changes lean towards the US model but with significant variations across countries and policy areas. Where labour markets are concerned, Australia has adopted arrangements that place the responsibility for finding work on individuals themselves, in the context of privately provided and 'contestable' employment service, which, through Centrelink, furnishes information about benefits and placements. While the job search regime is stringent, there are certain advantages - the foremost being that, for employment purposes, women are treated as individuals in their own right. This is a substantial change in favour of female independence, although household means tests continue to dictate benefit levels and state provision of care services are modest. The UK has also moved in a similar direction but, as pointed out in Chapter Four, New Labour governments have supplemented earlier Conservative rhetoric about welfare dependency with an economic rhetoric about labour market flexibility and 'efficiency', and a European-style discourse of 'social inclusion', leaving a real ambiguity in UK labour market policy. Like Australia, though, conditionality is high, with inactivity in both countries not being an option and penalties incurred for failure to comply with job search requirements. Here too, although women have to meet eligibility conditions as individual claimants, levels of support are determined by family means tests (Millar, 2004: 70). Both countries have developed 'enabling systems' to facilitate job search and preparation for work, although there is a 'work first' edge, particularly in the Australian case.

In relation to pensions, the UK has clearly broken with past traditions of social protection as the value of the state pension declines and a combination of meanstested supplements and private personal and occupational solutions are offered as substitutes for comprehensive public provision. With only minimum support from the means-tested 'citizen's pension', these policies individualize in the sense that people increasingly have to find their own salvation in retirement, the expectation being that individuals will increasingly have to self-fund retirement income by recourse to (frequently DC) occupational schemes or personal private provision. There is little sense of the state playing an enabling role here. Australia, in contrast, by opting for a mandatory private/occupational system is in the process of developing a comprehensive system of provision in old age. While these arrangements have certain disadvantages, not least their vulnerability to market movements, the redistributive element in the system, together with union representation on trustee boards mean that there is an element of 'solidarity', which is lacking in the UK.

\section{Continental regimes}

Social insurance regimes with embedded systems of industrial relations that privilege union-employer partnerships and 'wage replacement welfare' at the 
expense of wider citizen-oriented or solidaristic concerns are struggling to come to terms with pressures for change. In the very recent past, many continental regimes have begun to adjust their core social policies in ways that appear to lean towards neoliberal solutions. Faced with the difficulties created by reunification as well as the impact of GEPs, Germany has started to reorganize employment services to reflect demands for greater flexibility and the need to connect unemployed individuals to available work. Private job agencies are emerging, benefit periods are being reduced and penalties for those refusing work being imposed (and, more importantly, enforced). However, while Germany is beginning to move towards a more individualized and conditional approach to labour market policy, there is little indication of enthusiasm for the market as the sole provider of material wellbeing and the new policies that are being introduced are clearly 'enabling' in intent. For example, as Ostner (2004: 52) points out, while women are now treated as (at least) part-time labour market participants, key 'defamilializing' measures such as publicly-funded child and social care support are being increased - the point being that, as increasing numbers of women enter the labour market, various ancillary forms of public provision are regarded as necessary to keep them there. Where other groups are concerned, different measures may apply: younger people, for example, are likely to be more exposed to the rigours of an increasingly flexible labour market in an effort to develop 'constructive' attitudes to employment. The pensions system, too, is beginning to change. Until recently reforms remained firmly in the mould of incremental adjustments to existing social insurance arrangements but efforts to introduce private pension plans in the form of the RiesterRente scheme may herald a new approach to retirement provision. The scheme itself has yet to take off properly, but the fact that it was introduced at all is an indication of a greater preparedness to supplement the social insurance system with arrangements that, by providing investors with a choice of private schemes, would introduce an individualized and self-conditioning component into the existing system. With financial market reforms also being introduced and German corporations becoming impatient with what they regard as the limiting structures of pension fund co-management, it may be that global economic factors will contribute to the further loosening of German pension provision as trade union power wanes. To date, however, these movements are tentative and any fundamental departure from the social insurance model has yet to take place.

In France, too, there are signs of liberalization but, as yet, few indications of a systematic preference for private alternatives. Where the labour market is concerned, the fragmented social insurance system has been supplemented in recent years by tax financed safety net arrangements for the long-term unemployed combined with activation measures for the young jobless, which exhibit the individualized and conditional features of similar policies elsewhere. Employment services have been enhanced, however, and social inclusion remains a principle that guides policy, albeit increasingly ambiguously. The fact that low-wage employers have been exempted from payroll taxes in an effort to increase flexibility and that wages are low for those - particularly women - entering service sector employment, means that although these changes hardly amount to a transformation 


\section{Conclusion}

of the French system into a privatized, individualized and conditional welfare regime, traditional solidaristic measures are under increasing pressure with ruling political and economic elites currently seeking further market-oriented reform. Pension reform has been stickier, particularly in the public sector, with changes to the social insurance system being largely restricted to adjustments to contribution periods and retirement ages as trade unions persistently contest attempts to meddle with existing arrangements (and their prominent role in them). It may be that signs of more extensive change are beginning to emerge in the growing interest in individual retirement accounts and other forms of private provision, but France is clearly some way from implementing policies of this highly individualized kind.

Although much has been made of Italy's recent efforts to alter its complex, fractured and inefficient social insurance system, recent developments suggest that governments have largely failed to build on the changes made in the mid-1990s. This verdict contradicts Pierson's (2001a: 451) view that in Italy, 'broad centrist coalitions of varying shades have succeeded in convincing key actors, including voters, of the necessity of reform and have introduced major changes'. The changes made to labour market policies have concentrated on reducing constraints on fixedterm contracts and shifting wage bargaining from national to firm level - with some success - but progress towards activation measures and the improvement of employment services has been slow, with difficult negotiations both between the social partners and within key trade union organizations themselves. The situation is similar with regard to pensions. Improvements anticipated in the wake of the (significant) Dini reforms are being introduced only gradually while contribution levels remain too high, meaning that the system itself will not change noticeably for some years to come. Moreover, attempts by the current Berlusconi government to increase the retirement age are unlikely to succeed, while the intention of transforming TFR funds into second tier private pensions funds for employees is currently being blocked by employers. Italy, then, can hardly be considered as a liberalizing regime - indeed moves towards greater individualization and conditionality in welfare provision remain embryonic and heavily contested. The real issue is whether the neocorporatist arrangements adopted in the later 1990s will yield sufficient change to offset the persistent problems of a poorly integrated welfare system, territorial and labour market segmentation (including marked gender differences), high levels of early retirement, and population ageing in an unforgiving global economic climate.

Turning finally to the Netherlands, there is evidence in Dutch labour market policies of a significant increase in individualization and conditionality (in both senses of the term), which displays clear neoliberal tendencies. Activating strategies come with stringent conditions governing individual job search, while particular segments of the unemployed - young people and single parents, for example - are targeted for specific support and guidance. Moreover, part-time working has been institutionalized more firmly in the Netherlands than elsewhere, with women making up a high percentage of the part-time workforce. Employment services are increasingly privately run and have been made 'contestable', the original role of the social partners, and thus the culture of social solidarity, being correspondingly 
reduced. Moreover, there appears to be a 'work first' element in Dutch labour market policies, particularly where young people are concerned. But this trend needs to be set in the context of a genuinely 'enabling state' that is keen to ensure that comprehensive employment services help individuals towards work, albeit in the context of a flexible labour market. There is perhaps a greater flavour of social solidarity where pensions are concerned. For one thing the citizens' pension provides generous cover for those lacking complete employment records and, for another, the system of private $\mathrm{DB}$ occupational provision is as good as mandatory in view of the high levels of coverage. The corporate and sector-wide occupational schemes are managed by the social partners, with little competition among different sectors, so in many ways these arrangements continue to be organized on solidaristic principles, thus limiting the tendencies in private systems towards individualized approaches to retirement saving. However, recent decisions by the Dutch government indicate a desire to alter pension fund management to accord with AngloAmerican financial practices that could undermine the existing model and lead to more 'marketized' pensions arrangements, which may, in turn, result in increasingly individualized retirement planning.

\section{Social democratic regimes}

Denmark is a complex and mixed case. Liberalization plainly constitutes a core theme in recent labour market and pensions reforms, but these changes need to be understood against the backdrop of a generous citizens' state and a culture of social partnership, both of which balance some of the more individualizing elements in recent policy changes. Policies relating to the unemployed have been tightened considerably, for example, with the accent on the individual's 'right and duty' to work or participate in employment schemes - and penalties for those who reject offers of employment or training. Employment protection is low and labour flexibility correspondingly high, which, in the context of a rigorous activation strategy, will enhance a DIY approach to employment. However, these factors must be set in the context of an enabling state, which provides a coherent structure of employment services coordinated mainly by the social partners and municipalities. Retirement provision displays a similar mix of solidaristic and liberal elements. The basic pension is reasonably generous, particularly when supplemented by ATP, but the real change has been the marked shift towards DC occupational pensions for all employed individuals, managed by the social partners. While these can currently be characterized as solidaristic to the extent that the industry-based funds are 'collectively' managed, DC arrangements are inherently individualizing and self-conditioning. Finally, the increasing influence of AngloAmerican financial practices in the context of the rise of global market interest in retirement provision in Denmark could mean that the current structure of Danish pensions management is likely to come under growing pressure.

As Pierson (2001b) notes, Swedish social policies have aimed at cost containment in the context of the maintenance of a citizen-based, universalist welfare regime. There is much that remains solidaristic within Swedish labour market and pensions 


\section{Conclusion}

policies, although it would be inaccurate to suggest that 'individualizing' and 'conditioning' elements are entirely absent. In relation to labour market policies, there has been a tightening of the 'work line' and a developing sense of activation as oriented towards employment as opposed to training in recent years, with the 'activity guarantee' helping to ensure that claimants cannot remain in receipt of benefits while not engaged in an approved work-related activity. Although there is more in the way of individual guidance and 'targeting' the unemployed towards jobs - and also a corresponding stress on conditionality - it is hard to see these shifts as having undermined Sweden's long history of using labour market policies to maintain employment levels as a core focus of social solidarity. In gender terms, solidarity is expressed through the high degree of 'participatory parity' in the labour market, which has seen the gap between men's and women's share of entitlements narrowing over time (Hobson, 2004). 'Individualization', then, has clearly benefited women, particularly in a policy environment characterized by a strong emphasis on defamilialization. Pensions tell a rather different story. The recent reform is more dramatic than the incremental adjustments made to labour market policies and there is no doubting the fact that Sweden has enhanced the market element in retirement provision both through the creation of the pension reserve and, less directly, through the greater investment in equities by the National Pension Funds. Moreover, changes in eligibility rules for first tier provision may not turn out to be particularly favourable to women (Hobson, 2004: 81). Whether or not these moves lead to a more individualized and conditioned approach to retirement saving remains to be seen as the new reforms become embedded. There is certainly disillusionment among those who initially chose to manage their private plans in the pension reserve, suggesting the private alternatives may not become particularly popular. Furthermore, the citizens' pension remains generous and the shift to notional defined contribution second-tier arrangements simultaneously privileges solidaristic principles even as it encourages greater individual awareness of retirement planning. With these issues in mind, it is hard to see Sweden moving decisively down the path of liberalization.

\section{Tipping points, 'flexicurity' and 'brittle' recalibration}

'Reformulating', 'recasting', 'recalibrating', 'adjusting' - these are the stock terms used to describe how welfare regimes are responding to the challenges examined in this book, the consequence being that regimes are 'unsettled', 'destabilized' or 'loosened'. But what images of change do these terms convey? Just as importantly, are these processes of adjustment likely to have an end point? If change itself appears to be endemic as regimes continually confront a variety of pressures and risks in a constrained economic climate, its intensity varies. With respect to the liberal regimes considered here, the evidence suggests, in Paul Pierson's (2001b: 427 ) words, that 'these already highly commodified welfare states have become more so', with the UK exhibiting the clearest case of extensive institutional change. In view of the weakness of non-market forms of coordination in these regimes, they are likely to embrace further market-oriented welfare reforms as GEPs increase. 
Where social and continental regimes in Europe are concerned, the picture is considerably more mixed - and it is with regard to these countries that it is important to probe the nature of 'recalibration' or 'reformulation' a little further. Meaningful generalizations are difficult to make, but if these welfare systems are 'unsettled' in the majority of cases, change appears to take the form of new policy combinations which mix different 'worlds of welfare' within each country (Lamping and Rüb, 2004: 169). A key issue is whether these processes of mixing, recalibration and adjustment are likely to continue to a point where the regimes themselves could ultimately 'tip' into a different (i.e. neoliberal) type. If the argument of this book is that changes of this kind are unlikely at present, at least in the dramatic sense of across-the-board transformation, it is nevertheless the case that recalibration processes remain far from complete. With persistent pressures on postwar institutional structures in the majority of cases, it is important to consider whether their continuing erosion will mean that processes of neoliberal drift will continue. Commentators who are optimistic about the capacity of existing regimes to contain future drift argue that there are sufficient solidaristic, socially oriented components in newly emerging forms of governance in Europe to preserve the core principles of the European 'social state'. Institutional developments of key importance are, first, the emergence of new corporatist institutions in certain European states and, second, the development of new methods of policy formulation and coordination in the European Union. Each of these dimensions will be considered here.

Ferrera et al. (2001) acknowledge that European welfare regimes face a number of 'adjustment problems' (created in their opinion mainly by engodenous challenges). They argue forcefully, however, that the impact of these pressures should not be exaggerated and, importantly, that 'they do not render different national responses or the search for equitable solutions impossible' (Ferrera et al., 2001: 155). These observers examine a range of possibilities for welfare state reform in terms of a series of 'functional, distributive and normative' recalibrations that are accompanied by associated political-institutional changes (see Ferrera et al., 2001: 158-9 also Ferrera and Hemerijck, 2003). There is a need for a functional adjustment of social policies to take better account of new needs and risks - growing child poverty and new forms of social exclusion, for example, in addition to those examined here - while recognizing that others associated with welfare provision in the postwar period have diminished substantially. Distributive adjustments need to take account of new inequalities - of employment, certainly, but also of gender and ethnicity - the effects of which were neither recognized, nor understood, by traditional welfare regimes. Changes in these areas are likely to have implications for the normative dimension of welfare - the moral role and purpose of welfare systems. Here a Rawlsian approach is adopted with Ferrera et al. (2001: 159) arguing that welfare states of all kinds need to place 'more emphasis within their normative framework on dynamic equality, being primarily attentive to the worst off, more hospitable to incentive-generating differentiation and flexibility, and actively vigilant with regard to the "openness" of the opportunity structure' - this latter point concerning the need to enhance educational and training opportunities and ensure that these can lead to genuine social mobility. 


\section{Conclusion}

To move towards these new parameters of welfare in policy terms demands different policy mixes capable of bridging a range of needs, risks and demands that have in the past been regarded as incommensurable. Thus efficiency and equality, growth and redistribution as well as competitiveness and solidarity need to be the focus of new welfare measures according to Ferrera et al. (2001: 159). To these ends, fiscal constraints, wage moderation and flexibility of employment together with suitable social protection for those with non-standard employment trajectories, and greater investment in education and training - the kinds of policies now being instituted in the majority of European regimes - are held to be the best means of ensuring security and inclusion while maintaining economic stability. Incremental adjustment is considered to be the optimum method of introducing policies of this kind because it permits the dialogic, negotiated and consensual approaches to change associated with social partnership, and is argued to be preferable to Westminster-style, liberal models, which are associated with more radical and exaggerated changes of direction. Recent politico-institutional innovations, in Europe at least, that involve new methods of concertation within nation-states and the development of forms of multi-level governance at EU level are considered to complement this dialogic perspective - but will they prove able to moderate neoliberal drift?

According to Ferrera et al. (2001: 163) 'social pacts' constitute an emerging form of neocorporatism, usually developing from the efforts of the central state to create consensus among the social partners, that produce different forms of 'concertation' and thus different approaches to industrial relations compared with traditional corporatist arrangements. For example, the new forms of 'flexicurity' in Denmark and the Netherlands are closely associated with the appreciation by the state and social partners alike of the centrality of part-time working and female employment, and the need to tailor wage policies, working conditions and so on to the needs of a rapidly changing labour market, as well as changing perceptions of family life and the work-life balance. Social pacts have developed in other European countries such as Portugal, Ireland and Spain, Martin Rhodes (1998, 2001) arguing that they introduce a new 'competitive corporatism' into the European industrial sphere which fosters greater economic stability and faster growth without entirely compromising egalitarian goals. As Rhodes (2001: 180) contends, 'all of the social pacts that have emerged since the mid-1980s seek to combine wage moderation, the quest for lower social charges and greater flexibility of work conditions [and] ... to this extent all the pacts contain both distributive and productivity-linked innovations'. Of significance, of course, is the implicit recognition of the need to move beyond forms of industrial relations in which relations between the social partners were becoming increasingly 'oppositional' - Denmark and the Netherlands again exemplifying this trend.

In the European arena, the emergence of these competitive corporatist institutions has been accompanied by other institutional changes that are held to facilitate the development of new distributional and productivity coalitions at supranational level. According to Hemerijck and others, the move towards EMU has a number of significant implications in this regard. Hemerijck (2002: 190) 
recognizes that EMU has produced clear economic constraints that mean that '(Keynesian) macroeconomic policy measures can no longer shield other areas of social policy and economic regulation from the need to adjust to international competition'. Low inflation policies have positively affected wage behaviour as well as facilitating deficit reduction, while greater macroeconomic stability has encouraged lower interest rates and thus proved beneficial for investment. Overall, Hemerijck is clear that 'looking back over the 1990s, we can only conclude that the introduction of EMU has been an immense success'.

This shift towards tighter management of the European economies has undoubtedly altered attitudes to welfare provision. Apart from contributing to the kinds of policy changes relating to labour market policies and pensions discussed in this volume, it is also suggested that EMU has made member states more amenable both to participating in efforts to develop Union-wide structures of coordination and to adhering - at least in principle - to the agreements about monitoring and benchmarking arrived at. Integration at this level has been complemented more recently by the emergence of different coordinating mechanisms that offer the prospect of greater policy integration from the 'bottom up'. One example here is the 'open method of coordination' (OMC), initially established at the EU Lisbon Summit in March 2000. With complaints about the top-down 'Community method' of policy making in Europe mounting in the later 1990s, the OMC has come to be regarded in some quarters as an alternative method of 'spreading best practice and of achieving thereby greater convergence' (de la Porte et al., 2001: 293). It is meant to do this via a number of agreed guidelines and benchmarks designed to establish the EU as a competitive and dynamic knowledgebased economy aiming at achieving 'sustainable economic growth with more and better jobs and greater social cohesion' (Presidency Conclusion, Lisbon European Council, quoted in Chalmers and Lodge, 2003: 3). Unlike the centralized, hierarchical approach to European governance of earlier periods, the objective is to develop 'new styles of Union-member state relations [that are] forged around the diffusion of a variety of transnational norms ... supposedly leading to national adaptation' (Chalmers and Lodge, 2003: 2). The EES, which, though pre-dating OMC, has nevertheless come to be regarded as a particular instance of it, constitutes one example of this attempt to establish such norms. This is a "soft law" governance mechanism', according to Trubeck and Mosher (2003: 39) and, as intimated in Chapter Four, it is essentially an iterative process, the idea being that, in time, key objectives will gradually harmonize across member states. Although the EES has no formal sanctioning powers, the European Council can make recommendations about policy revision and, judging by the responses to the Strategy from many member states, some of the key objectives of the EES are being taken seriously. For example, as Chapter Five noted, many of the country responses recognize the significance of 'activation', while also recognizing that flexibility needs to be increased and that women need to be properly incorporated into national labour markets. More specifically, certain countries (France to name one) have acknowledged the beneficial effect of the EES on their employment policies and, in the French case, have identified specific benefits of 'policy learning' from other 
countries' programmes (Trubeck and Mosher, 2003: 44). Moreover, 'cognitive harmonization' - 'the shaping and reshaping of perceptions of attitudes towards social problems and the way to tackle them' (Radaelli in Guillén and Palier, 2004: 204) - also constitutes a potentially important initiating point of coordination.

Taking account of the above, can it be said that new institutional forms like competitive corporatism and - differently - the OMC are capable of 'bounding' the processes of recalibration noted in previous chapters? While it is likely that they can slow the pace of change, it is by no means certain that they are capable of altering the neoliberal flavour of prevailing policy mixes. Taking competitive corporatism first, it is not coincidental that social pacts tend to characterize bargaining arrangements where the power of capital is in the ascendant and organized labour either historically weak or in contemporary decline - the argument being that the accent in 'competitive corporatism' is on the former rather than the latter word and that, as an institutional form, arrangements will not be sufficiently robust to prevent further shifts towards liberal social policies in such an economic environment, however 'negotiated' these may appear to be. In this respect, Denmark and the Netherlands are particularly apposite: economic constraints and weakening labour movements in the 1980s saw the development of competitive corporatist forms of social partnership, with both countries subsequently adopting marketoriented initiatives in the areas of labour market policy and pensions. Certainly the Dutch case has been described as one of 'corporatism and the market' rather than one of corporatism against the market (Visser quoted in Rhodes, 2001: 183). While it would be inaccurate to characterize the changes made by these countries since 1980 as transformative, or organized labour as excessively weak, the issue is how well competitive corporatist arrangements will deal with growing economic pressures. Recent evidence from the Netherlands suggests that, with employers demanding greater flexibility over wages at the level of the individual firm, 'sectorwide agreements are beginning to fragment [and] ... the ability of unions to exert control in the system is being diminished' (Rhodes, 2003: 138). If the unions were to retreat to their central roles of pay bargaining and defending members' interests, leaving 'broader distributive policies to the state' (Rhodes, 2003: 138), further neoliberal welfare adjustment would be likely.

Of course, other European countries with mature welfare systems have not developed competitive corporatist arrangements and it is important briefly to consider their position in relation to neoliberal drift. Both Germany and France, in different ways, have entrenched forms of bargaining, which have proved to be more institutionally sticky than the above examples. Recalibration processes in these cases are consequently complex, disorganized and 'brittle' as governments of all ideological persuasions struggle to contain social costs through ad hoc bargaining and (occasionally) pre-emptive policy initiatives in an unsettled institutional environment in which organized labour, in addition to significant numbers of the population, continues to be hostile to welfare reform. In the absence of agreed competitive corporatist arrangements, policy shifts, though gradual, do not emanate from a broad consensus about the need for reform as this has developed in both 
Denmark and the Netherlands (see Cox, 2001), but from a protracted process during which trade-offs and compromises are negotiated on a case-by-case basis. There is a lack of consistency and stability in arrangements of this kind, and it is not surprising that French and German policy mixes display signs of 'uneven development', with market-friendly policies appearing in some policy areas (or sub-areas), while more cautious adjustments maintain established forms of provision elsewhere.

If neither social pacts nor existing forms of corporatism can establish clear limits to recalibration, can supranational 'coordination' offer a means of limiting neoliberal drift? Evidence relating to the OMC is not promising. There are two aspects to this issue. First, a brief look at the EES suggests that this form of policy making may not be as influential as recent upbeat evaluations make out (see CEC, 2002d). To be sure, some observers comment favourably on the fact that the EES is evolving into a genuine example of multi-level governance built on assumptions about the primacy of national interests (see Goetschy, 2001). More generally, Teague (2001) believes that these developing 'deliberative' methods of coordination will become progressively more effective over time, resulting in an increasing degree of policy learning, 'best practice' in the EES spreading to other policy areas. However, as Goetschy (2003: 70) points out, the architecture of the EES is designed, above all, to favour national diversity with overall objectives set at European level but implementation being left to member states. Whether national diversity can really be combined with EU objectives as these are formulated through this permanent 'deliberative process of becoming' is doubtful. There is the awkward question, for instance, as to why, in view of the 'substantial evidence of turf-fights and non-learning in national government ... there should be grounds for so much optimism about "learning" and "preference adjustment" when it comes to the level of the European Union' (Chalmers and Lodge, 2003: 18). Moreover, as mentioned, not only did the EES precede the OMC, but even before the EES's inception, many member states had already adopted key policies that were subsequently included in the guidelines. As Taylor-Gooby (2005: 45) states,

while policies which promote activation, reform tax to reduce labour costs, advance equal opportunities, expand child-care and [encourage] the availability of more flexible jobs can be identified in EU Member countries, it is hard to establish how far these developments are the outcome of EU-level activity or of more far-reaching and simultaneous social and economic changes.

Second - and ironically - although it appears that the OMC may not be particularly influential as a vehicle for European integration, in so far as it is playing a role, 'competitiveness' is favoured over the social dimension. As Radaelli (2003: 28) argues,

Although at the general level the recalibration of the welfare state and the challenge of competitiveness are not mutually exclusive ... empirical evidence 


\section{Conclusion}

from employment policy, social policy, pensions and taxation points to conflicts between those organizations and policy-makers that put a premium on competitiveness and those who make 'social Europe' their ultimate goals.

Radaelli (2003: 29) goes on to observe that, "if and when there is a tension between competitiveness and "social Europe", the task is easier for those pushing for competitiveness'. It is not surprising, then, that the competitive elements of the OMC, such as the Broad Guidelines on Economic Policies (BGEP), are better developed than other components, stemming, as they do, from the budgetconstraining logic of the Maastricht Treaty and the relative failure of attempts in the 1990s to develop an integrated approach to social policy at EU-level (Chalmers and Lodge, 2003: 8; Taylor-Gooby, 2005: 44).

In this vein, it is worth pointing out briefly that the recent enlargement of the EU, taking in ten new countries, eight of which are from the old Communist bloc, is likely to compound its competitive rather than its social character. As Ferge and Juhász (2004: 234) remark, the bulk of economic and social policy in the countries of Central and Eastern Europe pre-accession was shaped by the World Bank and the IMF - the main elements being

the strengthening of individual responsibility and the weakening of public responsibility in social matters; the promotion of privatization and marketization in all spheres...the scaling-down of social insurance to strengthen private insurance and to decrease public spending; and the abolition of universal benefits as wasteful.

Where Hungary is concerned, for instance, although the distinctly 'European' issues of poverty and social exclusion were placed on the political agenda after 2000, the Regular Reports relating to Hungary's accession did not dwell on these topics, dealing instead with how to ensure 'economic growth and financial stability [through] budget stringency, including suggestions to reduce the level of social protection' (Ferge and Juhász, 2004: 248). With competitiveness already embedded in social policy debates at the European level, the similar emphasis in relation to enlargement does not suggest that a new 'social' dynamic will be injected into OMG processes. Far from it, as Ferge and Juhász, and others, argue. Lendvai (2004: 322), for example, notes that 'among scholars there seems to be quite a distinct consensus that the social imperatives of the accession process have been and continue to be rather weak'.

Of course, the apparent lack of attention to social policy issues at the accession stage will not necessarily prevent subsequent social policy learning and 'cognitive harmonization' among Member States old and new - indeed there is some evidence that the OMC can operate effectively in this way. However, even here, in view of the prevailing attachment to competitiveness, it is important to be clear about what is likely to be learned. As Guillén and Palier (2004: 206) observe, contemporary European social policy 'is not today what it was when previous accessions took place and poses many more challenges to incoming countries' - one of which is 
the noticeably greater orientation towards neoliberalism. These observers agree with Radaelli's conviction that there is a basic conflict between 'economically oriented' and 'socially oriented' actors, but in a context in which the European social model 'has changed and become closer to neo-liberal ideas'.

\section{Indeterminate drift and the 'process' of welfare}

The above suggests that currently emerging institutional structures within the EU are unlikely to be able to contain the element of neoliberal drift, which is such a feature of the various recalibration processes that are taking place in Member States. With liberal regimes elsewhere embracing liberalization more enthusiastically and their model of capitalism apparently in the ascendant, what is there to prevent 'drift' descending into a 'race'? A simple answer is that because the nature of the global-institutional nexus differs in the case of each regime it is unlikely that regimes themselves will entirely lose their character. In short, while its policy mix can be expected to change, Sweden will never become the USA! So, however much intra-regime policy changes appear to indicate a turn towards market solutions, institutional starting-points continue to be influential, despite the undoubted corrosion of key institutions themselves.

This answer is not entirely compelling, however, because, as argued in the course of this book, there is plenty of evidence to indicate that traditional welfare institutions are weakening, leaving 'their' regimes increasingly vulnerable to liberalization. A more complex - and paradoxical - approach would argue that, as this process continues, neoliberal drift, with its accompanying features of individualization and conditionality, offers new opportunities for social policy even as it constrains others, leading to different, more fragmented, understandings of welfare in the process. Viewed in this way, the notion of a 'race to the bottom' misses the point - and the notion of 'drift' itself, as the term suggests, has a certain indeterminacy. Liberalizing moves at welfare regime level which culminate in recalibrated policies, also recalibrate conceptions of the role and nature of welfare itself, as different interests, old and new, are affected by the changes. There is no reason to suggest, however, that newly emerging interests will demand further doses of liberalization, or that governments themselves will risk electoral defeat by 'pushing too far'. In this way, while liberalization can be 'accommodated' it cannot be heedlessly extended. Taking the changing role of women as an example of a rapidly emerging 'new interest', while women can benefit from greater labour market flexibility because it can enhance employment opportunities and, in some regimes at least, is accompanied by social entitlements, there is no reason to suppose that this form of individualization will culminate in demands for evermore flexible labour markets. Instead, as women come to play a more powerful (and empowering) role as paid workers, they are more likely to use their position to support core gains, contest adverse policy outcomes (the high incidence of part-time work and low wages could be issues here) and, as the process further unfolds, to reshape perceptions of welfare and employment in particular, defamilialized, ways. This is an emergent new welfare politics, not a race to the bottom. 


\section{Conclusion}

The main difficulty with arguments of this kind - that new interests can contribute to nationally focused recalibrations of welfare from 'below' - concerns whether such interests can become sufficiently well institutionalized to enable them to exploit potential sources of empowerment and participate fully in processes of social bargaining. Although there can be no guarantees of effective institutionalization in such a rapidly changing policy environment, there are nevertheless some grounds for optimism here. In socio-economic and political environments where state policy capacity is increasingly 'negotiated', 'relational' and "'hardwired" into the very constitution of multiple and fragmented arenas of governance' (Jayasuriya, 2004: 498) new groups may be able to forge negotiating space either alongside, or even from within, traditionally 'incorporated' bodies that can no longer 'manage' welfare change alone. Women's and pensioners' lobbies are surely cases in point. In doing so, they may, of course, support or contest, enhance or reduce neoliberal drift - or each of these possibilities at different times, depending on the areas and policy issues involved. In each case, their impact will depend on how contingencies and risks are configured in the context of the framing power of GEPs and the persistence, or otherwise, of regime characteristics. But the point lies in the potential of these and other new interests to become embedded in complex, non-linear and evolving sets of processes. For, increasingly, it is 'process' the persistent negotiation and management of policy formulation and implementation among constantly changing communities of welfare at various levels of governance - that will determine welfare outcomes. In such a context it is not only particular policies and aspects of welfare provision that are consistently debated and contested, but the very nature of welfare itself. 


\section{Bibliography}

Aarsland, L. (2005) 'Trades off', The Guardian, 21.2.05.

Abrahamson, P. and van Oorschot, W. (2002) 'The Dutch and Danish miracles revisited: comparing the role of activation policies within two different welfare regimes', paper presented to Cost-Action 15 conference, Oslo.

Albert, M. (1992) Capitalism Against Capitalism, London, Whurr.

Albrow, M. (1996) The Global Age, Cambridge, Polity Press.

Albrow, M. (1997) 'Travelling beyond local cultures: socioscapes in a global city', in J. Eade (ed.) Living in the Global City, London, Routledge.

Allen, J. and Massey, D. (eds) (1988) The Economy in Question, London, Sage.

Altassets (2002) www.altassets.com.casefor/countries/2002/nz2605.php

Ambrovici, G. (2002) 'Social protection: expenditure on pensions', Statistics in Focus, Theme 3 (6), Eurostat.

Amin, A. (1997) 'Placing globalization', Theory, Culture and Society, 14 (2): 123-37.

Amin, A. and Thrift, N. (2002) Cities: Reimagining the Urban, Cambridge, Polity Press.

Anderson, K. and Meyer, T. (2004) 'The third way in welfare state reform? Social democratic pension policies in Germany and Sweden', in G. Bonoli and M. Powell (eds) Social Democratic Party Policies in Contemporary Europe, London, Routledge.

Arts, W.A. and Gelissen, J. (2002) 'Three worlds of welfare capitalism or more? A state-ofthe-art report', Fournal of European Social Policy, 12: 137-58.

Aust, A., Bonker, F. and Wollmann, H. (2002) Welfare State Reform in Germany from 1982 to the Present, Report for WRAMSOC Conference, University of Kent.

Baldwin, P. (1990) The Politics of Social Solidarity: Class Bases of the European Welfare State, 1875-1975, Cambridge, Cambridge University Press.

Bambra, C. (2004) 'The worlds of welfare: illusory and gender blind?', Social Policy and Society, 3 (3): 201-11.

Barr, N. (2003) 'Reforming pensions: myths, truths and policy choices', in Reforming Public Pensions: Sharing the Experience of Transition in OECD Countries, Paris, OECD.

Bartlett, W., Roberts, J.A. and le Grand, J. (1998) A Revolution in Social Policy Quasi-market Reforms in the 1990s, Bristol, The Policy Press.

Bauman, Z. (2001) The Individualized Society, Cambridge, Polity Press.

Baumol, W.J. (1967) 'The macroeconomics of unbalanced growth', American Economic Review, 52 (3): 415-26.

Beck, U. and Beck-Gernsheim, E. (2003) Individualization, London, Sage.

Benner, M. and Vad, T.B. (2000) 'Sweden and Denmark: defending the welfare state', in F. Scharpf and V. Schmidt (eds) Welfare and Work in the Open Economy, Vol. 2, Diverse Responses to Common Challenges, Oxford, Oxford University Press. 


\section{Bibliography}

Bennett, F. (2004) 'Developments in social security', in N. Ellison, L. Bauld and M. Powell (eds) Social Policy Review 16: Analysis and Debate in Social Policy, 2004, Bristol, The Policy Press.

Besharov, D. J. and Germanis, P. (2001) 'Welfare reform: four years later', in D.J. Besharov, P. Germanis, J. Hein, D.K. Jonas and A.L. Sherman (eds) Ending Dependency? Lessons fron Welfare Reform in the USA, London, Civitas.

Best, S. and Kellner, D. (eds) (1997) The Postmodern Turn, New York, Guilford Press.

Beveridge, W.H. (1942) Social Insurance and Allied Services, Cmnd 6404, London, HMSO.

Beyeler, M (2003) 'Globalization, Europeanization and domestic welfare state reforms: new institutionalist concepts', Global Social Policy, 3: 153-72.

Bishop, B. (1999) The Natiojnal Strategy for an Ageing Australia, Independence and Self Provision Discussion Paper, Canberra, Commonwealth of Australia.

Bjorklund, A. (2000) 'Denmark and Sweden - going different ways', in G. Esping-Andersen and M. Regini (eds) Why Deregulate Labour Markets?, Oxford, Oxford University Press.

Blackburn, R. (2003) Banking on Death or Investing in Life: The History and Future of Pensions, London, Verso.

Bleses, P. and Seeleib-Kaiser, M. (2004) The Dual Transformation of the German Welfare State, Basingstoke, Palgrave.

Blien, U., Walwei, U. and Werner, H. (2002) Labour Market Policy in Germany, IAB Labour Market Research Topics, Federal Employment Services, Institut für Arbeitsmarkt-und Berufsforschung der Bundesanstalt für Arbeit (IAB), Nürnberg.

Blyth, M. (2001) 'The transformation of the Swedish model: economic ideas, distributional conflict, and institutional change', World Politics, 54 (Oct): 1-26.

Boeri, T. (2003) The Current Italian Pension Reform: Another Partial Solution, CEPR, WatsonWyatt Pension Policy Seminar, Milan, 22 October.

Bogler, D. (2002) 'Inside track: Germany's big pension idea', Financial Times, 11.7.02.

Bonker, F. and Wollmann, H. (2001) 'Stumbling towards reform: the German welfare state in the 1990s', in P. Taylor-Gooby (ed.) Welfare States Under Pressure, London, Sage.

Bonoli, G. (1997a) 'Classifying welfare states: a two-dimensional approach', fournal of Social Policy, 26 (3): 351-72.

Bonoli, G. (1997b) 'Pension politics in France: patterns of cooperation and conflict in two recent reforms', West European Politics, 20 (4): 160-81.

Bonoli, G. (2000) The Politics of Pension Reform, Cambridge, Cambridge University Press.

Bonoli, G. (2001) 'Switzerland: stubborn institutions in a changing society', in P. TaylorGooby (ed.), Welfare States Under Pressure, London, Sage.

Bonoli, G. and Gay-des-Combes, B. (2003) 'Adapting pensions systems to labour market changes in Western Europe', in C. Bochel, N. Ellison and M. Powell (eds) Social Policy Review 15: UK and International Perspectives, Bristol, The Policy Press.

Bonoli, G. and Palier, B. (2001) 'How do welfare states change? Institutions and their impact on the politics of welfare state reform in Western Europe', in S. Leibfried (ed.) Welfare State Futures, Cambridge, Cambridge University Press.

Boyer, R. (2000) 'The political in the era of globalization and finance: focus on some Régulation school research', International Journal of Urban and Regional Research, 24 (2): 274-322.

Boyer, R. and Hollingsworth, J.R. (1997) 'From national embeddedness to spatial and institutional nestedness', in J.R. Hollingsworth and R. Boyer (eds) Contemporary Capitalism: The Embeddedness of Institutions, Cambridge, Cambridge University Press.

Broby's website for active asset management (2002) www.broby.org/Danish. 
Brown, G. (1999) 'Equality - then and now', in D. Leonard (ed.) Crosland and New Labour, London, Fabian Society.

Bureau of Labor Statistics (2004) Union Members Summary, www.bls.gov/news.release/ union2.nr0.htm

Burgoon, B. (2001) 'Globalization and welfare compensation: disentangling the ties that bind', International Organization, 55 (3): 509-51.

Calmfors, L., Forslund, A. and Hemström, M. (2002) Does Active Labour Market Policy Work? Lessons From the Swedish Experience, Seminar paper 700, Institute for International Economic Studies, Stockholm University.

Campbell, J.L. (2004) Institutional Change and Globalization, Princeton, NJ, Princeton University Press.

Castells, M. (1996) The Information Age: Economy, Society and Culture. Vol. 1. The Rise of Network Society, Oxford, Blackwell.

Castells, M. (1998) The Information Age: Economy, Society and Culture. Vol. 2. The Power of Identity, Oxford, Blackwell.

Castles, F. (1986) Working Class and Welfare: Reflections on the Political Development of the Welfare State in Australia and New Zealand, London, Allen and Unwin.

Castles, F. (1996) 'Needs-based strategies of social protection in Australia and New Zealand', in G. Esping-Andersen (ed.) Welfare States in Transition, London, Sage.

Castles, F. (2001) 'On the political economy of recent public sector development', fournal of European Social Policy, 11 (3): 195-212.

Castles, F. (2004) The Future of the Welfare State: Crisis Myths and Crisis Realities, Oxford, Oxford University Press.

CEC (2001) Employment Policies in the EU and in the Member States, Joint Report, Employment and Social Affairs, Commission of the European Communities, Brussels.

CEC (2002a) UK Employment Action Plan, Commission of the European Communities, Brussels.

GEG (2002b) National Action Plan for Employment 2002 - France, Commission of the European Communities, Brussels.

CEC (2002c) Impact Evaluation of the European Employment Strategy: Italian Employment Policy in Recent Years, Commission of the European Communities, Brussels.

CEC (2002d) Impact Evaluation of the European Employment Strategy: Technical Analysis, Brussels, Employment and Social Affairs, Commission for the European Communities.

Cerny, P. (1990) The Changing Architecture of Politics: Structure, Agency and the Future of the State, London, Sage.

Cerny, P. (1993) 'The de-regulation and re-regulation of financial markets in a more open world', in P. Cerny (ed.) Finance and World Politics: Markets, Regimes, and States in the Post Hegemonic Era, Aldershot, Edward Elgar.

Cerny, P. (1997) 'International finance and the erosion of capitalist diversity', in C. Crouch and W. Streeck (eds) The Political Economy of Modern Capitalism: Mapping Convergence and Diversity, London, Sage.

Cerny, P. (2000) 'Restructuring the political arena: globalization and the paradoxes of the competition state', in R. Germain (ed.) Globalization and its Critics, Basingstoke, Macmillan.

Chalmers, D. and Lodge, M. (2003) The Open Method of Coordination and the European Welfare State, Centre for the Analysis of Risk and Regulation, London School of Economics and Political Science.

Chiesi, A.M. (1999) 'Unemployment policies in the Italian labour market transformation', in N. Genov (ed.) Unemployment Risks and Reactions, UNESCO - MOST, Paris and Friedrich Ebert Stiftung, Bonn - Sofia. 


\section{Bibliography}

Clark, G.L. (2003) European Pensions and Global Finance, Oxford, Oxford University Press.

Clarke, J. (2001) 'Globalization and welfare states', in R. Sykes, B. Palier and P.M. Prior (eds) Globalization and European Welfare States, Basingstoke, Palgrave.

Clarke, J. (2004) Changing Welfare, Changing States, London, Sage.

Clasen, J. (2002) 'Unemployment and unemployment policy in the UK: increasing employability and redefining citizenship', in J. Goul Andersen, J. Clasen, W. van Oorschot and K. Halvorsen (eds) Europe's New State of Welfare: Unemployment, Employment Policies and Citizenship, Bristol, The Policy Press.

Clasen, J. and Clegg, D. (2003) 'Unemployment protection and labour market reform in France and Great Britain in the 1990s: solidarity versus activation?', Fournal of Social Policy, 32 (3): 361-82.

Clasen, J. and Gould, A. (1995) 'Stability and change in welfare states: Germany and Sweden in the 1990s', Policy and Politics, 23 (3): 189-201.

Clayton, R. and Pontusson, J. (1998) 'Welfare-state retrenchment revisited: entitlement cuts, public sector restructuring, and inegalitarian trends in advanced capitalist societies', World Politics, 51 (1): 67-98.

Clift, B. (2004) 'The French model of capitalism: still exceptional?', in J. Perraton and B. Clift (eds) Where are National Capitalisms Now?, Basingstoke, Palgrave.

Coates, D. (2000) Models of Capitalism, Cambridge, Polity Press.

Commission on Social Justice (1994) Social Justice: Strategies for National Renewal, London, Vintage.

Commission on Strengthening Social Security (CSSS) (2001) Strengthening Social Security and Creating Personal Wealth for All Americans, www.csss.gov.reports/Final_report.pdf.

Cox, R. (2001) 'The social construction of an imperative: why welfare reform happened in Denmark and the Netherlands but not in Germany', World Politics, 53 (April): 463-98.

Craig, G. (2002) 'Ethnicity, racism and the labour market: a European perspective', in J. Goul Andersen and P.H.Jensen (eds) Changing Labour Markets, Welfare Policies and Citizenship, Bristol, The Policy Press.

Crouch, C. and Streeck, W. (1997) 'Introduction: the future of capitalist diversity', in C. Crouch and W. Streeck (eds) The Political Economy of Modern Capitalism: Mapping Convergence and Diversity, London, Sage.

Curry, C. and O'Connell, A. (2003) The Pensions Landscape, London, The Pensions Policy Institute.

Cutright (1965) 'Political structure, economic development and national social security programs', American Fournal of Sociology, 70: 537-50.

Daly, M. (2000) The Gender Division of Welfare, Cambridge, Cambridge University Press.

Daly, M. and Lewis, J. (2000) 'The concept of social care and the analysis of contemporary welfare states', British fournal of Sociology, $\mathbf{5 1}$ (2): 281-98.

Daly, M. and Rake, K. (2003) Gender and the Welfare State, Cambridge, Polity Press.

Deacon, A. (2000) 'Learning from the US? The influence of American ideas upon "New Labour" thinking on welfare reform', Policy and Politics, 28 (1): 5-18.

Deacon, A. (2001) 'Introduction: the realities of welfare reform: some home truths From the USA?', in D. J. Besharov, P. Germanis, J. Hein, D.K. Jonas and A.L. Sherman (eds), Ending Dependency? Lessons fron Welfare Reform in the USA, London, Civitas.

Deacon, A. (2003) 'The British perspective on reform: transfers from, and a lesson for, the US', in R. Walker and M. Wiseman (eds) The Welfare We Want? The British Challenge for American Reform, Britsol, The Policy Press.

De la Porte, C. and Nanz, P. (2003) 'OMG - A Deliberative-Democratic Mode of Governance? The Cases of Employment and Pensions', Paper presented to the ESPANet 
Conference, 'Changing European Societies - the Role of Social Policy', 13-15 November 2003, Copenhagen.

De la Porte, C., Pochet, P. and Room, G. (2001) 'Social benchmarking, policy, policy making and new governance in the EU', fournal of European Social Policy, 11 (4): 291-307.

Dell'Aringa, C. (2000) The Italian Labour Market: Problems and Prospects, www.users.ox.ac.uk/ -hine/dellaringa \%20paper.doc.

Department of Work and Pensions (1998) A New Contract for Welfare: Partnership in Pensions, London, The Stationery Office.

Dicken, P. (2003) Global Shift, 3rd edn, London, Sage.

Doremus, P., Keller, W., Pauly, L. and Reich, S. (1998) The Myth of the Global Corporation, Princeton, NJ, Princeton University Press.

Driver, S. and Martell, L. (1998) New Labour: Politics After Thatcherism, Cambridge, Polity Press.

Drøpping, J.A., Hvinden, B. and Vik, K. (1999) 'Activation policies in the Nordic countries', in M. Kautto, M. Heikkilä, B. Hvinden, S. Marklund and N. Ploug (eds) Nordic Social Policy: Changing Welfare States, London, Routledge.

Dwyer, P. (2000) Welfare Rights and Responsibilities, Bristol, The Policy Press.

Ebbinghaus, B. and Hassel, A. (2000) 'Striking deals: concertation in social reform of Continental European Welfare States', Journal of European Public Policy, 7 (1): 44-62.

Economic Policy Institute (2003) EPI Issue Guide: Retirement Security, www.epinet.org/content/ $\mathrm{cfm} /$ issueguides-retirement-security.

The Economist (2003a) 'The chancellor gets his way, so far', 5.6.03.

The Economist (2003b) 'The crumbling pillars of old age', 25.9.03.

The Economist Intelligence Unit (2002) 19.8.02, www.viewswire.com.

Eironline (2004) New National Agreement Signed in Commerce Sector, European Industrial Relations Observatory Online, www.eiro.eurofund.eu.int/2004/07/feature/it0407 108f.html.

Eironline (2005) LO Issues 10-Point Plan to Combat Relocation of Jobs, www.eiro.eurofund.eu.int/ 2005/02/inbrief/dk0502102n.html.

Eitrheim, P. and Kuhnle, S. (2000) 'Nordic welfare states in the 1990s', in S. Kuhnle (ed.) Survival of the European Welfare State, London, Routledge.

Elliott, L. (2004) 'Brown blocks pensions bail-out', The Guardian, 10.11.04.

Ellison, N. (1994) Egalitarian Thought and Labour Politics: Retreating Visions, London, Routledge.

Ellison, N. and Pierson, G. (eds) (1998) Developments in British Social Policy, Basingstoke, Macmillan.

Ellison, N. and Pierson, C. (eds) (2003) Developments in British Social Policy 2, Basingstoke, Palgrave.

Enjolras, B., Laville, J.L., Fraisse, L. and Trickey, H. (2000) 'Between subsidiarity and social assistance - the French Republican route to activation', in I. Lødemel and H. Trickey (eds) "An Offer You Can't Refuse": Workfare in International Perspective, Bristol, The Policy Press.

Esping-Andersen, G. (1985) Politics Against Markets, Princeton, NJ, Princeton University Press.

Esping-Andersen, G. (1990) The Three Worlds of Welfare Capitalism, Cambridge, Polity Press. Esping-Andersen, G. (ed.) (1993) Changing Classes: Stratification and Mobility in Post-industrial Societies, London, Sage.

Esping-Andersen, G. (ed.) (1996a) Welfare States in Transition, London, Sage.

Esping-Andersen, G. (1996b) 'Welfare states without work: the impasse of labour shedding and familialism in continental social policy', in Esping-Andersen, G. (ed.) Welfare States in Transition, London, Sage. 


\section{Bibliography}

Esping-Andersen, G. (1999) The Social Foundations of Post-industrial Economics, Oxford, Oxford University Press.

Evans, M. (2001) Welfare to Work and the Organisation of Opportunity: Lessons from Abroad, CASE Report 15, London, London School of Economics.

Evans, M. and Cerny, C. (2003) 'Globalization and social policy', in N. Ellison and C. Pierson (eds) Developments in British Social Policy 2, Basingstoke, Palgrave.

Featherstone, M. (1995) Undoing Culture, London, Sage.

Feldstein, M. and Horioka, C. (1980) 'Domestic savings and international capital flows', Economic fournal, 90: 314-29.

Ferge, Z. (1997) 'The changed welfare paradigm: the individualization of the social', Social Policy and Administration, 31 (1): 20-44.

Ferge, Z. and Juhász, G. (2004) 'Accession and social policy: the case of Hungary', fournal of European Social Policy, 14 (3): 233-52.

Ferrera, M. (1996) 'The southern model of welfare in Europe', Fournal of European Social Policy, 6 (1): 17-37.

Ferrera, M. (2000) 'Reconstructing the welfare state in Southern Europe', in S. Kuhnle (ed.) Survival of the European Welfare State, London, Routledge.

Ferrera, M. and Gualmini, E. (2000) 'Reforms guided by consensus: the welfare state in the Italian transition', in M. Ferrera and M. Rhodes (eds) Recasting the European Welfare State, London, Frank Cass.

Ferrera, M. and Hemerijck, A. (2003) 'Recalibrating Europe's welfare regimes', in J. Zeitlin and D.M. Trubeck (eds) Governing Work and Welfare in a New Economy: European and American Experiments, Oxford, Oxford University Press.

Ferrera, M., Hemerijck, A. and Rhodes, M. (2001) 'Recasting European welfare states for the 21 st Century', in S. Leibfried (ed.) Welfare State Futures, Cambridge, Cambridge University Press.

Finn, D. (1999) 'A job for the unemployed: lessons from Australian welfare reform', fournal of Social Policy, 28 (1): 53-72.

Finn, D. (2000) 'Welfare to work: the local dimension', Fournal of European Social Policy, 10 (1): $43-57$

Finn, D. (2003) 'Employment policy', in N. Ellison and C. Pierson (eds) Developments in British Social Policy 2, Basingstoke, Palgrave.

Flora, P. and Heidenheimer, A. J. (1981) The Development of Welfare States in Europe and America, London, Transaction Books.

Fougère, M. and Mérette, M. (1999) 'Population ageing and economic growth in seven OECD countries', Economic Modelling, 16: 411-27.

Frankel,J. (1991) 'Quantifying international capital mobility in the 1980s', in D. Bernheim and J. Shoven (eds) National Saving and Economic Performance, Chicago, IL, University of Chicago Press.

Frankel, J. (1992) 'Measuring international capital mobility: a review', American Economic Review, 82 (2): 197-202.

Franzini, M. (undated) Unemployment Benefits and Labour Market Policies in Italy, www.econpol.unisi.it/welfare/franzini.pdf.

Frieden, J. and Rogowski, R. (1996) 'The impact of the international economy on national policies: an analytical overview', in R. Keohane and H. Milner (eds) Internationalization and Domestic Politics, Cambridge, Cambridge University Press.

Fuchs, S. and Schettkat, R. (2000) 'Germany: a regulated flexibility', in G. Esping-Andersen and M. Regini (eds) Why De-regulate Labour Markets?, Oxford, Oxford University Press. 
Fij, E. and Chinn, M(2001) 'Fn de sièle real interest rate parity', Gournal of International Financial Markets, Institutions and Money 11: 289-08.

Gale, IGr. and Gzag, P. R200ß Private Pensions: Issues and Options, The Urban-Brookings Tax Policy Center, Discussion Paper 9, d\$hington DC, The Urban Institute.

Garrett, G. (1998) Partisan Politics in the Global Economy, Cambridge, Cambridge University Press.

Garrett, G. (2000) 'The causes of globalization', Comparative Political Studies, 33 (b7): 9491

Garrett, G. and Lange, P. (1995'Internationalization, institutions and political change’, International Organization, 49 ( $\$$ 87-5

Garrett, G. and Whell, D. (2001) 'Globalization, government spending and taxation in the ECD', European Fournal of Political Research, 39: 1377.

Gauthier, A. (1996 The State and the Family: A Comparative Analysis of Family Policies in Industrialized Societies, Word, Clarendon Press.

Gee, E.M2000) 'Population and politics', in E.MGee and G.MGutman (eds) The Overseeing of Population Ageing, Oord, Oord University Press.

Gershuny,Jand N₫s, I.D. (198ß3 The New Service Economy: The Transformation of Employment in Industrial Societies, London, Fances Pinter.

Giddens, A. (1990) The Consequences of Modernity, Cambridge, Polity Press.

Giddens, A. (1991) The Transformation of Intimacy, Cambridge, Polity Press.

Giddens, A. (1998) The Third Way: The Renewal of Social Democracy, Cambridge, Polity Press.

Giddens, A. (2000) Runaway World, London, Butledge.

Gilbert, N. (2002) The Transformation of the Welfare State, Oord, Oord University Press.

Ginn, J (2004 'European pension privatization: taking account of gender', Social Policy and Society, 3 (2): 1233

Glennerster, H. (1995 British Social Policy Since 1945, @ord, Blackwell.

Glynn, S. and Booth, A. (1996 Modern Britain: An Economic and Social History, London, Butledge.

Goetschy, J(2001) 'The European Employment Strategy from Amsterdam to Stockholm: has it reached cruising speed?, Industrial Relations fournal, 32 (5 $₫ 1-18$.

Goetschy, J (200ß'The European Employment Strategy, multi-level governance, and policy coordination: past, present and future', in J Zeitlin and D.MTrubeck (eds) Governing Work and Welfare in a New Economy: European and American Experiments, Oord, Oord University Press.

Goodin, R(2001) 'dkk and welfare: towards a post-productivist welfare regime', British Journal of Political Science, 31: 139.

Goodin, RHeadey, B., Mfels, Rand Dirven, H.-J(2001) The Real Worlds of Welfare Capitalism, Cambridge, Cambridge University Press.

Goodman, Rand Peng, I. (1996'The East Asian welfare states: peripatetic learning, adaptive change and nation building', in G. Esping-Andersen (ed.) Welfare States in Transition, London, Sage.

Gough, I. (1979) The Political Economy of the Welfare State, Basingstoke, Admillan.

Goul Andersen, J(2000) 'ANare crisis and beyond: Danish welfare policies in the 1980s and 1990s', in S. Whnle (ed.) Survival of the European Welfare State, London, Butledge.

Goul Andersen, J(2002a) 'Denmark: from the edge of the abyss to a sustainable welfare state', in JGoul Andersen, JClasen, Wan Orschot and KHalvorsen (eds), Europe's New State of Welfare: Unemployment, Employment policies and Citizenship, Bristol, The Policy Press. 


\section{Bibliography}

Goul Andersen, J. (2002b) 'Work and citizenship: unemployment and unemployment policies in Denmark, 1980-2000', in J. Goul Andersen and P.H. Jensen (eds) Changing Labour Markets, Welfare Policies and Citizenship, Bristol, The Policy Press.

Goul Andersen, J. and Halvorsen, K. (2002) 'Changing labour markets, unemployment and unemployment policies in a citizenship perspective', in J. Goul Andersen, J. Clasen, W. van Oorschot and K. Halvorsen (eds) Europe's New State of Welfare: Unemployment, Employment Policies and Citizenship, Bristol, The Policy Press.

Gould, A. (2001) Developments in Swedish Social Policy, Basingstoke, Palgrave.

Gow, D. (2003) The Guardian, 31.3.03.

Gow, D. (2004) 'Chancellor Schroeder's New Agenda 2010', The Guardian, 25.10.04.

Graham, S. and Marvin, S. (2001) Splintering Urbanism: Networked Infrastructures, Technological Mobilities and the Urban Condition, London, Routledge.

Gray, A. (2004) Unsocial Europe: Social Protection or Flexploitation?, London, Pluto.

Gray, J. (1997) Endgames: Questions in Late Modern Political Thought, Cambridge, Polity Press.

Gray, J. (1998) False Dawn, Cambridge, Granta.

Green-Pedersen, C. (2004) 'What to make of the Dutch and Danish "Miracles", in B. Södersten (ed.) Globalization and the Welfare State, Basingstoke, Palgrave.

Green-Pedersen, C. and Lindbom, A. (2002) 'Politics within paths: the trajectories of Danish and Swedish pension systems', Paper for ECPR Joint Sessions, Workshop 21, Turin.

Guillén, A.M. and Palier, B. (2004) 'Introduction: does Europe matter? Accession to EU and social policy developments in recent and new member states', Fournal of European Social Policy, 14 (3): 203-10.

Hajighasemi, A.N. (2003) The transformation of the Swedish welfare system. Fact or fiction?, unpublished $\mathrm{PhD}$ thesis, University of Durham.

Hall, P.A. and Soskice, D. (2001) 'An introduction to varieties of capitalism', in P.A. Hall and D. Soskice (eds) Varieties of Capitalism: The Institutional Foundations of Comparative Advantage, Oxford, Oxford University Press.

Hamann, A.J. (1997) The Reform of the Pension System in Italy, A Working Paper of the International Monetary Fund, WP/97/18.

Harris, D. O. (2004) Pension Reforms and Ageing Populations: Lessons from Australia and the United Kingdom, Testimony Before the US Senate Special Committee on Ageing, 18.5.04.

Hay, C. (1999) The Political Economy of New Labour: Labouring Under False Pretences?, Manchester, Manchester University Press.

Hay, C. (2000) 'Globalization, social democracy and the persistence of partisan politics: A commentary on Garrett', Review of International Political Economy 7 (1): 138-52.

Hay, C. (2001) 'Globalization, economic change and the welfare state: the "vexatious inquisition of taxation"?', in R. Sykes, B. Palier and P.M. Prior (eds) Globalization and European Welfare States, Basingstoke, Palgrave.

Hay, C. and Rosamund, B. (2002) 'Globalization, European integration and the discursive construction of economic imperatives', fournal of European Public Policy, 9 (2): 147-67.

Held, D., McGrew, A., Goldblatt, D. and Perraton, J. (1999) Global Transformations, Cambridge, Polity Press.

Helleiner, E. (2001) 'Markets, politics, and globalization: can the global economy be civilized?', Global Governance 7 (3): 243-63.

Hemerijck, A. (2002) 'The self-transformation of the European social model(s)', in G. Esping-Andersen, D. Gallie, A. Hemerijck and J. Myles (eds) Why We Need a New Welfare State, Oxford, Oxford University Press.

Hemerijck, A., Unger, B. and Visser, J. (2000) 'How small countries negotiate change: twenty-five years of policy adjustment in Austria, the Netherlands and Belgium', in F. 
Scharpf and V. Schmidt (eds) Welfare and Work in the Open Economy, Vol. 2, Diverse Responses to Common Challenges, Oxford, Oxford University Press.

Hemerijck, A. and van Kersbergen, K. (1997) 'Explaining the new politics of the welfare state in the Netherlands', Acta Politica, 32: 258-301.

Hering, M. (2002) 'Turning ideas into policies: implementing modern social democratic thinking in Germany's pension policy', in G. Bonoli and M. Powell (eds) Social Democratic Party Policies in Contemporary Europe, London, Routledge.

Hills, J. (2004) 'Heading for retirement? National insurance, state pensions, and the future of the contributory principle in the UK', Fournal of Social Policy, 33 (3): 347-72.

Hinrichs, K. (1998) 'Reforming the public pension scheme in Germany: the end of the traditional consensus?', ZeS-Arbeitspapier Nr 11/98, Centre for Social Policy Research, University of Bremen.

Hinrichs, K. (2001) 'Elephants on the move: patterns of public pension reform in OECD countries', in S. Leibfried (ed.), Welfare State Futures, Cambridge, Cambridge University Press.

Hinrichs, K. (2002) 'Basic security plus private employment-related pensions: do Australia, Denmark, the Netherlands and Switzerland show the way for public pension reform in European social insurance countries?', Paper prepared for World Congress of Sociology, Brisbane, July.

Hinrichs, K. (2003) 'New century - new paradigm: pension reforms in Germany', paper delivered to Pension Reform in Europe conference, London School of Economics/ European Institute, December.

Hirst, P. and Thompson, G. (1999) Globalization in Question, 2nd edn, Cambridge, Polity Press.

Hobson, B. (2004) 'The individualised worker, the gender participatory and the gender equity models in Sweden', Social Policy and Society, 3 (1): 75-83.

Holcomb, P.A. and Martinson, K. (2002) 'Putting policy into practice: five years of welfare reform', in A. Weil and K. Finegold (eds) Welfare Reform; The Next Act, Washington, DC, Urban Institute Press.

Holcomb, P.A. and Martinson, K. (2003) 'Welfare reform in the United States: the first five years of TANF', in C. Bochel, N. Ellison and M. Powell (eds) Social Policy Review 15: UK and International Perspectives, Bristol, The Policy Press.

Hollingsworth, J.R. (1998) 'New perspectives on the spatial dimensions of economic coordination: tensions between globalization and social systems of production', Reviere of International Political Economy, $\mathbf{5}$ (3): 482-507.

Huber, E. and Stephens, J. (2001) Development and Crisis of the Welfare State, Chicago, IL, University of Chicago Press.

Hutton, W. (2004) 'Europe is reaching crisis point', The Observer, 12.9.04.

Hvinden, B., Heikkilä, M. and Kankare, I. (2001) 'Towards activation? The changing relationship between social protection and employment in Western Europe', in M. Kautto, J. Fritzell, B. Hvinden, J. Kvist and H. Uusitalo (eds) Nordic Welfare States in the European Context, London, Routledge.

Ingram, P. and Clay, K. (2000) 'The-choice-within-constraints new institutionalism and implications for sociology', Annual Review of Sociology, 26: 525-46.

International Reform Monitor (2004) Issue 9, Bertelsmann Stiftung.

Investment and Pensions in Europe (2003) 'Germany sees revival in occupational pensions', Top 1000 European Directive Debate, September, London, IPE.

Investment and Pensions in Europe (2004) 4.11.04, 'Dutch scheme faces government overhaul', www.ipe.com. 


\section{Bibliography}

Iversen, T. (2001) 'The dynamics of welfare state expansion: trade openness, deindustrialization, and partisan politics', in P. Pierson (ed.) The New Politics of the Welfare State, Oxford, Oxford University Press.

Iversen, T. and Cusack, T. (2000) 'The causes of welfare state expansion', World Politics, 52 (April): 313-49.

Iversen, T. and Pontusson, J. (2000) 'Comparative political economy: a northern European perspective', in T. Iversen, J. Pontusson and D. Soskice (eds) Unions, Employers and Central Banks: Macroeconomic Coordination and Institutional Change in Social Market Economies, Cambridge, Cambridge University Press.

Iversen, T. and Wren, A. (1998) 'Equality, employment and budgetary restraint: the trilemma of the service economy', World Politics, 50 (4): 507-46.

Jackson, W.A. (1998) The Political Economy of Population Ageing, London, Edward Elgar.

Jay, A. (2004) 'General Motors to cut 12,000 European jobs', The Guardian, 14.10.04.

Jayasuriya, K. (2001) 'Globalization and the changing architecture of the state: the regulatory state and the politics of negative coordination', fournal of European Public Policy, 8 (1): 101-23.

Jayasuriya, K. (2004) 'The new regulatory state and relational capacity', Policy and Politics, 32 (4): 487-501.

Jessop, B (1994) 'From the Keynesian welfare state to the Schumpeterian workfare state', in R. Burrows and B. Loader (eds) Towards a Post-Fordist Welfare State?, London, Routledge.

Jessop, B. (2002) The Future of the Capitalist State, Cambridge, Polity Press.

Jochem, (2000) 'Nordic labour market policies in transition', West European Politics, 23 (3): $115-38$.

Johnson, C. and Tonkiss, F. (2002) 'The third influence: the Blair government and Australian Labor', Policy and Politics, 30 (1): 5-18.

Jonas, D.K. (2001) 'The Florida devolution model: lessons from the WAGES welfare reform experiment', in D.J. Besharov, P. Germanis, J. Hein, D.K. Jonas and A.L. Sherman (eds) Ending Dependency? Lessons from Welfare Reform in the USA, London, Civitas.

Karger, H.J. (2003) 'Ending public assistance: the transformation of US public assistance policy into labour policy', Journal of Social Policy, 32 (3): 383-402.

Kasza, G.J. (2002) 'The illusion of welfare "regimes" ', Fournal of Social Policy, 30 (2): 271 87

Kellner, D. (1998) 'Globalization and the postmodern turn', in R. Axtmann (ed.) Globalization and Europe: Theoretical and Empirical Investigations, London, Pinter.

Kersbergen, K. van (1995) Social Capitalism: A Study of Christian Democracy and the Welfare State, London, Routledge.

Kersbergen, K. van (2000) 'The declining resistance of welfare states to change?', in S. Kuhnle (ed.) Survival of the European Welfare State, London, Routledge.

Kersbergen, K. van and Hemerijck, A. (2004) 'Christian democracy, social democracy and the continental "Welfare to Work" syndrome', in N. Ellison, L. Bauld and M. Powell (eds) Social Policy Review 16: Analysis and Debate in Social Policy, 2004, Bristol, The Policy Press.

King, D. (1995) Actively Seeking Work? The Politics of Unemployment and Welfare Policy in the United States and Great Britain, Chicago, IL, University of Chicago Press.

King, D. and Wood, S. (1999) 'The political economy of neoliberalism: Britain and the United States in the 1980s', in H. Kitschelt, P. Lange, G. Marks and J.D. Stephens (eds) Continuity and Change in Contemporary Capitalism, Cambridge, Cambridge University Press.

Kitschelt, H. (1999) 'Convergence and divergence in advanced capitalist democracies', in H. Kitschelt, P. Lange, G. Marks and J.D. Stephens (eds) Continuity and Change in Contemporary Capitalism, Cambridge, Cambridge University Press. 
Klausen, J. (1999) 'The declining significance of male workers: trade union responses to changing labor markets', in H. Kitschelt, P. Lange, G. Marks and J. D. Stephens (eds), Continuity and Change in Comtemporary Capitalism, Cambridge, Cambridge University Press.

Klein, R. and Millar, J. (1995) 'Do-it-yourself social policy: searching for a new paradigm?', Social Policy and Administration, 29 (4): 303-16.

Knijn, T. (2004) 'Challenges and risks of individualization in the Netherlands', Social Policy and Society, 3 (1): 57-66.

Korpi, W. (1983) The Democratic Class Struggle, London, Routledge and Kegan Paul.

Krol, R. (1996) 'International capital mobility: evidence from panel data', Fournal of International Money and Finance, 15 (3): 467-74.

Krugman, P. (1998) The Age of Diminished Expectations, Cambridge, MA, MIT Press.

Kuhnle, S. (2000) 'European welfare lessons of the 1990s', in S. Kuhnle (ed.) Survival of the European Welfare State, London, Routledge.

Kurzer, P. (1993) Business and Banking: Political Change and Economic Integration in Western Europe, Ithaca, NY, Cornell University Press.

Kvist, J. (1997) 'Welfare reform in the Nordic countries in the 1990s', Fournal of European Social Policy, 9 (3): 231-52.

Kvist, J. (2002) 'Activating welfare states: how social policies can promote employment', in J. Clasen (ed.) What Future for Social Security? Debates and Reforms in National and Crossnational Perspective, Bristol, The Policy Press.

Lamping, W. and Rüb, F.W. (2004) 'From conservative welfare state to an "uncertain something else": German pension politics in comparative perspective', Policy and Politics, 32 (2): 169-91.

Land, H. (1999) The Changing Worlds of Work and Families, Buckingham, Open University Press.

Lane, C. (2000) 'Globalization and the German model of capitalism - erosion or survival?', British Fournal of Sociology, $\mathbf{5 1}$ (2): 207-34

Larsen, T. and Daguerre, A. (2003) EU Policy Maps: Working Papers for WRAMSOC, www.kent.ac.uk/wramsoc/workingpapers/index.htm

Lash, S. and Urry, J. (1987) The End of Organized Capitalism, Cambridge, Polity Press.

Leibfried, S. (1993) 'Towards a European welfare state', in C. Jones (ed.), New Perspectives on the Welfare State in Europe, London, Routledge.

Leibfried, S. and Obinger, H. (2001) 'Welfare state futures: an introduction', in S. Leibfried (ed.) Welfare State Futures, Cambridge, Cambridge University Press.

Leinert, J. and Esche, A. (2000) Advance Funding of Pensions, Gütersloh, International Reform Monitor, Bertelsmann.

Leisering, L. (2001) 'Germany: reform from within', in P. Alcock and G. Craig (eds) International Society Policy, Basingstoke, Palgrave.

Lendvai, N. (2004) 'The weakest link? EU accession and enlargement: dialoguing EU and post-communist social policy', fournal of European Social Policy, 14 (3): 319-33.

Levitas, R. (1998) The Exclusive Society: Social Exclusion and New Labour, Basingstoke, Macmillan.

Levy, J. (1999) 'Vice into virtue? Progressive politics and welfare reform in Continental Europe', Politics and Society, 27 (2): 239-73.

Levy, J. (2001) 'Partisan politics and welfare adjustment: the case of France', fournal of European Public Policy, 8 (2): 265-85.

Levy, J. (2004) 'Activation through thick and thin: progressive approaches to labour market activation', in N. Ellison, L. Bauld and M. Powell (eds) Social Policy Review 16: Analysis and Debate in Social Policy, 2004, Bristol, The Policy Press. 


\section{Bibliography}

Lewis, J. (1992) 'Gender and the development of welfare regimes', Fournal of European Social Policy, 2 (3): 159-73.

Lewis, J. (2001) 'The decline of the male breadwinner model: implications for work and care', Social Politics, 8 (2): 152-69.

Lewis, J. and Bennett, F. (2004) 'Introduction to themed issue on gender and individualization', Social Policy and Society, 3 (1): 43-7.

Lister, R. (1994) ' "She has other duties" - women, citizenship and social security', in S. Baldwin and J. Falkingham (eds) Social Security and Social Change: Nerw Challenges to the Beveridge Model, Hemel Hempstead, Harvester Wheatsheaf.

Lødemel, I. (2004) 'The development of workfare within social activation policies', in D. Gallie (ed.) Resisting Marginalization: Unemployment Experience and Social Policy in the European Union, Oxford, Oxford University Press.

Loprest, P. (2001) How Are Families that Leave Welfare Doing? A Comparison of Early and Recent Leavers, Policy Brief B-36, Washington, DC, The Urban Institute.

Loprest, P. (2002) 'Making the transition from welfare to work: successes but continuing concerns', in A. Weil and K. Finegold (eds) Welfare Reform: The Next Act, Washington, DC, The Urban Institute.

Ludovici, M.S. (2000) 'Italy: The long times of consensusal re-regulation', in G. EspingAndersen and M. Regini (eds) Why Deregulate Labour Markets?, Oxford, Oxford University Press.

McKeown, T. (1999) 'The global economy, post-Fordism, and trade policy in the advanced capitalist states', in H. Kitschelt. P. Lange, G. Marks and J.D. Stephens (eds) Continuity and Change in Contemporary Capitalism, Cambridge, Cambridge University Press.

Maerkedahl, I. (2000) 'The active labour market policy in Denmark', in Labour Market Policies and the Public Employment Service, OECD Proceedings, Prague Conference, July 2000, Paris, OECD.

Mandelson, P. and Liddle, R. (1996) The Blair Revolution, London, Faber and Faber.

Mandin, C. and Palier, B. (2003) Policy Maps - France, www.kent.ac.uk/wramsoc/ workingpapers/index.htm.

Mann, M. (1997) 'Has globalization ended the rise and rise of the nation-state?', Review of International Political Economy, 4 (3): 472-96.

Manow, P. and Seils, E. (2000) 'Adjusting badly: the German welfare state, structural change and the open economy', in F.W. Scharpf and V. Schmidt (eds) Welfare and Work in the Open Economy, Vol. 2, Diverse Responses and Common Challenges, Oxford, Oxford University Press.

March, J.G. and Olsen, J.P. (1998) 'Institutional dynamics and international political orders', International Organization 52 (4): 943-69.

Maré, M. and Pennisi. G. (2003) 'Financial constraints and policy options: the pension reform process in Italy and its relevance to transition European economies', in Reforming Public Pensions: Sharing the Experience of Transition in OECD Countries, Paris, OECD.

Marklund, S. and Nordlund, A. (1999) 'Economic problems, welfare convergence and political instability', in M. Kautto, M. Heikkilä, B. Hvinden, S. Marklund and N. Ploug (eds) Nordic Social Policy: Changing Welfare States, London, Routledge.

Martin, H.-P., Schumann, H. and Camiller, P. (1997) The Global Trap: Globalization and the Assault on Prosperity and Democracy, New York, St Martin's Press.

Martin, J. (1998) What Works Among Active Labour Market Policies: Evidence From OECD Countries' Experience, Labour Market and Social Policy - Occasional Paper No. 35, Paris, OECD.

Mead, L. (1986) Beyond Entitlement: The Social Obligations of Citizenship, New York, Free Press. Mercer (2004) www.mercerhr.com/common. 
Merrien, F.-X. and Bonoli, G. (2000) 'Implementing major welfare state reforms: a comparison of France and Switzerland - a new institutionalist approach', in S. Kuhnle (ed.) Survival of the European Welfare State, London, Routledge.

Meyer, T. (1998) 'Retrenchment, reproduction, modernisation: pension politics and the decline of the German breadwinner model', Fournal of European Social Policy, 8 (3): $195-211$.

Millar, J. (2002) 'Adjusting welfare policies to stimulate job entry: the example of the United Kingdom', in H. Sarfati and G. Bonoli (eds) Labour Market and Social Protection Reforms in International Perspective: Parallel or Converging Tracks?, Aldershot, Ashgate.

Millar, J. (2004) 'Squaring the circle? Means testing and individualisation in the UK and Australia', Social Policy and Society, 3 (1): 67-74.

Minns, R. (2001) The Cold War in Welfare, London, Verso.

Mishra, R. (1996) 'The welfare of nations', in R. Boyer and D. Drache (eds) States Against Markets, London, Routledge.

Mishra, R. (1999) Globalization and The Welfare State, London, Edward Elgar.

Mitchell, W. J. (2004) Me ++: The Cyborg Self and the Networked City, Cambridge, MA, MIT Press.

Moreno, L. (2001) 'Spain, a via media of welfare development', in P. Taylor-Gooby (ed.) Welfare States Under Pressure, London, Sage.

Murray, C. (1984) Losing Ground: American Social Policy, 1950-1980, New York, Basic Books.

Myles, J. (1989) 'Postwar capitalism and the extension of social security into a retirement wage', in M. Weir, A.S. Orloff and T. Skocpol (eds) The Politics of Social Policy in the United States, Princeton NJ, Princeton University Press.

Myles, J. (2002) 'A new social contract for the elderly?', in G. Esping-Andersen with D. Gallie, A. Hemerijck and J. Myles (eds) Why We Need a New Welfare State, Oxford, Oxford University Press.

Myles, J. and Pierson, P. (2001) 'The comparative political economy of pension reform', in P. Pierson (ed.), The New Politics of the Welfare State, Oxford, Oxford University Press.

Natali, D. (2004) 'Italy: the reformed pension system', unpublished paper from research project: 'La Méthode Ouverte de Coordination (MOC) en Matiere des Pensions et de l'integration Européenne, Observatoire Social Européen'.

Natali, D. and Rhodes, M. (2004) 'Trade-offs and veto players: reforming pensions in France and Italy', French Politics, 2: 1-23.

Nightingale, D.S. (2002) 'Work opportunities for people leaving welfare', in A. Weil and K. Finegold (eds), Welfare Reform: The Next Act, Washington DC, The Urban Institute.

Obstfeld, M. (1995) 'International capital mobility in the 1990s', in P. Kenen (ed.) Understanding Interdependence, Princeton, NJ, Princeton University Press.

O'Connor, J. (1993) 'Gender, class and citizenship in the comparative analysis of welfare state regimes: theoretical and methodological issues', British fournal of Sociology, 44 (3): 501-18.

O'Connor, J. (1996) 'From women in the welfare state to gendering welfare state regimes', Current Sociology, 44 (2): 1-124.

O’Connor, J., Orloff, A. S. and Shaver, S. (1999) States, Markets, Families: Gender, Liberalism and Social Policy in Australia, Canada, Great Britain and the United States, Cambridge, Cambridge University Press.

OECD (1993) Key Issues for Labour Market and Social Policies, Paris, OECD.

OECD (1994) The OECD fobs Study, Paris, OECD.

OECD (1996) Ageing in OECD Countries: A Critical Policy Challenge, Paris, OECD. 


\section{Bibliography}

OECD (1998a) The OECD Fobs Strategy: Progress on Implementation of Country-specific Recommendations, OECD Economic Department Working Papers, No. 196, Paris, OECD.

OECD (1998b) Maintaining Prosperity in an Ageing Society, Paris, OECD.

OECD (1999) OECD Economic Surveys: Australia, Paris, OECD.

OECD (2000a) Reforms for an Ageing Society, Paris, OECD.

OECD (2000b) Swedish Country Response, Paris, OECD.

OECD (2001a) Historical Statistics, 1970-99, Paris, OECD.

OECD (2001b) Innovations in Labour Market Policies: The Australian Way, Paris, OECD.

OECD (2001c) OECD Economic Surveys: Australia, Paris, OECD.

OECD (2001d) Fiscal Implications of Ageing, Paris, OECD.

OECD (2002) Employment Outlook, Paris, OECD.

OECD (2004a) Employment Outlook (statistical annex), Paris, OECD.

OECD (2004b) Labour Market Statistics, Paris, OECD.

Offe, C. (1984) Contradictions of the Welfare State, London, Hutchinson.

Ohmae, K. (1990) The Borderless World, London, Collins.

Ohmae, K. (1995) The End of the Nation-State, New York, Free Press.

Oorschot, W. van (2002) 'Labour market participation in the Netherlands: trends, policies and outcomes', in J. Goul Andersen, J. Clasen, W. van Oorschot and K. Halvorsen (eds) Europe's New State of Welfare: Unemployment, Employment Policies and Citizenship, Bristol, The Policy Press.

Orloff, A.S. (1993) 'Gender and the social rights of citizenship: the comparative analysis of gender relations and welfare states', American Sociological Review, 58 (3): 303-28.

Ostner, I. (2004) ' "Individualisation" - the origins of the concept and its impact on German social policies', Social Policy and Society, 3 (1): 47-56.

Overbye, E. (1996) 'Pension politics in the Nordic countries: a case study', International Political Science Review, 17 (1): 67-90.

Palier, B. (2000) " "Defrosting" the French welfare state', West European Politics, 23: 113-36.

Palier, B. (2001) 'Reshaping the social policy-making framework in France', in P. TaylorGooby (ed.) Welfare States Under Pressure, London, Sage.

Palmer, E. (2000) The Swedish Pension Reform Model: Framework and Issues, SP Discussion Paper 0012, World Bank.

Park, J. (1994) 'Trading blocs and US-Japan relations in Pacific trade and cooperation', in M. Landeck (ed.) International Trade: Regional and Global Issues, New York, St Martin's Press.

Pascall, J. and Lewis, J. (2004) 'Emerging gender regimes and policies for gender equality in a wider Europe', fournal of Social Policy, 33 (3): 373-94.

Pauly, L. and Reich, S. (1997) 'National structures and multinational behaviour: enduring differences in the age of globalization', International Organization 51 (1): 1-30.

Peck, J. (2001) Workfare States, London, The Guildford Press.

Peck, J. and Theodore, N. (2001) 'Exporting workfare/importing welfare-to-work: exploring the politics of third way policy transfer', Political Geography, 20: 427-60.

Penner, R. (2002) 'The Moving Pieces of Social Security Reform', Washington DC, The Urban Institute, www.urban.org/urlprint.cfm?ID $=8246$.

Pensions Commission (2004) Pensions: Challenges and Choices, First Report of the Pensions Commission, London, The Stationery Office.

Pensions Policy Institute (2003) State Pension Models, London, Pensions Policy Institute.

Pierson, C. (2001) Hard Choices, Cambridge, Polity Press.

Pierson, P. (1994) Dismantling the Welfare State? Reagan, Thatcher and the Politics of Retrenchment, Cambridge, Cambridge University Press. 
Pierson, P. (1996) 'The new politics of the welfare state', World Politics, 48 (2): 143-79.

Pierson, P. (1998) 'Irresistible forces, immovable objects: post-industrial welfare states confront permanent austerity', Fournal of European Public Policy, 5 (4): 539-60.

Pierson, P. (2000a) 'The limits of design: explaining institutional origins and change', Governance, 13 (4): 475-99.

Pierson, P. (2000b) 'Increasing returns, path dependence, and the study of politics', American Political Science Review, 94 (2): 251-67.

Pierson, P. (2000c) 'Three worlds of welfare state research', Comparative Political Studies, 33 (6/7): 791-821.

Pierson, P. (2001a) 'Post-industrial pressures on the mature welfare states', in P. Pierson (ed.), The New Politics of the Welfare State, Oxford, Oxford University Press.

Pierson, P. (2001b) 'Coping with permanent austerity: welfare state restructuring in affluent societies', in P. Pierson (ed.), The New Politics of the Welfare State, Oxford, Oxford Unversity Press.

Pieterse,J.N. (2004) Globalization and Culture: Global Mélange, Oxford, Rowman and Littlefield.

Pisani-Ferry, J. (2001) Employment in France, www.ambafrance-uk.org/asp/service. asp?SERVID $=100 \& \mathrm{LNG}=\mathrm{en} \& \mathrm{PAGID}=346$.

Ploug, N. (2002a) Impact Evaluation of the European Employment Strategy - Denmark, Copenhagen, The Danish National Institute of Social Research.

Ploug, N. (2002b) The Re-calibration of the Danish Old-age Pensions System, Danish National Institute of Social Research, Copenhagen.

Plougmann, P. and Madsen, P.K. (2002) Flexibility, Employment Development and Active Labour Market Policy in Denmark and Sweden in the 1990s, CEPA Working Paper 2002-04, New York, New School University.

Polanyi, K. (1957) The Great Transformation, Boston, MA, Beacon Press.

Putnam, R. (2000) Bowling Alone, New York, Simon and Schuster.

Quadagno, J. (1994) The Color of Welfare, Oxford, Oxford University Press.

Rabobank International (2004) FTK and IFRS Shake-up Dutch Pension Funds, April, www.rabotreasuryweb.com.

Radaelli, G.M. (2003) The Open Method of Coordination: A New Governance Structure for the European Union, Report 1, Swedish Institute for European Policy Studies, Stockholm.

Raffarin, J.-P. (2002) General Policy Address, delivered to Members of the French National Assembly, 3.7.02.

Ramia, G. and Carney, T. (2000) 'Contractualism, managerialism and welfare: the Australian experiment with a marketised employment services network', Policy and Politics, 29 (1): 59-83.

Reich, R. (1991) The Work of Nations: Preparing Ourselves for Twenty-first Century Capitalism, New York, Simon and Schuster.

Reich, R. (2002) The Future of Success: Work and Life in the New Economy, London, Vintage.

Rhodes, M. (1998) 'Globalization, labour markets and welfare states: a future for "Competitive Corporatism"?', in M. Rhodes and Y. Mény (eds) The European Welfare State: A New Social Contract?, Basingstoke, Macmillan.

Rhodes, M. (2001) 'The political economy of social pacts: "Competitive Corporatism" and European welfare reform', in P. Pierson (ed.) The New Politics of the Welfare State, Oxford, Oxford University Press.

Rhodes, M. (2003) 'National "Pacts" and EU governance in social policy and the labor market', in J. Zeitlin and D.M. Trubeck (eds) Governing Work and Welfare in a New Economy: European and American Experiments, Oxford, Oxford University Press. 


\section{Bibliography}

Rhodes, M. and van Apeldorn, B. (1998) 'Capital unbound? The transformation of European corporate governance', Fournal of European Public Policy, 5 (3): 406-27.

Rhodes, M. and Natali, D. (2003) 'Berlusconi has failed to heed the lesson of history', Financial Times, 23 October.

Rieger, E. and Leibfried, S. (1998) 'Welfare state limits to globalization', Politics and Society, 26 (4): 363-90.

Rieger, E. and Leibfried, S. (2003) Limits to Globalization, Cambridge, Polity Press.

Ritzer, G. (1993) The McDonaldization of Society, London, Sage.

Rodrik, D. (1998) 'Why do more open economies have larger governments?', Journal of Political Economy, $\mathbf{1 0 6}$ (Oct): 997-1032.

Rodrik, D. (2000) 'How far will international economic integration go?', Fournal of Economic Perspectives 14 (1): 177-86.

Rosch, J. (1998) Unemployment Insurance in the USA', tiss.zdv.uni-tuebingen.de/webroot/sp/ spsba01_W98_1/usa6d.htm.

Rosdahl, A. and Weise, H. (2000) 'When all must be active - workfare in Denmark', in I. Lødemel and H. Trickey (eds) "An Offer You Can't Refuse”: Workfare in International Perspective, Bristol, The Policy Press.

Rostagno, M.V. and Utili, F. (1998) The Italian Social Protection System: The Poverty of Welfare, A Working Paper of the International Monetary fund, WP/98/74.

Rothstein, B. (1998) Fust Institutions Matter, Cambridge, Cambridge University Press.

Sachs, J.D. and Warner, A.M. (1995) 'Economic convergence and economic policies', Harvard Institute of Economic Research Working Papers, No 1715, University of Harvard.

Sailer, M. (2002) Supplementary Pension Provision in Germany, www.bfa.de/eng/eng_ zulagenstelle.g/eng_g_riester.html.

Sailer, M. (2003) 'Pension reform in Germany: an assessment', in Reforming Public Pensions: Sharing the Experiences of Transition and OECD Countries, Paris, OECD.

Sainsbury, D. (ed.) (1996) Gendering Welfare States, London, Sage.

Sarfati, H. (2002) 'Labour market and social protection policies: linkages and interactions', in H. Sarfati and G. Bonoli (eds) Labour Market and Social Protection Reforms in International Perspective: Parallel or Converging Tracks?, Aldershot, Ashgate.

Saunders, P. (1999) 'Social security in Australia and New Zealand: means-tested or just mean?', Social Policy and Administration, 33 (5): 493-515.

Sbragia, A. (2000) 'Governance, the state, and the market: what is going on?', Governance, 13 (2): $243-50$.

Schaeffer, R.K. (2003) Understanding Globalization: The Social Consequences of Political, Economic and Environmental Change, 2nd edn, Oxford, Rowman and Littlefield.

Scharpf, F. (1999) Governing in Europe: Effective and Democratic?, Oxford, Oxford University Press.

Scharpf, F. (2000) 'The viability of advanced welfare states in the international economy: vulnerabilities and options', Fournal of European Public Policy, 7 (2): 190-228.

Scharpf, F. and Schmidt, V. (2000) Welfare and Work in the Open Economy, Vol. 1, Oxford, Oxford University Press.

Schiller, H. (1991) 'Not yet the post-imperialist era', Critical Studies in Mass Communication, 8 (1): 13-28.

Schram, S.F. (1995) Words of Welfare: The Poverty of Social Science and the Social Science of Poverty, Minneapolis, MN, University of Minnesota Press.

Schroeder, G. (2003) 'Modernise or die', The Guardian, 8.7.03. 
Schwartz, H. (1999) 'The Danish "miracle”: pluck, luck or stuck', www.people.virginia.edu/ $\sim$ hms2f/Sass-99.html

Schwartz, H. (2000) 'Internationalization and two liberal welfare states: Australia and New Zealand', in F.W. Scharpf and V. Schmidt (eds) Welfare and Work in the Open Economy, Vol. 2, Diverse Responses to Common Challenges, Oxford, Oxford University Press.

Schwartz, H. (2001) 'Round up the usual suspects!', in P. Pierson (ed.) The New Politics of the Welfare State, Oxford, Oxford University Press.

Settergren, O. (2001) Two Thousand Five Hundred Words on the Swedish Pension Reform, Workshop on Pension Reform, German Embassy, on behalf of the Urban Institute.

Shaver, S. (1997) Universality and Selectivity in Income Support: An Assessment of the Issues, Aldershot, Ashgate.

Shaver, S. (1999) 'Gender down under: welfare state restructuring in Australia and Aotearoa/New Zealand', Social Policy and Administration, 33 (5): 586-603.

Shaw, E. (1996) The Labour Party Since 1945, Oxford, Blackwell.

Sianesi, B. (2002) 'Swedish active labour market programmes in the 1990s: overall effectiveness and differential performance', London, Institute for Fiscal Studies.

Siebert, H. (1999) The World Economy, London, Routledge.

Simmons, B. (1999) 'The internationalization of capital', in H. Kitschelt, P. Lange, G. Marks and J.D. Stephens (eds) Continuity and Change in Contemporary Capitalism, Cambridge, Cambridge University Press.

Sinclair, J., Jacka, E. and Cunningham, S. (2000) 'Peripheral vision', in F.J. Lechner and J. Boli (eds) The Globalization Reader, Oxford, Blackwell.

Sklair, L. (2002) Globalization: Capitalism and its Alternatives, Oxford, Oxford University Press. Skocpol, T. (1995) Social Policy in the United States, Princeton, NJ, Princeton University Press.

Smith, S.R. (2002) 'Privatization, devolution, and the welfare state: rethinking the prevailing wisdom', in B. Rothstein and S. Steinmo (eds) Restructuring the Welfare State: Political Institutions and Policy Change, Basingstoke: Palgrave.

Social Security Administration (2004) Fact Sheet: Social Security, www.ssa.gov/pressoffice/ factsheets/basicfact-alt.htm.

Soskice, D. (1997) 'German technology policy, innovation, and national institutional frameworks', Industry and Innovation 4 (1): 75-96.

Soskice, D. (1999) 'Divergent production regimes: coordinated and uncoordinated market economies in the 1980s and 1990s', in H. Kitschelt, P. Lange, G. Marks and J.D. Stephens (eds) Continuity and Change in Contemporary Capitalism, Cambridge, Cambridge University Press.

Spies, H. and van Berkel, R. (2000) 'Workfare in the Netherlands - young unemployed people and the jobseekers' Employment Act', in I. Lødemel and H. Trickey (eds) 'An Offer you Can't Refuse": Workfare in International Perspective, Bristol, The Policy Press.

Stafford, B. (2003) 'Beyond lone parents: extending welfare-to-work to disabled people and the young unemployed', in R. Walker and M .Wiseman (eds) The Welfare We Want? The British Challenge for American Reform, Bristol, The Policy Press.

Stahlberg, (1995) The Swedish Pension System, Past, Present and Future, Series 465, Swedish Institute of Social Research, Stockholm University.

Stephens, J. (1996) 'The Scandinavian welfare states: achievements, crisis, prospects', in G. Esping-Andersen (ed.) Welfare States in Transition, London, Sage.

Sundén, A. (2004) How Do Individual Accounts Work in the Swedish Pension System?, Issue in Brief 22, Centre for Retirement Research, Boston College.

Swank, D. (2001) 'Political institutions and welfare state restructuring: the impact of institutions on social policy change in developed democracies', in P. Pierson (ed.) The New Politics of the Welfare State, Oxford, Oxford University Press. 


\section{Bibliography}

Swank, D. (2002) Global Capital, Political Institutions and Policy Change in Developed Welfare States, Cambridge, Cambridge University Press.

Swedish Bureau of Statistics (2004) www.scb.se/templates/pressinfo__ 103590.asp.

Swenson, P. and Pontusson, J. (2000) 'The Swedish employer offensive against centralized bargaining', in T. Iversen, J. Pontusson and D. Soskice (eds) Unions, Employers, and Central Banks, Cambridge, Cambridge University Press.

Tanner, M. (2001) 'Social security shortchanges African Americans', USA Today, July 2001, www.findarticles.com/p/articles/mi_ml272/is_2674_130/ai.

Taylor-Gooby, P. (2005) Welfare Reform and the Management of Societal Change, Final Report, HPSE-CT2001-00078, www.kent.ac.uk/wramsoc.

Taylor-Gooby, P. and Larsen, T.P. (2004) 'The UK - a test case for the liberal welfare state?', in P. Taylor-Gooby (ed.) New Risks, New Welfare: The Transformation of the European Welfare State, Oxford, Oxford University Press.

Teague, P. (2001) 'Deliberative governance and EU social policy', European fournal of Industrial Relations, 7 (1): 7-26.

Tesar, L. (1991) 'Savings, investment and international capital flows', fournal of International Economics, 31: 55-78.

Thelen, K. (2000) 'Why German employers cannot bring themselves to dismantle the German model', in T. Iversen, J. Pontusson and D. Soskice (eds) Unions, Employers and Central Banks: Macroeconomic Coordination and Institutional Change in Social Market Economies, Cambridge, Cambridge University Press.

Thelen, K. (2001) 'Varieties of labour politics in the developed democracies', in P.A. Hall and D. Soskice (eds) Varieties of Capitalism: The Institutional Foundations of Comparative Advantage, Oxford, Oxford University Press.

Theodore, N. and Peck, J. (1999) 'Welfare-to-work: national problems, local solutions?', Critical Social Policy, 19 (4): 485-510.

Theodore, N. and Peck, J. (2000) 'Searching for best practice in welfare-to-work: the means, the method and the message', Policy and Politics, 29 (1): 81-98.

Third National Pension Fund (2002) Third National Pension Fund Annual Report, 2001, www.ap3.se

Thompson, J. (2002) Recent Developments: Financial Market Trends Impact on Private Pensions, Working Party on Private Pensions, Paris, OECD.

Timmins, N. (1996) The Five Giants: A Biography of the Welfare State, London, Fontana.

Timonen, V. (2001) 'Earning welfare citizenship: welfare state reform in Finland and Sweden', in P. Taylor-Gooby (ed.) Welfare States Under Pressure, London, Sage.

Timonen, V. (2003) Policy Maps - Finland and Sweden, www.kent.ac.uk/wramsoc/ workingpapers/index.htm.

Timonen, V. (2004) 'New risks - are they still new for the Nordic welfare states?', in P. Taylor-Gooby (ed.) New Risks, New Welfare: The Transformation of the European Welfare State, Oxford, Oxford University Press.

Titmuss, R. (1963) 'The social division of welfare', in R. Titmuss, Essays on the Welfare State, London, Allen and Unwin.

Torfing, J. (1999) 'Workfare with welfare: recent reforms of the Danish welfare state', Journal of European Social Policy, 9 (1): 5-28.

Traxler, F. (1997) 'European transformation and institution building in East and West: the performance of and preconditions for neocorporatism', in R.W. Kindley and D.F. Good (eds) The Challenge of Globalization and Institution Building, Boulder, CO, Westview Press.

Traynor, I. (2004) 'Record loss for Schröder in biggest state', The Guardian, 27.9.04. 
Trickey, H. and Walker, R. (2000) 'Steps to compulsion within British labour market policies', in I. Lødemel and H. Trickey (eds) "An Offer you Can't Refuse": Workfare in International Perspective, Bristol, The Policy Press.

Trubeck, D.M. and Mosher, J.S. (2003) 'New governance, employment policy and the European model', in J. Zeitlin and D.M. Trubeck (eds) Governing Work and Welfare in a New Economy: European and American Experiments, Oxford, Oxford University Press.

Ughetto, P. and Bouget, D. (2002) 'France: the impossible new social compromise', in J. Goul Andersen, W. van Oorschot and K. Halvorsen (eds) Europe's New State of Welfare: Unemployment, Employment Policies and Citizenship, Bristol, The Policy Press.

United Nations (2004) Human Development Report.

Urry, J. (2003) Global Complexity, Cambridge, Polity Press.

Uzuhashi, T. (2001) 'Japan: bidding farewell to the welfare society', in P. Alcock and G. Craig (eds) International Social Policy, Basingstoke, Palgrave.

Veen, R. van der and Trommel, W. (1999) 'Managed liberalization of the Dutch welfare state', Governance, 12 (3): 289-310.

Visco, I. (2001) The Fiscal Implications of Ageing Populations in OECD Countries, Oxford Centre on Population Ageing, Symposium, 7th June.

Visser, J. (2002) 'The first part-time economy in the world: a model to be followed', fournal of European Social Policy, 12 (1): 23-42.

Voges, W., Jacobs, H. and Trickey, H. (2000) 'Uneven development - local authorities and workfare in Germany', in I. Lødemel and H. Trickey (eds) "An Offer You Can't Refuse": Workfare in International Perspective, Bristol, The Policy Press.

Walter, A. (1991) World Power and World Money: The Role of Hegemony and International Monetary Order, Brighton, Harvester Wheatsheaf.

Watson, M. (1999) 'Rethinking capital mobility, re-regulating financial markets', New Political Economy, $\mathbf{4}(1):$ 1-12.

Watson, M. and Hay, C. (2003) 'The discourse of globalization and logic of no alternative', Policy and Politics, 31 (3): 289-305.

Webster, E. and Harding, G. (2000) Outsourcing Public Employment Services; The Australian Experience, Melbourne Institute Working Paper No 4/00, March, Melbourne Institute of Applied Economic and Social Research.

Weil, A. (2002) Ten Things Everyone Should Know About Welfare Reform: Assessing the New Federalism, Washington, DC, Urban Institute Press.

White, D. (2003) 'Divided by more than water', Investment and Pensions in Europe, September: $32-3$.

Whitehouse, E. (1998) Pension Reform in Britain, SP Discussion Paper 9810, World Bank.

Wilson, G. (2000) Understanding Old Age: Critical and Global Perspectives, London, Sage.

Wilson, W.J. (1987) The Truly Disadvantaged: The Inner City, the Underclass and Public Policy, Chicago, IL, Chicago University Press.

Wiseman, M. (2000) 'Welfare in the United States', in R. Walker and M. Wiseman (eds) The Welfare We Want? The British Challenge for American Reform, Bristol, The Policy Press.

Wood, B. (2005) China's Huge Trade Surplus with US Erodes Free Trade Support, www.voanews.com, February.

Wood, S. (2001) 'Labour market regimes under threat? Sources of continuity and change in Germany, Britain and Sweden', in P. Pierson (ed.), The New Politics of the Welfare State, Oxford, Oxford University Press.

World Bank (1994) Averting the Old Age Crisis, New York, Oxford University Press.

World Bank (2004) World Development Indicators, www.worldbank.org/data/onlinedatabases/ onlinedatabases.html. 


\section{Bibliography}

Wurzel, E. (1999) 'Getting Germany back to work', OECD Observer, 4.2.99, www.oecd observer.org/news/fullstory.php/aid/148/.

Xiao, G. (2005) Round-Tripping Foreign Direct Investment in the People's Republic of China: Scale, Causes and Implications, Research Paper 58, ABD Institute, January.

Yeates, N. (2001) Globalization and Social Policy, London, Sage.

Zijl, M., van der Meer, M., van Seters, J. and Keusenkamp, H.A. (2002) Dutch Experiences with the European Employment Strategy, Amsterdam, Ministry of Social Affairs and Employment. 


\section{Index}

Accords 75, 91, 149, 150

activation 117, 119, 180-1, 186

active ageing 130

active labour market policies (ALMPs)

81-4, 97; Denmark 119-20; Germany

103; Italy 113-14; Netherlands 115;

Sweden 121, 122, 123-4

activity guarantee, Sweden 123

age pension (AP) 147, 148

Agenda 201066

Aid to Families with Dependant Children (AFDG) 85, 86

äldreförsörjningsstöd (AFS) 172-3

Algemene Onderdomswet (AOW) 166

Allocation de Solidarité Spécifique 107

Allocation Unique Dégressive 107

Amato reforms 163-4

Anglo-American financial systems 156

Anglo-American model of economy, pensions 136, 171

Arbetsmarknadsstyrelsen (AMS), 121, 122

Asia-Pacific trade networks 32

Association of German Pension Insurance Bodies (VDR) 154

Australia: abolition of Department of Social Security 92; Accords 75, 91, 149, 150; age pension (AP) 147, 148; discriminatory employment policies

75; Family Tax Initiative 92; global

economic pressures (GEPs) 75;

indigenous people 94 ;

individualization 182; industrial relations 75, 93, 149-50; Job Compact 91-2; Job Network 93; labour market policies 91-4; non-employed spouses 92; pensions 147-51; population ageing 147-8; social assistance 92; social policy 75-6; superannuation 149; Superannuation Guarantee 148; welfare policies 91-4; withdrawal of unemployment benefits 92; 'work first' (WF) 93; Working Nation strategy 91, 92; Youth Training Initiative 92

Australian Confederation of Trades Unions (ACTU) 149

Australian Labor Party 149, 150

balance of savings and investment 39

Balladur, Edouard 109, 159

Basic State Pension (BSP) 146-7

Bauman, Z. 179

Baumol's law 52-3, 54

Beck-Gernsheim, E. 179-80

Beck, U. 179-80

benefits: cuts 83; in-work 83; penalties

119, 180; restrictions 95, 107, 115, 116,118

Berlusconi, Silvio 164, 165

Beyeler, M. 3

Biagi Law 114

bicameral political systems 3

Bismarckian systems of welfare 17-18

Blair, Tony 95

Bonoli, G. 18

borderless world 28

Boyer, R. 45

Broad Guidelines on Economic Policies (BGEP) 192

Brown, Gordon 95-6

Burgoon, B. 54-6

Bush, George W. 140-2

Campbell, J.L. 4

capital accumulation 9 capital mobility $37-8$

capitalism, varieties 43

cassa integrazione ordinaria 112

cassa integrazione straordinaria 112

Castells, M. 24, 25, 54-5

Cerny, P. 44-5, 47 


\section{Index}

change 3-4

Charpin Report 160

Childcare Strategy, UK 97

Clarke, J. 9, 12

Clinton, Bill 141-2

CMEs see coordinated market economies cognitive harmonization 190

Commissariat Général du Plan 160

Commission on Social Justice 95

Commission on Strengthening Social

Security, USA 141, 142

communication technology 26, 27

community care 132

competition state 44

competitive corporatism 188-91

complexity 4

conditionality $180-6$

conservative corporatist welfare regimes

12

consociational systems 3

constitutional systems 3

continental welfare regimes 100 see also individual countries: neoliberalism

182-5; pensions 152-3

Contribution Sociale Généralisée (CSG) 160

convergence 29, 30, 44-5, 46; divergent

48; labour market policies 83

coordinated market economies (CMEs)

43-4, 47, 136

corporate welfare, USA 71-2

Crouch, C. 44

cultural imperialism 26

cultural theory 26

currency devaluations, Sweden 121

Cusack, T. 51, 53

decentralization 58, 62, 69, 70, 87;

Australia 75-6, 92; Denmark 170, 171;

Germany 103; Netherlands 116;

Sweden 124; USA 72-3

decommodification 12, 14, 18

defamilialization 15, 183

defined benefit (DB) 131

defined contribution (DC) 131

deindustrialization 52-4, 77-8; France

158; global economic pressures (GEPs)

56; UK 94; USA 87

Denmark: activation 119; active labour market policies (ALMPs) 119-20;

Anglo-American model of economy

171; benefit restrictions 118; coalition governments 170; competitive

corporatism 190; economic crisis
61-3; female employment 120; global economic pressures (GEPs) 63; human capital 119; immigration 121;

individualization 185; industrial

relations 119, 170, 171; labour market policies 117-21; Labour Market

Reform Act 118; Labour Market Supplementary Pension (ATP) 169, 171; Local Committees for Preventive Labour Market Measures 119; occupational pensions 170-1; old age dependency ratios 169; older workers 120; penalties 119; pensions 169-72; population ageing 169; retirement 120 ; right and duty 118-19; Social Commission 171; solidarism 185; tax system 120; Taxation and Pension Investment Returns Act 171; trade union confederation 170 ; unemployment 117-19; 'work first' (WF) 119; workfare 119; youth unemployment 119; Zeuthen Report 118

developing countries 77 ; trade openness 30-1

Dicken, P. 33

Dini reforms 164

discourse, globalization 10

disorganization 25

'divergent convergence' 48

Doremus, P. et al. 36

Earned Income Tax Credit (EITG) 90

economic crises: Denmark 61-3; Sweden 121

economic determinism 41, 44

economic growth 52

economic-institutional nexus 6

economic liberalization 41

economic openness 54, 55-6

economic-political tension 9

embedded assumptions 5

'embeddedness' of policies 4, 111

employment agencies, Germany 105

employment policies, discriminatory 75

Employment Service, UK 96

Employment Services Regulatory

Authority 92

employment, sustainable 90

EMU see European Monetary Union

enculturation 26

enmeshment 40

Enron 142-4

Esping-Andersen, G. 11-17, 81, 101 
Essen European Council 82

EU Pensions Directive 136, 157, 168

European Council 189

European Employment Strategy 189, 191;

France 106-7, 109; Italy 113;

Netherlands 115

European Monetary Union 63-4, 106, 158, 163, 188-9

European Union (EU) 188-93; enlargement 192-3; neoliberalism 179; trade networks 32

European welfare systems, Bonoli's categorization 18

evolutionary adjustment 4,5

Family Support Act, USA 87

Family Tax Initiative, Australia 92

FDI see foreign direct investment

federal political systems 3

Federal Supplemental Security Income programme 85

Feldstein-Horioka study 39

female employment 70, 77, 79-81, 115, 120, 163, 183; labour force participation rate (LFPR) 134

Ferge, Z. 180

Ferrera, M. et al. 187-8

fertility rates 128, 134

Field, Frank 146

financial integration 39-40

Financieel Toetsingkader (FTK) 167-8

flexibilization, pensions 127

flexicurity 188

foreign direct investment (FDI) 33-7, 51, 64

fragmentation 25; France 111; French pension system 157-8; Italian pension system 163; of marginalized groups 99

France: 35 hour week 110; conditionality

183-4; deindustrialization 158; earned income tax credit 109; European Employment Strategy 106-7, 109; fragmentation 111; individual retirement accounts 161; individualization 183-4; industrial relations $158-60$; job creation 110 ; labour force participation rate (LFPR) 158; labour market changes 158; labour market policies 106-11, 158; liberalization 109-10; National Employment Agency 109; nonstandard working 109; pensions 157-62; population ageing 158; production regimes $66-7$; restriction of benefits 107; social inclusion 107-8, 110; subsidiarity 106; trades unions 159-60, 161; unemployment 106; unemployment protection 107; welfare fragmentation 111; 'work first' (WF) 110; workfare 108-9; youth unemployment 108-9, 110-11

Frankel, J. 39

full employment 77

Garrett, G. 33-4, 46

gender roles 80

General Agreement on Tariffs and Trade (GATT) 29, 30

generosity, in welfare 17-18

GEPs see global economic pressures

Germany: Active labour market policies

(ALMPs) 103; Agenda 2010 66; AngloAmerican financial systems 156;

benefit restrictions 103; conditionality 183; decentralization of employment services 103; disability pension reform 155; disparity of East and West 106; employment agencies 105; Federal Employment Service 104; financial market reforms 156; global economic pressures (GEPs) 64-5, 105, 153;

Hartz Commission 104; Help Towards Work 103-4; individualization 183; industrial relations 65-6, 105-6, 157; Job-Aqtiv Act 2002 104; job placement services 103-4; labour market policies 101-6; male breadwinner model 153; non-standard working 103; occupational pensions 155, 156; older workers 105; pension privatization 155; Pension Reform Act 1992 154; pensions 153-7; population ageing 153; post-war welfare regime 101-2; production regimes 64-6; reunification 102, 105, 154; service sector 102; social budget 102; social insurance 153; subsidiarity 101, 103; support for welfare reform 106; unemployment 102-3, 105; workfare 103

Giddens, A. 24, 28

Gilbert, N. 6-7, 50

global economic pressures (GEPs) 194;

Australia and New Zealand 75; capital accumulation 9; as challenge to national government 23; coordinated market economies (CMEs) 44; deindustrialization 56; Denmark 63; differential effects on welfare 57 ; effect 


\section{Index}

on nation-states 45-7; as factors in change 8; Germany 64-5, 105, 153; indirect effects 55 ; institutional character of regimes 6; Italy 68; liberal market economies (LMEs) 70-1; liberal regimes 186; as myth 9-10; and national sovereignty 27 ; pensions 56 , 127, 135-8, 176-7; UK 74; USA 71; weakness 52; welfare regimes 48, 76, 178-9

global-institutional nexus 6, 57, 193

global interconnections 24

global-national-local tension 7

globalization: as contested concept 23-6; core assumptions 24-5; key indicators 30 ; passive 28

globalization sceptics 27, 30, 31, 36, 38, 48; deindustrialization 53-4; and welfare regimes 48

globalization thesis 49-50, 56-7

Goul Andersen, J. 118-19

governance 29, 43

Gray, J. 49, 105

'growth to limits' argument 8

Guaranteed Pension (GP) 172

Guigni income agreement 113

Hartz Commission 104, 105

Hay, C. 9-10

health and social care, population ageing 131-2

Helleiner, E. 41

Help Towards Work, Germany 103-4

Hemerijck, A. 188-9

Hirst, P. 34-6, 38

Hollingsworth, J.R. 45

household structures, changes 79-80

Howard, John 92-3

Huber, E. 13, 51

human capital (HC) 83, 95, 98, 114, 119 , 123

Hungary 192

hyperglobalization 28-9, 48

identities, fragmentation 25

immigration, Denmark 121

indigenous people, Australia 94

individualization 179-81, 193; Australia

182; Denmark 185; France 183-4;

Germany 183; Italy 184; liberal regimes

181-2; Netherlands 184-5; Sweden

186; UK 182; women 181, 182, 186

industrial relations 188; Australia 75, 91, 93, 149-50; Denmark 119, 170, 171;
France 67, 158-60; Germany 65-6, 105-6, 157; Italy 67-8, 113;

Netherlands 69; New Zealand 75;

Sweden 175, 176; UK 73-4; USA 72

industrializing economies $30-1$

inequality 99

information technology 26, 27

institutional stickiness 3, 4, 42, 101, 190;

pensions 150, 176; Switzerland 21

institutionalism 2, 3, 4, 6, 42

interest group representation 58

interest rate parity $37-8,39-40$

international economic activity, growth 29

international integration of markets 29, 33

intra-firm trading (IFT) 36

investment: pension funds 131, 149; stabilizing factor 52

Italy: active labour market policies (ALMPs) 113-14; Amato reforms 163-4; Biagi Law 114; Dini reforms 164; economic crisis 68; employers' associations 114; European Employment Strategy 113; European Monetary Union 163; global economic pressures (GEPs) 68; Guigni income agreement 113; human capital 114; individualization 184; industrial relations 67-8, 113; labour flexibility 113; labour market policies 111-14; labour market regulation 112; nonstandard working 113; Onofri

Commission 164-5; pay as you go (PAYG) 165; pensions 68, 163-6; population ageing 163; production regimes 67-9; Public Employment Services (PES) 113, 114; redundancy funds 112-13; retirement age 165; segmented labour market 111; severance pay investment 165-6; Treu Package 113; unemployment 112; unemployment benefit 113; welfare spending 67

Iverson, T. 51, 53

Japan, multinational companies (MNGs) 36

Jayasuriya, K. 45

Jessop, B., modes of capitalist accumulation 7-8

Job-Aqtiv Act 2002104

Job Compact, Australia 91-2

job creation, France 110

Job Network 93 
Jobcentre Plus, UK 96

Jobseeker's Allowance (JSA), UK 95, 96

Jobseeker's Employment Act, Netherlands 115

Jospin, Lionel 109, 110, 160-1

Juppé, Alain 109, 159

Keynesian Welfare National State 7

King, D. 74

Kitschelt, H. 43, 46

Kohl, Helmut 103, 154

Krol, R. 39

labour force participation rate (LFPR) $134,158,166$

labour, free market 87

labour market policies 77-8 see also individual countries: continental Europe 124-5; convergence 83; liberal regimes 98-9; New Labour 96; welfare analysis 21-2

Labour Market Reform Act, Denmark 118

Labour Market Supplementary Pension (ATP) 169, 171, 172

labour markets $11,77-8$

Lane, C. 28-9

Lange, P. 46

Law on Penalties and Measures, Netherlands 116

Levitas, R., welfare discourses 98

liberal market economies (LMEs) 43, 47, 98-9; global economic pressures (GEPs) 70; pensions 127, 135-6

liberal regimes: global economic pressures (GEPs) 186; individualization 181-2; labour market policies 98-9; pensions 136, 150-1; welfare 12, 84

liberalization 109-11, 178-9, 193

Liebfried, S. 8, 9, 42, 48, 87

LMEs see liberal market economies

Local Committees for Preventive Labour

Market Measures, Denmark 119

local production regimes 46

Loi Thomas 161

male breadwinner model 14, 17, 100, 127,153

Mann, M. 41-2

March, J.G. 2

markets: international integration 29, 33, 40 ; open 51

Marxism 12

minimum veillesse 158,159
Minns, R. 136

minority ethnic groups, pensions 140 , 172

Mishra, R., globalization thesis 49-50

MNCs see multinational companies

Modern Apprenticeships 97-8

morality: social democratic welfare regimes 187; in welfare $85-6,94,97$, 98

Mouvement des Entreprises de France MEDEF) 110

multinational companies (MNCs) 34-7

multiplexity 26

mythology, of globalization 9-10

NAFTA, trade networks 32

Natali, D. 161, 165

nation-state: autonomy 40, 52; global economic pressures (GEPs) 45-7; institutional power 45 ; reorganization $44,45-6$

National Insurance, UK 144

national savings $37-8$

neocorporatism 188

neoliberal drift 179, 193-4

neoliberalism 74, 124, 182-6

Netherlands: accountability of pension funds 167; activation 117; Active labour market policies (ALMPs) 115; Algemene Onderdomswet (AOW) 166; benefit restrictions 115, 116; Central Employment Board 117; Centres for Work and Income 117; competitive corporatism 190; decentralization 116 ; disability benefits 115 ; female participation 115; financial assessment framework 167-8; individualization 184-5; industrial relations 69, 114-5; Jobs and Income Collaboration Project 117; Jobseeker's Employment Act 115-16; labour force participation rate (LFPR) 166; labour market policies 114-17; Law on Penalties and Measures 116; occupational pensions 167; pensions 166-8; population ageing 166; privatization 116; Public Employment Services (PES) 116-17;

Social Assistance Act 115; unemployment 115; Wassenar agreement 69, 114; welfare spending 69-70; workfare 116; Youth

Employment Act 115; youth unemployment 115-16

network society 24 


\section{Index}

New Apprenticeships, Australia 93

New Course agreement 69-70

New Deal, UK 96

New Deal for the Young Unemployed (NDYP), UK 96

New Labour 10, 95; labour market policies 96; pensions 146-7

New Zealand 75

newly industrializing economies (NIEs) 51,55

non-employed spouses 92

non-standard working 63, 87, 94, 103, $109,113,143$

Nouveaux Service-Emploi Jeunes 108-9

Obinger, H. 48

O'Connor, J. 14

OECD, pensions 129-35

Ohmae, K. 28

old age dependency ratios 128-9, 133, $134,140-1,169$

Old-Age Survivors and Disability Insurance, USA 139, 141

older workers 105, 120

Olsen, J.P. 2

Omnibus Budget Reconciliation Act, USA 87

Onofri Commission 164-5

open method of coordination (OMC) 189-92

openness, economic 54-6

part-time work see non-standard working passive globalization 28

path dependency 3, 4, 5, 42

patterns of employment, pensions 126-7, $137-8$

pay as you go (PAYG) 129, 130, 152, 157, 165

pension funds: accountability 167; Anglo-

American 161; international investment 136-7; portfolio management 131, 157; severance pay investment 165-6

Pension Reform Act 1992 (Germany) 154

pensions: äldreförsörjningsstöd (AFS)

172-3; Anglo-American model of economy 136; Australia 147-51; challenges 126; continental welfare regimes 152-3; coordinated market economies (CMEs) 136; defined benefit (DB) 131; defined contribution (DC) 131; Denmark 169-72; emergence 126; expense 53; financial institutions 137; France 157-62;

George W. Bush administration 140-1; Germany 153-7; global economic pressures (GEPs) 56, 127, 135-8, 176-7; indexing 135; institutional stickiness 150; intergenerational contract 129; investment 166-7; Italy 68, 163-6; labour force participation rate (LFPR) 134; liberal market economies (LMEs) 127, 135-6; liberal regimes 136, 138-9, 150-1; means testing 131 ; minority ethnic groups 140, 172; mis-selling, UK 146; move to direct contribution 137-8; Netherlands 166-8; New Labour 146; notional defined contribution (NDC) 173; occupational schemes 137-8, 143, $144,146,155,156,167,170-1$;

OECD recommendations 129-35; patterns of employment 126-7, 137-8; pay as you go (PAYG) 129, 130, 152; population ageing 126 ; privatization 150, 161, 166, 170, 174-5; recasting 56; reform 176-7; self-financing 143-4; Social Democratic Regimes 168-9; Sweden 172-6; three pillars 129-30; UK 135, 138, 144-7; USA 138, 139-44; welfare analysis 21-2; women 139-40, 146, 148, 174; World Bank 129-35

Pensions Commission, UK 147

Personal Responsibility and Work Opportunity Reconciliation Act (PRWORA) 88-9

PES see Public Employment Services

Pierson, Christopher 128, 134

Pierson, Paul 2, 4, 52; de-familialization 15; on globalization thesis 56-7; population ageing 53-4

Plan d'aide au Retour à l'Emploi (PARE) 110

policies, legacies of 4

political systems 3

population ageing 53, 56; Australia 147-8; as crisis 133; Denmark 169; France 158; Germany 153; health and social care 131-2; Italy 163;

Netherlands 166; and pensions 126; as problem 133; projections 133-4; USA 140-1

population trends 128

portfolio investment 37

post-Fordism 7

privatization: France 161; Germany 155; 
Italy 165 ; Netherlands 116 ; pensions $150,166,170,174-5$

process 194

production regimes 43, 59-60; Denmark

61-2; France 66-7; Germany 64-6;

Italy 67-9; Sweden 60-1

Public Employment Services (PES) 82,

113, 114, 116-17

public sector employment, Sweden 121-2

Putnam, R. 179

Radaelli, C.M. 191-2

radical change 4

Raffarin, Jean-Pierre 110, 161

rational choice institutionalism 3

Reagan, Ronald 87, 141

recalibration $190-1,193-4$

regional trade integration 32

regulatory state 5

Rehn-Meidner model 121, 123

retirement, Denmark 120

Revenu Minimum d'Insertion 107-8

rhetoric, political 10

Rhodes, M. 161, 165, 188

Rieger, E. 8, 9, 42, 87

Riester-Rente funds 155, 156, 183

right and duty, Denmark 118-19

Rodrik, D. 32

Rosamund, B. 10

Rothstein, B. 5

Rürup Commission 156

SAP 175

Sarfati, H. 78, 81

Schaeffer, R.K. 31-2

Scharpf, F. 50-1, 52

Schroeder, Gerhard 103, 104

Schumpeterian Competitive State 7

Schumpeterian Workfare State 119

Schwartz, H. 51, 54

service sector 52-3, 77, 79-81, 94, 102

Shaver, S. 92

Simmons, B. 34

small and medium-size enterprises (SMEs) 34

Smith, S.R. 5

'social amelioration' 9

Social Assistance Act, Netherlands 115-16

social assistance, Australia 92

social care, welfare regimes 14

Social Commission, Denmark 171

social democracy 9-10, 49-51

social democratic welfare regimes 12-13,

168-9, 185-8 social divisions 100

social inclusion 94, 98, 107-8, 110, 188

social insurance 101; Germany 153

social pacts 188, 190-1

social policy: Australia 75-6; labour

market change 81

social protection, institutional framework 6-7

social security 140-2, 158, 188

Social Security Trust Fund, USA, projections 141

sociological institutionalism 3

solidarism 185-6

Soskice, D. 43, 59-60

Spain 21

stakeholder pensions 147

State Earnings Related Pension Scheme (SERPS) 144-6

state, role in welfare 12

State Second Pension (S2P) 147

Stephens, J. 13, 51

stigmatization 85

Streeck, W. 44

subsidiarity 101, 106; Germany 103

Superannuation Guarantee 148

Swank, D., core characteristics of welfare regimes 57-9

Sweden 5-6, 53; activation 186; Active labour market policies (ALMPs) 121, 122, 123-4; activity guarantee 123; Arbetsmarknadsstyrelsen (AMS) 121, 122; conditionality 186; currency devaluations 121; economic crises 121; growth in public sector employment 121-2; Guaranteed Pension (GP) 172; human capital 123; individualization 186; industrial relations 175, 176;

labour market policies 61, 121-5; notional defined contribution (NDC) 173; pensions 172-6; production regimes 60-1; Rehn-Meidner model 121, 123; solidarism 185-6; unemployment 122-3, 124; universalism 124; welfare spending 61 ; workfare 123

Switzerland 21

Taddéi Study 160

tax credits UK 97

tax system, Denmark 120

Taxation and Pension Investment Returns Act, Denmark 171

Temporary Assistance to Needy Families (TANF), USA 85, 88-90 


\section{Index}

tension: economic-political 9; globalnational-local 7

Teulade Report 160-1

Thatcher, Margaret 94-5

Thompson, J. 34-5, 38

time-space distanciation 24, 25, 41

Titmuss, R. 11

trade: developing countries 30-1; integration 29, 32; international 51; openness 29; triadic structure 32-3; volatility $51-2$

trade union confederation, Denmark 170

Treu Package 113

UK: active labour market policies (ALMPs) 97; Basic State Pension (BSP) 146-7; Childcare Strategy 97; deindustrialization 94; Employment Service 96; global economic pressures (GEPs) 74; individualization 182; industrial relations 73-4; labour market policies 94-9; National Insurance 144; neoliberalism 74; occupational pensions 146; Partnership in Pensions 147; pensions 144-7; Pensions Commission 147; pensions mis-selling 146; postwar welfare regime 73; restriction of benefits 95; service sector 94; stakeholder pensions 147; State Earnings Related Pension (SERPS) 144-5; State Second Pension (S2P) 147; tax credits 97; US influence 94, 97, 98; welfare retrenchment 74; welfare spending 74; welfare-to-work 95; 'work first' (WF) 98

unemployment 78; Denmark 117-19; France 106; Germany 102-3, 105; Italy 112; Netherlands 115; Sweden $122-3,124$

Union nationale interprofessionelle pour l'emploi dans l'industrie et le commerce (UNEDIC) 107

United Kingdom see UK

United States of America see USA universalism 124, 169, 174-5

Urry, J. 25

USA: conditionality 181-2; corporate welfare 71-2; cultural domination 26; definition of welfare 84; global economic pressures (GEPs) 71; individualization 181-2; industrial relations 72 ; labour market policies 84-9; multinational companies (MNCs) 36; occupational pension schemes 143, 144; old age dependency ratios 141; Old-Age Survivors and Disability Insurance 139, 141; pensions 139-44; population ageing 140-1; private individual accounts (IAs) 140, 142, 143; social security 140-1; stock market decline 142; unemployment 85-6; welfare reform 84-91; welfare retrenchment 71; welfare spending 72

varieties of capitalism 43-6

veto points 3,58

'wage earner' welfare 75

Wassenar agreement 69, 114

Watson, M. 37, 38-9

weak globalization perspective 27, 48-9

welfare: active 82 ; Bismarckian systems

17-18; economic rationale in UK 97; and fertility rates 134; ideology 85-6; male breadwinner model 14, 17, 100, 127, 153; morality 85-6, 94, 97, 98; spending 178; stigmatization 85; 'wage earner' 75; weak globalization perspective $48-9$

welfare dependency 86, 94-5, 97

welfare regimes 11-18; anomalies 17; differential effects of global economic pressures 57; Esping-Andersen 13, 15-16; feminist approaches 14; France 67; generosity 17-18; global economic pressures (GEPs) 48, 76, 178; as ideal types 17,59 ; impact of global change 58-9; institutional structures 57-9; liberalization 178-9; position of women 14-15, 22; preservation 52; social care 14; social divisions 100; terminology 17 ; weakening 49-51

welfare retrenchment 71,74

welfare spending: Denmark 62; Germany 64; Italy 67; Netherlands 69-70; Sweden 61; UK 74; USA 72

welfare systems: advantage in global market 7-8; classification 11

welfare-to-work: investment 90-1; UK 95; USA 87

women see also female employment: individualization 181, 182, 186; labour market flexibility 193; pensions 139-40, 146, 148, 174; welfare demands 163 ; in welfare regimes $14-15,22$

Wood, S. 74 
'work first' (WF) 83, 84; Australia 93-4; Denmark 119; France 110;

Netherlands 116; social inclusion 94; UK 95, 96, 98; USA 88

Work for the Dole, Australia 93

workfare: Denmark 119-20; France

108-9, 110; Germany 103;

Netherlands 116; Sweden 123; USA 86, 87

Working Families Tax Credit, UK 97

Working Nation strategy, Australia 91, 92
Working Tax Credit, UK 97

World Bank, pensions 129-35

World Trade Organization (WTO) 30, 31

Yeates, N. 31

Youth Employment Act, Netherlands 115

Youth Training Initiative, Australia 92

youth unemployment 122; Denmark 119; France 108-9, 110-11; Netherlands 115-16

Zeuthen Report, Denmark 118 
